\title{
Language learner cognition: Exploring adult migrants' L2 activity beyond the classroom
}

\author{
By \\ Diego Navarro
}

\begin{abstract}
A thesis
submitted to Victoria University of Wellington in fulfilment of the requirements for the degree of Doctor of Philosophy in Applied Linguistics Victoria University of Wellington 2016
\end{abstract}




\begin{abstract}
For years, understanding the relationship between behaviour and cognition has been a central concern of research conducted in the social sciences. In fields as diverse as anthropology, business, medicine, and education it is widely accepted that the development of practice (as a type of behaviour), depends on a precise understanding of how thought gets carried into action. However, studies investigating the complex interplay between a learner's cognition (i.e. thoughts, knowledge, beliefs, and feelings about L2 learning) and their behaviour (i.e. languagerelated activity) are only recently garnering attention. In addition, only few studies have looked at this dynamic process with adult participants beyond the language learning classroom. Framed within the context of naturalistic language learning, this investigation explores the social construction of adult (over 30 years of age) L2 learners' cognition in an ESOL setting. Specifically it aimed to answer the following research questions:
\end{abstract}

RQ 1. What are the prior language learning experiences of a group of adult migrant learners living in New Zealand?

RQ 2. How have these prior language learning experiences influenced the construction and development of their beliefs, assumptions, knowledge (BAK) about language learning?

RQ 3. What is their perceived need for English in their current socio-cultural context?

RQ 4. How do adult migrant language learners engage in language related activities beyond the classroom?

RQ 5. How can this language learning behaviour be reflected in a model of language learner cognition?

The study combined a longitudinal, ethnographic approach, with elements of narrative and case study inquiry. Six 'recently arrived' (Dunstan, Roz, \& Shorland, 2004a) Colombian migrants (five refugees; one immigrant) were asked to talk about and discuss both prior and current experiences learning and using an L2. Through these lengthy in-depth, conversation-like interviews conducted in Spanish (the participants' L1), told over time, a nuanced picture of the participants' L2-related cognition emerged. As a result, I was able to more clearly observe the dynamic process in which a language learner's mental life both impacts and is impacted on by language-related activity throughout their day-to day interactions. The participants are seen engaging in the L2 across a range of settings including at home, the doctor's office, supermarkets and work. Moreover, in their accounts of this engagement we see change and revision (i.e. development) in their thinking about L2 learning and themselves as language learners, as well as their feelings toward the $L 2$, other $L 2 s$ and $L 2$ users. A single participant was selected as an exemplary case to examine in detail, and facilitate understanding of this development. A case study approach allowed for a more intricate exploration of how the interplay between thought, emotion, and context impacted on the learner's approaches to language-related activities. Issues regarding readiness to interact in the L2, intelligibility, language variety, and aversion to the 'sound of English' were seen as playing significant roles in the learner's language development. This analysis resulted in the construction of a framework depicting language learner cognition in action. In terms of implications, this research supports the case for more qualitative research in SLA which centres 
learners' perspectives of their L2 related experiences, particularly when so much of what seems to be affecting learning is the learners understanding of themselves and their actions. It also argues that studies in L2 cognition should focus their investigations on the developmental processes involved in the social construction of the mental factors which impact language learning and use. Finally, while belief studies in SLA are expanding the scope of their investigations - by looking to include more emotion and other affective factors, as well as by branching out into selfrelated constructs such as self-concept and self-efficacy in the foreign language domain - these studies remain limited in their almost microscopic view of learners' mental lives. The picture of cognition I offer provides a more holistic understanding of this phenomenon which helps account at a macro-level for L2 behaviour. The study also highlights the potential and power of data gathering methods which foreground the participants' voices and ideas (i.e. in-depth, unstructured interviews told over time) - reminding us that it is important when looking for what drives language learning behaviour to consider what the learners feel and think. 


\section{Dedication}

Dedicated to the memory of my father, Ricardo Ernesto Navarro de Romaña The coolest language learner I have ever known

$1945-2016$ 


\section{Acknowledgments}

Firstly, I would like to acknowledge Victoria University of Wellington for the financial support provided by way of scholarship during the researching and writing of this thesis. Without this support this thesis would not have been possible. I am also grateful of the financial support provided by the Faculty of Humanities and Social Sciences which allowed me to present this research abroad.

Second, I would like to express my profound gratitude to my primary supervisor, Associate Professor John Macalister. His patience, perspective, sense of humour, careful reading, and trust were all key in helping me develop my skills as an emerging researcher. I would also like to thank my secondary supervisor Dr. Anya Siyanova for her enthusiasm and energy throughout this project.

Also, the interest and support I received from my fellow-postgraduate students in the School of Linguistics and Applied Language Studies at Victoria University of Wellington was something very special and dear to my PhD experience.

Many other people have assisted me during this project. I would like to thank Roxanna Navarro for helping me with some of the more challenging translation work; the New Zealand Red Cross branch in Wellington for helping me connect with potential participants; all of my pilot participants; everyone in LALS: I feel extremely fortunate to have landed in such an accepting and stimulating school.

A heartfelt thank you for my family: My dad, my mom and Graham, and my sister have provided me with nothing but love and affection (Muchas gracias). Kuniyo and Tzusuko Tanoue, and the Nishimura-clan, without their support and infinite kindness this thesis could not have been completed (どうもありがとうございました). My son Azul, for reminding me everyday that we work so that we can play; my daughter Nico for her verve and fiery independence; my wife Yumiko, who has stood by me every step of the way, keeping me in check and holding me up when things got difficult - I could not have done any of this without you.

Finally, I owe a debt of gratitude to all my participants, who opened their doors to me and welcomed me in with warmth and generosity. They took a complete stranger into their homes and shared their personal histories and stories with me so that I could complete this thesis. I cannot thank you enough. 


\section{Table of Contents}

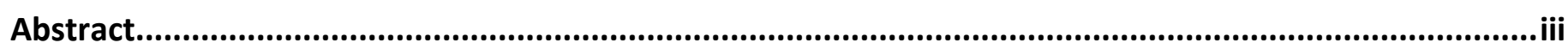

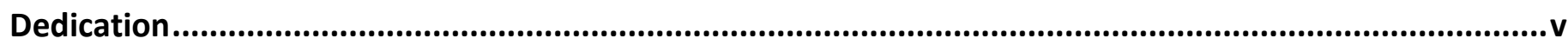

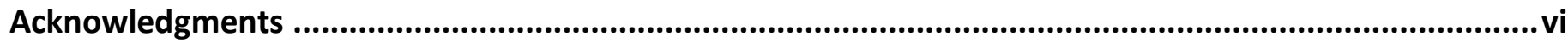

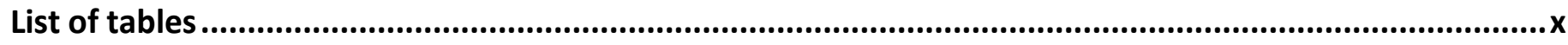

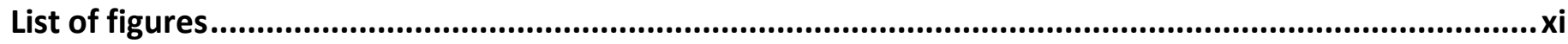

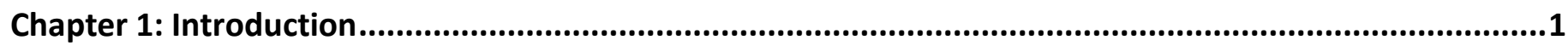

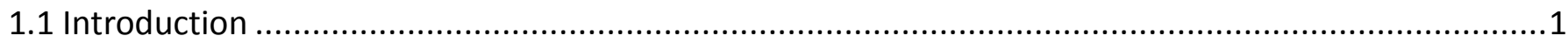

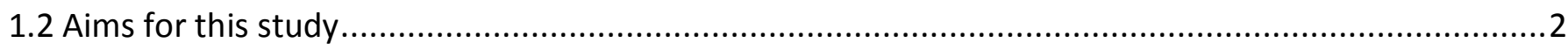

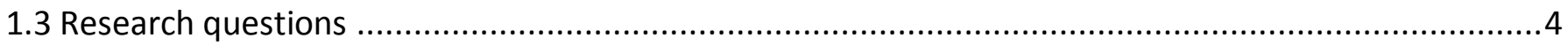

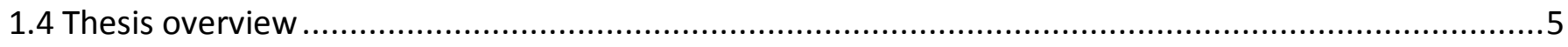

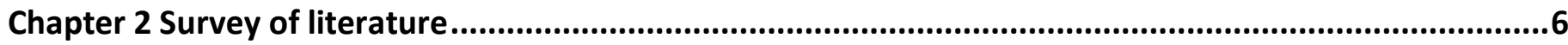

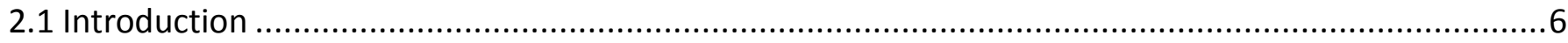

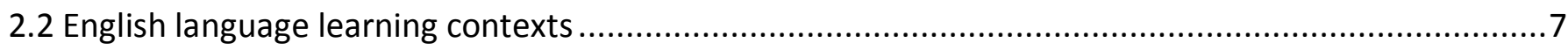

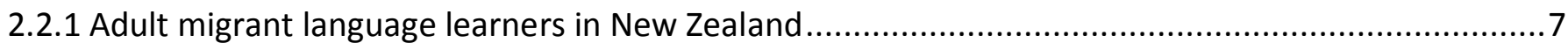

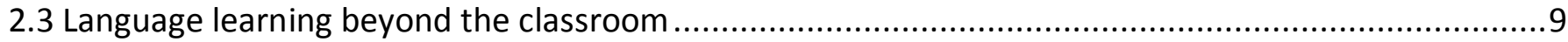

2.4 The mental lives of learners and teachers: Cognition studies in language education .......................11

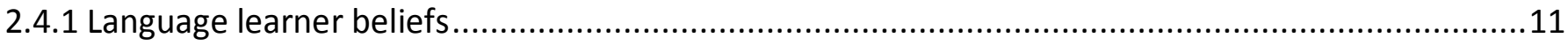

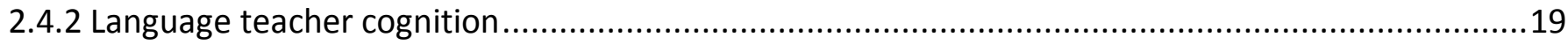

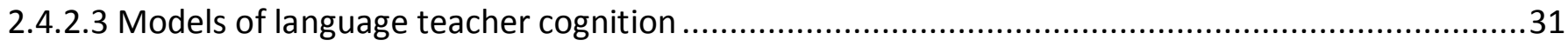

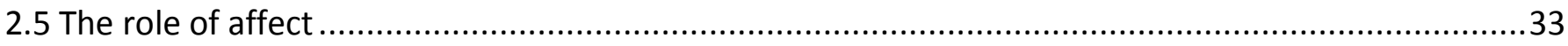

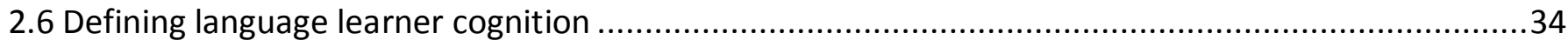

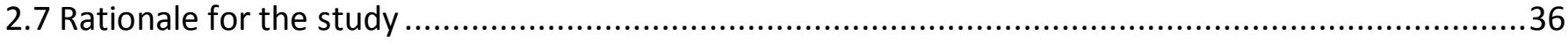

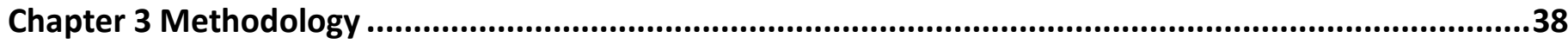

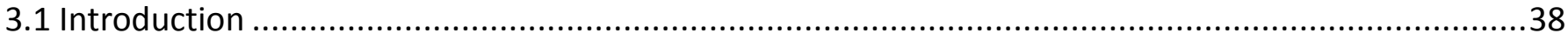

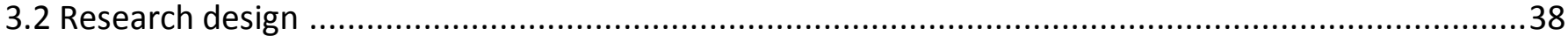

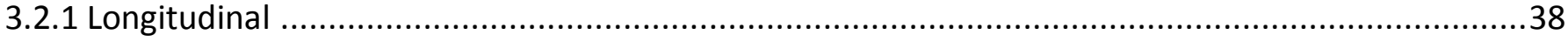

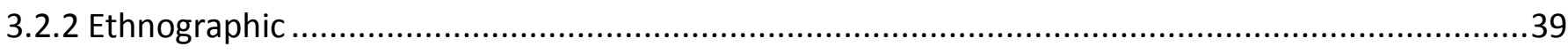

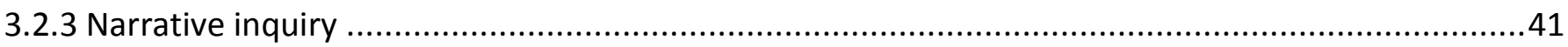

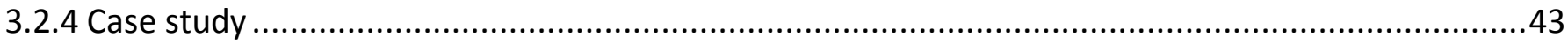

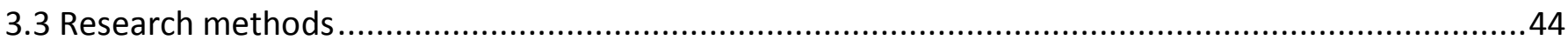

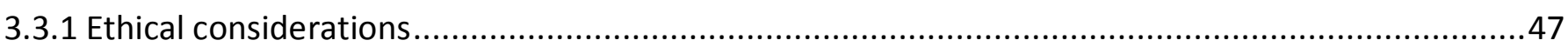

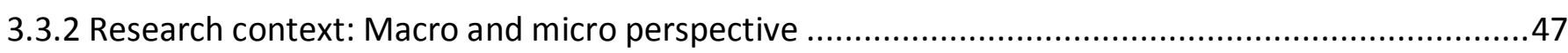

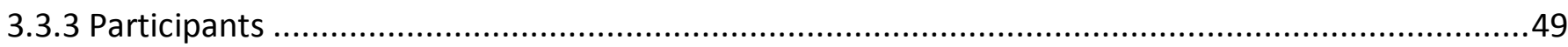

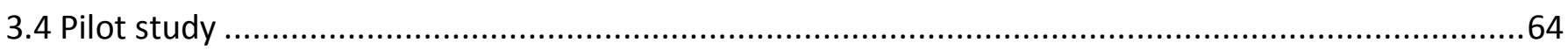

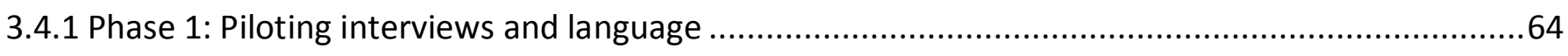

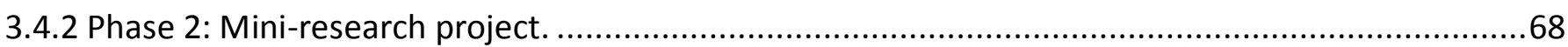




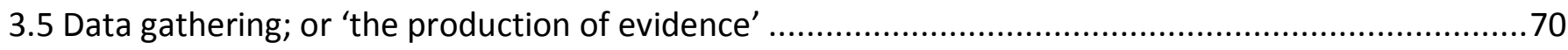

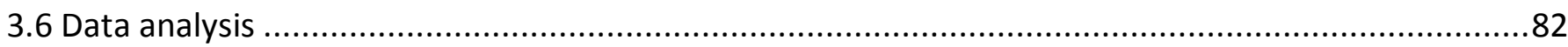

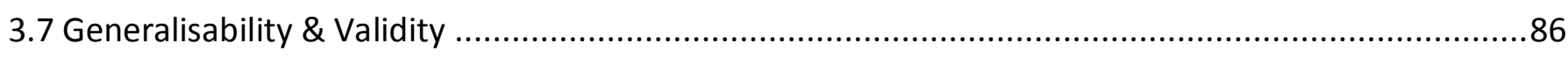

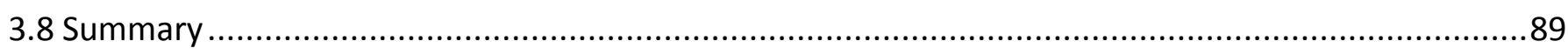

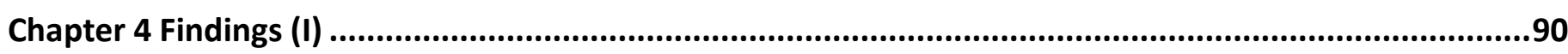

4.1 Introduction

4.2 The impact of prior language learning experiences on the construction of L2 BAK: A portrait of

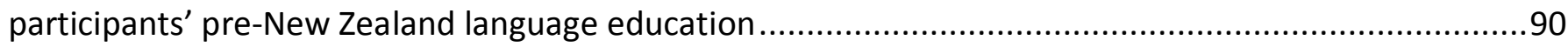

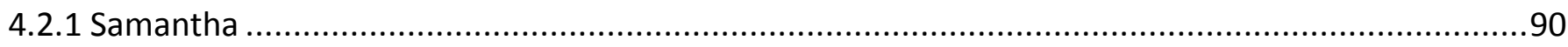

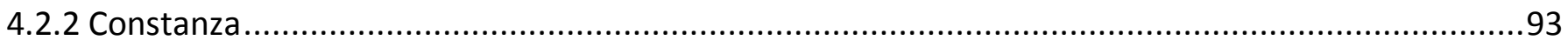

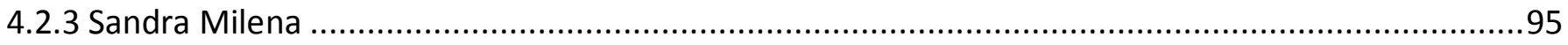

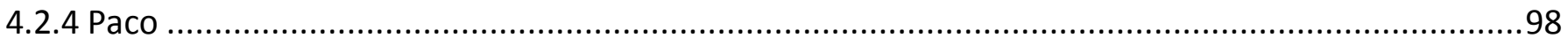

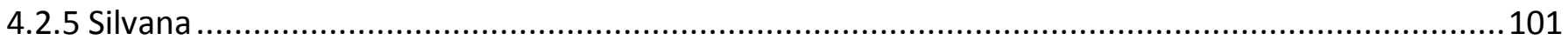

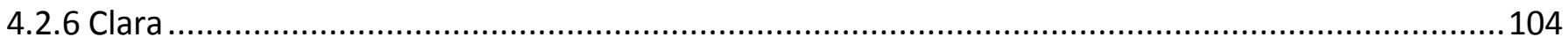

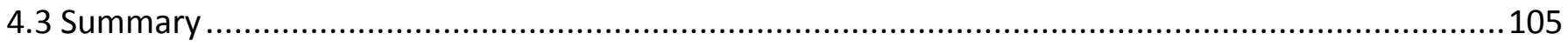

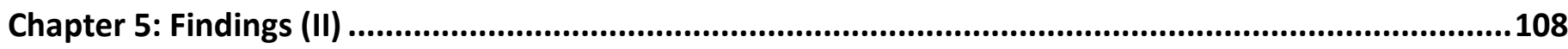

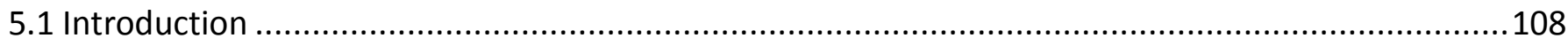

5.2 The perceived need for English in the participants' lives in New Zealand ....................................108

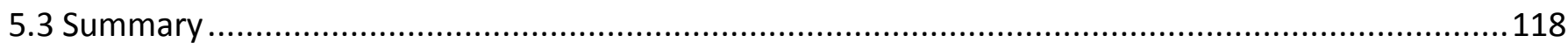

5.4 A description of adult language learners' L2 activity beyond the language classroom....................118

5.5 Participants' stories: Accounts of language-related activity ....................................................119

5.5.1 Language-related activity in a 'religious' context .................................................................. 119

5.5.2 Language-related activity in a 'work' context....................................................................... 123

5.5.3 Language-related activity in a 'volunteer' context ............................................................. 127

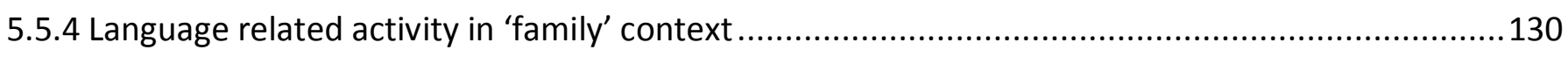

5.5.5 Language related activity in a 'social transaction' context ...................................................133

5.5.6 Language related activity in a 'transactional interactions' context ............................................ 136

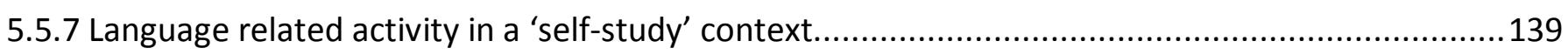

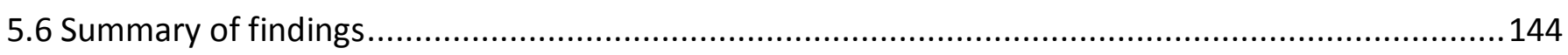

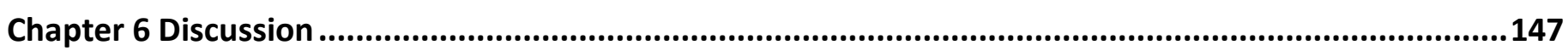

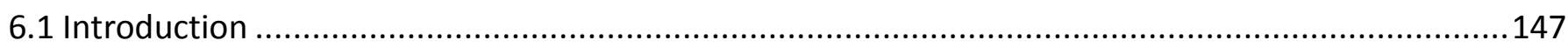

6.2 The storied experiences of an adult language learner in New Zealand: A case study of language

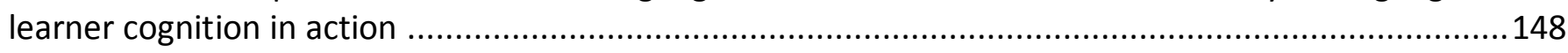

6.3 Constructing cognition: A tale of tension, reflection, and discovery ........................................ 149

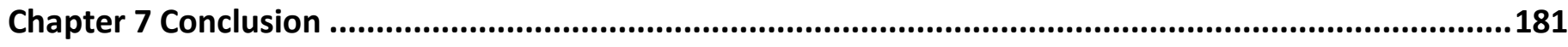

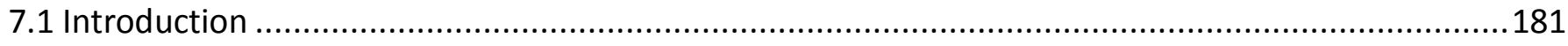

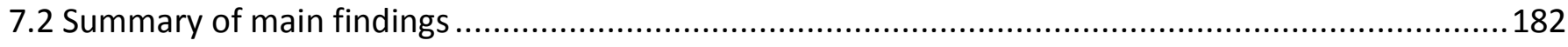

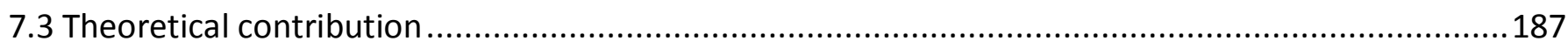




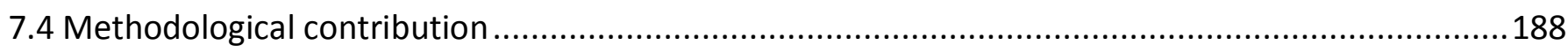

7.5 Implications \& directions for future research: Language learner cognition across contexts .............189

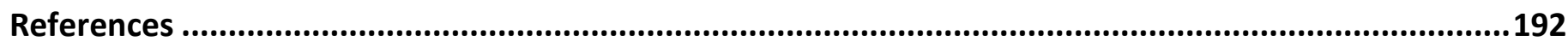

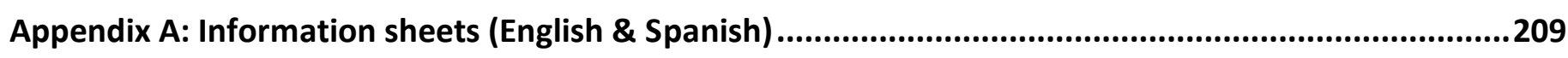

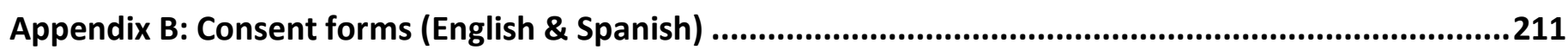

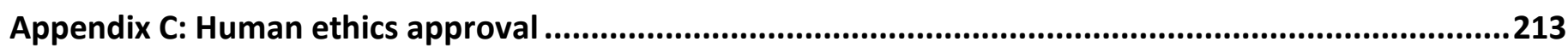

Appendix D: Indirect observation tool (English \& Spanish)...................................................................214

Appendix E: Interview schedule dates of the interviews for all of the participants ...............................216

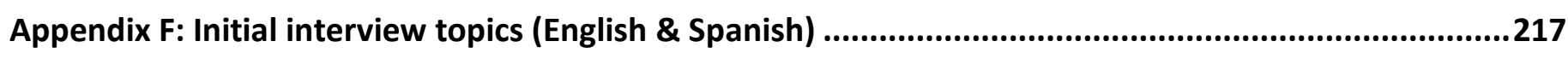

Appendix G: Sample translations/transcriptions (Spanish) .................................................................219

Appendix H: Sample translations/transcriptions (English) ....................................................................221 


\section{List of tables}

Table 1: Classification of language teacher cognition models. .31

Table 2: Description of participants (general) .59

Table 3: Technical insights gained (Phase 1) .67

Table 4: Interactional insights gained (Phase 1) .68

Table 5: Insights gained (Phase 2) .69

Table 6: Interview-specific information for 'principle' participants .78

Table 7: Samantha's prior language learning experiences \& BAK .93

Table 8: Constanza's prior language learning experiences \& BAK. .95

Table 9: Sandra Milena's prior language learning experiences \& BAK .98

Table 10: Paco's prior language learning experiences \& BAK 101

Table 11: Silvana's prior language learning experiences \& BAK. 103

Table 12: Clara's prior language learning experiences \& BAK 105

Table 13: Language-related activities' contexts and types: Religious 119

Table 14: Language-related activities' contexts and types: Work 123

Table 15: Language-related activities' contexts and types: Volunteer 127

Table 16: Language-related activities' contexts and types: Family 130

Table 17: Language-related activities' contexts and types: Social transaction 133

Table 18: Language-related activities' contexts and types: Transactional interactions 136

Table 19: Language-related activities' contexts and types: Self-study. 139

Table 20: Description of model of language learner cognition in action 179 


\section{List of figures}

Figure 1: A model of language learner cognition in action 173

Figure 2: A populated model of language learner cognition in action: Transactionial context 176

Figure 3: A populated model of language learner cognition in action: Social transaction context 177 


\section{Chapter 1: Introduction}

'Life is not what one has lived, but rather what one remembers, and how one remembers it to recount it'

- Gabriel Garcia Marquez

\subsection{Introduction}

\section{Vignette: Experiencing language learning}

For as long as I can remember, language learning has played a significant role in my life. I have experienced it firsthand across a variety of contexts, and I have also witnessed it impact a number of important people around me. Whether these language-related experiences are the natural consequence of the longstanding human tradition of migration and intercultural interaction (Appel \& Muysken, 2006; Geraghty \& Conacher, 2014) or the inevitable result of cultural and economic globalisation (Collins, Slembrouck, \& Baynham, 2009; Lin \& Martin, 2005), they have nevertheless been responsible for shaping, not only who I and those closest to me have become but to a larger extent, who we are capable of becoming.

In immigrating to Canada, my family and I were able to effectively integrate into Canadian society through the 'successful' process of acquiring English. I remember my father telling my mother, sister, and me that it was to be 'English only from now on' at home. Years later, lamenting how little Spanish we were using, he overturned his ruling and asked that we use 'only Spanish'. This family language 'switch' was important as it introduced a unique language learning experience, where I was developing and maintaining my L1 as it competed with the more dominant L2. Nevertheless, my participation in Canadian society was conducted almost exclusively in English. Spanish was relegated for home use (with constant switching between English and Spanish), public outbursts of emotion (usually anger), and our yearly visits during summer vacation to Peru. During school, my sister and I also learned mandatory French for a number of years, as part of the Canadian government's effort to promote a bilingual language policy. This was my first experience with formal language learning and unfortunately not a particularly effective or positive one.

After university, I immigrated to Japan and lived and worked there for approximately 14 years. This time my experiences with formal language learning were through my roles as an English teacher and language learning advisor, helping people to learn English (and other languages) as a foreign language. At the same time, I again became a language learner, learning Japanese as a third language. While a large number of my non-Japanese friends and colleagues studied Japanese formally, in class with teachers, textbooks and tests, almost all of my own learning took place outside of the classroom through my day-to-day interactions. This process 
was effective enough for me to be able communicate independently across a range of informal contexts; I could watch Japanese television, spend time with friends who knew little or no English, communicate with my wife and in-laws, and manage all of my day-to-day interactions. My most recent migration (nearly four years ago) brought me and my family to New Zealand. Here again, I have witnessed on a daily basis the effects and impact of the language learning process as it relates to the opportunities and challenges it affords myself and others around me. I see my Japanese wife engaging with local New Zealanders and other migrants through English as she 'negotiates' her own integration; I observe my children confronting the challenges of balancing their English, Japanese, and Spanish learning; and all around me, I notice international colleagues and friends (almost all from non-English speaking countries) striving to manage the demands of studying and working in an L2.

Throughout these varied experiences, one thing that has always impressed and inspired me, professionally and personally, is the diversity of this phenomenon. Each individual, as they participate across a range of L2-related activities, develops a particular way of perceiving and evaluating their communicative interaction, and it is through these idiosyncratic interpretations that the diversity and totality of the language learning experience can best be appreciated. As Benson (2004) has aptly noted, an interest in the 'difference and diversity' of language learning 'presupposes an interest in learners' (pg. 5). And I believe that an interest in learners inevitably involves moving beyond a focus on their linguistic achievements, toward a more holistic appreciation of the varying thoughts, emotions, and contexts impacting the experience of learning an additional language. Thus, it is with this conviction for the need to include, in applied linguistic and second language learning research, comprehensive accounts of language learners' L2-related experiences, that this study is situated. Below I outlined the explicit aims for this research.

\subsection{Aims for this study}

The primary purpose of this study is to investigate the totality of the L2 experience from the perspective of the language learner beyond the setting of a language learning classroom. More specifically, I aim to construct an intricate, participant-specific understanding of how adult language learners manage out of class, day-to-day L2 interactions. To construct this comprehensive picture of this L2-related activity, I will explore the interplay over time between learners' perceptions of L2related themes and their accompanying behaviour.

Benson (2004) has argued that learner-centered research in SLA and applied linguistics has been a cornerstone of the field for nearly 70 years (pg. 6). In fact, the substantial body of work in areas such as learner motivation (Dörnyei \& Ushioda, 2009) strategies (Oxford, 1989), aptitude (Skehan, 1991), and autonomy (Benson, 2001) (to name but a few) clearly illustrates that the learner and the learning process are considered central to our understanding of how individuals acquire a 
second or additional language. However, despite this focus, research centralising participants' 'experiences' learning an additional language and the impact of these experiences on L2 development, remains relatively underexplored. With the exception of some excellent work in this area (Barkhuizen, 2013; Block, 2005; Font \& Mendez, 2014; Menard-Warwick, 2009; Mercer \& Williams, 2014; Norton, 2013; Pavlenko, 2007) research in applied linguistics and second language acquisition has traditionally tended toward a conception of learners more as objects of exploration than as active subjects of impact within the larger, multifaceted process of learning an additional language.

Furthermore, studies on adult participants' L2-related activity have largely remained limited (Bellingham, 2004). Ortega and Iberri-Shea (2005), in their in-depth survey of longitudinal SLA research, beside noting the 'dearth of methodological discussions about longitudinal research in applied linguistics', also point out that research on adult L2 learning remains an underexplored domain, particularly in 'non-university contexts' (pg.28). The fact that adults' L2-related experiences remain peripheral in applied linguistics and SLA study is an issue that needs to be addressed. It is an issue that Ortega (2014a) has argued is largely the result of SLA work 'privileging' age over experience as predictors of success. She adds that it is important for research in this area to reconceptualise how it views $L 2$ exposure and experience and asks that research view not only the 'constraints of maturation' but also the many 'opportunities' it affords. Bellingham's (2004) study on mature adult (i.e. over 40), in-class language learners in fact shows that there is a lot to be learned about the L2 learning process from careful examination of adults and their approaches to L2 learning and use.

In addition to the interest in adult language learning experiences, this study also delves into another area of previously limited exploration: language learning beyond a formal classroom setting. While there has been a recent rise in interest in this area (Benson \& Reinders, 2011; Nunan \& Richards, 2015), our knowledge of how adult language learners manage their L2-activity outside of a classroom remains insufficient. This study aims to remedy this dearth through an investigation into the opportunities and challenges afforded this particular group of language learners and how, with minimal support, they are able (or not able) to navigate these highly affective interactions. In exploring L2-related activity beyond the classroom, the focus will be on learning not only what it is that learners do (and how they do it) but to a larger extent, what is motivating this behaviour and how this behaviour is being recognised by the learners themselves. In other words, how they are experiencing this behaviour. Situating my argument in the field of language learner beliefs (cf. Kalaja \& Barcelos, 2006) and language teacher cognition (cf. Borg, 2006), I posit that exploring what people think and feel (including what they say they think and feel) can help us develop a nuanced picture of the different internal motivations and external parameters affecting L2-related activity beyond the language classroom. In this thesis, I explore this argument in detail across a group of recently arrived adult migrants in New Zealand. In looking at the language-related experiences of migrant language 
learners across a range of naturalistic contexts, I aim to also construct a descriptive account of the migration experience and how it is directly associated with L2-related activity.

In light of these explicit research aims, I present in the following section, the study's research questions.

\subsection{Research questions}

This study carries at its core the explicit assumption that the 'mental lives' of language learners drive their language-related behaviour. In other words the assorted intermingling of beliefs, self-beliefs, assumptions, attitudes, self-knowledge, along with the associated, inseparable emotions that language learners carry (consciously or unconsciously), underlie their approaches to language learning and use, while also operating as reflections of their language learning experiences. The study also holds that beyond the 'mental context' impacting on L2-activity, the socio-cultural context plays an equally significant role in determining what learners (can) do and experience. With that said, I adopted 5 research questions to guide my exploration into the development of this L2cognition in a group of adult migrant language learners. These questions are presented below:

RQ 1. What are the prior language learning experiences of a group of adult migrant learners living in New Zealand?

RQ 2. How have these prior language learning experiences influenced the construction and development of their beliefs, assumptions, knowledge (BAK) about language learning?

RQ 3. What is their perceived need for English in their current socio-cultural context?

RQ 4. How do adult migrant language learners engage in language related activities beyond the classroom?

RQ 5. How can this language learning behaviour be reflected in a model of language learner cognition?

In research questions 1 and 2, I will explore the participants' prior language-related experiences to provide a type of L2-related, cognitive profile. This exploration will hinge on investigating how any past L2-related activity or exposure may have led to the construction of L2related beliefs, assumptions, and knowledge (BAK) in the participants. The profile will be useful in helping illuminate and understand the participants more current language-related activity (research questions 3 and 4), within the greater ESOL immersion context, and across more specific day-to-day interaction. This investigation of the participants' naturalistic L2 interaction will support the consequent exploration of the interplay between their cognition and their behaviour as language learners. The final research question explores the extent to which an in-depth examination of a language learner's L2-related experiences can be reflected in a framework of their cognition in context-specific action. 


\subsection{Thesis overview}

In Chapter 1, I introduce the primary motivation and aims for the study. I also present the study's guiding research questions. In chapter 2, I position my research within the field of language learner beliefs (in SLA) and language teacher cognition (in educational psychology). I survey significant research on language learning beyond the classroom as well, as the primary type of L2 activity investigated in this research is naturalistic (i.e. takes place out of a more formal classroom setting). Chapter 2 concludes with a working definition of language learner cognition. The third chapter is a detailed description of the research methodology adopted for this study. In this chapter, I introduce the research design and rationale for the approaches to data generation and analysis. The study's participants are described along with a detailed depiction of the process of gaining and maintaining access, as this proved a significant factor in shaping the nature of the generated data. An extensive pilot study is also presented as it illustrates the importance of not only trialling and 'learning' about the primary methods used for gathering data (in-depth, ethnographic interviews) but also the value of practicing and developing these approaches as skills integral to the success of this research. In chapters 4 and 5, I present the main findings for the study. Chapter 4 frames a picture of the participants' pre-New Zealand language-related experiences and the impact of these experiences on their developing cognition as language learners. Chapter 5 examines the participants' L2-related experiences in New Zealand, investigating the interaction between their developing 'perceived' needs for English and their language-related activity. In chapter 6, I adopt a case-study approach while framing the final research question around an in-depth exploration of the developmental process of language-learner cognition. A framework of this complex process in action, centralising the language learner, is constructed from this discussion. Chapter 7, beyond offering a concluding word on the research project, presents the study's main theoretical and methodological contributions. Finally, directions for future research, such as adopting the constructed framework of language learner cognition into the classroom, are presented. 


\section{Chapter 2 Survey of literature}

\subsection{Introduction}

This chapter begins by considering English language learning across different contexts. A description of research conducted on adult migrants as language learners specifically in the New Zealand context follows. Next, studies on second language learning beyond the formal classroom are discussed. These sections highlight the need for research in language learning development to extend its conception of locations for learning, and thereby gain a more nuanced picture of L2 development. Following this, I examine relevant research on certain psychological constructs in language learning. Mercer, Ryan, and Williams (2012), associating language learning psychology (LLP) with educational and social psychology, define LLP as 'the mental experiences, processes, thoughts, feelings, motives, and behaviours of individuals involved in language learning' (pg. 2). Specifically, I evaluate the rationale, development and position of work conducted on learner beliefs (Kalaja \& Barcelos, 2006; Kalaja, Barcelos, Aro, \& Ruohotie-Lyhty, 2015) (a subset of second language acquisition studies). Learner beliefs are of particular significance for this study as research conducted in this area has led the way in promoting the need to more intricately understand how certain sociopsycho-emotional factors impact both approaches to language learning and actual language development. An overview of research on language teacher cognition (Borg, 2006; Woods, 1996) (a branch of education studies) follows. The rationale for including work on language teacher cognition in this project lies primarily in its comparatively expansive conception of cognition - language teacher cognition essentially provides a more encompassing, holistic picture of the different mental constructs at play at different levels of time and place (i.e. than learner beliefs). The concept of cognition (as a representation of a variety of possible attitudes, assumptions, knowledge, beliefs including self-beliefs - and a host of other constructs - in chaotic interplay) thus makes it easier for investigators to adopt a more complex, multifaceted view of their subject of inquiry. The sections on LLBs and LTC offer a perspective on significant 'where' and 'how' aspects of second language (L2) learning. Through the survey of this research, I argue that adapting some of the key perspectives (e.g. the centralisation of learners in belief studies; the extensive view of mental constructs in cognition research) from these distinct but complementary fields can help advance understanding of the intricate interplay between cognition and behaviour in an L2 learning context from the learner's perspective. The argument for adopting more transdisciplinary approaches to help build theory and develop research agendas in language education and language learning research has been recently made effectively by the Douglas Fir Group (2016). The Douglas Fir Group is a collection of SLA scholars from across a range of subfields, who together argue that a transdisciplinary view 'treats disciplinary perspectives as valid and distinct but in dialogue with one another in order to advance real-world issues' (pg. 20). Moreover, they are explicit in their position that: 
SLA must now be particularly responsive to the pressing needs of people who learn to live and in fact do live - with more than one language at various points in their lives, with regards to their education, their multilingual and multiliterate development, social integration, and performance across contexts (pg. 20)

In order for SLA research to meet these 'pressing needs' of the individuals it takes as its subjects, objects, and participants, the group strongly promotes the need for studies in SLA to support not only language theory building and additional language learning, but also 'crucially', language teaching (pg. 22). Thus, in this light, this study can be regarded as a kind of first step for what can be valuable collaboration between the field of language teacher cognition and second language learning. The chapter concludes with the study's research questions.

\subsection{English language learning contexts}

The rapid rise of globalisation (in all its vice and virtue) means that now more than ever learning an additional language is a highly sought after endeavour. Amongst the most commonly learned second and foreign languages, English remains the most popular. In fact, according to Crystal (2003) approximately only $25 \%$ of English users in the world are native speakers - the remaining $75 \%$ are learning English in some capacity. It is also the language most frequently associated with international trade, development, and intercultural communication. Seidlhofer (2005) has termed it the 'global lingua franca' (pg. 339). Thus, learning English is very much an international phenomenon. As a consequence of this significant role, English language education has been extensively researched across a diverse range of settings. For example some research looks at English education in places where English is not the most commonly used language (English as a foreign language context), while other research is dedicated to understanding English language education in a context where English is the most commonly used language (English as a second or additional language). In New Zealand, an English-speaking country with one of the highest percentages of overseas born people in the OECD (Ministry of Social Development, 2008), an increasing number of immigrants and refugees are from non-English speaking backgrounds (Watts, White, \& Trlin, 2002). As a result, a variety of language-related issues have been identified and investigated within this setting to help better understand and accommodate for the inevitable linguistic and cultural diversification resulting from this phenomenon. The section below highlights some of the language-related studies that have been conducted in the New Zealand context (the setting for this study) on migrants and refugees (the participants for this study).

\subsubsection{Adult migrant language learners in New Zealand}

As previously mentioned, a number of important studies in the New Zealand setting have explored the language-related ( $L 1$ \& L2) experiences of immigrants and refugees. Barkhuizen and Knoch (2005) investigating language-related experiences of Afrikaans-speaking immigrants from 
South Africa living in New Zealand, identified a type of 'linguistic longing' in the participants which resulted from the 'gap' between their 'language behaviour' in South Africa and their language use in New Zealand. The researchers argued that this sense of longing is rooted to large extent in the participants' perceptions of potential language loss and shift of their L1. Revis (2015) explored more directly the factors affecting language loss and shift through her ethnographic investigation into family language policy across two refugee communities (Colombian and Ethiopian) in New Zealand. She found that despite the respective community members' positive attitudes towards their ethnic languages, their attempts to develop and maintain these languages were significantly constrained by the perception of English as carrying 'considerable cultural capital' in New Zealand. Gharibi and Boers' (under review) study on young heritage speakers' vocabulary knowledge, offered a different perspective on the conception of language-related experience, looking specifically at how vocabularly development affects and is affected by the migration experience. While these studies have examined language-related issues (e.g. linguistic longing; language shift; language loss; family language policy; vocabulary knowledge) for immigrants and refugees in New Zealand, the challenges surrounding language learning, specifically learning English in New Zealand, remain relatively unexplored (section 3.3.2 has more information regarding the micro and macro context of this study). The work of the 'New Settlers Programme', undertaken by Watts, White, and Trlin (2001) has offered some of the most substantial information into this particular language-related experience. This work has extensively surveyed adult immigrants' and refugees' experiences with ESOL provision offered in New Zealand, including their perceptions of these provisions. In addition, it has looked at the 'providers' perceptions' of the needs and challenges for these learners. In Watts et al. (2002) study entitled, 'New Zealand as an English-language learning environment: Immigrant experiences, provider perspectives and social policy implications' the researchers acknowledge the importance of 'individual effort and investment' in developing the necessary language skills to settle into their new lives, and make a call for greater commitment from surrounding communities to help facilitate this often daunting process:

While formal English-language instruction is extremely valuable for NESB immigrants, it cannot provide ongoing opportunities for participating in everyday social interaction and community networks, which form much of mainstream life in New Zealand. Most importantly, the commitment of the entire community is essential to the inclusion of immigrants in everyday life, with the adjustments this entails, and the fostering of this is a key part of any successful immigration policy

(pg. 160)

This call is noteworthy, as it alludes quite appropriately to the significance of adult immigrants' and refugees' language-related experiences beyond the classroom, i.e. in naturalistic settings. Despite the knowledge that significant $L 2$ development takes place in naturalistic settings (particularly in immersion contexts), work on out-of-class language learning experience (regardless 
of the target language) remains limited. While research has been conducted on out-of-class language learning in New Zealand (Barkhuizen, 2015; Pearson, 2004) only Barkhuizen's (2015) recent study worked with adult migrants. Although this research appreciated that 'not all language learning takes place in classrooms' (pg. 282), it nevertheless focused on a particular mode of language learning (home tutoring), rather than on individuals' experiences of learning an L2 beyond a formal context. As the majority of interaction for recently arrived migrants, outside of their established L1 community will inevitably take place across a range of naturalistic L2 contexts, it is important to survey in more detail this influential context as a site for $L 2$ development.

The section below explores work that has been conducted on out-of-class language learning, illustrating the value of this type of work in helping build a more comprehensive knowledge base of L2 learners and their development, as we see change and learning taking place beyond classroom interactions.

\subsection{Language learning beyond the classroom}

Ortega (2014a) argues that SLA theory, in accounting for late bilingual language development, needs to at best centralise and at least include, 'experience of language'. In fact, she calls SLA work failing to account for experience of language, 'insufficient'. And if we extend the study of language development to include learners' development of self, and its interrelated subsections such as identity or cognition, the need to consider language-related experience becomes even more significant. Not only should the range of investigations into language learner development be expanded to include experience as a unit of analysis, but the range of surveyed experience itself needs to also be extended. For example, in adult immersion contexts (e.g. recently arrived immigrants \& refugees), where learners have low-to-no proficiency in the L2, a considerable amount of the interactions outside of the home are a type of L2-related experience. In other words, the daily interactions taking place beyond the traditional confines of a language classroom have the potential to act as language learning experiences which affect not only subsequent language use but also prospective behaviour. As Baquedano-Lopez and Figueroa (2011) have discussed, the interactive contexts of immigrant populations are important sites for understanding how immigrant groups negotiate participation in and influence new communities and social institutions (pg. 538). In addition, positioning these day-to-day interactions as language-learning domains offers valuable glimpses into some of the physical and social boundaries which adult language learners experience.

While it remains relatively peripheral, learner experience in the foreign/second language classroom has been growing in interest, particularly with the advent of a more social approach to SLA (Duff, 2006; Mackey \& Polio, 2010; Ochs, 1991). However, little is known about learners' experiences with language outside the classroom in relation to cognition. That is, few studies have looked at how language learning beyond the classroom, specifically the day-to-day interactions in an individual's L2 impacts and is impacted by, cognition. Investigations into language learning that take 
place outside conventional parameters of classroom learning can add value to the discourse of language education by providing a different way of perceiving the socio-cognitive process impacting language learning, as an example of individual experience. In other words, focusing on the L2 behaviour 'beyond the classroom' (Benson \& Reinders, 2011) can advance the development of SLA research by expanding our conceptions of the practice of language learning. In his attempt to define language learning beyond the classroom, Benson (2011) explains how this type of naturalistic learning can differ from 'out-of-class', 'informal', 'self-directed' and 'autonomous' learning in both scope and practice. It is more than the supplementary classroom learning that students perform 'independently to broaden their knowledge of a subject' (p. 9). Language learning beyond the classroom includes: dimensions of location, formality, pedagogy, locus of control, and a distinction between settings and modes of practice ( $p .17)$. The individuals involved are not necessarily 'students' in the traditional sense, and the setting in which this learning takes place is more than location; it is 'a set of circumstances' within a physical and social space that facilitates and limits possibilities for development (p. 13). Although studies on L2 learning beyond the classroom do exist (Hosenfeld, 2006; Navarro \& Thornton, 2011; Pearson, 2004; White, 1999) and are drawing increased interest, they remain sporadic. A cursory glance at journal and book publications concerned with SLA research suggests that foreign and second language learning is almost exclusively concentrated on the formal classroom setting. It remains a reality that a great deal of the territory for language learning beyond the classroom' have yet to be explored to their full potential. The highly personal and unconventional nature of this type of learning, including the diversity in learner type, invites innovative use of research methods. Capturing it in its proper complexity suggests the use of qualitative methods, particularly those with an ethnographic proclivity rooted in descriptions and evaluations of experience. Through these interpretive methods, which traditionally rely on observation and discourse analysis, we can gain a richer understanding of how context shapes content; in other words, how the myriad of social, historical, and cultural factors (both physical and psychological) can affect the language learning practices of different individuals.

Additionally, the findings of this type of research can help redefine how we perceive language learning generally, and L2 learning specifically. Divita's (2011) ethnographic study, for example, exploring the naturalistic language learning experiences of two Spanish women in France found that in language learning settings beyond the traditional classroom, the idea of 'acquisition' shifts toward a conception of becoming 'multilingual'. Work conducted on the social psychology of language learning should seek to better understand the inherent complexity of different mental constructs as they play out in the real lives of learners. In many ways, when we look at the language learning experiences of people in immersion contexts, we are exploring their lives. And to do this well - to look closely at and try to make sense of someone's life - demands a holistic approach which begins with and focuses on real learners in 'real' action. With that said, we know then that as much learning happens in as out of the language classroom. It is therefore also worth exploring 
'how' this learning might occur and what factors, internal and external, affect its practice and development.

\subsection{The mental lives of learners and teachers: Cognition studies in language education}

Social science research, which carries at its core an interest in descriptions of human development, has long grappled with the 'relationship' between thought and behaviour. Studies conducted in fields as diverse as marketing, business, health, and education posit that the progress of practice, i.e. making practice more effective, hinges to a large extent on a precise understanding of how an individual's thinking impacts their actions (Coviello, Brodie, \& Munro, 2000; Grol \& Grimshaw, 2003; Korthagen, 2010). A relatively recent extension of this idea maintains that for practice (as a domain-specific type of behaviour) to develop, it is imperative that the practitioner or individual first undergo some type of psychological change. In the context of language learning, two areas have focused specifically on this notion of development: learner beliefs and language teacher cognition. Unfortunately, while both fields are concerned with the intricacies of language education, and both centralise the effects of cognitive constructs on language learning-teaching behaviour, there exists almost no evidence of contact between the two. Their distinct points of origin may be partly responsible for this lack of collaboration.

Studies on learner beliefs have traditionally been grounded in the area of second language acquisition, while language teacher cognition research is rooted in teacher cognition studies (including work on teacher beliefs, knowledge, and thinking), a subset of educational research. However, in a very recent publication, some of the world's most influential and respected scholars working in second language acquisition have made a powerful call for a 'reimagined' SLA that would ensure that research and theory feed directly into the teaching of second and additional languages:

In our estimation, then, SLA, precisely because of its unmistakable focus on language development, ought to contribute useful knowledge for the improvement of education and instruction of any and all languages, including English with its special status as a global language

(Atkinson et al., 2016)

Below is an exploration of the developmental trajectories of learner beliefs and language teacher cognition, as I look to introduce points of overlap.

\subsubsection{Language learner beliefs}

Learner belief studies aim to explore change in and development of learning (i.e., language learning behaviour) in the learners who embark on this process. Beliefs themselves have most 
commonly been viewed as a type of unique learner quality or feature which help account for learner outcomes (cf. Dörnyei, 2005; Dörnyei \& Ryan, 2015). A relatively new area of research interest in second language acquisition (SLA), it is broadly defined by Kalaja and Barcelos (2006), two of the field's foremost scholars, as investigations into the 'opinions and ideas that learners (and teachers) have about the task of learning a second/foreign language' (p. 1). As the focus in SLA shifted toward learners and their contributions and roles in the language learning process, more and more researchers were exploring learner thinking through beliefs (Kalaja \& Barcelos, 2006), with the rationale that beliefs affected how learners behaved in the language classroom, including how they interacted with classmates, teachers, and materials (Horwitz, 1988, 1999). Originally, research explored ways of managing the 'clash of expectations' experienced by learners as they were increasingly exposed to unfamiliar communicative language teaching-learning methods (Horwitz, 1985 , 1988). Later, the scope of belief studies expanded and began looking at various learner beliefrelated areas such as learners' readiness for self-directed, autonomous language learning (Cotterall, 1999; Wenden, 1998). Similar to a lot of the earlier work in teacher education, the underlying assumption underpinning this branch of study was that learners' beliefs could serve as an explanatory principle for learner behaviour. While this early research was important in paving the way for studies into the relationship between what learners think and how they behave, the methodologies, as well as the key assumptions they carried about beliefs, were limited. Almost all of the early studies on learner beliefs used closed-item questionnaires developed by teachers (the most common, by far, being the Beliefs about Language Learning Inventory - BALLI - created by Horwitz). While some questionnaires did try to eventually include open-ended items to help more accurately capture the different perceptions students might carry about language learning, their understanding of beliefs, and consequently the methods used to investigate them, remained narrow. Beliefs were seen as static, 'preconceived notions' (Hosenfeld, 2006) or unchanging misconceptions and opinions that learners have about language learning and the best way to uncover them was to measure learners' responses to Likert-scale instruments.

Fortunately, the field continued to evolve and research on learner beliefs worked on developing new ways of understanding these constructs along with innovative ways of investigating the different ways this mental phenomenon is constructed and revised. Kalaja and Barcelos (2006), following a special issue of System (Wenden, 1999), presented an edited collection of studies illustrating some major advancements in the field of learner beliefs. Framed within the underlying view that beliefs are 'contextual', meaning that they are embedded in different socio-learning contexts, the research in this collection presents a diverse set of data collection and analysis techniques. Ranging from the discursive (see Kalaja, 2006) to the social constructivist (Alanen, 2006), these studies reflected a complexity and dynamism of learner beliefs previously unrecognised. Additionally, this research helped reconceptualise our understanding of learner thinking. Whereas past investigations ignored the role of experience on belief development and refinement, more 
current studies were positioning experience as a key component. As Ana Maria Ferreira Barcelos (2006) explains in her critical review, current approaches seek to 'understand beliefs about SLA in the social context' (p. 26). In other words, the role contextualised interactions (as experience) have on creating and enacting beliefs has become integral in their understanding.

Barcelos and Kalaja (2011) revisited beliefs research in an effort to further trace developments in the field. As editors of the most current special issue of System on beliefs, they highlight expanding geographical interest (papers in the 'Special Issue' come from a variety of locations including Japan, Brazil, China, Korea, Turkey, Singapore and Austria), but more importantly point to a significant shift in focus. Barcelos and Kalaja indicate how whereas previous belief studies were primarily interested in describing 'what' language learners believed about language learning, research was now more interested in 'how' beliefs develop, fluctuate and interact with actions, emotions, identities or affordances and how they are constructed across a range of contexts (pg. 282). This interest in the processes involved in belief appropriation, negotiation, emergence, and change has resulted in further important developments; most notably, the adoption of developmental theory and an 'emic' perspective. As Barcelos and Kalaja (2011) explain, most of the studies in the special issue draw on sociocultural theory or similar approaches (pg. 281) which hold at their center the development of the individual. The introduction of sound theoretical frameworks to the study of beliefs in SLA is important as it addresses a significant criticism of the field (e.g. Dornyei, 2005), questioning the extent to which traditional belief research carried an adequate 'theoretical basis' (pg. 216). Furthermore, while the majority of traditional research used questionnaires and carried an 'etic' perspective, more contemporary studies are focused on capturing participants' perspectives of experience, i.e. emic (similar to Woods' 1996) 'participant centred' study). In fact, all of the studies use interviews, many with open-ended questions and in combination with other tools such as document analysis, reflective journals, learner histories or autobiographies. However, only one longitudinal study, Mercer's (2011b) investigation into complex systems and self-concept, adopted in-depth, unstructured interviews (the majority of belief studies continue to use semi-structured interviews, asking explicitly about particular beliefs. cf. Kalaja \& Barcelos, 2006; Kalaja et al., 2015). Studies on language teacher cognition (cf. Woods, 1996; Freeman, 2012) have questioned the method of 'asking' explicitly about beliefs, as often what learners and teachers believe and feel lies below the surface of our awareness or consciousness. Mercer explains how her data collection methods (multiple informal interviews covering varying time scales \& weekly journal entries) were ideal in helping reveal cognitive variability in her participant, as well as demonstrating the complex and dynamic nature of change (pg. 338) within an individual. In fact, of all the studies in the special issue, Mercer's was the only study which actually provided clear evidence of dynamism and complexity in regards to belief development. As a result of these developments in beliefs research, a more complex picture of beliefs and their role in language learning has been painted. 
Some of the most current research on learner beliefs has been conducted in response to calls for more 'contextual' and 'interconnected' approaches (Kalaja et al., 2015, pg. 4). In addition, this newer work focuses as much on learner beliefs as it does on teacher beliefs, while also incorporating both the learning and teaching of English and other languages. These contemporary approaches to beliefs research no longer view beliefs as strictly psychological constructs 'residing in the minds of teachers and learners' but rather as constructs that emerge in specific contexts and that are co-constructed in interaction (pg. 5). Finally, there is also important innovation in the methodological approaches and design of this research (e.g. methodologies that are exclusively qualitative or interpretive; 'truly' longitudinal; and rooted in a contextual understanding of development). As a result of these attempts to address some of the field's more significant challenges, studies have been able to promote a more complex, emergent understanding of beliefs. Of particular importance is the expanding picture of these constructs as they 'interconnect' with learners' developing agency and identity.

In Aros's (2015) study on two female Finnish learners of English, she explores, over a 14 year period (first interview at age 7; final interview at age 21), the agency of her participants as it manifests itself in the context of a research interview. Agency, in Aro's research, is viewed from a 'dialogically informed perspective' (pg. 51), meaning that it is observed in action through the participants' discussion of their ability or inability to engage in certain language learning activities, such as learning English through reading and writing or watching television. In other words, for Aro, the focus is on how the participants 'talk about their agency' as a capacity to engage with learning English and how this discourse manifests itself over time. It is through the talking about agency that Aro observes some of the different contextual factors (the formal classroom; out-of-class) at work across a range of English learning activities which serve to enable or inhibit one's ability to act. In this regard, it was important to note that the participants were enacting their agency both as language learners as well as language-learners-as-interviewees (pg. 52). This led Aro to the insightful declaration that it is 'not only the Others and the contexts of the learning situation that have an effect on how they express agency, but also the Other and the context of the interview situation'. Aro's research on the relationship between agency and language learners' beliefs is of particular importance in how agency is conceptualised within SLA. Rather than viewing agency as an individual capacity or ability, she argues for the need to appreciate and examine 'the entire system where learning takes place' (pg. 64), exploring how beliefs and assumptions, interact with learners' practices.

In her work, Barcelos (2015) explores the complexity of 'identify formation' in studentteachers of English in Brazil. Using written narratives and oral interviews, Barcelos worked with her participants over a three year period as they embarked on a Bachelor's programme in English teaching. Her research adds value to the field of language learning beliefs as it depicts the interplay between beliefs, motivation and the formation of individuals' identity, in this case, their 
'professional identity' (pg. 71). Few studies exist that have looked at this interplay, especially in teachers. Her longitudinal research describes the effects of national culture and associated ideologies on student teachers'motivation to enter the profession, arguing how in some places (e.g. Brazil, some African and South Asian countries), teaching as a profession is considered 'semiprofessional' and carries a low status 'due among other factors, to the easy entry into the profession' (pg. 73). Students' negative attitudes toward learning English were also seen as a factor affecting the student-teachers' motivations to declare themselves as teaching professionals. In fact, Barcelos' study illustrates how the student-teachers' beliefs and their 'lack of motivation' to become teachers impacts 'their ambivalent identities as future English teachers' (pg. 81). The fact that they enjoyed learning English, and valued their identity as language learners, but did not particularly like or respect teaching it as a subject, served as a rather clear example of how beliefs and motivation, as parts of a larger system can play key roles in the formation of one's context-specific identity.

In sum, current research on learner beliefs, which is moving toward viewing these constructs in interaction as parts of a complex system, rather than as individual explanatory forces, can help advance not only the theory underpinning this SLA sub-discipline, but also the ways in which teachers and learners understand each other and their behaviour, including their capacity to act (agency) and be (identity). As the authors and editors (Kalaja et al., 2015) of this excellent volume on learner beliefs declare, an important discussion of 'beliefs, agency and identity as interrelated phenomena' (pg. 218) traced over time across contexts of foreign language learning and teaching has been started, and now more research in this area will be needed to take the exploration further and deeper.

With that said, while studies on learner beliefs have progressed in their approaches to investigating beliefs, including how they are conceptualised, there remain significant limitations and challenges which need further attention. For example, more work needs to be conducted on the origin and emergence of learners' beliefs. While some studies have looked at this area (Alanen, 2006; Hosenfeld, 2006), further explorations would benefit from looking more specifically at the role of prior experience with formal education; experience with language; experience with family; experience in a particular language-related interaction, on the construction of beliefs about general 'learning' and language learning, specifically. In addition, it is important that this work focuses not only on an implied construction but also on the process of this construction. In other words, more studies need to spend time with the participants (learners and students) to explore belief construction in action. Little research has actually observed how beliefs interact with behaviour over time. Although noted as a key area for further exploration (Barcelos, 2006), only a handful of studies have attempted to add to our understanding of this relationship (see Aragão, 2011; Navarro \& Thornton, 2011; Peng, 2011). In Navarro \& Thornton's (2011) investigation, the researchers analysed the interplay between belief and action in a self-directed language learning context. Specifically, their study focused on the role of spoken and written dialogue between learning advisors and 
learners (Mynard \& Navarro, 2010) as a catalyst for belief development. Through face-to-face advising sessions and written reflective journals, the advisor-researchers aimed to help learners become more effective autonomous language learners. They argued that to do so, awareness of their language learning beliefs, including beliefs about independent learning, would need to be raised. The study not only demonstrated the impact language advising dialogue can have on belief development, but also showed how dialogue as a form of interaction can act as a type of belief-inaction. In other words, the nature of conversations about language learning can facilitate the communication of personal evaluations (as illustrations of belief) of $L 2$ related concepts. While the study did not observe the learners 'learning' or interacting (an inherent challenge of studies on out of class learning), it did evaluate learners' extensive documentation of their out-of-class work, and focused on learners' interpretations of their out-of-class learning. In the end, the authors concluded that the advisor-learner dialogue as an example of beliefs-in-action was essential in eliciting, refining, changing, and creating beliefs. However, they found evidence against assuming belief change from verbal commentaries and suggested triangulating dialogic evidence with documentation (pg. 299).

One of the main concerns with the studies which have looked at belief change over time is that they tend to mostly offer snapshots of change. Often, claims regarding belief change are made in terms of learner 'improvement' or 'regression' based on pre- and post interviews. There is little description of actual 'processes of change' or of beliefs in action, i.e. how beliefs emerge and change as a direct result of interactions at different times, and how these beliefs shape not only the interaction itself but also the interpretation of these experiences. Even in studies that are considered 'truly longitudinal' (e.g. 14 years in Aro's (2015) study on young Finnish learners beliefs about language learning), only four interviews were conducted and they asked questions directly related to the participants' beliefs and possible factors affecting their development. While this study is longitudinal, the fact that the interviews were not carried out on a consistent basis over time, but rather more like 'one-off' meetings meant that it is a challenge to actually observe the process of belief development as it relates to their experiences. In other words, there is evidence of beliefs changing but little indication of how this change has come about. Because the process of gathering data and interviewing was not ongoing, it is not to understand the comprehensiveness of this phenomenon and the different factors impacting it. In many regards, what we see from these types of studies is categorisations of various beliefs, indicating development. Unfortunately, it remains a challenge to ascertain, at an individual level, how these beliefs evolved.

Furthermore, when claims about belief change are advanced, it seems like it is the context which is changing, more than the actual beliefs themselves. Peng's (2011) study of a first year college student's beliefs about English for example, argued that 'substantive' changes had taken place as the student transitioned from high school to university (pg. 318). The student initially reported positive beliefs toward learning English for communicative purposes but shifted toward 
more negative ideas as he progressed through his studies. Peng interviewed the student three times (beginning, middle, end) over two trimesters (a total of 6 interviews) and claimed to observe belief change over this time. However, it is important to note that positive beliefs toward oral communication were being expressed while the student was in an English proficiency class, meant to develop oral communication skills, and the more negative beliefs were reported while the student had transitioned to his 'medical English' class, where the focus was on learning medical terminology. While, Peng claims that the difference in the student's responses is evidence of belief 'formation' or change (pg. 320) it seems as likely that change in context (moving from an English proficiency class focused on oral communication to a medical English class focused on medical terminology and reading) is affecting how the student reports his ideas regarding English. This study in fact, is an excellent example of the situated nature of cognition. It illustrates the importance in carefully evaluating the interaction between individual, context, and behaviour. Specifically, the nature of a particular interaction in a particular setting, the other members in the setting (including the researcher), the goals and motives of the individuals, will all affect the emergence of particular beliefs; particularly, when the beliefs are being evaluated through verbal reports. Participants' responses can be as much a product of their interpretation of a new situation as them actually having undergone belief change. In fact, it is easy to imagine beliefs in a state of constant action, affecting and being affected by context. As Yang and Kim (2011) demonstrate, beliefs are 'constantly (re)shaped in accordance with L2 goals in the context of social interaction'. This argument seems a more apt picture of trajectories of belief movement, where it becomes less a question of changing 'established' beliefs and more to do with adjusting and reacting to situations and interactions.

In many ways, the studies conducted on belief and action have only just begun to scratch the surface of understanding how our mental lives interplay with our social behaviour. A good example of the potential for beliefs research to explore the dynamic processes associated with belief construction and activity, is Dufva's (2003) dialogic study of Finnish adults' views on language learning and teaching. She adopted a 'cognitive' (as opposed to 'cognitivist') view of beliefs which sees them in ongoing activity and interaction with the world (pg. 135), whereby change and development are constant and products of the dynamic interplay between the social and the individual. Dufva argues that beliefs can be effectively evoked by having participants speak (or write) about personal experience. In this way, one memory usually evokes another, and the associations keep coming to mind, either by themselves or with the help of the interviewer' (pg. 140). In other words, through dialogue, experience becomes the object of study, resulting in the inevitable communication of both consciously and unconsciously held beliefs. Also, more longitudinal research needs to be conducted in more of an 'on-going' manner, across different contexts to develop a more nuanced understanding of the different ways learners' mental lives interact with their everyday interactions, both within the language learning classroom and out. Ongoing interpretation of experience from the participants would serve as an ideal way of exploring beliefs in action. 
Collection methods can be designed to capture this type of continuous interpretation. As a consequence, development in beliefs can not only be accounted for in observed or described interactions, but also discursively, through verbal commentaries. This aligns closely with Mercer's (2012; 2014) call for more holistic studies which work closely and intensively with learners in an effort to better illuminate the process of belief emergence and change - belief emergence as a new way of thinking and believing, but also as a factor regulating and being regulated in each interaction.

(consider the issue of belief studies always asking explicitly about beliefs - centralising their role - rather than examining how beliefs underly the language and activity of particular individuals a more accurate picture of what someone thinks and feels is available in more naturally occurring data - interviews that set out to 'uncover' beliefs and observations used to illuminate these constucts are in some ways 'contaminating' the data.

Finally, one of the most significant limitations of studies on learner beliefs is that they only investigate beliefs, which are but a microcosm of a larger cognitive system. Belief studies, by focusing exclusively on a single aspect of learner thought, not only limit the parameters for exploration, they also constrain our conceptions of how learners think and behave. Like work in mainstream education, beliefs in learner learning need to be seen as a subset of a larger cognitive system which include other constructs, including attitudes, emotions, and knowledge. There is an issue with the idea of beliefs as the central motivating factors behind action. Studies positioning beliefs as central motivating factor behind behaviour and practice, rather than as key subsets of a larger cognitive system, will inevitably describe a less than comprehensive picture of people's actions and continue to experience difficulties in affecting change in our thinking and acting. Particularly within the current SLA climate, with calls for a greater appreciation of complexity and interconnectedness (Atkinson et al., 2016; Larsen-Freeman \& Cameron, 2008a), beliefs research would greatly benefit from seeing how beliefs interact with not only a range of interactive languagerelated experiences and contexts, but also with the host of other psychological constructs at play throughout. In fact, the oft-discussed problem of observing incongruities between belief and action may be a result of promoting a limited view of people's mental lives. As Borg (2006) explains, research which has focused on one psychological construct in particular has 'found it difficult not to include others in the discussion' (pg. 51).

Nevertheless, belief studies have led to important and insightful innovations in relation to language learning behaviour, the most noteworthy being the much needed focus on the learner and the learning process as a socially situated act (Donato \& McCormick, 1994; Richardson, Anders, Tidwell, \& Lloyd, 1991; White, 1999). The potential for work coming out of this field remains significant. However, if research examining the interplay between thinking and behaving in learners wishes to delve deeper, it needs to extend its conception of learner thinking. At the moment, the picture we have of learners' mental lives remains fragmented. Furthermore, creating a hierarchy, through separatism, of mental constructs (e.g. arguing again that some constructs are more 
influential than others) falls into the age-old trap of over-generalisation, reductionism and simplification; this is an unfortunate consequence, particularly when the current academic environment highly values the influence of multifaceted contexts and complexity. A cursory glance at contemporary work on language teacher research for example, shows how this field, although continuing to marginalise the learner, has expanded its conception of cognition. One way this has been achieved is by incorporating and inclusive, overarching conceptualising of beliefs, assumptions and knowledge, i.e. BAK (see section 2.4.2). Another way has been by researching beyond what 'teachers think, know and believe' to include constructs such as identity and emotion, recognising that they are equally connected to 'the unobservable dimension of teaching' (Borg, 2012, pg.11). If work on learner beliefs in SLA continues to neglect the range of mental constructs that contribute to the construction of learners' cognition, it will continue to present a narrow view of how learners' minds and behaviour interplay. A more accurate depiction of how language learners' thinking interacts with their behaviour would present beliefs as subsets of a multidimensional cognitive system which links directly and indirectly to various other psychological constructs. What may be needed then is a different, more expansive way of conceptualising this multifaceted psychological phenomenon. This in turn, implies adopting a new definition as well. However, because research is quite frequently inundated with new terms and definitions, which can often add to further confusion, it is worth, before adding yet another term, looking toward a 'neighbouring field' to see what has been previously said and done. With this in mind, I explore research on teacher's beliefs and thinking to see what can be adapted in the context of learners.

\subsubsection{Language teacher cognition}

The rise in interest over the past 30 years in research into the relationship between teacher thinking and practice in education is generally recognised as the result of three major conceptual shifts: (1) the belief of contemporary cognitive psychology that thinking guides behaviour (2) the recognition of teachers as active, thinking participants playing pivotal roles in the language acquisition process and (3) the growing awareness that research preoccupied exclusively with models of teachers' behaviour is inherently limited (Borg, 2006; Day, Calderhead, \& Denicolo, 1993; Sealey \& Carter, 2004; Skott, 2015). Before this, educational research was primarily focused on describing what teachers do in the classroom with the aim of understanding how these actions impact learning outcomes (Guskey, 2002; Richardson, 1996). The primary object of study was teacher behaviour, the dominant theoretical perspective was behaviourist, and classroom observation was the preferred method for collecting evidence. This 'teaching = learning' model also helped support the dominant view within the field that research on teachers should focus on finding and fixing 'practical' classroom problems (Allwright, 2003, pg. 113) with the ultimate aim of making teaching better. Thus, to a large extent, the growth of teacher thinking research can be viewed as a rejection of the long-standing process-product picture of the teaching-learning relationship, where 
learning is seen as a product of teaching and teaching is the culmination of discrete, in-class teacher behaviours.

Consequently, interest in teacher thinking research served to advance an appreciation of the inherent complexity of individual development. Scholars, recognising the need for a more nuanced understanding of what teachers do in the classroom and the consequences of these actions, began exploring the different ways in which cognitive constructs impact teacher behaviour. The idea was that if research is to adequately make sense of what was happening in classrooms, with the aim of improving teacher efficiency and effectiveness, it would need to also understand the thinking processes behind the actions playing out before (planning), during (decision-making) and after class (reflection). Additionally, questions about how particular types of teacher thinking are constructed and what can be done to influence change in thinking were being explored. As Ashton (2015) explains in her 'historical overview' of research on teachers' beliefs, a certain complexity is needed 'to capture the messy construct that is so multiply determined by unconscious as well as conscious influences' (Pg. 42).

Interestingly, a similar trajectory, carrying similar rationales, can be traced across studies on language learner beliefs in SLA. As Kalaja and Barcelos argue throughout their work on beliefs (2011; 2006; 2015), it was the reconceptualization of learners as key contributors to the language learning process which resulted in the growing interest in the field. In other words, this 'shift in focus' (pg. 1), where individuals were viewed as subjects rather than objects of study, meant that the mental lives of both language teachers and learners would be important areas for investigation.

As a result of this emerging appreciation of the role of teacher thinking on practice, alternative research designs were adopted to look at the range of teachers' mental constructs and processes. Investigations into teachers' 'decision making' (Shavelson, 1976; Shavelson \& Stern, 1981), 'information-processing' (Clark, 1980; Yinger, 1986), 'knowledge' (Shulman, 1986, 1987); and 'beliefs' (Nespor, 1985; Pajares, 1992) were being conducted with increasing frequency and rigor. Of these teacher thinking sub-sections, the most influential was (and remains), teacher beliefs. Fives and Buehl's (2012) extensive review of empirical investigations and seminal reviews of teachers' beliefs found over 700 articles published in this area. This significant interest in beliefs is largely predicated on the understanding of beliefs as playing a central role in personal and professional interactions. Specifically, beliefs are said to: (1) filter and interpret information, (2) frame problems and tasks, and (3) guide or direct action accordingly (Buehl \& Beck, 2015). Moreover, as a consequence of this appreciation of the multifaceted function of teachers' beliefs, they have developed the reputation as the primary 'explanatory principle for practice' (Skott, 2015, pg. 16), and are positioned as central facilitators or impediments to progress (Cross francis, Rapacki, \& Eker, 2015). In essence, beliefs are considered ' $a$ ' (in many cases, 'the') central determinant of teaching behaviour and student learning. And it is with this conception of beliefs in mind that many 
researchers approach investigations into the challenges of reform and implementation, i.e. teacher development.

A common challenge associated with belief studies in language education has to do with distinguishing beliefs from other subsets of cognition. In Pajares' (1992) seminal review, he sets out to unpack the problem of properly conceptualising and defining teachers' beliefs as a research construct. He explains how the problem of defining beliefs generally revolves around the distinction between belief and knowledge and understanding how these two constructs differ in their effects on teacher behaviour (pg. 309). In order to break away from this conundrum and allow research to progress through a proper conceptualisation of beliefs, Pajares offers the following generalisation: 'Knowledge and beliefs are inextricably intertwined, but the potent affective, evaluative, and episodic nature of beliefs makes them a filter through which new phenomena are interpreted' ( $p$. 325). In terms of offering a definition, he defines beliefs as a '...judgement of the truth or falsity of a proposition, a judgement that can only be inferred from a collective understanding of what human beings 'say', 'intend' and 'do' (p. 316,). The 'beliefs-as-subjective'; 'knowledge-as-objective' distinction adopted by Pajares remains to this day an important conceptual feature of this research domain. In addition to offering a more precise definition of beliefs, Pajares' review also served to support and promote the view of beliefs as explanatory principles for practice (i.e. teacher's teaching or learner's learning), referring to them as 'the best indicators of the decisions individuals make throughout their lives' (Pg. 307).

While there is little doubt that beliefs can (and should) be used to more accurately understand and explain human behaviour, there are problems with situating them as principal predictors of behaviour. First of all, it creates a type of hierarchy of mental constructs. Arguing that certain aspects of our minds impact our behaviour more than others leads to a modular view of cognition (this same issue exists in learner beliefs study), which fails to adequately appreciate the complexity and interconnectedness of the mind at work. Mental constructs may indeed be different and variable (e.g. knowledge vs. belief vs. affect), and there may indeed by differences in belief types (e.g. self-concept; self-efficacy; beliefs about language varieties; etc.) however, the distinction should be appreciated as something more in degree than in kind. What is essential to educational research (as well as in SLA) should be focusing on how mental constructs influence cognitive processes as a whole, and how these processes in turn affect and are affected by behaviour. Chopping mental constructs down into sub-category after sub-category may have its place (namely to facilitate the research process) but it ends up producing a fragmented picture of both the brain and behaviour. In other words, within the mind, research on beliefs traditionally presents the idea that things work in relation to but are distinct from each other, rather than as an inseparable whole, and between the mind and behaviour a similar dichotomy exists. Fortunately, more and more studies are beginning to promote a non-modular mind, where constructs such as knowledge and beliefs and affect are increasingly viewed as inherently, and dynamically connected (Ashton, 2015; 
Fives \& Buehl, 2012; Woolfolk Hoy, Davis, \& Pape, 2006). Emphasising the connectivity between different mental constructs themselves (intra-mind) and these constructs with behaviour (intermind) can also help us better understand the development of cognition, as this perspective offers a more situated and social interpretation of the dynamism between thinking and doing.

A further issue related to the conceptualisation of beliefs as explanatory principle relates to what Skott (2015) calls 'the congruity thesis' (pg. 21). Basically, if beliefs are positioned as determinants of practice then ideally, there should be a causal relationship between reported or stated beliefs and practice. However, this is not always the case. In fact, according to Fives and Buehl (2012) there are as many studies showing a mismatch between beliefs and practice as there are studies showing compatibility. Discordance between beliefs and behaviour, according to Skott (2014), is usually attributed either to issues in research methodology (i.e. methods used to uncover beliefs are not always reliable) or to contextual factors (i.e. beliefs cannot always be 'enacted' due to institutional constraints). However, in addition to methodology and context affecting the congruency of beliefs and practice, a larger constraint seems to be the overly simple, unidirectional model of this process. Skott (2014) argues that the expectation of 'immediate belief impact' reflects a conventional, 'acquisitionist' perspective on how individuals' thinking relates to their behaviour (pg. 22). In this model, beliefs are considered 'reified mental constructs' 'constructed' out of social interactions which directly impact teachers' classroom actions (Skott, 2014, pg. 22). However, these acquisitionist underpinnings often carry a limited (i.e. static; peripheral) appreciation of context and practice and as a result, are not able to adequately account for the beliefs-practice quandary. Moreover, the explanatory principle view of beliefs maintains that as constructs, they are stable and resistant to immediate change. This further reflects the asocial, acquisitionist understanding of cognition where mental constructs such as beliefs and knowledge are a type of 'material' emerging from interaction as experience, stored in the mind (as a kind of container), to be accessed by the individual when needed (Sfard, 1998). Finally, the view of beliefs as the default explanation for actions - as guides and impediments to practice and progress - will inevitably raise questions regarding belief 'construction'. If beliefs directly impact what teachers do in the classroom, and if teacher development programs are meant to improve these practices, then it becomes important to understand how beliefs are established, if for no other reason than to simulate similar conditions for belief change. The most common conception of belief construction, until fairly recently, has employed a constructivist model, arguing that beliefs are products of prior experiences. In other words, beliefs develop from comprehensive social interactions, which they then carry and enact as needed. Richardson's (1996) survey of teacher education research, as well as work in life history and socialisation, shows three main categories of experience associated with the development of teachers' beliefs: (1) personal experience; (2) experience with schooling and instruction; and (3) experience with formal knowledge: 
(1) 'Personal Experience' relates to 'aspects of life that go into the formation of world view; intellectual and virtuous dispositions; beliefs about self in relation to others; understandings of the relationship of schooling to society; and other forms of personal, familial, and cultural understandings' (p. 105). It is the experience bound in different social and cultural features that individuals carry including gender, socioeconomic background, religious upbringing and ethnicity.

(2) 'Experience with schooling and instruction' is related to individuals' experiences as students. It is the experience of participation in and contact with formal classroom settings and the type of instruction and learning that takes place within this environment. Richardson describes various studies on teacher education (e.g. Anning, 1988; Britzman, 1991; Knowles, 1992) which demonstrate how student teachers carry 'deep seated beliefs' about teaching and learning rooted in their own experiences as students (pg. 105). In fact, prior experience as a student is often considered a more powerful influence on shaping beliefs about teaching and learning than the experience of formal teacher education programs (at least in the case of pre service teachers) (Brousseau, Book, \& Byers, 1988; Feiman-Nemser, 1983). This idea of experience with formal schooling very much reflects Lortie's (1975) wellestablished 'apprenticeship of observation' theory. It should be noted however that recent work in pre-service language teacher education (Macalister \& Musgrave, 2015) has addressed the challenge of changing established beliefs by trying to create 'dissonance' between what has been experienced in the past and what is being learned in the present.

(3) 'Experience with formal knowledge' is the exposure to knowledge that has 'been agreed on within a community of scholars as worthwhile and valid' (p. 106). Experience with formal knowledge is gained through the learning of different school subjects, out-of-class readings, television, and religious classes.

In addition to outlining possible origins of teachers' beliefs, Richardson's conceptual framework supports the need to more accurately understand the complexities of individuals' thinking processes and actions within specific contexts (pg. 104). However, her argument continues to reflect the common constructivist view of context as a constraint on the enactment of beliefs rather than as a central component of their dynamic emergence and change.

More recent work on teachers' beliefs, carrying a more participatory or situated perspective is showing beliefs as either rooted in or emerging from context (Putnam \& Borko, 2000; Skott, 2015). This move or shift also mirrors the work in language learner beliefs, particularly in studies that adopt the 'contextual approach (Dufva, 2003; Kalaja et al., 2015). This socially situated evaluation of beliefs stands in almost direct contrast with the more common asocial, acquisitionist evaluation. Studies working toward a participatory approach question some of the long-standing assumptions about the nature of beliefs, including what they are, how they develop and change, and their effects on behaviour (Fives \& Buehl, 2012; Lerman, 2002; Schoenfeld, 2011; Skott, 2015). In addition, this handful of studies is expanding some of the conventional conceptions of the teaching-learning relationship, showing it as more dynamic and context-specific. For example, some research suggests a dialectical relation between beliefs and practice where context and interaction affect the enactment and development of teachers' beliefs in an ongoing process of 'changing and becoming' (Fives and Buehl, 2012, pg. 490). Others studies, adopting an emergent perspective on classroom practice, maintain that teachers' beliefs 'emerge' dynamically out of both classroom interaction and 
the larger social situation surrounding the interaction (Johnson, 1994; Skott, 2015); the nature of the interaction; the individuals involved; the setting; the time; and a host of other contextual factors all serving to activate and influence a teacher's beliefs in action.

As a consequence of these alternative perspectives on the nature and role of cognition, the focus is beginning to shift from getting 'access to reified mental constructs in the form of beliefs' (Skott, 2014, pg.24) toward understanding the teaching-learning interplay as it emerges across a variety of learning contexts. Explorations are being conducted not only into conditions for change in teacher practice but also some of the inherent social characteristics of this phenomenon. This evolving understanding of beliefs in teacher education is presenting a less stable, more complex picture of beliefs in action, where context, cognition, and behaviour are centralised and shown to be dynamically interacting. Thus, a more expansive picture of how different mental constructs interact with what teachers do in the classroom and how they impact aspects of teacher identity, emotion and behaviour is being created.

With that said, this new direction, while indeed adding another layer of complexity to the equation, rejecting purely behaviourist models, has unfortunately not progressed far enough beyond its original limitations. In fact, Allwright (2003) maintains that while many researchers and practitioners 'would probably strenuously reject such "behaviourist" notions'... many people in our field nevertheless do seem generally to act as if this is what they actually believe' (pg. 114). In addition, and as a probable ramification of the influence of the teacher beliefs = teacher practice = 'student achievemen't model, teacher belief studies continue to look for ways of improving efficiency in teaching, i.e. advancing practice (Carlgren, Handal, \& Vaage, 1994; Day et al., 1993), rather than trying to gain deeper understanding of what is happening in classrooms. In other words, the field remains limited through its overarching view of beliefs as an explanatory principle for practice. In their introduction to the current International Handbook on Research on Teachers' Beliefs, Gregoire-Gill and Fives (2015), calling for studies to develop theoretical frameworks that 'specify the influence and interaction of teachers' beliefs within self-systems and sociological contexts', point out that while few models of beliefs in action actually show teachers' beliefs directly influencing either practice or student achievement, researchers continue to look for this 'direct link' (pg. 7). As a result, instead of developing and expanding the understanding of beliefs as part of a multidimensional complex system, the conceptualization of teachers' beliefs within the field of education, remains to a large extent, fragmented, overly simple and one-dimensional. Researchers and practitioners alike should set out with the goal of developing a more profound understanding of how teaching and learning relate to beliefs and other mental constructs (including affect) before looking for ways of fixing and improving classroom practice. If we can more adequately understand what is happening when teachers teach and learners learn (including what teachers and learners perceive is happening), it is likely that we can contribute to more effective, meaningful, long-lasting learning. Cognition-related work in education should look to studies which are attempting to 
reconceptualise the role of beliefs and related constructs, viewing belief enactment and emergence as an important component of contextualised social practice (Atkinson et al., 2016; N. Ellis \& LarsenFreeman, 2009). Furthermore, rather than looking at how beliefs directly impact student achievement, research needs to consider expanding its parameters to explore how beliefs influence the overall learning experiences of both teachers and learners. In sum:

- Research on teacher thinking in general education has evolved out of a rejection of processproduct conceptions of teaching

- Constructivist orientations, focusing more on teachers' prior experience and the processes of teaching have long dominated the field, and to a large extent continue to dominate both theory and practice

- Teacher thinking has long struggled with ways of conceptualising the 'mental lives' of teachers - definitional challenges, e.g. distinguishing beliefs from knowledge, have been ongoing and in many regards have slowed progress in other areas

- A handful of studies on teachers' beliefs have adopted situated or participatory views of teaching

- The field remains limited in its conceptualisation of teacher thinking and its 'relationship' with practice; in its almost myopic view of trying to find 'the most efficient' or 'the most effective ways' to teach; in its scant attention to more social, situated understanding of teacher behaviour; in its scant look at teacher development. This final issue relates directly to methodological issues - and obvious dearth of in-depth, longitudinal work; limited data collection methods

The above discussion on teacher thinking in mainstream educational research has helped frame a picture of the origin and development of studies on cognition in education. It has highlighted some of the field's underlying assumptions, as well as some central challenges it continues to face. Furthermore, through this broad examination of work conducted on the psychology of teachers, various relevant and overlapping constructs, particularly in relation to the picture of 'experiential development' it paints, can be seen as inherently relevant to general reseearch on learning and language learning, specifically.

With this in mind, I now move on to an evaluation of cognition research directly related to foreign and second language education: language teacher cognition. I do this is a way of introducing a different way of thinking about the mental lives of language learners and will revist these ideas in the discussion.

As discussed above, language teacher cognition research is rooted in mainstream educational research, generally and teacher cognition studies, specifically. According to Borg (2006), in what is currently the most comprehensive evaluation of research on language teacher cognition, most work in this area began appearing in the 1990s. Surveying work from 1976-2006, mostly in first language (L1), second language (L2), and foreign language (FL) contexts, he identified a total of 180 published studies. Later, in a follow-up, smaller scale evaluation of 'contemporary studies' (defined as 'work published in 2011'), Borg (2012) identifies a further 25 sources. He also notes expanding geographical interest as well as an extension of the field's research potential, highlighting as an 
example, an increase in studies looking at non-native English speakers (it is important to mention however that work in this area has almost exclusively focused on contexts where English is taught as a first, second, or foreign language). Borg's (2012) follow up study is in many ways depicting a healthy progression of the field, with growing significance, developing theory, and expanding contexts. The growing body of work points to far-reaching research potential with the capacity to push the field of language education into new realms of understanding. Interest in more social approaches to language learning and teaching (Duranti, Ochs, \& Schieffelin, 2011; Shulman \& Shuman, 2004; Woods, 2006) however holds promise for developing explorations and increased attention into the role of cognition and language learning. One reason may be because social approaches tend to place a higher value on the role of context in human activity. Crandall (2000), describing teacher cognition as 'situated in practice', pushes for research to consider the effects of context on teacher decision-making and teaching and learning (pg. 39). She argues that while teacher education programs try to account for some of the diversity of language teaching situations, it is not always possible for them to provide adequate training for the "heterogeneity of learners or contexts that teachers actually encounter' (pg. 39). This idea not only stresses the need to appreciate context's central role but also its diversity and range. Crandall suggests that a key part of preparing language teachers for the reality experienced in 'situated' pedagogical interactions is having their cognition made explicit, i.e. foregrounding, both pre- and in-service teachers' thoughts and feelings about language education, language learners, the relationship between teaching and learning, and a host of other relevant issues (I would argue that this is necessary in learner belief work as well) How these surfaced cognitions become relevant and how they are used then becomes a key factor of language education development. For example, rather than value-judging different beliefs or assumptions as good (helpful) or bad (detrimental), the focus should be on looking for ways of building a deeper understanding of what the process of language teaching (and learning) actually entails. To do this, researchers need to find ways of learning about the experiences of teaching from the teachers (i.e. participants) themselves. Surfacing cognition can then become an integral step in improving classroom practice (teacher behaviour). However, by shifting the focus toward building understanding of the role of cognition and its development, the idea of improving becomes less value-laden. Instead, learning about teacher behaviour is connected more with making sense of a teacher's experience than with the changing of teacher practice. This appreciation of the influence of context on behaviour, along with the need to understand experience from the perspective of the practitioner, therefore carries an inherent interest in properly 'conceptualising the agent' (Dörnyei, 2009, pg. 230). Language education research, adopting participatory views of teaching emphasises the need to more accurately make sense of the dynamic between context, the individual, and different modes of interaction and reflection.

Woods' (1996) longitudinal, 'ethno-cognitive' (pg. 47) exploration, one of - if not the - first major studies conducted on teacher cognition in language education, was instrumental in promoting 
a contextualised view of teaching that included the different ways in which practitioners' attitudes, beliefs, knowledge and experience shape their perceptions of and approaches to teaching. Using classroom observation, unstructured interviews and video stimulated recall with a group of eight ESL teachers, Woods centralised his participants' 'understanding of events in context' (pg. 15). Essentially, he asked teachers to talk extensively over the length of their language course (6-13 weeks) about different aspects of their decision-making, from how they plan, to what they do and say in class. Woods maintains that through this talk, in the form of personal narratives or stories about concrete teaching events and experiences, teachers' reported cognition is 'more likely to be grounded in actual behaviour' (pg. 27). He rejected using abstract questions and categories (common in most cognition work up, even to this day) for two reasons: (1) much of teachers' cognition may lie below consciousness and therefore will not be immediately accessible (especially in a traditional interview setting) and (2) set questions and categories prepared by the researcher will inherently limit teachers' talk, not always allowing them to communicate what is most important to them (pg. 28). According to Woods, the study, more than advancing 'specific conclusions' about the nature of effective teaching, highlights the importance of reflection and dynamic interaction in bringing about change (pg. 297). When cognition becomes a central consideration of our behaviour (e.g. through discussion; awareness-raising; and in-the-moment decision-making) there is greater potential to affect teaching, and consequently learning. In a sense this ties in to the idea that awareness of what you are doing will in fact change your behaviour. Adopting an interpretive approach to teaching research was therefore useful, not only in helping construct an understanding of teaching from the point of view of the teacher-participants themselves, but was also key in positioning teachers' cognition as a key component of the developing theory in the field of language education. In this regard, Woods argues that the results of his study support Lave and Wenger's (1991) notion of knowledge as a situated phenomenon. Woods' 'research on participants' understanding of events in context' (pg. 15) presents a fascinating account of the pedagogical reasoning and action processes employed by second language teachers in action. It remains highly relevant (yet still somehow marginalised) in the field, cautioning against the conceptualisation of teaching strictly in terms of teaching methodology or behaviours.

Finally, Woods' study advanced the theory of language teacher behaviour by producing a model of teachers' decision-making processes. The model highlights internal and external factors affecting these processes and how teachers' decisions impact the structuring of a classroom's actions and events. As mentioned above, a key component of the model is the interpretive process which influences teachers' understanding of the events in their classes. Woods argues that for teachers, all actions and events are interpreted through an interrelated cognitive system of beliefs, assumptions, and knowledge (BAK). BAK is Woods' way of managing the inherent difficulty in distinguishing between beliefs, assumptions, and knowledge. Through BAK, Woods positions these interwoven entities as 'points on a spectrum of meaning' (pg. 195) rather than distinct abstractions. 
In fact, in his research he found no qualitative difference between participants' use of knowledge or beliefs (pg. 195). This supports the suggestion that a clearly demarked distinction between beliefs and knowledge is less relevant than investigations into how these interrelated factors affect an individual's behaviour (Thompson, 1992). While Woods' model makes no attempt to describe how teacher's BAK is developed, it does position BAK as playing an integral role in how teachers interpret and talk about their thinking and acting. Simon Borg's $(2003,2006,2011)$ extensive evaluation of research on language teacher cognition, while acknowledging the significant contributions from general teacher cognition work, further advances the need for comprehensive contextualisation of both language teaching and any investigation into it. To aid in this contextualisation, Borg offers a working definition of language teaching cognition, describes fundamental characteristics of language teachers, centralises the role of context, promotes a dynamic view of the processes involved in classroom language teaching and suggests alternative ways of understanding cognition.

Borg's definition of language teacher cognition has been evolving for nearly 20 years - a reflection as much of the developing nature of the field, as of the challenge in trying to pin down such a nebulous concept. Initially, he referred to the 'stores of beliefs, knowledge, theories, assumptions, and attitudes' shaping teachers' decisions as 'personal pedagogical systems' (Borg, 1998, pg. 9). Later, he introduced the more holistic term 'cognition' to describe the psychological context under which language teachers work (Borg, 1999; 2003; 2006). Cognition, therefore, is Borg's way of synthesising the various constructs (e.g. beliefs; knowledge; theories; attitudes; assumptions; conceptions; thinking; principles) which have been used to explore this 'unobservable dimension of teaching' (2003, pg. 81). In his seminal survey of research conducted on teacher cognition and language education, Borg (2006) explains how teachers carry cognitions about all aspects of their work, and as a phenomenon can be characterised as 'an often tacit, personally held practical system of mental constructs held by teachers and which are dynamic - i.e. defined and refined on the basis of educational and professional experiences throughout teachers' lives' (pg. 35). This idea of cognition as dynamic is important as it alludes to both the ways in which cognition impacts behaviour and also how it emerges and develops. More recently, Borg's (2012) definition has been evolving, calling language teacher cognition 'what second- or foreign-language teachers think, know, and believe' in relation to classroom practice (pg. 11). Moreover, while he maintains that thinking, knowing, and believing are the most commonly used terms in this area, he acknowledges that other constructs such as attitude, identity, and emotion are beginning to emerge as key players in making sense of the cognitive base of teachers' instructional decisions and practice.

To further contextualise foreign and second language teaching, Borg (2006) provides an important characterisation of language teachers, describing them as 'active, thinking, decisionmakers' playing key roles in shaping classroom events (pg. 1), again, an idea mirrored closely in works on learner beliefs about SLA. This characterisation of teachers as integral, thinking-acting agents in the formal language learning process recognises the complexity of their role. It addresses 
the reciprocal relation between what (and how) teachers think and their in-class behaviour. Whereas before (and in many cases even now), teachers were more or less thought of as 'technicians' responsible primarily for transferring relevant information and implementing 'instructional strategies and curricula - devised and imposed by others' (Borg, 1999, pg. 95), current understanding of teachers acknowledges that there is a lot more happening than teaching = learning. Essentially, it is asking practitioners, learners, and others involved in education to reconsider the overly simplistic input-output view of teaching (in its various capacities) and learning. Centralising the influence of context on teachers' cognition is one of the most significant contributions Borg's work has made to the field. He (2006) argues that work into cognition and practice conducted 'in isolation of the contexts in which they occur will inevitably...provide partial, if not flawed characterisations of teachers and teaching' (pg. 275). In other words, any meaningful understanding of language teaching requires a detailed description not only of the individuals and processes involved, but also recognition of the influence of different social, institutional and physical settings. While many studies on cognition in education describe a congruent relationship between thinking and behaviour, there are almost as many which show incongruence. However, this mismatch is not necessarily a reflection of practitioners' inconsistency or unreliability. Borg presents a strong argument to recognise context - these social and physical and institutional settings within which teachers operate - as a major determinant in both the enactment of cognition and also, in shaping and revising cognition itself. As Borg (2006) explains, 'Contextual factors may interact with teachers' cognitions in two ways; they may lead to changes in cognitions or else they may alter practices directly' (pg. 275). Essentially, this understanding of context's impact on how individuals think and behave reflects a situated view of cognition and echoes some of the evolving conceptions of cognition found in teacher development research. As Putnam and Borko (2000) argue, the idea of a situated cognition advances the view that 'the physical and social contexts in which an activity takes place are an integral part of the learning that takes place within it' (pg. 4). Moreover, theories in education which encourage a view of cognition as situated, social, and distributed (e.g. Cobb, 1994; Lave, 1991), rather than exclusively concentrating on individualistic notions of cognition, call for evaluations of whole systems in action, including the dynamic interaction between cognition, context, materials and tools, and experience. While Borg never explicitly mentions this 'situated perspective' of cognition, nor does he refer outwardly to cognition's 'social nature', his description of a 'mutually informing' interplay between cognition, context, and practice (2006, pg. 276) does however suggest a rejection of overly acquisitionist accounts of thinking and doing and a recognition of cognition's interactional quality. In essence, it supports the view that interaction with people in a specific setting determines the 'what' and 'how' of what gets done. In other words, Borg's view of cognition maintains that what we understand as cognition and how we communicate it (through action and language) is the result of our interactive experiences over time and across different places. To illustrate this, he has constructed a methodological framework which advances the major 
theoretical underpinnings in the field. His model serves as an excellent reference useful for prospective explorations into the chaotic world of teachers' mental lives and practice. An example of how this framework has been implemented in the field can be seen in a relatively recent study on teachers' cognitions regarding extensive reading in higher education. Macalister (2010) adapts Borg's framework to help investigate what language teachers on university preparation courses at language centres in New Zealand believe about extensive reading (a previously under-researched area in teacher cognition work). He uses the model initially as a way of examining the 'role that teacher cognition plays in determining what happens in the classroom' (pg. 61). Later, he re-adapts the model to represent more specifically, the dynamic relationship between teacher cognition and classroom practice in relation to extensive reading. In doing so, Macalister's study serves as a valuable example of how Borg's (2006) framework as theory, can be used to facilitate not only more insightful research into teacher cognition and its impact on teaching, but also consolidate the research in this area. This latter point is particularly important, as a common critique of teacher cognition work is that the field fails to build on or even recognise established research.

The above discussion has highlighted some of the major developments and changes affecting the study of language teacher cognition. As noted above, these evolving perspectives on the nature of language teaching has led to the development of various conceptual frameworks and models trying to describe the connection between teachers' mental lives and their behaviour. In a sense, they are attempts to develop the theory underpinning the different investigations into teacher learning and practice. Dealing with educational practice in light of psychological considerations means adding a layer of complexity to the picture we have of learning; a layer requiring new terms and tools to aid investigation. As Pajares (1992) notes in his extensive discussion of teachers' beliefs, 'all broad psychological constructs at some point come before the reductionist, multidimensional, or hierarchal chopping block to better suit the needs and requirements of research' (pg. 315). This raises an interesting point when working with models and frameworks. While they are useful in helping researchers conceptualise and explain core concepts necessary for understanding intricate processes and contexts, they remain limited in their capacity to relate an exact representation of a context-specific reality. A model, according to Woods' (1996) constructivist idea, does not represent a version of the truth but instead acts as a lens through which to view 'aspects of the processes that we are studying that we may have not considered before. And once they have been seen and appreciated, the model can be abandoned, and we can move on to the other issues and ways of looking at things and other models' (p. 224). That said, with their limitations properly appreciated, models have proven to be useful tools in investigating the intricate interplay between cognition and behaviour.

Below I highlight three models of language teacher cognition as they pertain to the above discussion on cognition in language education: 
Table 1: Classification of language teacher cognition models

\begin{tabular}{|c|c|c|c|}
\hline MODEL & Woods (1996) & Borg (2006) & Macalister (2010) \\
\hline ORIGINS & $\begin{array}{l}\text { Cognitive psychology } \\
\text { Educational research }\end{array}$ & $\begin{array}{l}\text { Cognitive psychology } \\
\text { Educational research }\end{array}$ & $\begin{array}{l}\text { Educational research } \\
\text { Cognitive psychology }\end{array}$ \\
\hline SYSTEM & Dynamic & Dynamic & Dynamic \\
\hline COMPONENTS & $\begin{array}{l}\text { Planning; } \\
\text { Actions/Events; } \\
\text { Interpreting }\end{array}$ & $\begin{array}{l}\text { Language teacher } \\
\text { cognition; Schooling; } \\
\text { Professional coursework; } \\
\text { Classroom practice; } \\
\text { Context }\end{array}$ & $\begin{array}{l}\text { Teacher cognition; Prior } \\
\text { knowledge and experience; } \\
\text { BAK; Professional } \\
\text { coursework; Classroom } \\
\text { practice; Context }\end{array}$ \\
\hline PURPOSE & $\begin{array}{l}\text { Explain the process of } \\
\text { teacher planning, } \\
\text { implementing, and } \\
\text { assessing }\end{array}$ & $\begin{array}{l}\text { Explain elements and } \\
\text { processes in language } \\
\text { teacher cognition; } \\
\text { foreground the role of } \\
\text { cognition in language } \\
\text { teaching practice }\end{array}$ & $\begin{array}{l}\text { Explain elements and } \\
\text { processes in teacher } \\
\text { cognition in relation to } \\
\text { extensive reading practices } \\
\text { in higher education }\end{array}$ \\
\hline INNOVATIONS & $\begin{array}{l}\text { Introduces the idea of } \\
\text { BAK }\end{array}$ & $\begin{array}{l}\text { Changes teacher cognition } \\
\text { to language teacher } \\
\text { cognition; Emphasises } \\
\text { prior experience; Stresses } \\
\text { the influence of context on } \\
\text { practice }\end{array}$ & $\begin{array}{l}\text { Positions BAK as a subset of } \\
\text { teacher cognition; Positions } \\
\text { context affecting both } \\
\text { practice and cognition; } \\
\text { Positions cognition and } \\
\text { practice equally }\end{array}$ \\
\hline
\end{tabular}

All three models reflect advances in cognitive psychology (Cole, 1985; Vygotsky, 1978) and educational research (Munby, 1982; Shavelson \& Stern, 1981). In Woods' (1996) model, cognitive science (e.g. Clark \& Clark, 1977; Miller, Galanter, \& Pribram, 1960) provides the primary analytical 'techniques' (pg. 47) to conduct his study. Borg (2006) and Macalister (2010), adapt as their primary source of influence educational research (e.g. Clandinin \& Connelly, 1987; Freeman, 2002; Meijer, Verloop, \& Beijaard, 1999). Also, each model describes a dynamic relationship between the teachers' mental processes and their practice. This presents a significant development, moving away from traditional stimulus-response representations of behaviour to illustrate how teachers' cognitions and practices interplay with context.

Despite these similarities, it is the differences between the models which adds value to understanding of cognition in a language education context. Woods' (1996) model focuses on language teachers' decision-making processes. It highlights internal and external factors affecting these processes and how teachers' decisions impact the structuring of classroom activity. A key 
component of the model is the interpretive process which influences teachers' understanding of the events in their classes. Woods argues that for teachers, all actions and events are interpreted through an interrelated system of beliefs, assumptions, and knowledge (BAK). Through BAK, Woods positions these interwoven entities as 'points on a spectrum of meaning' (pg.195) rather than distinct abstractions, thus avoiding the seemingly never-ending attempts at distinguishing one from the other (i.e. what is the difference between 'believing' and 'knowing' something?). In fact, as noted earlier, his research found no qualitative difference between participants' use of knowledge or beliefs (pg. 195). This supports the suggestion that a clearly demarked distinction between beliefs and knowledge is less relevant than investigations into how these interrelated factors affect an individual's behaviour (Thompson, 1992).

Borg's (2006) model is a tool for 'conceptualising' language teacher cognition research (pg. 281). Based on his rigorous review of studies conducted in this area, he synthesises the key elements into a single schematic framework. The model is useful in that it can help curb 'isolated studies' on language teacher cognition that lack a comprehensive understanding of the 'key dimensions, themes, gaps, and conceptual relationships' (pg. 284). In the structure of the model, teacher cognition becomes more specifically language teacher cognition and is centralised and defined. The model shows how language teacher cognition is constructed and developed through its relationship with schooling, professional coursework, and classroom practice - which is in turn affected by context. It shows how 'language teachers have cognitions about all aspects of their work' (pg. 283) and introduces prior experience as a principal influence on cognition.

Macalister's (2010) model, as discussed above, is a modification of Borg's model with noteworthy innovations. In Macalister's revised framework, BAK is no longer used to define cognition, but instead becomes a subset of cognition which influences its development - suggesting that there is likely more to cognition than beliefs and knowledge. That said, in attempting to investigate how mind and behaviour interact across the language learning-teaching system, BAK is one of most the frequently studied 'focal points'. Focal points allow researchers to manage the potentially 'paralysing holism' (Larsen-Freeman \& Cameron, 2008a, pg. 234) that can arise out of investigations into complex phenomena. By foregrounding system components, such as BAK, researchers can explore specific interrelations in greater detail, while at the same time appreciating the dynamic nature (and influence) of a larger system at work. Finally, Macalister's model has context influencing both practice and cognition directly rather than affecting practice exclusively.

Of the three models, only (2006) Woods' was applied to a study of second/foreign language learners. In fact, despite repeated criticisms of this omission (Pajares, 1992; Borg, 2006), it remains a major issue in teacher education. In fact, while the past two decades have seen language teacher cognition research emerge as an important area of language education, complete with a unique discourse and set of research methods, there exists almost no evidence of investigations in teacher education into learner cognition or how language teacher cognition relates to learners and learning. 
Failing to recognise the relationship between learning and teacher practice, presents a significant challenge, particularly when it has been suggested that '[m]ore important ... than the ability to get into the skin of the native speaker is the ability to get into the skin of the foreign learner' (Seidlhofer, 1999, pg. 243). Language teacher cognition research, essentially studying the ways in which language teachers' mental lives affect their classroom behaviour, assumes that what teachers do in class impacts directly on both the learning process and the learners. This presents a significant assumption reminiscent of earlier approaches, where learners are positioned as empty vessels to be filled, and teachers, the transmitters of knowledge and strategies. According to Borg (2006), language teacher cognition studies need to do a better job of working with SLA. Indeed, it is rather surprising that after nearly 30 years of research focusing on teacher education within the field of language education, such scant attention has focused on the actual learning that takes place (or is assumed to take place). It remains quite difficult, I believe, to make any claims about teacher development, without including information about the effects on learners/learning. This is why, in many ways, the fields of learner beliefs in SLA and language teacher cognition in education have a lot to offer each other.

\subsection{The role of affect}

Before moving on, it is important to mention a significant limitation of both teacher cognition and learner belief studies: the lack of systematic research on the role and impact of affect. For years, research has tried to separate the affective dimension from the mental, portraying emotion as an irrational element in need of control and too unpredictable to consider (O'Loughlin, 2006; Wetherell, 2012). More recently however, work in the social sciences, particularly in education, has been shifting away from this dualism and has begun arguing for a more interconnected view of emotions and thinking (Forgas, 2001; Golombek \& Johnson, 2004; Sutton \& Wheatley, 2003). This view, reflecting growing recognition of the importance of affect (Schutz \& DeCuir, 2002; Trainor, 2008; Zembylas, 2005), not only offers a more comprehensive understanding of behaviour, it presents a range of possibility for further explorations into interactive development. Contemporary studies in education illustrate the potential for research incorporating the affective domain. Studies adopting an emotive-inclusive approach have been conducted on embodied critical literacy practices (Johnson \& Vasudevan, 2012), race and literacy (Haddix, 2009), the mobilisation of emotion in urban classrooms (Lewis \& Tierney, 2013), and affective enhancement among older adults (Swain, 2013). Increasingly, researchers are suggesting that we can no longer afford to neglect this powerful dimension of human consciousness. In fact, discussions surrounding the 'emotional dimension' (Borg, 2012; Mahn \& John-Steiner, 2002; Ortega, 2014b) have also been taking place in language education. The work of Sara Mercer (2011a, 2011b; 2014) on learner self-concept, learner agency and multilingual self, has been particularly valuable in incorporating this relatively underexplored dimension of language learning. In language learning, affect, similar to cognition, is a 
complicated and multilayered concept. Research working with the affective dimension has sometimes, in trying to more clearly define this construct, attempted to tease out differences in related terms. Aragao's (2011) study on beliefs and emotions for example, tries to separate 'emotions' from 'feelings' and 'affect'. Arguing that research conducted on affective factors have primarily been quantitative (pg.303), Aragao explains how he prefers the term emotion. In this way, he distinguishes his novel qualitative investigation on emotions from traditional quantitative studies focusing on affect. Unfortunately, similar to teacher cognition research (cf. Borg, 2006; Woods, 1996; Richardson, 1996; Shavelson \& Stern, 1981), this tendency to separate different mental constructs (affect is very much a mental construct) can lead to a field overwrought with terms and ideas which are essentially arguing the same point. In fact, there is little evidence demonstrating that (a) such distinctions affect how learners behave and (b) that these distinctions can help learners. As Woods (1996) found, implementing knowledge is essentially no different from implementing belief (pg. 195). In other words, the effect on behaviour or practice, whether it is belief in action or knowledge in action, or emotion or affect in action, remains fundamentally the same. Affect therefore, like cognition, is better viewed as part of a socio-cognitive structure. It is clear that discussions incorporating a more holistic, inclusive view of affect remain peripheral, and language education studies need to make a concerted effort to examine the impact of this highly influential component in detail.

For cognition studies to develop beyond their current level of influence, researchers and practitioners need to better understand the different ways affective-cognitive factors influence the language learning process. One way to help manage this challenge can be by incorporating a definition of learners' mental lives which assumes the inseparability of emotion and cognition. In fact, a definition which looks to integrate rather than separate different psychological constructs, including the affective with the cognitive, specifically related to learners, would inherently expand our conception of individuals' mental lives as they relate to language learning. Atkinson et al. (2016), in their recent publication where they highlight '10 fundamental themes' for SLA research and theory, put forth the similar notion that 'emotion and affect matter at all levels' of second language learning (pg. 36).

\subsection{Defining language learner cognition}

Drawing on the proceeding discussion of language teacher cognition, the definition of language learner cognition I propose promotes the dynamic interplay between what L2 learners think, know, believe, and feel, and their language-related behaviour. It recognises cognition as an overarching, often unconscious, unobservable phenomenon which carries a significant influence on an individual's behaviour. As a definition, it reflects Borg's (2006) understanding of language teacher cognition; particularly in its appreciation of the role of context on change. However, there are three significant variations. First, it is concerned with language learners, not teachers. Centralising learning 
and learner addresses a long-standing issue in educational research. Second, it is referred to it as an interplay, rather than relationship as the term relationship implies a separation between how we think and behave, which as Richardson (1996) points out, 'although useful for research, may make little sense in practice' (pg. 104). In fact, I see thought and behaviour as inherently interconnected. All action requires thought and all thought emerges from action. Finally, it incorporates the neglected dimension of emotion, promoting the view that affect needs to be seen as an inseparable component in our conception of cognition.

It is important to clarify a few other ideas regarding the term. Although this area of study relates directly to SLA - looking particularly at English language learning and learners - the term 'beliefs' does not seem to always accurately capture the complexity and inseparability of the system. Beliefs, as I have argued above, can be too narrow a construct on their own to fully explore the different ways language learners behave. There is no doubt that they affect what learners do. However, it is in their inseparability with other mental constructs that their true power can be derived. This argument essentially reflects Ellis and Larsen-Freeman's (2006) understanding of language as the 'emergent properties of a multi-agent, complex, dynamic, adaptive system' (pg. 558). Ellis and Larson-Freeman (2006) argue that applied linguistic research which seeks to uncover a correlation between a single 'dependent variable' (e.g. beliefs about SLA) and a 'preferred probable cause' will inevitably produce an insufficient picture of what is taking place (pg. 559) because in actuality each determinant 'is but a small part of a complex picture' (pg. 559). Therefore, borrowing from educational research, I use the term 'cognition'. Firstly, by using this term I am suggesting that there is more to learner thinking than beliefs, assumptions, and knowledge (BAK) - that there is more going on in a learner's socio-cognitive world than any research could hope to capture, while at the same time providing a reasonably comprehensive focal point for exploration which can be of particular benefit to both learners and teachers. In fact, the concept of learner cognition I propose appreciates that there is a host of mental constructs (e.g. self-concept; attitudes; emotions; motivation; self-efficacy) which are inseparable in their impact on what language learners do. And while it may be the case that humans invariably separate 'things, events and ideas' into distinct categories or variables, these phenomena are more mutually dependent than exclusive (Ellis and Larsen-Freeman, 2006, pg. 580). Secondly, adopting the term 'cognition' acknowledges the (theoretical and practical) influence language teacher cognition research has played in promoting greater understanding of the role social psychology plays in language education. For example, the use of mainly qualitative methods to survey experience has been integral in portraying 'in rich detail' some of the key factors influencing the language learning process (Borg, 2006, pg. 288). In sum, the term 'language learner cognition' is a way of bringing together two fields which share not only numerous concepts and principles, but also a similar spirit of research.

The above discussion on the role of cognition in foreign and second language learning has traced the development of research in this area. It describes progression from a rather simple, one- 
dimensional understanding of beliefs to a more complex, multidimensional conception of the psychological constructs language learners carry. It has stressed the value in operationalising the dynamic interplay between the language learner, behaviour, and context. It supports what Beckner et al. (2009) refer to as an 'agent-based framework' (pg. 13) which views both prior and current experience as integral in affecting individual speakers' language-related behaviour. Furthermore, it recognises the significance of naturalistic interaction as a context where different speakers, as a result of the variance of their experiences, exhibit different behaviour when communicating with members of a community (Beckner et al., 2009, pg. 13). Language learning studies interested in investigating interaction as a site of development - in exploring how both prior and current experiences affect behaviour - would therefore benefit from considering the full range of situations in which language learners use and learn an additional language.

\subsection{Rationale for the study}

Continued development of SLA research requires that the range and scope of investigations into foreign and second language learning be expanded. It is important that efforts to advance the field, cultivate a more encompassing view of who language learners are and to seek greater understanding of their experiences across different learning contexts. For example, more qualitative explorations into the totality of learners' experiences in contexts outside the language classroom in immersion settings need to be undertaken. Ultimately, it is this context-specific experience that can reveal valuable insight into the motivations and decisions behind learners' consequent behaviour. Scholars have shown recently, for example, how adult language learners' exposure to an L2 in immersion settings is severely limited (Muñoz, 2008; Muñoz \& Singleton, 2011; Ranta \& Meckelborg, 2013), meaning that they do not engage in as much $L 2$ use as might be assumed and additionally, this engagement may lack a certain quality of experience. Ortega (2014a), in her survey of adult L2 learning in immersion context, argues that adults not only have insufficient access to relevant $L 2$ use, but also the $\mathrm{L} 2$ use they do engage in lacks the necessary components for effective development. Furthermore, the majority of studies evaluating out-of-class language learning have adopted quantitative approaches, looking more at categorising the types of interactions rather than exploring in a nuanced manner, experiential processes and how they are interpreted. Finally, there is a surprising dearth of research conducted specifically in collaboration with recently arrived migrants and refugees as language learners in New Zealand. Rich, nuanced descriptions of individual's whole language learning development are lacking. Studies examining how adult language learners' day-today interactions (as language-related experiences) affect their cognition and how this cognition, in turn, affects these interactions need to be as much about the social construction of this process as they are about individuals' own interpretations. In other words, to better understand migrant participants' language learning experiences, research needs to incorporate views from both the outside (researcher) and the inside (participant). This can help ensure that studies in SLA provide an 
adequate contextualised understanding of a language learner's mental life in action - an understanding of L2-related cognition which recognises the inherent complexity of this construct as it plays out in the real lives of particular learners in specific contexts. With that in mind, my study seeks to answer the following research questions:

RQ 1. What are the prior language learning experiences of a group of adult migrant learners living in New Zealand?

RQ 2. How have these prior language learning experiences influenced the construction and development of their beliefs, assumptions, knowledge (BAK) about language learning?

RQ 3. What is their perceived need for English in their current socio-cultural context?

RQ 4. How do adult migrant language learners engage in language related activities beyond the classroom?

RQ 5. How can this language learning behaviour be reflected in a model of language learner cognition?

The next chapter describes the research design and the methods used to gather and analyse the data for this study. 


\section{Chapter 3 Methodology}

\subsection{Introduction}

In this chapter I present the research questions, outline the research design, and describe the context, participants and methods for data collection and analysis. To help manage issues with definition and 'research legitimacy' (Davis, 1995, p. 434), I also make explicit the philosophical and theoretical assumptions guiding the study's methodology. Constructing clear connections between adopted theory and design help bring to light a researcher's underlying 'assumptions, beliefs, and values' regarding the nature of scientific inquiry (DeMarrais \& Lapan, 2004). This in turn ensures greater accountability, transparency and transferability (i.e. generalisability).

\subsection{Research design}

Research design, not to be confused with research methods (which are born of design), is driven by the 'intended purpose' (Patton, 2002, p. 12) of an investigation. In other words, a study's design, the result of considered exploration and evaluation of the various available approaches, helps ensure that the adopted structure suits its planned objective by 'specifying the type of evidence needed to answer the research question, to test a theory, to evaluate a programme or to accurately describe some phenomenon' (de Vaus, 2001, p. 9). Essentially, it is a way to conceptualise the study. Typical types of design include: experimental, case study, longitudinal, and cross-sectional (de Vaus, 2001, p. 10). Creswell, referring to research design as 'approaches to inquiry', adds to the typology: ethnographic, grounded theory, phenomenological and narrative research (Creswell, 2012, p.13). Although establishing a research design is an important part of any empirical investigation, its implementation however remains complex and imprecise. In qualitative explorations particularly, there exist no set rules or guidelines for researchers to follow. In fact, much like strategic plans in organisational management, designs at best are a culmination of a researcher's informed decisions based on the various contextual constraints impacting a study. As Patton explains, 'any given design reflects some imperfect interplay of resources, capabilities, purposes, possibilities, creativity, and personal judgments by the people involved' (2002, p.12). With these considerations in mind, the research design for this study combines a longitudinal ethnographic approach, with elements of narrative and case study inquiry. In the next section, I present underlying assumptions about the rationale supporting this design.

\subsubsection{Longitudinal}

Longitudinal research supports the observation of phenomenon in action over a prolonged period of time. As a research component it is especially useful when investigating complex, developmental processes across different social contexts (Holland, Thomson, \& Henderson, 2006). 
Its inherent extended timescale allows researchers to capture 'variability', unique to an individual's change within and across nested levels and timescales (Larsen-Freeman \& Cameron, 2008a, p. 245). This in turn helps uncover connections integral to understanding different socio-cognitive processes. The emergent, self-organising nature of mental phenomenon, such as learner cognition, and social behaviour, such as language learning, operate at these hierarchical levels and scales. Research attempting to trace the patterns of behaviour of a complex system needs to account for the ways in which 'activity on one level and scale influences what happens on other levels and scales' (LarsenFreeman \& Cameron, 2008b, p. 205). Therefore, the more time afforded to explore these relationships in action, the more nuanced the picture of this process becomes. Additionally, the nature of the phenomenon under investigation needs to be considered. Because this research explores individual's development in thinking and behaving in relation to naturalistic language learning, i.e. change that can be observed as influencing and being influenced across contexts over time, it is necessary that the observed change not be simply a one-time occurrence. In fact, timescale research in social science argues that it is not possible for particular types of processes, such as constructing identity, shifting attitudes, or changing beliefs, to materialise over short timescales. As Lemke (2000) indicates:

Even if short-term events contribute toward such changes, it is only the fact that they are not soon erased, do not quickly fade - that subsequent events do not reverse the change that makes it count. It is the longer-term process, including the effects of subsequent events, that determines for us the reality of basic human social development

Finally, looking systematically at a myriad of interconnecting factors, including individuals' thoughts and feelings, and their contextualised behaviour, requires extended temporal parameters to develop a theoretically rigorous picture of the intricacy of the process under investigation. Pettigrew (1990) explains in his support of longitudinal work that, 'The focus is on changing, catching reality in flight; and in studying long-term processes in their contexts, a return to embeddedness as a principal of method' (p. 268). In sum, my research recognises that the emergence of change is unpredictable and bounded in time, and that the more complex the system being explored, the more time needed to accurately capture these potentially chaotic trajectories.

\subsubsection{Ethnographic}

This study, underpinned by sociocultural theory, maintains that 'the individual and the social are mutually constitutive elements of a single interacting system' (Cole, 1985, p. 148). I argue that through the dynamic interaction of individuals with the world around them, development of higherorder mental functions (e.g. cognition) and behaviour, exemplified by the second language learning process, takes place. Thus, accounting for development of mind without considering patterns of 
interaction is not possible (just as it is not possible to explain patterns of behaviour without considering the role of cognition). To manage this conundrum, research needs to adopt 'a methodology of interpretation' (Lantolf \& Thorne, 2006, p. 46); an approach that can facilitate our understanding of how situated activity can lead to the development of thinking, and vice versa. Ethnography, which is focused on describing, interpreting and explaining 'what people do in a setting (such as a classroom, neighbourhood, or community), the outcome of their interactions, and the way they understand what they are doing (the meaning interactions have for them)' (WatsonGegeo, 1988, p. 575), provides some important resources needed to undertake this type of investigation. Through its centralisation of both naturally-occurring settings and participants' perspectives of activity within these settings, it enables me to effectively explore adult migrants learning English through naturalistic interactions; helping me learn about how real people learn in real situations.

Moreover, studies in second/foreign language education which in the past have adopted ethnography (or modified forms of ethnography) (Allen, 1996; A.M.F. Barcelos, 2000; Woods, 1996) have often done so because it not only centralises the observation of behaviour from the outside but, equally, from the inside (e.g. participant observation; emic perspective). Ethnography's concern with the 'culturally based perspectives, interpretations, and categories' from a study's participants (Watson-Gegeo, 1988, p. 580), reflects the idea that this unique insider understanding is largely responsible for directing behaviour. Riley's critique (1997) of applied linguistic research's failure to account for language learners' beliefs sums it up well when he states that although it is true that some participants' beliefs may be 'wrong', the point of research which traces patterns of behaviour should not exclusively be about uncovering objective truth; equally important is understanding participants' 'subjective reality' or 'their truth', since it is this interpretation 'more than anybody else's that will influence their learning' (p. 127).

Lastly, and related to the importance of incorporating an emic, participant-centred approach to the study of language learning is ethnography's potential in offering ways to expand SLA's exploration of unique and often marginalised populations or groups of individuals (O'Reilly, 2005). My interest in approaching the naturalistic world of Latin-American adult migrants learning and using English in the suburbs of Wellington, is predicated on the ability to step into the lives of my participants, and engage with them in their everyday activities in whichever way possible. In sum, the underlying motives of ethnography, along with its various research methods (participant observation/observation of participation; in-depth interviews; document and artefact analysis) are invaluable resources in helping me accomplish these objectives. However, it is imperative to note that this study should not be considered pure ethnography, in that it is not focusing on culture, or cultural aspects of a particular group. Instead it has adopted and adapted ethnographic methods (e.g. prolonged participant observation; in depth interviews; document analysis) and theory (e.g. human experience is irreducible; understanding and representing experience requires a participant 
centred, or 'emic', perspective; primarily concerned with peoples' daily lives) to serve its purpose. The focus remains on the ascribed meaning individuals construct and how these meanings interplay with their language-related interactions.

\subsubsection{Narrative inquiry}

At its most basic level, this research examines the interplay between individual experience and thought. It explores the ways present-day, language-related behaviour becomes personal experience which is directly responsible for shaping critical elements of an individual's cognition. These socially situated events, in the form of interaction, happening now, become the prior experience which affects and guides the construction and revision (i.e. development) of cognition, including (but not exclusive to) beliefs, attitudes, and emotions. This cognition, in turn becomes a powerful influence on consequent behaviour (including the retrospective interpretation of behaviour). Therefore, the challenge remains for this study to produce an intricate, in-depth picture of these experiences. One possible way to manage this challenge, as I have discussed above, is through observation and interpretation. However, this is not the only approach available. In fact, this approach alone can carry significant limitations. As Gaddis (2002) states in his evaluation of the difficulty of trying to accurately capture past experience:

But the past, in another sense, is something we can never have. For by the time we've become aware of what has happened it's already inaccessible to us: we cannot relive, retrieve, or rerun it as we might some laboratory experiment or computer simulation. We can only represent it

The inherent issues in trying to accurately 'access' the past, i.e. lived experiences, through observation have led many social scientists to the use of alternative forms of 'representation' - the main one being narrative inquiry. As a research approach, narrative inquiry, not to be confused with 'narrative study', which is focused more on the 'discursive construction' of stories, or how the narratives we tell are structured, provides the means to explore individuals' personal understanding of their local and historical experiences. Narrative inquiry, as Bell (2002) attests, hinges on the idea that 'people make sense of their lives according to the narratives available to them, that stories are constantly being restructured in the light of new events, and that stories do not exist in a vacuum but are shaped by lifelong personal community narratives' (pg. 208). It does what careful observation cannot always manage, offering 'a way of coming to understand by being open to the stories individuals tell and how they themselves construct their stories and therefore themselves. (Kramp, 2004, p. 111). Through their 'stories', participants connect ideas about behaviour, experiences, and perceptions across varying timescales into a cohesive, comprehendible whole, thus making meaning from these stories of interaction. Narrators, in constructing their narratives, are in a 
sense 'unravelling' what Barkhuizen (2011) calls the complexity of their lived experience (pg. 393). Additionally, using first-person accounts of experience adds an important layer of detail to the interpretation of behaviour. Combining this inside perspective with an outside one aids in the construction of a nuanced picture of the participant's lived experiences. In analysing the content of a person's story, researchers (and to a large extent the participants themselves) gain access to the often hidden or unconscious assumptions and expectations that drive and develop our behaviour. As Riessman (1993) asserts, narrative inquiry supports the 'systematic study of personal experiences and meaning: how events have been constructed by active subjects' (p. 70). Finally, and possibly the most important reason for using narratives in this study, is the understanding that it is within these storied representations of language-related behaviour and prior language learning experiences that the participants' cognition is embedded. And through careful examination of these varied narratives of experience told over time, connections between embedded cognition and (self) observed behaviour can be made. As Kramp (2004) states, 'Narratives preserve our memories, prompt our reflections, connect us with our past and present, and assist us to envision our future' (p. 107). In many ways, they are the frames holding up the pictures of how and what we think. As a final note, the narratives used in this study are not traditional narratives in that the participants were not asked to compose or retell 'stories' relating to their language learning, per se. Rather, the narratives evolved out of ethnographic interviews (O'Reilly, 2009). These lengthy, participant-led, open, and conversation-like interviews revolved around participants' descriptions and interpretations of their past and present language-related behaviour, essentially resulting in the construction of narrative accounts of their language-related experiences (for more detailed discussion of the interviews see section 3.5 on Data gathering).

It is important to note that narrative research, while quite prevalent across the social sciences, does not carry a definitive approach to its application. However, this is not an inherent limitation, but rather a characteristic of its complexity and the multifaceted nature of narrative as a socio-cognitive activity. Framed within the context of the communication of personal experience, narrative research is a meaning-making endeavour where explorations seek to understand what and how individuals 'know' about the world (Barkhuizen, 2013, pg. 7). In attempting to gain this understanding, various conceptions on what constitutes a narrative, as well as different views on collecting and analysing narrative accounts are employed. Barkhuizen's (2013) discussion on the distinction between the 'content' and 'form' of narratives (pg. 8) serves as an example of this diversity. In clarifying this distinction, he explains that narrative research concentrating on the content of and reflection on participants' experiences constitutes 'narrative inquiry'; while research focusing on 'how they are put together; what they look like, rather than what they tell' is 'narrative study' (pg. 9). This study's emphasis on exploring the day-to-day L2 interactions of adult focuses on the 'snippets' (Barkhuizen, 2013, pg. 9) that come out of the conversations we share as researcher and participant. The narrative approach I adopt is not particularly focused on the larger 'life 
narrative' of each individual, with its tidy beginning, middle and end 'plotline' (Early \& Norton, 2013, pg. 134). However, in some capacity this study is also making use of the 'big narrative' that develops from evaluating a series of smaller tales together (as a kind of on-going dialogue). To some extent then it must be appreciated that a larger, multifaceted narrative will most likely emerge. Finally, it is important to reiterate that I see the gathering of narratives in this research as very much coconstructed; the research context is stimulating the telling of these experiences and the various roles the participants and I play during these lengthy meetings are but a few of the factors affecting the construction of stories. Finally, beyond the central focus on stories as transmitters of lived experience, narrative research appreciates that the meaning-making process transcends actual narrative construction. As Barkuizen's (2011) innovative idea on 'narrative knowledging' proposes, researchers adopting narrative inquiry will make sense of and revise experience not only through the act of narrating, but also in the analysis of narratives, the reporting findings, and the reading of other narrative-related work (pg. 396).

Thus, this research as 'narrative inquiry' focuses on collecting illustrative accounts from the conversations of unstructured interviews told over time. The focus is on the content and themes of the narratives as they are communicated, exploring not only what is being said directly about participants' lived L2-experiences, but also the underlying cognition running throughout these narrated experiences.

\subsubsection{Case study}

According to Duff (2012), 'Case study research seeks depth rather than breadth in its scope and analysis. Its goal is not to universalize but to particularize and then yield insights of potentially wider relevance and theoretical significance' (p. 96). While this investigation as a whole may not be considered a 'pure' case study (e.g. I do not make cross-case comparisons), it does carry several principles of case study research, as well as adopting a 'pure' case study approach in answering research question 5: 'How can this language learning behaviour be reflected in a model of language learner cognition?' Research question 5 calls for a more in-depth, granular insight into an individual's experiences, in order to help illuminate both the inherent complexity of the process of language learner cognition in action. Narrowing the focus from several to a single research participant can be a useful technique when attempting to uncover significant 'patterns or perspectives' that are sometimes lost when working with large sample sizes (Duff, 2012, p. 96). An intricate understanding of these patterns can then contribute to more refined theorizing about the phenomenon under investigation; particularly when that phenomenon is a complex, developmental process. A noteworthy point regarding case study research in SLA is that the participant, i.e. the case, is not necessarily the focus of the investigation (Dyson \& Genishi, 2005 cited in Duff, 2012, p. 96). As Duff (2012 p. 96) asserts, it is often instead 'a case of something - of a phenomenon of interest', which is explored in greater detail. By choosing to focus on the phenomenon of interest, it becomes possible 
to advance and refine a study's proposed theory. For the purposes of this exploration, a case study approach offers an additional (alongside the ethnographic approach described above) fine-grained lens with which to view the participant's naturalistic language learning experiences, producing an indepth perspective on the mental process and social dynamics associated with second language development. Finally, case studies also carry an inherent flexibility, allowing data to be observed both in a holistic manner, addressing in this study questions of settlement and integration, and in a more process-level manner, such as uncovering change in individual's cognition as it relates to every day interactions in English - all supported through thick description of the case study participant and the different situations the participant interacts across. This flexibility also extends to the various roles played by the researcher and the participant. With case study analysis, in some instances my role as a researcher will become 'privileged', but in other instances the participant's own interpretations of their experience will be foregrounded, 'sometimes in discussion with the researcher and other times more independently' (Duff, 2012 p. 96).

\subsection{Research methods}

While the research design frames a study's focus, it does not necessarily dictate the methods used to collect and analyse the data. A study's methods are chosen through careful consideration of how effectively they can support the design. As Erickson (1986 p. 120) suggests, what makes a study interpretive or qualitative is more a matter of 'substantive focus and intent', than of collection procedure. Both the research questions and the research design for this investigation suggest rich description of individual behaviour, experience, and mental phenomena over a prolonged period of time. Therefore I have chosen to employ interpretive-qualitative methods for the data collection and analysis. Leading research methodology scholars (Berg, 2001; Creswell, 2009; Patton, 2002) promote qualitative methods as useful for exploring processes requiring attention to the idiosyncratic nature of both participants and context. Some maintain that qualitative methods have been specifically 'designed' for inquiries into 'the experiential life of people', arguing that experience's 'vertical depth' necessitates methods which can help illuminate phenomenon 'not directly available to public view' (Polkinghorne, 2005, p. 138). In other words, collection methods such as first person accounts, self-reports, and participant observation facilitate deep exploration of development by generating individuals' first-person understanding of their experiences in light of their behaviour. In terms of SLA (a type of experience), these methods allow researchers to focus on features of change processes in language learning/use that can often be overlooked. As Holland et al. (2006) attest, qualitative methods illuminate human experience as it appears in people's lives, helping us 'understand the importance of what might be statistically insignificant differences' (p. 2). There are also practical reasons for conducting a qualitative investigation of this nature, the most significant being the challenge of gathering sufficient individuals who meet the required criteria and are willing to participate in this study. In the simplest 
terms, it was more feasible and realistic to get detailed information from a few individuals than to spend a large amount of time and effort in gathering a larger sample population. Before moving on, it is important to highlight some conceptual and terminological issues associated with the research methods underpinning this study. In other words, the concepts and terms used in this study reflect the language of qualitative research, which are distinct from more quantitative investigations.

\section{Languaged data as accounts of experience}

In any empirical investigation, the way data is understood (as a concept and as evidence) influences how it is talked about and used. In the case of qualitative research, much of what is currently known (theory) and done (approach) is a direct result of the influence of statistical design experiments. This influence has inevitably led to the transfer of terminology. For example, terms like 'sampling', 'significance', 'reliability' and 'validity', signposts of quantitative studies, have shaped how qualitative investigations are conducted and discussed. Unfortunately however, this transferring effect has sometimes led to important misunderstandings, not to mention unjustified criticism. The idea of data is a good illustration of how borrowed terms can be problematic for the purposes of research. To this day, the dominant conception of data carries connotations of objectivity, reality, truth and fact. In other words, data continues to imply information which is 'a direct reflection of the thing that it is about and independent of those who gathered it' (Polkinghorne, 2005, p. 138). One example of this is the tendency to refer to interview data as a report, implying some kind of factual document which the interviewee provides the interviewer through a series of questions and answers. However, this view seems to be changing, particularly in the context of qualitative research, where information gathered through intensive (discursive; longitudinal) exploration with participants becomes 'languaged data' (Freeman, 2012; Polkinghorne, 2005). With languaged data the focus is less about 'single words' which can be turned into numbers and counted for predictive purposes, and more about the interrelations of words (Polkinghorne, 2005 , p. 138), including the contexts shaping their expression. In other words, data in qualitative research represents individuals' interpretation of experience presented in the form of discourse. This alternative understanding of data significantly changes the nature of research, as languaged data is not meant as an exact representation of the phenomena it describes. Rather, it is as a coconstructed product of interaction between the participant and the researcher, with the focus being on constructing meaning rather than uncovering truth. Because of this, some qualitative researchers have argued that a more accurate understanding of the term data would be to view it as 'accounts' (McLeod, 2011; Polkinghorne, 2005). With that said, understanding qualitative data as accounts of experience, carries unique consequences for its application in research. For example, one underlying assumption in qualitative studies is that the (socially constructed) meaning behind the words used to describe lived experiences is subject to the interpretation of both participant and researcher.

Moreover, it is meaning derived but also removed from actual lived experiences. Therefore, data in 
this study, both as spoken and written discourse, should be viewed as a type of indirect evidence of experience.

\section{Languaged data as evidence of experience}

As direct subset from the above point, qualitative research's use of languaged data rests (mainly) on the assumption that language is the primary vehicle for exploring the minds (and therefore behaviour) of people. It is in the minds of an individual that experiences are stored, relived, and changed. Therefore, to access these lived experiences and explore how they affect participants (emotionally, mentally, and in how they behave), it becomes necessary to have people talk (or write) about them. Qualitative methods, such as interviews and self-report documents, are the tools which researchers use to generate this evidence of experience. However, it is critical that we remain conscious of the fact that this evidence (in the form of languaged data) is but an affected representation of the actual experience. It is a subjective 'interpretation' (from the eyes and mouth of both the participant and the researcher) of experience. Thus, we need to exercise caution in assuming that what people say is actually an honest account of what they think. As Freeman (2012) asserts in his commentary on how language in qualitative studies is used in particular contexts to capture experience which lies outside it, language is 'socially constituted and situated' (p. 82); meaning that the various, changeable roles participants and researchers play in the research process, will affect what is said, as well as what is meant by what is said. In fact, Freeman (2012) goes as far as to suggest that 'it borders on the naïve to say that people are telling you what they think' (p. 85). In this sense again, we see how the textual evidence (languaged data) gathered is in fact layers removed from the actual experience being described. With that said, there is a great deal of relevant information to be examined in participants' accounts (representations) of experience, particularly if these accounts are for the most part led by the participant, open, and gathered over time and across varying time scales.

In sum, there is no denying that lived human experience is nearly impossible to 'objectively' capture; experience, unlike behaviour, is not directly observable; nor is it universal, as people experience moments through their own individual cognitive system. Our understanding of others' experiences is highly dependent on an individuals' ability to 'reflectively discern aspects of their own experience and to effectively communicate what they discern through language' (Polkinghorne, 2005, p. 138). Although, different people use, produce and interpret language in different ways, language data remains one of the most valuable resources we have of making sense of other's experiences and it is the researcher's task to ensure that he/she is not only using the appropriate tools, but also using them appropriately, to facilitate this exploration into meaning.

Below, ethical considerations and research context are outlined. This is followed by a description of the participants and the qualitative tools used for data collection and analysis. 


\subsubsection{Ethical considerations}

The sensitive nature of this type of qualitative research makes it necessary to recognise and respect the ethical concerns involved. While ethical issues regarding the extent to which researchers need to be 'open and honest' are debateable (O'Reilly, 2005, p. 61), I feel that as much as possible needs to be done to ensure that the participants are not exploited or harmed in anyway. No fieldwork, including contacting potential participants, was conducted before my human ethics application was reviewed and approved. The study received human ethics approval from the VUW Human Ethics Committee on the $5^{\text {th }}$ of June, 2013.

Once I received ethics approval, participant selection and search began. In this regard, after initial contact was made with a participant, I requested the opportunity to meet face-to-face to introduce my research. During this introductory meeting I provided a verbal overview of the research. I also sought informed consent through an information sheet and consent form (see appendix $A$ and $B$ ). Both the information sheet and consent form were in Spanish (the participants' native language). The information sheet explained the main features of the project and some logistic information (e.g. how long the project would run). Participants were given as much time as they needed to read over the information, as well as having the opportunity to ask questions. The consent form made clear what they were participating in, assured them of complete anonymity (pseudonyms are used throughout), as well as stressing that their participation was completely voluntary. They were also assured that they could drop out of the study at any time with no questions asked. Information about how the data would be stored and used (publication; conference) was described. Finally, I let the participants know that I was available via telephone or email in case of any questions or problems.

\subsubsection{Research context: Macro and micro perspective}

\section{Macro perspective}

This research takes place in an adult ESOL context in Lower and Upper Hutt (cities in the greater Wellington region, New Zealand). Although New Zealand is becoming a 'linguistically diverse' nation as a result of 'successive migrations and immigration policies' (Spence, 2004), English remains the predominant language of communication. According to a report by the Office of Ethnic Affairs (OEA) (2014), the majority of migrants entering New Zealand arrive from countries where English is not their first language (pg. 1). Therefore, it can be assumed that migrants arriving in New Zealand will need to develop the ability to communicate competently in English if they wish to carry out daily tasks and eventually integrate into society. With that said, the role of English in New Zealand, along with the perceived need for migrants to 'acquire' it, is quite contested and carries a host of issues, including 'linguistic imperialism' (Canagarajah, 1999) and the potential loss of the migrants' native/heritage language (Seals, forthcoming ). 
Nevertheless, as the OEA report details, migrants' English language ability correlates directly with employment and earning capacity, as well as their ability to 'socialise and cultivate a sense of belonging in New Zealand' (pg. 23). This, for better or worse, highlights the importance of learning English in New Zealand. With that said, the extent to which migrants do develop the necessary English skills remains an issue - particularly for adults. The OEA (2014) document, which specifically examined the role of 'language and integration' in New Zealand, explains how 'a migrant's ability to acquire proficiency in English will decrease as his or her age at migration increases (pg. 14). Moreover, beyond age, the report argues that educational background will also affect the acquisition of English. In other words, the more education a migrant has had before arriving in New Zealand, the easier it will be for them to learn English. While initiatives have been proposed by the New Zealand government to support the English language needs of students from non-English speaking backgrounds (including newly arrived migrants), these initiatives, which have been criticised for their ineffectiveness, are aimed almost exclusively at student-aged children (Franken \& McCormish, 2003). According to The Adult ESOL Strategy, a government policy document on refugees and migrants in New Zealand, around 200,000 adults 'can speak English but not as well as they could' (Ministry of Ministry of Education, 2003, p. 2). The document also indicates that there were around 17,000 families with children where either one or both parents could not speak English. Roach and Roskvist (2007, p. 45), in their more recent study on ESOL provision for adult immigrants and refugees in New Zealand, explain how 88,000 people do not speak English well enough to carry out an English conversation on everyday matters.

Both policy and practice reflect the belief that to make the most out of the experience of living in New Zealand, individuals should be able to use English effectively. The inability to communicate in English while living in Wellington will inevitably result in a variety of personal, social, and socio-economic challenges. Unfortunately, there is a dearth of current research available which has empirically investigated adult migrants and their experiences with learning English in New Zealand. The few studies that have been conducted (predominantly with refugees) (Altinkaya \& Omundsen, 1999; Benseman, 2012; Roach \& Roskvist, 2007; Watts et al., 2001) have all highlighted the shortcomings of the English provisions offered for adults. In fact, according to Altinkaya and Omundsen (1999) the inability of these provisions to (linguistically and socially) prepare adult refugees for life in New Zealand 'has the potential to create an underclass of refugees who subsequently experience significant direct and indirect discrimination' (pg. 7).

\section{Micro perspective}

In terms of the micro context, I am interested in examining the L2 learning-related experiences that migrants engage in outside the formal language classroom. I am interested in where this kind of learning takes place, the kinds of activities that go on, and the ways these experiences affect the participants' behaviour (specifically in regards to prospective language- 
related interactions). I use Benson's concept of 'language learning beyond the classroom' (2011) to guide my depiction of the participants' naturalistic L2 interactions. Basically, the micro context is the everyday life of the participants as it relates to their interactions in English.

\subsubsection{Participants}

\section{Purposeful participant selection}

Similar to the above discussion on data, the concept of sampling also carries unique distinctions for qualitative inquiry. While sampling principles in quantitative inquiry are designed to support the reliability of a study's predictions and generalisations about a specified population, in qualitative data the focus is instead on constructing a nuanced description and understanding of experiences. Patton (2002) boldly suggests that the distinction between 'statistical probability sampling' and 'purposeful sampling' represents the quintessential difference between the two methodological approaches (p. 46). In fact, this difference in sampling strategy has led qualitative researchers (Berg, 2001; Patton, 2002; Polkinghorne, 2005) to prefer the term 'selection', as it more accurately captures the process of purposely seeking out 'fertile exemplars of the experience for study' (Polkinghorne, 2005, p. 140). It is important then to stress that the participant (and data) selection not be random, keeping in mind that the primary aim of purposeful selection is to work with people who can provide a broad, rich spectrum of insight and 'maximise what we can learn' (Dörnyei, 2007, p. 126). Given the qualitative roots of this study, I also use the term 'selection' throughout.

Qualitative research, with its intensive collection and analysis procedures, is inherently limited in the number of people and locations that can be used. These logistic parameters make it imperative that we base our purposeful participant selection on well-established principles. It has been suggested that studies use 'selection plans' to help set the parameters (Dörnyei, 2007, p. 126); essentially outlining in a systematic manner why participants were chosen. One small issue with the reasoning associated with participant selection is that it assumes groups of individuals willing and able to take part in research; the reality is that it is often very difficult to attain access to potential participants. Even if the plan to select the participants is sound, the practice is often much more messy. For this study, the participants were selected by combining two similar selection strategies: criterion sampling (Dörnyei, 2007; Polkinghorne, 2005) - selecting participants who meet specific predetermined criteria - and snowball sampling (Browne, 2005; Podesva \& Sharma, 2014) - a strategy used to contact hard to reach populations.

\section{Criterion sampling}

This study carries very specific criteria for participants: they need to be adults, as this is an under researched language learner population in SLA (Ortega \& Iberri-Shea, 2005) that merits 
further attention; they need to be relatively new to the language (in this case English as the study takes place in an ESL context). In other words, the participants should be in the early stages of their language learning. The simple assumption here is that their development (change over time) in terms of socio-cognitive language learning behaviour will be most obvious at the early stages of learning. Because the participants were just recently learning the language, i.e. not yet proficient or fluent, and because of the intricate and exhaustive nature of the interviewing process, including the sensitivity of the topics for discussion, it is imperative that the participants be able to communicate in their L1. As I am bilingual (English-Spanish), the decision was made to search for Spanish-speaking participants. More specifically, the participants should be relatively newly arrived (one year or less) L1 Spanish speakers learning English primarily in naturalistic settings. Naturalistic language learning, or learning 'beyond the classroom' is also a significantly under researched, area (Benson \& Reinders, 2011; R. Ellis, 2008) that I wanted to investigate - especially in an ESL context. Thus, the following criteria for participant selection were established at the outset: Spanish-speaking, English-learning adults (learning primarily in contexts outside of the classroom) who had been living in New Zealand no longer than six months at time of contact (In the end, this final parameter was adjusted, as explained below).

\section{Snowball sampling}

It was a challenge to find participants who fit the strict criteria requirements, not to mention adults willing to participate in a year-long ethnographic investigation into their language learning. Moreover, I had no ties to the Spanish-speaking community in Wellington. I had only been living in the city for eight months when I started data collection, arriving as an international PhD student. Additionally, the Spanish speaking community in Wellington is relatively small. The community that is here is well-established (meaning they have been in New Zealand for several years). The initial contacts that I made all pointed me in the direction of either family or friends (who had all been living in Wellington well over the one year limit), or community groups (who unfortunately were not able to help); Wellington also has five Spanish-speaking embassies (Argentina; Chile; Cuba; Mexico; Spain) all of which I contacted without success. It was frustrating looking for (and not being able to find) participants and was in many ways one of the most significant challenges of this research. In the end, one of the participant requirements had to be adjusted - length of time living in New Zealand. Whereas at the beginning of the study the ideal time in New Zealand was (maximum) six months, it became increasingly clear that this was nearly impossible. Most newly arrived immigrants were more concerned with other things than helping out with research. The refugee and immigration organisations recommended I reconsider this point. Later, I adjusted the length of time to one year maximum living in New Zealand. Unfortunately, this proved equally difficult. In the end, I had to move the number up to two years and even eventually accepted a participant who had been here 26 months from the time the research commenced. It is possible that had I continued to wait, I 
may have met some people to work with around the one year mark, but I felt I had to get on with the study. Despite the extended length of life in New Zealand, all of the participants in this study were still very much at beginner to low-beginner proficiency levels. The following two excerpts from my field notes allude to this frustration:

After feeling very sceptical about the possibility of getting participants for my study today there were some breakthroughs

(Field notes, 19/08/2013)

On October $2^{\text {nd }}$ I contacted Alvaro (a pseudonym), a former EPP (English proficiency program) student who I have gotten to know this semester through my teaching and advising at the university. Alvaro helped me get in touch with my first two participants. I was getting desperate looking for participants and I thought maybe asking him again for some help would be able to produce something as he appears to be well connected with a refugee services group in and around Wellington

(Field notes, 15/10/2013)

The first entry is dated the $19^{\text {th }}$ of August, nearly three months after having officially received ethics approval from the university to begin research (ethics was officially cleared on $5^{\text {th }}$ of June). After three months of searching extensively for participants, I finally had someone potentially interested (this lead resulted in my first two participants, Paco and Silvana). The second 'desperate' entry comes almost exactly two months later. Basically, five months after officially beginning my research I only had two participants. Luckily, at least in some ways, a large selection of participants is not necessary for this type of study. Duff (2012) for example suggests using one participant for a pilot and 'several' for a larger study, asserting that, 'Three or four can be very rich', particularly for a dissertation (p. 105). Patton (2001) believes that 'There are no rules for sample size in qualitative inquiry', but that it really depends on what you want to find out; he calls it a trade-off between breadth and depth (p. 118). Regardless of the exact number, qualitative scholars (Patton, 2002; Podesva \& Sharma, 2014; Polkinghorne, 2005) essentially favour of a small number of participants who fit defined criteria. Next, I outline another major issue regarding the study's participants: the process of gaining and maintaining access.

\section{Gaining and maintaining access}

To capture an intricate picture of aspects of adult's lives as language learners demands rigorous examination of their lived experiences (in and out of the classroom). This involves generating information from both the perspective of the participant and from within the context of their (language-related) behaviour (O'Reilly, 2005). Prolonged observation, in-depth interviewing, and document analysis are useful methods for gaining this particular type of insight. In other words, meaningful participation in the lives of individuals (facilitated through particular research methods) makes it possible for researchers to establish the essential 'insider meanings' and participant- 
researcher interpretations (Swann \& Maybin, 2008, p. 24) which support the different discussions and theories regarding people's naturally occurring behaviour. However, not all individuals are equally approachable. Gaining access to people, especially those considered hard to reach, is a common issue in qualitative and ethnographic studies. In fact, many qualitative research methodology texts include discussions on gaining 'access' or 'entry' (Berg, 2001; Bryman, 2001; O'Reilly, 2009; Patton, 2002). While this issue of 'getting in' can be viewed as a 'problem' (Berg, 2001, p. 136) (it certainly poses a challenge to fieldwork), it seems more like an inevitable component of relationship building, which in many ways is at the heart of any study which carries an interpretive perspective. Building an intimate and intricate research relationship between participant and researcher, like any real world relationship, thrives off dimensions of contact dimensions which, although intertwined, carry important distinguishing features. Below I discuss, these distinct dimensions of contact as they pertain to this investigation. I illustrate how gaining access to participants was primarily a question of establishing contact, while maintaining access was a layer beyond, and dealt instead with negotiating contact. In this research, I am entering the lives of individuals, with the assumption that there is much to be learned about the second language learning process by building in-depth knowledge of contextualised, highly personal experiences of individuals.

\section{Gaining access as establishing contact}

Finding low proficiency (beginner-level) adult English learners who speak Spanish as an L1, and who were learning English primarily outside of class (through day-to-day use) was, as mentioned above, an important challenge for this project. My limited social network in Wellington's Latin community essentially forced me to start from scratch and find people to act as 'guides' or 'informants' (Berg, 2001, p. 145) who could introduce me to people who might be potential participants. Eventually, I found three people who played key roles in helping me gain access to participants: A colleague investigating different refugee communities in Wellington; a former Colombian refugee background student who I taught (Alvaro); and a refugee officer/cross-cultural liaison (Diana) who worked specifically with the Colombian community in Lower Hutt where the majority of refugees reside. It is important to point out, however, that this study is not intentionally focusing on refugees (and is not about refugees specifically). Rather, it happened that the most reliable contacts were working closely with Colombian refugees who also closely fit my criteria (only one of the participants is not a refugee but immigrant-background).

Initial contact with my first participant was made through an invitation from my colleague to attend a refugee welcome dinner at a community church. As it turns out, I walked to the dinner with my colleague and, Alvaro, (a Colombian refugee and who turned out to be one of the most important resources in helping me gain access to participants). Both were aware of the type of participant I was looking for. At the dinner I met a few people but being sensitive of the context and 
my newness did not feel comfortable immediately soliciting help with my research. I introduced myself and communicated with all the Colombians that I spoke with in Spanish. This seemed to help create a kind of bond between us and even though I was not Colombian (I am originally from Peru), my Spanish ability and connection to South America seemed, at least outwardly, to work in my favour. Talking it over with my colleague and my student, we agreed that it was best to use this opportunity to establish contact and to follow up at a later date. After the party, when making my research notes, I reflected on who I had met and considered who best fit the criteria. There was one man, Paco, who seemed like he could help. He had been in New Zealand a little over a year but was not learning English in classes and was quite low proficiency. When I observed him throughout the party, he was very affectionate with his children, hugging and playing with them and also sociable with others, laughing a lot and helping whenever he could. The next day, I asked my student about him (I had seen the two talking at the party) and wondered if he might help put us in touch. Alvaro said he would see what he could do. Eventually, I had Paco's phone number and assurance that he was willing to hear about the project. I called the house immediately and we arranged to meet at his home the following Sunday. During our one hour meeting, I explained the project in general terms, provided an information sheet and asked if he and his wife, Silvana, who was also there, would be willing to help. They both agreed and signed the consent forms on the spot. I had established contact and procured consent from my first two participants. Over the next month, through sustained contact with Alvaro (who as it turns out was, despite his young age, highly respected and well-known amongst the Colombian refugee community; partly because of his advanced English proficiency and partly because of his out-going nature and willingness to help people), I met two additional participants, Samantha and Clara. Samantha worked with me the longest of all my participants, while Clara, who was Alvaro's mother incidentally, decided she could not continue after the second interview.

About four months later (I continued the whole time to search for participants as a precautionary measure, aware that at any moment a participant might decide to drop out), through a different contact (a New Zealander who worked with refugee communities in the city that I met at a community language learning conference), I began communicating with Diana, the cultural liaison officer for the Red Cross who was in charge of looking after all the in-coming Colombian refugees. In an introductory email, I provided general details of the research, including its potential social implications, as well as a description of the type of participants I was looking for. She responded that she would be happy to help in any capacity but cautioned that due to the criteria, it would be difficult to find people. A few days later, she invited me to a picnic arranged through the Refugee Services/Red Cross organisation in Wellington, explaining that there would be various families that I could approach and that she would introduce me to the people she thought might be willing to help. Thanks to her invitation and introductions, I met another one of my participants, Constanza. At the picnic I explained to her what I was doing in my research and asked if she might be interested in 
hearing more. She said the project sounded interesting and that she would help. She told me to bring the information sheet and consent form to her house and explained that we could do our first interview then as well. After almost exactly one month of exchanges between the two of us (mostly via email), persistence paid off and I was invited to Constanza's home. I explained the research again and got formal consent. Once this was finished, we had our first interview. Diana also put me in touch with two male participants (I was trying to strike some kind of gender balance). However, after numerous attempts, no access was gained. Finally, after some more back-and-forth emailing, she mentioned that her mother (Sandra Milena), who had heard about the project, was interested in talking with me. Her mother was a Colombian retiree who had immigrated to Wellington to live with her about two years ago. Once Diana confirmed her mother's interest (nearly a month later), she provided me with the contact information, and like each previous participant, I made contact via telephone, introduced myself and the project, made arrangements to meet in person at her home and explain more. I provided the information sheet, received formal consent, and proceeded to conduct the initial interview. To sum up, my experience with accessing participants was very much in line with most ethnographic work. It was through a combination of 'luck', 'willingness to take advantage of opportunities' as they arose, doing the necessary 'preparatory background work', using my own social 'circles', 'making the right contacts', and above all 'being appreciative' of my participants (Ostrander, 1993) that I was able to 'get in'. After seven months of participant selection and gathering, with the help of three key informants, I had established contact with the five individuals who would make up the participant population of my study. The next step then was to find ways of effectively developing these relationships so that they could produce the most useful information. However, as Ostrander (1993) reports, certain aspects of negotiating access would be more challenging than others ( $p .16)$. In the next section, I highlight some of the inherent challenges in this (ongoing) negotiation of maintaining access.

\section{Maintaining access as (ongoing) negotiation of contact}

Deepening access into a person's life, like any 'relational process', hinges on building rapport and trust (Feldman, Bell, \& Berger, 2003, p. x). And like all rapport building, it is an ongoing process with no clear-defined end. There is however, a constant negotiation between researcher and participant, where aspects of control, transparency and commitment are dynamically shaping the transfer of information and the consequent construction of insight.

One key aspect of this negotiation process is the insider-outsider role of the researcher. As an insider it can be easier to establish rapport, as participants will carry a certain 'affinity' when they feel they are talking with one of their own (Fincham, 2006, p. 191). Similarities between participant and researcher can act as interpersonal links, which provide a kind of head start on building valuable trust and understanding. However, the insider role is not without its problems, the most obvious being the difficulty in maintaining the necessary 'analytic distance' (Rampton, 2007, p. 591) required 
to recognise and appreciate the subtle and idiosyncratic behavioural patterns of participants. In other words, it is important for a researcher to also play an outsider role as this helps to notice 'the strange' and produce honest accounts of 'the little things that happen' (O'Reilly, 2005, p. 92) as they relate to behaviour and change. Duff (2012) argues that 'reflexivity' regarding such matters is important as it makes clear a researcher's 'connections to the target languages and communities' and any 'possible investment' with the participants - connections which inevitably affect 'recruitment, analysis, and findings or interpretations' (p. 106). By making explicit these connections and disconnections (e.g. gender; cultural and educational background; socioeconomic status) between the researcher and the participants, different biases and attitudes which can impact the key interpretations constructed throughout this research are brought to the surface. This in turn facilitates a better understanding of the discussion at hand. With that in mind, below I provide a brief narrative to highlight aspects of my insider-outsider status in this investigation.

\section{Positioning the researcher}

I am originally from Peru but moved to Canada at the age of five with my parents and sister. Only my father was able to use English when we arrived, having spent a decade living in England. My mother, who was in her early-thirties, had no English ability and worked hard for years developing her skills. My sister, who was two years old and was just starting to speak Spanish when we left Peru, stopped speaking altogether for around six months. Apparently the transition from Spanish to English at home (a rule my father tried to enforce) caused her some trouble. We arrived in late March and by September I was attending kindergarten. I have no memory of learning English. I only remember being able to use it with teachers and classmates. I had a middle-class upbringing, where education was valued and promoted. It felt like there was a constant discussion about language learning and use in my family. I grew up speaking Spanish at home, while using English outside the house, at school and in other day-to-day interactions. My family and I remained close with my relatives in Peru and we would return almost yearly for visits. This was done partially to ensure that we continued to communicate in Spanish. My parents were quite serious about my sister and me 'keeping up' our Spanish ability while living in Canada. At the age of 22, I moved to Japan and lived there for 15 years. I studied Japanese formally but most of my Japanese language knowledge came from naturalistic interactions including relationships with Japanese friends and colleagues. After this, I moved to Wellington as an international PhD student, with my Japanese wife and two children. I have been involved in language education (teaching and advising for over 18 years), a fact which my participants were aware of and spoke about with me often. They viewed the fact that I could speak in Spanish, but also had experience teaching English, as helpful and something which they could potentially benefit from. I also believe that this combination of English-Spanish ability helped put them at ease during the research process. There were instances during some of the interviews where I think they saw me more as a university English teacher than as a researcher. Finally, the fact 
that they were native Spanish speakers and I was a fluent but not native Spanish speaker helped shift some of the perceived power imbalance to the participants. This was most obvious when I would ask them what they meant by a particular term or when they sometimes checked my pronunciation. It was obvious they liked to teach me a thing or two about Spanish.

In terms of similarities and differences with my participants, i.e. shared experiences, we have a common Latin American ethnicity and language. However, there is no denying that there are differences in dialect between the Spanish spoken in Colombia and the Spanish spoken in Peru, not to mention differences in national cultures and the attitudes toward these respective cultures. This insider-as-Latin-American, outsider-as-Peruvian aspect was explicitly brought to my attention early on in the research when I called Samantha's home to set up an interview. Her daughter Sofia answered the phone and when she called for her mother, yelled out Mama, el Peruano! (Mom, the Peruvian!). In fact almost every time I called and Sofia answered the phone, she would refer to me as el Peruano. An additional similarity is the fact that all of us had experienced migration to countries where the dominant language was different from our native one. Still, my immigration to Canada was very different, mainly because of age, but also because of circumstance. As I mentioned before, all but one of the participants moved to New Zealand as refugees and the migratory experience of a refugee is different from the migratory experience of an immigrant; a refugee's migration is rooted in necessity, whereas immigrants usually move by choice. That said, I was witness to the various challenges adult Spanish-speakers face in their day-to-day lives as they learn English through direct observation of my mother. And in many regards, the challenges I faced learning Japanese as an adult connected me with those of my participants. Throughout various interviews, we often compared my experiences learning Japanese in Japan with their experiences learning English in New Zealand. Another connection between us is that we are all migrants to New Zealand, and needed time to learn about the various idiosyncrasies of 'Kiwi' culture. Again, however, because of my English speaking background, this process was often quite different. Finally, another connection worth mentioning is that we are all parents of bilingual, or potentially bilingual, children - a similarity which was often discussed in our interviews.

There were also many obvious differences between the participants and me, which marked me as an outsider. In terms of experience with formal education, only one of my participants had completed high school, with the majority of them never making it through middle school, whereas I had spent a large part of my life navigating formal educational contexts, including my current roles as a PhD researcher. Socio-economically, my participants all came from rather poor backgrounds, many of them experiencing difficult working conditions on farms and coca leaf plantations from early on in their lives. I, on the other hand, had very minimal experience with labour-related work. And of course, the fact that I grew up in an English speaking country (even though I spoke Spanish fluently and was from Peru) was an apparent point of distinction, which all of the participants made frequent reference to. 


\section{Prior knowledge of participants}

Another significant aspect in the ongoing negotiation of access deals with how much I knew about my participants. Berg (2001) claims that effectiveness of researchers' 'strategies' in their investigations, including the facility with which entry and rapport are established, is largely determined by the amount of background information they have about the participants (p. 144). Rock (2001) mirrors this sentiment, stating that 'ethnography characteristically begins not in the field but in the library' (p. 33). Although this was true to a certain extent, my own experience with rapport building hinged more on trying to understand who my participants were in the present, and becoming familiar with how they were managing their daily routines (of course, to a large extent this meant finding out about their past experiences and habits as well). I was also conscious of the fact that certain vulnerable individuals, such as low-proficiency adult English learners living in Greater Wellington, can carry a distrust of outsiders (scholars, with their research agendas, can be particularly intimidating), and assuming too much about anyone, as a representative of a group, for example, can potentially increase the level of suspicion directed toward the investigator. I felt it vital to see my participants as unique individuals, rather than abstract representations (a possible consequence of too much background work) and wanted them to recognise my honest and authentic interest in them as people and in their experiences as language learners, rather than as preconceived archetypes. Additionally, determining how much I would have to learn beforehand in order to 'operate effectively within a setting' is not a straight forward endeavour. As O'Reilly (2005) maintains, when negotiating contact with participants, it is important to strike a balance between being 'naïve' and 'knowledgeable' (p. 89), but in the end a qualitative researcher needs to, through field work, explore the real world.

\section{Research bargains}

Forming 'research bargains' (Berg, 2001, p. 144), was also integral to maintaining and deepening contact throughout the study. These (often) organic arrangements, again similar to most interpersonal relationships, reflect the need in research for some sort of reciprocation. This reciprocation, in turn, contributes to the overall social harmony and positive feelings about taking part in research of this nature. For this study, I made the conscious decision to not offer any kind of incentive for participation (monetary; coupon; etc.), believing that this in some way might affect the reliability of the information I received. I did not want participants granting me permission to work with them because they expected to receive something tangible in return. Rather, I wanted the research to be, as much as possible, voluntary. However, I was aware that the participants were being very generous with their time. And the fact that they were opening up sensitive areas of their present and past lives to me did not go unappreciated. I told each participant throughout the process, from our first official meeting to the exit meeting (and beyond) that if there was something 
they needed me to do for them, I would do whatever I could to help. The research bargains that developed between us were also important in that they shaped (and were shaped by) the roles which the participants and I assumed. These bargains reflect the idiosyncratic nature of the research relationships and provide some interesting insights about my participants themselves, and our interactions together. For example, it was obvious that Constanza saw me not only as a researcher, but also as a language resource, taking every available opportunity to contact me (via phone, text, or email) when she had some issue with English. At least monthly she contacted me, asking for assistance with things like calling her internet provider, her bank, and her local GP. When she had homework or bills that she did not understand, I would translate for her. And in every interview she would ask me about the accuracy of her English use, checking to see if she had said something correctly. On the other hand, Samantha never asked me English specific questions. She never once called or emailed me. We did often talk about her personal life though, and many times throughout the research, it felt like she considered me a close confidant, and viewed the interviews as opportunities to get things off her chest (exit interview). The ongoing development of our research relationships were in many ways deepened by these important and interesting bargains. Similar to what Feldman et al. (2003) attest, different people will interact in different ways, and this consequently leads to a unique research experience. But regardless of these differences, the importance of arrangements in rapport building and establishing trust was undeniable.

Next, I move on to the description of the study's participants. I begin with a general description of all the participants (everyone interviewed at least twice). This is followed by brief narrative descriptions of the study's three 'principal participants' (Samantha, Constanza, and Sandra Milena). The principal participants are those individuals who I worked with the longest and most intensely. These participants represent what Patton (1990) deems 'information rich cases' (p. 169), necessary for nuanced exploration of phenomena. Many of the issues of central importance to this study arose from the information gathered from my interactions with these three individuals. In addition, in-depth exploration of multiple participants allowed for the construction of detailed accounts of migrants' L2-related experiences. Chapelle and Duff (2003) argue that multiple cases are preferable to single cases, especially if the cases are not exactly representative of a particular population and when 'a range of behaviour/profiles, experiences, outcomes, or situations is desirable' (p. 165). Therefore, a more in-depth description of these key participants is warranted. It is important to note however, of these three principal participants only one (Constanza) was examined as a focal case (see Chapter 6: Discussion). I wanted to ensure that the essence of this study remains on exploring a developmental process in action. In other words, this research is less concerned with a categorisation of varied 'experiences' or a description of 'profiles', and more with investigating the complex ways in which L2 learners' mental lives interplay with their surrounding contexts and how this 'relationship' inevitably impacts approaches to language learning. Thus, I believe in-depth exploration of a single case allowed me to delve into these necessary depths. 


\section{Description of participants (general)}

Below is a description of all the participants for this study:

Table 2: Description of participants (general)

\begin{tabular}{|c|c|c|c|c|c|c|c|}
\hline NAME & AGE & $\begin{array}{l}\text { PLACE } \\
\text { OF } \\
\text { BIRTH }\end{array}$ & $\begin{array}{l}\text { TIME IN } \\
\text { NEW } \\
\text { ZEALAND } \\
\text { (months) }\end{array}$ & $\begin{array}{c}\text { FIRST } \\
\text { CONTACT }\end{array}$ & $\begin{array}{c}\text { FIRST } \\
\text { INTERVIEW }\end{array}$ & $\begin{array}{c}\text { FINAL } \\
\text { CONTACT }\end{array}$ & $\begin{array}{c}\text { EXIT } \\
\text { INTERVIEW }\end{array}$ \\
\hline Paco & 34 & Palmira & 13 & $19 / 08 / 2013$ & 08/09/2013 & $18 / 01 / 2014$ & N/A \\
\hline Silvana & 35 & Palmira & 13 & $19 / 08 / 2013$ & $08 / 09 / 2013$ & $30 / 09 / 2014$ & N/A \\
\hline Clara & 55 & Bogota & 21 & $8 / 10 / 2013$ & $14 / 10 / 2013$ & $\mathrm{~N} / \mathrm{A}$ & Withdrew \\
\hline Samantha & 31 & $\begin{array}{l}\text { Porto } \\
\text { Asis }\end{array}$ & 20 & $8 / 10 / 2013$ & $14 / 10 / 2013$ & Present & $15 / 12 / 2014$ \\
\hline Constanza & 40 & Cali & 20 & $14 / 12 / 2013$ & $13 / 01 / 2014$ & Present & $15 / 12 / 2014$ \\
\hline $\begin{array}{l}\text { Sandra } \\
\text { Milena }\end{array}$ & 74 & Medellin & 26 & $16 / 01 / 2013$ & $25 / 01 / 2014$ & Present & $17 / 12 / 2014$ \\
\hline
\end{tabular}

All six of the participants were born in Colombia. However, they are all from different parts of the country. All of them are also over 31 years of age. All but one participant (Sandra Milena, 26 months), have been in New Zealand under two years. Also, four of five of them are refugeebackground participants. Sandra Milena was the only immigrant-background participant I worked with. For each of the refugees, New Zealand was the second country that they had lived in as refugees. They had all previously lived in Ecuador for a minimum of four years as refugees as well. Officially, they are part of a third country resettlement program organised by the United Nations High Commissioner for Refugees (UNHCR) in collaboration with a handful of other countries, including Australia, Canada, the United States and New Zealand. Resettled refugees, according to the UNHCR are admitted to a third state with permanent residence status and carry the 'opportunity to eventually become a naturalised citizen of the resettlement country' (UNHCR, 2014, p. 3).

Paco and Silvana were husband and wife and had three children (Veronica, 13; Rosario, 9; Francisco, 7). Clara, Samantha, and Constanza were single mothers with one, three, and three children respectively. Sandra Milena was a retired 'grandmother', living with her Colombian-born 
daughter, her New Zealand son-in-law and their two children. Sandra Milena, Constanza, and Samantha were the only participants attending English classes.

\section{Description of the principal participants (specific)}

As mentioned, this study had three principal participants whose extensive interactions with me allowed me to conduct in-depth analysis of L2-related experiences across a range of naturalistic contexts. These participants are the participants I worked with the longest (Samantha 14 months; Constanza and Sandra Milena 11 months) (see table 6 for more principal participant interview information) They also exhibit characteristics of what might be considered 'extreme cases' (Duff, 2012, p. 106), where each case presents 'extreme' variance in their language-related behaviour. Below I provide a short narrative of each key participant to help paint a picture of what life in New Zealand might be like for recently arrived migrants from non-English speaking backgrounds. In the interest of space, the descriptions are by no means extensive. Instead, they are an initial attempt to help 'set the scene' for later discussion of a single case (see Chapter 6)

\section{Samantha}

Samantha is a single mother with three children. Sebastian, Sofia, and Jimena $(7,11,16$ years old respectively). Unlike the other refugees who arrived together in larger groups, Samantha and her children came to New Zealand on their own. This meant that they did not meet any other Colombians for the six weeks of her orientation in Mangere, Auckland. In fact, they were the only Colombian family present for this particular induction. As a consequence, her connection to the Colombian community living in and around Wellington was not as strong as others. She mentioned this as a positive fact, however, preferring not to mix too much with other Colombians. That said, she did have close connections with one or two other Colombians and mentioned them throughout our time working together.

Samantha and her family lived in Clarksville, a suburb of Lower Hutt, with a population of about 3000 people. According to Statistics New Zealand, Roughly $24 \%$ of the people living in Clarksville were born overseas (comparatively larger than the population of Lower Hutt City as a whole). The most common birthplace of people born overseas in Clarksville is cited as Asia. After English, Samoan is the most common spoken language. Samantha's main reason for seeking resettlement to New Zealand was the medical condition of her youngest child, Sebastian. He had a severe medical condition and, while living in Ecuador was worried about his safety. Samantha was told that while she was living as a refugee in Ecuador, Sebastian would not be able to receive the necessary treatment for his survival, and that it was unlikely he would live past 15 . This motivated her to apply for a third country resettlement program. She said she did not know anything about New Zealand before arriving, only that the medical treatment for children with her son's condition 
was very good. When I asked her what she knew about New Zealand before coming she said nothing at all, and that all she did was search online for information about New Zealand's medical care for children like Sebastian.

Samantha came from a very large and poor family. She grew up living and working on coca plantations and other types of farms. She left home when she was young, but did manage to finish primary school. She said her parents stressed this point to her, but admits that when she was younger she saw no purpose to going to school. At the age of 15 or so she says she left home. She was having problems at home with her mother in particular from too much partying as she puts it. She mentioned that her position as a mother definitely changed her. A family friend suggested she move to Ecuador where life was calmer and more stable and less dangerous. She said it sounded like a good idea and moved to Ecuador, received refugee status and lived there for close to 15 years, working mostly in restaurants. My first impression of her was that she was a serious but warm person definitely not the too much party type of person. This seemed to be the case throughout our interactions. She was a strict but loving mother, always making sure her children did all their homework and encouraging a mix of Spanish and English at home. She said she wanted to give her children the best opportunities for success and when referring to other Colombian families she knows, she disparaged how lazy they were with the kids in regards to their school work and English. She was fiercely independent and worked very hard to earn money. Beginning with one house, she ended up having over six, where she cleaned and looked after children, getting paid under the table. She set different goals for herself throughout our time together (get a driver's license; buy a new TV; save for tickets for trip back to Colombia/Ecuador) and met them all. She was very religious and went to church every Saturday and prided herself on being able to keep secrets and being honest with people. She was also an excellent cook and each time I visited her I could smell some excellent dishes being prepared in the kitchen.

\section{Constanza}

Constanza is a single mother with three children (Mateo, Paula, and Tomas). They were 6 , 12, and 17. She arrived in Mangere as part of a group of Colombians and often spoke fondly of this initial period in New Zealand. ). Constanza, while extremely loquacious in regards to her languagerelated activities in New Zealand, rarely talked about the experiences in her life which led her to apply for refugee status (both to Ecuador and to New Zealand). She did mention that she had always wanted to live in an English speaking country. She confessed to really enjoying her time in Mangere because she appreciated the convenience of having everything done for her. In Mangere, incoming refugees have an interpreter available for them to explain all about the orientation and even to accompany them when they venture out to the city. She said she also enjoyed meeting the refugees from other countries and even though they could not verbally communicate, they used a lot of gesture and did their best to communicate together. She seldom had Colombian friends over to the 
house although she did occasionally meet other Colombians on arranged picnics and trips. Constanza was often critical of the time she spent with other Colombians as a problem for her English learning. Overall, she did not spend much time with others, and led more or less a rather isolated life. She and her family lived in Harbourview (one train stop away from where Samantha and her family lived). Another suburb of Lower Hutt City, it has a population of about 3000 . Statistics New Zealand says that over $28 \%$ of Harbourview's population comes from overseas. The most common birthplace of people born overseas in Harbourview is South Pacific. Te reo Maori, Northern Chinese, Yue, and Hindi are the most spoken languages after English in east and west Harbourview respectively. She was not particularly pleased about living in Harbourview. She sometimes said she was afraid of the neighborhood and did not want her children walking around by themselves, particularly near the station.

In her descriptions of her childhood, Constanza says she was on her own from a very young age and never finished primary school. She says she travelled all over Colombia, working wherever she could, and mostly always on her own. She seemed proud of how much of Colombia she had seen and was enthusiastic about travel (both domestic and international). She seldom spoke about her parents or siblings. I was surprised after several months into the study when she mentioned that she had a sister who was interested in moving to New Zealand. She said life in Ecuador was very hard because Colombians were frequently discriminated against. Constanza, Paula and Mateo all met regularly with different psychologists for what she explained as different reasons. She said she often had terrible migraines and had trouble sleeping. A lot of these issues she said were directly related to her problems with English.

I found her to be very friendly and talkative but admitted that as a child she was very timid and shy and easily embarrassed. She often talked about feeling embarrassed when speaking with others but it seemed to me that when she was determined she could accomplish quite a lot, often resorting to what she called idiotic gestures. With me she did not appear timid and admitted that after having the children she had to change how she interacted. She always prepared meals and drinks when I visited and seemed to really enjoy our talks and meetings. Of all the participants she was the only one who always asked me when I would come back and in fact, would sometimes request to meet more often. She was a devoted mother but not at all strict with her children. She said she never helped them with their homework and was not even aware if they had homework or not. In fact, it was not uncommon for the kids to be out of school during the week for no other reason than they did not want to go. She always cleaned after them and admitted that she did not want her children to experience too hard a life. Of all the participants, she used the most English with me during out meetings, mostly to either inquire about the correct way to say something (a type of rehearsal) or to see if she had made a mistake in some language-related interaction she was describing (a type of checking). While some of the other participants (e.g. Sandra Milena and Samantha) also occasionally used 'snippets' of English when describing a language-related incident, 
usually to illustrate what they said in the situation, Constanza did so with much more frequency and for longer chunks of the interviews. She spent a lot of money on household goods and would often rely on credit and loan companies to help. In fact, one of my main roles was to communicate on her behalf with the different loan agencies she used. She did not spend a lot of time studying English, suggesting that while she really wanted to, she did not have enough time. She was religious but not nearly as devout as the other participants. Constanza also had the lowest English proficiency of all the participants, which was particularly noteworthy considering that she was also the most interested in acquiring the language.

\section{Sandra Milena}

Sandra Milena was the eldest participant. She was also the only immigrant-background participant. She was the mother of two daughters and grandmother to four grandchildren. Her eldest daughter was still in Colombia with her husband and two daughters of her own but the family in New Zealand had applied to bring them over as part of family unification program. They had been waiting for over three years for the paperwork to get processed.

Sandra Milena lived in the home of her youngest daughter, Diana. Diana was married to a New Zealander (Douglas) and they had two children, Daniel (7) and Carolina (9). Diana was the crosscultural officer who introduced me to Constanza and her mother as participants. They lived in Hillside, a suburb of Upper Hutt. It has a population of close to 3600 people. $22 \%$ of the people who live in Hillside were born overseas, similar to the Lower Hutt statistics. However according to Statistics New Zealand, the most common birthplace of people born outside of Hillside was UK and Ireland. After English, French is the most common spoken language in Hillside. It was a middle class suburb. The main reason that Sandra Milena cites for immigrating to New Zealand was to live a more comfortable life. She explains that life in Colombia (Medellin) even for the middle class is hard and can be dangerous. Life in New Zealand offered her more tranquillity, which is what she said she wanted at this stage of her life. Initially when she came to New Zealand to visit, she did not enjoy her visits, saying mostly that she found it too cold. After her second prolonged (6 month) visit however she decided to apply for residency. She says she got used to the weather and she was now very happy living in New Zealand.

Sandra Milena was a very industrious woman. In Colombia, she put herself through high school as an adult taking night classes. She opened up and ran her own shop in her neighbourhood and worked hard every day to put both her daughters through university. She was very proud of the fact that she could do everything on her own with little help from others. Her husband had passed away years ago, and she had learned to take care of her family and herself very well she said. She gave Diana the money to leave Colombia and to move to New Zealand as well. Although being from an upper-middle class background, she was unpretentious, friendly, open, and polite. She also lived a very active life, taking daily walks, commuting into the city a lot and gardening. She worked hard to 
develop her English every day while also taking care of various household activities. She was devout catholic and went to church every Sunday. She knew who Constanza was and were in fact, kind of friends. Sandra Milena also had various other non-Colombian, Spanish speaking friends who she often met for tea and coffee.

Next, I provide a description of the pilot conducted for this study, before moving on the data collection and analysis methods.

\subsection{Pilot study}

Once human ethics was approved and participants identified, I conducted an extensive pilot study. Although human ethics was approved in early June, it remained a challenge to find participants who fit the description of the type of individual I was interested in working with. I made use of the time that I was without participants, by piloting various key components of the research. The pilot for this study was rather involved. It ran for eight weeks from June to August, 2013. A total of eight participants took part in the pilot, including the researcher as participant. The pilot study produced important insights that informed the research in important ways. It was also valuable in that it provided me with the opportunity to practice and hone my data gathering technique.

Below is a description of the pilot and as well as highlights of the knowledge gained from the pilot useful in informing the larger study. There were essentially two phases to the pilot and important variation between each of the phases.

\subsubsection{Phase 1: Piloting interviews and language}

The first phase of the pilot was mainly focused on learning about the interview process and honing my skills as qualitative interviewer. I have extensive experience with interviewing from my previous positions as a language learning advisor (Mynard \& Carson, 2014). I have worked, both in Japan and in New Zealand, with university language learners in one-to-one settings similar to the interviews I would conduct with my participants, but with a narrower focus. The advising role requires me to create conditions where learners take control over the interactions, deciding (to a large extent) the content of our discussions, as well as directing the flow of these sessions (interviews). In my advising position, I am more like a (learning) facilitator than a (language) teacher (Morrison \& Navarro, 2012), although knowledge of language learning theory and practice is vital. Through active listening and questioning, I am responsible for raising critical awareness in learners about what they were doing (and saying), in an effort to help them become more effective in reaching their goals. Another important aspect of this position was suggesting language learning resources and activities to experiment with. Through my advising experience, I worked on professional development and research projects gaining important interactional skills borrowed from client-centred counselling (Rogers, 1951), such as, 'negotiation of meaning', 'paraphrasing', 
'confronting' and 'concluding' (see Kelly, 1996; Mozzon-McPherson, 2014). In addition, I have formal training in 'managing-silence', 'turn-taking', and 'challenging'. Although, I am aware that the advisorlearner relationship is different from a researcher-participant one (e.g. the study's participants are all much older than university language learners; the language of the interviews will be Spanish, not English), I believed that many of these skills would be useful in helping me manage the interactions with my research participants. However, since the majority of my data collection would be from interviews, I felt it important that I continue to learn about (and practice) interviewing techniques specific to the context of my research. I wanted to explore what works well and what does not, and develop the skills necessary to create effective qualitative research interviews. Mann (2011) in his critical review of interview management in applied linguistics, explains that to produce optimal results, that is to generate the most useful data, qualitative interviewers need to work on 'recruiting and setting up interviews, managing the interview itself, developing a reflective and sensitive approach, and feeding sensitivity into the analysis and representation' (p. 19) of these complex and sensitive interactions. That said, after numerous conversations with colleagues conducting various types of interviews in their work, all of them mentioned that even after hours of interview practice and hands on experience, there will continue to be 'good' interviews and 'bad' interviews; the main thing is that the 'bad' ones tend to decrease in frequency and the awareness of how to construct a 'good' interview is sharpened. Thus, phase 1 of the pilot served several purposes: to raise awareness of potential interactional issues (not exclusively technical issues but also affective and cognitive issues related to qualitative interviews); to consider the logistics of interviewing; to sensitise myself to the difference in language (interviewing in both English and Spanish); and to get more practice.

Phase 1 was comprised of seven pilot interviews, beginning on the $27^{\text {th }}$ of June 2013 and ending on the $5^{\text {th }}$ of August. The first pilot interview had me in the role of participant. I wanted to see how it would feel to respond to questions and volunteer information about my own experiences with education generally and with language learning specifically. I believed that this experience would help me empathise with my participants, allowing me to understand better what they might be feeling and thinking when asked about their experiences. Another proposed benefit of this type of 'bracketing' interview is that it raises awareness of a researcher's presuppositions and assumptions. According to Kramp (2004), insights gained from bracketing interviews help open researchers up to the influence of their own experiences (and perspectives) on the research. This is useful in recognising the effects of bias, but also in ensuring that a researcher's insights 'derived from a particular way of seeing things' are valued (p. 115). I am not by nature a talkative person when it comes to personal information, but I found myself, during this interview, sharing more information about myself than I am normally used to. I was surprised at how easily it was to talk when being asked about myself. This perceived ease could have been because I knew what kind of information I would be looking for as an interviewer myself, and was trying to provide this type of information (and situation) for my colleague who was helping me with this pilot in order to make her 
job easier; in essence, I was trying to please the interviewer. An additional benefit of this first pilot was to provide me with a better idea of how to structure the interviews. I thought about whether it was better to use prepared questions or themes and topics. When answering questions I felt it was too much like an interview whereas the topics allowed for a more organic dialogue. This was my first thought, one that would be confirmed during the subsequent pilots and through my readings on sociolinguistic/ethnographic interviews.

After the bracketing interview session, I conducted six more pilot interviews; three in English and three in Spanish. These pilots were intended to mirror the structure and content of the initial interviews I would conduct with my participants. The initial interviews in my study are meant to elicit background and demographic information, as well as information about any past experiences with (language) education, and get a general idea of how the participants feel and think about education and why. The data from initial interviews is used to profile the participants and their 'histories' with a focus on education. In addition, these interviews would be key in establishing rapport, and helping to demonstrate to the participants that the research had some value, would be interesting, and not something they would want to avoid. In addition, they were a good way of demonstrating to the participants that I knew what I was doing, establishing important credibility, which again is a key component of the trust building process (Ostrander, 1993). Also, the language of the participants is Spanish so I wanted to practice interviewing in both languages. The English interviews were useful in helping me decide what topics to introduce and how to proceed (the English pilots were more content-focused). The Spanish interviews were useful in helping me work out phrasing, timing, and other language considerations, including the shift in and between register. As a result, the Spanish pilot interviews were more linguistically and pragmatically focused than the English ones. Although a fluent speaker of both English and Spanish, my command of English is at the moment stronger due to frequency and opportunity of use. This produced an interesting occurrence. As I was able to understand more easily and produce language more easily in English, I tended to interject more and also talk more. However, in Spanish, I was less interruptive and the participants had more space to work out what they wanted to say. Occasionally, they would say something quite important but I would miss it in the moment and only later when listening back did I lament not asking for further elaboration. Fortunately, the longitudinal component of my actual research would be able to manage this issue as each time I listened back to the interviews, I was able to pull out one or two issues to revisit during the following interview. These Spanish pilot interviews were invaluable in helping me prepare to use Spanish again.

One other important aspect of phase 1 of the pilot was to trial the use of narrative frames (Barkhuizen \& Wette, 2008; Macalister, 2012). The idea was to use these frames in collaboration with interviews to help paint a more comprehensive picture of the participants and their experiences with education and language learning. Also, I thought the data from written accounts might be quite different from the interview data. I created a narrative frame template, initially in 
English, and trialled it with a colleague. Next I translated it into Spanish and trialled it with a pilot participant. After analysing the responses to the frames and getting feedback from the pilot participants on their experiences completing the frames, I deemed them redundant and decided not to use them. I was getting essentially the same information from the initial interviews. Also, the added task of completing a frame was added work for the participants, and for minimal return. Keeping my participants interested in this project for a year was going to be a challenge enough so unless something was absolutely necessary I did not want to use it.

In sum, phase 1 of the pilot offered valuable insight into the practice of interviewing; insight which transferred to the main study. Below are two tables highlighting the insights gained from this phase of the pilot:

Table 3: Technical insights gained (Phase 1)

\section{TECHNICAL INSIGHTS}

Timing of (average) 45 minutes

interviews

Equipment

Hi fidelity, small unobtrusive IC recorder and mic; lined note pad; clipboard; (backup) recorder

Recording

Record as soon as possible; ensure participants are aware of recording

procedure

Note taking

Keep to a minimum (disruptive); explain that notes are not evaluation of ideas, instead used as reminders for follow up questions 


\section{INTERACTIONAL INSIGHTS}

Beginning the initial interview

Register in Spanish
Model 'self-introduction'; provides example of how to respond to: 'Please tell me about yourself'; keep interview participant-centred; do not speak for too long; participants get bored

Begin with the formal form; observe participants' responses; move to casual form once initiated by participants

Assure participants that all the information is important; no 'correct' answers

Desire to please the interviewer

Discussion topics

Prepare topics rather than questions; eventually, participants introduce topics (describing daily language-related interactions)

Follow-up questions

Begin with yes-no questions; lead into open-ended questions; allow for pauses; monitor researcher interjections

Establish dialogue through authentic interest in participant responses; comment on participant experiences to facilitate naturally occurring speech conversations

Interviews are

interviews
Careful of over socialising; careful of advising;

\subsubsection{Phase 2: Mini-research project.}

Over the course of three weeks, I ran a compressed version of the entire research project with one single participant who closely (but not completely) fit the criteria of my upcoming extensive investigation. Unfortunately, I was not able to find a Spanish-speaker to help me with this phase of the pilot so the participant was a Taiwanese national. However, the participant for this phase of the pilot was a newly arrived NNES migrant who was not studying English formally in a class, so there were important overlapping features. This phase of the pilot included:

1. an initial interview

2. cursory analysis of the interview

3. completion of an Indirect Observation tool by the participant that I created to document the participant's language-related activity (a type of language-related activity self-report log/journal)

4. cursory analysis of the Indirect Observation tool

5. an interview discussing these recorded language-related activities

6. direct observation of the participant engaging in language-related activities

7. a final interview discussing these observed activities; discussion regarding the participants experience with the research 
I was interested in running a mini-version of my research project for various reasons: (a) to see logistically how the project might run, (b) to trial the indirect observation tool and explore what kind of data this tool could elicit and to get a better idea of what it felt like-from the participants' perspective- to record these language-related activities (see Data production III: Documentation section for more information; appendix D for a sample of the tool), (c) to further my development as a qualitative interviewer and see how varied the different interviews could be, (d) to get some hands on experience directly observing a participant in the field as she interacted in different languagerelated activities. When conducting ethnographic research over a prolonged period of time with participants that are hard to reach, it was important to take every available precaution to minimise the burden. There is a type of tension to be navigated, as I was concerned that the participants may drop out of the study if they lost interest or if the commitment proved too much. The tools used needed to be doing what they are supposed to be doing, as it was unlikely that I would get a second chance to re-administer. As a researcher I could read all about how to conduct this type of research in books and articles, but until I actually engaged in it, I had very little idea of how it would actually turn out. This phase of the pilot also allowed me to ask my participant how she felt about the different parts of the projects and to see what she thought of the observations (both indirect and direct). Her feedback and my reflection contributed significantly to my awareness and development as a qualitative researcher. It also allowed me to further reflect on my technique as an interviewer and as an observer.

Table 5: Insights gained (Phase 2)

CONSEQUENCES FOR DATA GENERATION \& ANALYSIS

Indirect observation tool

Comments section on indirect observation tool

Analysis of Indirect observation tool

Field notes

In-field rapport building

Best practice for observing
Participant explained that it was easy to use. Cursory analysis showed it produced insightful information

Participant admitted to 'writing a lot' to help me; Stress to participants that this section is optional; 'Only write ideas that you want to talk about'

Need to take quick notes about noticeable events or ideas as observed; use notes to structure the interview; Create notes after listening to recording of each interview for consequent interviews

Develop classification system for field work observations (e.g. representational observation-opinion/evaluative description; presentational description-description of event; thoughts; etc.)

Moving from site to site with participant divulged valuable information; illuminating interactions; remain open to interaction during observation; however, minimise interference; allow behaviour to be 'as natural' as possible.

Initial awkwardness of observing fades with time; participant forgets you are there

(2) 
A final noteworthy discovery, directly related to both phases of the pilot relates to the decision to adopt as the primary method for collecting data ethnographic rather than semistructured interviews. The semi-structured interviews were proving far less effective in consistently eliciting participant narratives about their language-related behaviour. This may have been because the topics we discussed were based on ideas I had pre-selected and deemed significant. In other words, these semi-structured interviews carried more of a top-down structure, where the interviewer was controlling more of the interview than I desired. It may also have had something to do with the inherent rigidity of this type of interview. Even though, I tried to keep them open and organic, there was still a sense of an agenda, with prescribed topics to get through. During these meetings, participants (from both phase 1 and 2), were producing mostly short, descriptive responses to the topics I was introducing. As a consequence, these may or may not have been accurate representations of their cognition. As Freeman (1996) notes, simply because a person tells you something in response to a question, it does not necessarily mean that they believe or think that; there is an inherent danger in taking people 'at their word'. At the very least, I felt that these interviews were not sufficiently participant-centred and carried less investment on their part. To capture a more accurate and honest representation of the participants' discursively embedded cognition, and with the explicit aim of providing an arena for participants' voices to be heard, I felt it necessary to establish more flexible parameters, where the participants would be afforded the space to talk at length about the language-related experiences that were most relevant to them. I learned that through ethnographic interviews, which often look and sound like conversations, (O'Reilly, 2009) participants would naturally produce stories which provided a more refined shape and texture to the representations of their lived experiences. However, this transition was by no means easy, as I had to learn to trust my instincts and believe that in these lengthy ethnographic interviews, valuable data was being generated - the type of data I was seeking. There were times during the interviews (particularly in phase 2) when I felt I should have been more direct in the questioning and worried that the interviews were not producing enough relevant information; by letting the participant speak at length about her ideas, I was missing opportunities for more focused talk. However, after conducting some transcript analysis I saw how rich the data we were generating was. Through patient, lengthy, participant-led, conversation-like interviews, there was an abundance of significant insights into the participant's cognition being generated.

The next section discusses these interviews, along with the other data generation (collection) methods in more detail.

\subsection{Data gathering; or 'the production of evidence'}

Qualitative researchers, in their attempts to gain a full and detailed understanding of the characteristics of lived experience, rely on three primary sources of data: interviews, observations and documents. According to Polkinghorne (2005) interviews provide 'first-person accounts'; 
observations record the researcher's accounts; and documents offer 'written accounts' of the experience under study (p. 141). In addition, combining these three sources supports the triangulation of data, adding an important layer of legitimacy, or validity, to the claims put forth in a study. However, Polkinghorne (2005) also cautions against the longstanding notion that data (as evidence) in these three forms is 'simply lying about on the surface' waiting to be collected (p.141). Instead, it seems more appropriate to understand data in qualitative studies as being produced between researcher and participant, particularly when these primary methods are predicated on intensive interaction and interpretation.

\section{The interactive nature of interviews \& observations}

Commonly referred to as 'production sites of knowledge' (Holstein \& Gubrium, 2003; Kvale \& Brinkmann, 2009; Talmy, 2010), qualitative research interviews are a specific type of social practice, where meaning is co-created between the interviewer and interviewee. In fact, Kvale and Brinkmann (2009) argue that any insights into experience gained from interviews should be understood as: 'produced, relational, conversational, contextual, linguistic, narrative and pragmatic' (pg. 54). In Applied Linguistics, this means that the conventional conceptualisation of the interview, where knowledge is held and controlled by the participant or the researcher, is shifting toward a more socially oriented perspective which views interviews as collaborative endeavours, where beliefs, emotions, descriptions, and stories are co-produced. Mann's (2011) critical review of qualitative interviews in applied linguistics, outlining important issues common to interview practice within the field specifically and across social science research generally, argues for the need to centralise the 'interactional context' of this intensely social encounter; failing to do so, he maintains, 'limits any view of interactional development' (pg. 12). Furthermore, he qualifies the view of interviews as co-constructive acts by contending that research using qualitative interviews should carry a greater focus on the role of the interviewer (including elements of their identity and the language used), more explicit appreciation of how interviews enact their own generic expectations, and more robust researcher reflexivity. Too often he says, research fails to adequately account for the ways interviewer-interviewee roles and relationships affect the interview process. In addition, there is an obvious neglect (at least in the reporting) of the ways in which the interviewee's contributions are related to the interviewer's. There is a lack of transparency indicating for example, how 'turns' dynamically shape the talk and ideas generated, as well as other important matters such as the effects of audio/video recorders. In other words, there tends to be an overemphasis on the content of interviews and insufficient attention to the 'form' and 'contexts' of meaning construction within interviews (pg. 17). In sum, as a data generation method, interviewing is an inter-active, interpersonal process between two people (sometimes more) whose unique relations to each other, including the language used to communicate, gender, age, and ethnicity, directly (and indirectly) affect the data that is consequently generated. 
Similar to interviews, observation, including participant observation, as a tool for data generation, is also an intensely interactive process. In cases where researchers-as-observers attempt to remove themselves from the 'action' and limit their influence, the resulting 'observer's paradox' (Cowie, 2009; Labov, 1972) acts as a type of interaction, where the presence of an observer can affect the behaviour of the observed participant and the consequent data that is produced.

Observing is to a large extent a form of interacting (albeit, 'indirect' interaction) with the people and the surrounding context. In addition, participant observation, an essential data generation tool for ethnographers, representing a 'direct' form of interaction, hinges on active participation in the lives of a study's participants. As O'Reilly (2005) outlines, participant observation entails learning about peoples' lives from their own perspective: 'learning from them by observing them, participating in their lives, and asking questions that relate to the daily life experience as we have seen and experienced it' (pg. 84). Through this shared experience, participants and researchers ultimately coconstruct the social world around them. Consequently, this interactive-participation affects the behaviour of participants, and in turn the data produced. As Agar (2004) explains, researchers are never just watching a study run, they are in it as well, 'part of the machinery that makes it run' (pg. 20). Indeed, similar to qualitative interviews, the researcher's gender, age, ethnic background and other marked features of identity are in constant interaction with the participants' own cognition and behaviour. Participants' attitudes and perceptions, their values and impressions, will consciously or subconsciously (or both) affect their behaviour in action as well as their behaviour toward a researcher (and vice versa). As an example, regardless of how stringent my checks are and how systematic and meticulous I am in the process of observing, the cognition I carry as a researcher, as a language learner, as an immigrant and as an adult male language educator all impact on the ways participants and I interact. As integral aspects of who I am, they will inevitably impact the data that is generated. This is why it is essential that as a researcher conducting a qualitative survey of individuals' experiences, I remain reflexive about my role and influence on the processes of data generation and analysis.

\section{Interpretive nature of observation \& interviews}

Tied closely to the idea that interviews and observations are inherently interactive processes which influence the production of data is the understanding that, as data sources, they are underpinned by their powerful interpretive nature. As Blommaert and Jie (2010) maintain, data generated from interviews and observations is used by researchers to reflexively 'tell a story' about social roles, positions and events (pg. 85). Moreover, there are varying levels of this story-telling element running throughout the data generation processes which need to be accounted for. For example, researcher-subjectivity runs through: the ways I view the participants; the ways I perceive their behaviour and make sense of their accounts; the ways I code and analyse the generated discourse; and the ways I report my observations and analysis. Also, as I have mentioned earlier, the 
accounts produced by the participants during the interviews present a challenge as they are representations (i.e. interpretations) of their lived experiences, reflecting their cognition and rooted in their daily experiences and interactions. This multi-layered interpretive aspect of the production process, relates to what Connelly and Clandinin (1990) refer to as the 'multiple l's' of research. Outlining a major challenge for researchers in producing narrative accounts, they illustrate the need to convey a sense of the complexity of all the "I's" involved in reliving and reporting experience (pg. 10). Finally, there is also a significant subjective element throughout the data transcription and translation process (see section 3.7 for further discussion). Thus, aware of the significance of the challenge of managing the inherent intersubjective quality of this research, I aim to depict the participants' cognition in action, by presenting detailed and extensive excerpts of our interactions (albeit translated and transcribed excerpts) along with my own reflexive interjections. In other words, to ensure that interactive development is adequately captured and interpreted with appropriate rigour, I include as much as possible, the co-constructed language of the participants.

Moving on, below I outline how these tools are used in this study to produce data, as evidence of individuals' naturalistic language learning experiences.

\section{Data generation I: Interviews}

For the purpose of this study, I adopt in-depth (O'Reilly, 2009; Seidman, 2006), unstructured (Berg, 2001; Mishler, 1986) ethnographic (Heyl, 2001) interviews as the primary data generation tool. Heyl (2001) in distinguishing ethnographic interviews from other types explains that the former are based on an established relationship with a participant. Establishing a relationship, she argues, is dependent on both time and on a sensitive and respectful exchange of views between equals. Another important distinguishing feature of ethnographic interviews is that they are unstructured, allowing participants to guide the research in personally meaningful directions. This approach to interviewing offers a variety of benefits. Firstly, it is useful in eliciting participant narratives. As discussed earlier, narratives represent a 'natural' cognitive and linguistic way of organising and communicating meaning and knowledge (Kvale \& Brinkmann, 2009, pg. 53). Through rich and lengthy statements and responses, participants 'reconstruct' their experiences within the topic under study (Seidman, 2006, pg. 15). This 'reconstruction of experience' is essential for this study which seeks to learn about the 'inner worlds' of individuals from the perspectives of those who experience them (Barkhuizen, Benson, \& Chik, 2014, pg. 2). In addition, the experiences described and reflected on in these in-depth interviews are all self-selected, meaning the participants choose what they want to talk about and (as much as possible) for how long. This provides valuable relevance to the topics discussed as they are all, to a large extent, participant-led. Furthermore, there is a higher likelihood that by selecting their own experiences to describe and share, a fuller range of the participants' cognition can be explored. As O'Reilly (2005) argues, research interested in exploring the 'feelings and thoughts and opinions' of individuals and aiming to produce a rich and 
descriptive account 'that respects the irreducibility of human experience' will benefit most from an unstructured, informal approach to data gathering. (pg. 126).

Secondly, adopting these narrative-type interviews addresses a notable gap in beliefcognition research. As Borg (2006) states in his survey of the various data collection methods used in language teacher cognition research, there is almost no evidence of research in this area using unstructured interviews (pg. 190). In fact, the only studies which I found to adopt in-depth, unstructured interviews were Woods' (1996) study investigating the relationship between teacher cognition, decision-making, and classroom practice and Hayes' (2005) research on the development of non-native English speaking TESOL teachers. In language learner belief research, it appears that only Mercer's (2011a) extensive 3-year study into language learner self-concept adopts in-depth interviews. This presents a fundamental problem in research up to this point as studies aiming to 'uncover' cognition, rather than exploring these ideas and feelings organically and extensively, in a participant-generated manner, tend to be overly prescriptive in assuming what they are looking for. In other words, having researcher-generated lists of items or statements (questionnaires), questions (structured interviews), or even prepared topics (semi-structured interviews) based on particular presuppositions can all too often limit the potential for discovery and understanding. However, if participants are instead afforded the space to explore their thoughts and feelings through the telling of their own narratives over time, they can open up to new and more relevant ways of understanding themselves and their actions. As Kvale and Brinkmann (2009) propose, interviews can be as much a learning process for the interviewee as for the interviewer (pg. 31).

Thirdly, in-depth interviewing helps manage a common critique of cognition studies, which is that explicit elicitation of cognition (i.e. asking directly about cognition) is inherently limited. Often participants' responses to a direct line of questioning will either carry an element of 'conscious dishonesty' (Kagan, 1990, pg. 427) (e.g. reporting ideas they believe the researcher wants to hear; saying something they hope to be true) or will be vulnerable to the fact that much of cognition is held unconsciously and is therefore difficult to communicate accurately. Research acknowledging cognition's sub-conscious nature has argued that much of these tacit mental phenomena are in fact embedded in language. By using narrative-type accounts in relation to real-life events and experiences, several studies (Dufva, 2003; Navarro \& Thornton, 2011; Woods, 1996) have illustrated that it is possible to not only construct understandings of one's cognition and its construction (as a by product of the telling of the account) but also appreciate how this cognition is rooted in actual behaviour.

Finally, a primary objective of this study is to find a way to capture and convey, in a nuanced manner, the experiences of an often marginalised population in second language learning research. Using in-depth, unstructured interviews over a prolonged period of time can help create conditions of 'normal' communication between social beings. Thus, these interviews-as-conversations not only provide my adult participants the necessary spatial and temporal parameters to communicate and 
understand their own lived experiences, but equally important they help position them as active participants rather than 'objects of study' (Cameron, Frazer, Harvey, Rampton, \& Richardson, 1993, pg. 86) in the construction of knowledge. By conducting research 'with', rather than 'on' or 'for' participants (Cameron et al., 1993, pg. 87) I hope to centralise their individual voices and 'demarginalise' their experiences.

It is important to note however, that while there are numerous advantages to adopting unstructured interviews there are also inherent limitations that have to be considered. Ostrander (1993) argues that in any ethnographic interview (a type of in-depth interview), expectations have to be negotiated and restructured from typical social relationships, particularly between persons of higher and lower status (pg. 21). Although, the relationships between the participants and myself were not explicitly about 'higher and lower status', there are factors, such as language, gender, socio-economic background, including experience with formal education, which if not accounted for can affect in negative ways the interaction and consequently the data generated. Research interviews carry a fundamental power imbalance, perpetuated by their position within an academic context and their function as an 'instrumental dialogue' (Kvale \& Brinkmann, 2009, pg. 33). This essentially means that the goal of the 'conversation' taking place within the interview is primarily to provide the researcher with descriptions and narratives which will be interpreted and reported according to the researcher's own research interests. As a result, there can exist distrust for research as a practice which maintains these fundamental power structures by investigating less powerful, more vulnerable populations from a place of ascribed prestige and privilege (Barnard, 2006). Such issues related to the control participants or researchers have during the interviews impact the development of the participant-researcher relationship. My ability to 'get in' and 'stay in' for example, hinged on this power imbalance. I had to consider the fact that the participants, with their limited formal educational background might be suspicious of me as a researcher, at times potentially feeling self-conscious (even after discussion and explanation) about why I was interested in their stories. One example of this perceived suspicion was with Paco. Both, during an interview and during a lunch date, when talking about his aspirations and expectations in terms of employment while living in New Zealand, he mentioned that it was 'not the same thing' for me, as my goals are very 'different' and much 'bigger' than what he was talking about. From these exchanges I could sense that he perceived our backgrounds and current positions as not comparable, that there was distance between what he was saying and what I could understand or relate to. In order to combat these types of issues it became vital that I find ways of restructuring the social contact between myself and the participants. One such way was to make sure to use the participants' L1 when talking with them. By communicating with them in their own L1, a language I was fluent in but not equal to their level of proficiency, they were able to assume more control over the interviews, and to some extent, our relationship. Another way to balance the power dimension of these interactions was to create situations where they could lead, or dictate the flow of the 
conversations. As mentioned above, I established an interview context that allowed them to identify the language-related interactions they wanted to talk about and gave them the space they needed to elaborate and reflect. Using the indirect-observation tool, the participants were able to note salient exchanges that they felt important or interesting enough to discuss. I also used a very open introductory question at the beginning of each interview, essentially just asking them how their week was or how they have been. While conventional qualitative research interviews may be structured as one-way dialogues, where 'the role of the interviewer is to ask, and the role of the interviewee is to answer' (Kvale \& Brinkmann, 2009, pg. 33), I tried, as much as possible, to avoid this structure and rather aim for a conversation-like exchange. As a result, participants felt freer to sometimes ask me questions as well, and were open to listening to what I had to say. This function of our exchanges often prolonged the meetings and resulted in me talking more than would be expected in an interview, but I believe it also helped create a more equal, natural, and honest arena for communication of ideas. Obviously, these talks still carry inherent social imbalance in that they are always within the confines of a research situation, but the participants did have more control over the conversations, choosing what to talk about and for how long. Meeting in the participants' home also helped them feel at ease with the interviews, as they were in a familiar setting. It also was useful for me to observe them at home, and to see how they lived. After a few interviews with each participant, the interviews became more and more like conversations between two people, and felt much less like an investigation.

There is, however a fine line between finding balance in the participant-researcher relationship and being 'too deferential and overly concerned with establishing positive rapport' (Ostrander, 1993,pg. 19), as I later found out. With Pablo and Silvana I had tried too hard to have them see me as an equal or a friend so that I felt at times I was taken advantage of and the seriousness of my work was not adequately respected. On a few occasions when I went to their home for interviews, I was left waiting outside their home for close to an hour or more. Another time, when I arrived for the interview they were sitting in the living room with some other friends watching a movie. I had to wait for two hours before I could conduct the interview. In end, Paco and Silvana slowly removed themselves from the research. This was undoubtedly due to a variety of reasons, but one of them, I feel, was that I was too deferential and did not properly establish the necessary control in the relationship. I failed to find ways of actively challenging them from the outset of the research, and as a result we were not able to work together in constructing a useful research relationship. In the end, my attempts to turn the interviews into more 'socialising' interactions ended up compromising the legitimacy of my fieldwork, and cost me two participants. This was an important learning experience for me, and luckily I learned it in time to adjust my approach with my other participants. I had to make sure that we all still understood that this was research, and when I was interviewing them, I was working. I did this by showing up with the IC recorder in my hand, my notes, and papers ready to go. I was also better at keeping the 
conversations on track and making sure we were talking (primarily) about their language related activity. Moving on, the next section details the data gathering process, briefly outlining the logistics for the interviews, including specific information regarding the study's principal participants, the role of observations, and document collection.

\section{Interview logistics}

Data gathering lasted a total of 16 months. The first interviews were conducted on the $8^{\text {th }}$ of September, 2013; the final interviews took place on the $17^{\text {th }}$ of December, 2014. Appendix E provides a detailed description of the interview schedule with all the study's participants. Below, Table 6 outlines interview-specific information for the study's main participants, i.e. the learners who I worked with most closely (Samantha, Constanza, and Sandra Milena). Unfortunately, I was not able to work with Paco (four months), Silvana (four months), and Clara (two months) for as long as I would have liked. Nevertheless, data from all the participants was useful in informing the research questions. 
Table 6: Interview-specific information for 'principle' participants

\begin{tabular}{|c|c|c|c|c|c|}
\hline PARTICIPANT & $\begin{array}{l}\text { LENGTH OF } \\
\text { TIME IN } \\
\text { STUDY }\end{array}$ & $\begin{array}{c}\text { TOTAL } \\
\text { NUMBER OF } \\
\text { INTERVIEWS }\end{array}$ & $\begin{array}{c}\text { INTERVIEW } \\
\text { TYPE }\end{array}$ & $\begin{array}{l}\text { AVERAGE } \\
\text { LENGTH OF } \\
\text { INTERVIEW }\end{array}$ & $\begin{array}{c}\text { TOTAL } \\
\text { INTERVIEW } \\
\text { TIME }\end{array}$ \\
\hline Samantha & 15 months & 11 & $\begin{array}{c}\text { Semi- } \\
\text { structured } \\
1,7,11 \\
\\
\text { Unstructured } \\
2,3,4,5,6,8, \\
9,10\end{array}$ & 58 minutes & 635 minutes \\
\hline Constanza & 12 months & 11 & $\begin{array}{c}\text { Semi- } \\
\text { structured } \\
1,7,11 \\
\\
\text { Unstructured } \\
2,3,4,5,6,8 \\
9,10\end{array}$ & 81 minutes & 894 minutes \\
\hline Sandra Milena & 12 months & 9 & $\begin{array}{c}\text { Semi- } \\
\text { structured } \\
1,5,9 \\
\\
\text { Unstructured } \\
2,3,4,6,7,8\end{array}$ & 74 minutes & 669 minutes \\
\hline
\end{tabular}

As mentioned, Samantha and I worked together the longest, for a total of 15 months. During this period we met 11 times for interviews. Both Constanza and Sandra Milena worked with me for 12 months. I met Sandra Milena 9 times for interviews and Constanza 11 times. However, as the table 6 indicates, Constanza and I spent the most amount of time working together (close to 900 minutes of interview time). To a large extent, the total interview time spent with each participant reflects the type of relationship we developed. Constanza was by far the most verbose and dependent, of all the participants. Beyond my role as a researcher, she often saw me as a language resource (i.e. teacher; translator; interpreter) and used as interview meetings as opportunities to have me look over bills, language exercises that she had been working on and to ask explicit questions about English. She also contacted me at least once a month for English-related assistance. As a result of this more frequent and intensive contact, I grew to know her in a more varied capacity. In contrast, if we look at my contact with Samantha, we see that both average length of interview 
and total interview time is considerably lower (particularly when I worked with her for an additional three months). Meetings with Samantha were often 'straight to the point'. She was the participant who completed the indirect observation forms most frequently and consistently and used them to structure our talks. It should be noted that of the three participants, Samantha was by far the busiest, juggling various jobs in and out of home while making time to meet with me. This affected our meeting times as well, as she usually informed me beforehand exactly how long she could meet with me for.

All interviews were conducted in Spanish. This was done to ensure that participants could as clearly and easily as possible, communicate their thoughts and feelings. As Mann (2011) argues, the language used between the interviewer and interviewee is integrally connected to the coconstruction of meaning and experience (pg. 15). Therefore, asking the participants to use a language other than their L1 would have potentially distorted the clarity of their narratives.

All but three of the interviews were in-depth, unstructured interviews. The three semistructured interviews were: the initial interview; a mid-point interview; and the exit interview. For the initial interview I had prepared specific topics to discuss with the participants. In addition, as it was my first official interview with the participants, I wrote out some specific questions in Spanish to use during the meeting. This initial semi-structured interview was useful in developing a profile of the participants' cognition and gather general background information. Essentially, it was valuable in helping me establish an introductory understanding of the individuals I would be working with and gather pertinent information regarding their previous experiences, including information about past language learning activity. A complex systems approach to researching language learning development holds that gauging 'the initial conditions' of any system is integral to understanding development. As Larsen-Freeman and Cameron (2008a) argue, the ways in which the system is set up when it commences the activity under investigation will 'influence the trajectory of the system as it changes' (pg. 230).

The second semi-structured interview incorporated specific questions I had developed based partly on my on-going readings around my study and partly on the analysis of the transcripts I had completed up to this point. After transcribing each interview, I would jot down notes that I wished to explore further in an upcoming interview. This was also useful in checking how certain each participant was about some of their professed ideas. It was a way of confirming, checking, clarifying, through further elicitation. This was also a direct benefit of longitudinal study of this nature as I was able to follow up on particular themes as they arose over time. The longitudinal aspect resulted in a useful cyclical type of interview process. Echoing Barcelos' (2000) assertion that 'each interview with each participant provided questions for subsequent interviews in a cyclical process' (pg. 112). The benefit of a prolonged period of interviewing became obvious throughout this process of data collection and supports other scholars' claims that 'one shot' interviews are more often than not insufficient in contextualising an individual's' experiences (Polkinghorne, 2005; Seidman, 2006). 
Finally, the exit interview was also semi structured. Similar to the initial interview, I prepared a mix of topics and specific questions to discuss. This interview was an opportunity for the participants to reflect on their experience as research participants and to comment on any aspect of the process they deemed important.

Other than the three semi-structured interviews, all interviews were in-depth, unstructured discussions meant to help the participants form narratives of their naturalistic language-related behaviour. As previously mentioned, I avoided asking too many questions, unless they were followup queries or questions to push for more detail or reflection. Instead, as a way of 'privileging' the participants, I let them develop and communicate their own stories and anecdotes, as this would most likely reflect salient and significant experience. As Kramp (2004) explains, not only are narratives an effective tool in learning about 'life as experienced' from the point of view of the storyteller, but they also 'become the embodiment of an intimate relation between knower and the known, between storyteller and listener, between researcher and subject' (pg. 111). There were numerous occasions throughout the data gathering process where simply talking about some seemingly trivial or random topic would stimulate an insightful story about a language-related interaction.

\section{Data generation II: Observing and participating}

I employ observations as an additional tool to generate data. They provide an alternative perspective into the lives of the participants, allowing me to construct a more complete understanding of their behaviour in context. Whereas in-depth interviews offer interpretations (i.e. accounts) from the participants' perspective (key for this type of participant-centred exploration), observations are valuable in constructing researcher accounts of what is happening, consequently functioning as a layer of verification and credibility. As Patton (2002) points out, there are limits to how much can be learned from what people say (pg. 21). Observations can help mitigate these limits by providing a more fine-grained focus to the emerging picture of participants' cognition in action. Through observations, I can better understand how particular meanings are ascribed to particular actions, and learn about the interplay between participants' intentions and behaviour. According to O'Reilly (2005), social scientists should be primarily concerned with understanding 'meaningful' action, or 'the action we take to achieve an end... which has meaning for the actor, and which is directed towards, or involves, other people' (pg. 50). Additionally, spending time observing participants can help me to better appreciate the lives of these individuals in a more intimate and nuanced manner, as often through this observatory process I am in fact participating in their lives. During the year or more I spent with each participant, I had numerous occasions to both observe them interacting in English and also participate in many significant events. There were also occasions where they participated in my family life. As a result we were able to learn more about each other's lives. 
Interviews were the primary source of observation, allowing me to spend hours with each participant in their homes - in their dining rooms; in their yards; in their kitchens and living rooms observing them with their neighbours, friends, visiting doctors, delivery service workers, and of course family members. In addition to this form of observation, there were numerous other occasions where I observed and participated in their daily lives: I watched movies with them and their friends; I attended a First Communion celebration along with other Colombians and New Zealanders; we shared lunches and picnics with other refugee families; we had barbeques and attended local city festivals together; we cooked and baked together; I visited them at work; I heard them deal with door-to-door salespeople and make phone calls to various agencies and institutes; and we spent time in their neighbourhoods, walking and talking and interacting with the community. Furthermore, all of my participants visited my home for meals and got to know my family. In sum, beyond the intensive interview schedule, observing my participants in a variety of different situations, allowed me to immerse myself in their lives and ultimately become a part of their language-related experiences.

\section{Data generation III: Documentation}

I also collected (and constructed) written documents throughout the study which contributed to the overall understanding of the experiences of my participants. Below I describe these documents and their relevance as data sources.

First, the indirect observation tool is a self-report tool where participants can record what they consider significant or insightful language-related episodes (see appendix D). During the interview meetings we then talk about these episodes. These reports are meant mostly to describe the logistics of a particular noted interaction. However there is space to comment as well. While these documents were not always completed, with some participants completing them more frequently than others, they nevertheless were able to provide some interesting insights into participants' interpretations of their language-related behaviour. If nothing more, the fact that they noted a particular incident, marks it as significant. The indirect observation tool therefore is also a type of 'reflection stimulator', useful in organising the interview discussion.

Second, I collect samples of the participants' English related activities and exercises. These documents are in the form of journals and diaries, worksheets, and reading logs, and emails. Through these documents, I can see what kind of English related work the participants are doing on a weekly or daily basis, and am also able to notice development (although at a very superficial level) in their language-development. I can see if and when their English work over time is getting more complex for example. In addition, showing me these exercises and worksheets and talking about what they are doing throughout the week to learn English, produces valuable anecdotes and statements, which can express underlying cognition about English-related issues. 
Finally, extensive field notes (over 22,000 words of total text) compiled both during- and post-observation (the majority of these were written on trains travelling to and from participant meetings) were extremely valuable as a data source. They represent personal (i.e. subjective) records of my interactions with the participants, offering rich and detailed descriptions of our meetings. As documents, they help to preserve important contextual details such as: descriptions of participants' homes and how they live; features of the participants' personal characteristics; my own feelings and ideas regarding our interactions; descriptions of behaviour and mood; register of new or recurring theme; and various other impressions relevant to my work in the field. While selective and inherently biased as a data source, field notes, according to O'Reilly (2009) can 'illuminate the interconnected process of observation, data collection, theorising and analysis' (pg. 76). In other words, they help add an extra layer of analytical triangulation between data sources. As Blommaert and Jie (2010) explain, the line between during and after fieldwork often becomes blurred 'as much interpretation (read: analysis) has already been done in the field' (pg. 63-64). It is in field notes as records, where much of this analysis is documented. Thus, it is important to recognise these data gathering (and production) methods and instruments as integral components of the sustained and intensive experience with participants, which inevitably help me make sense of the data. As Patton (2002) argues, the 'analytic insights and interpretations' emerging during data gathering are key sources in organising the analysis (pg. 437). In other words, the experience of data gathering is in constant interplay with the process and product of data analysis. The section below outlines this analysis process.

\subsection{Data analysis}

This section provides information on the methods for data analysis, including: the approach to analysis; transcription and translation of interviews; and coding procedure.

\section{Approach to analysis}

Data analysis for this research follows an iterative-inductive approach. Iterative, according to O'Reilly (2005) 'implies both a spiral and a straight line, a loop and a tail' and inductive 'implies open a mind as possible, while allowing the data to speak for themselves as far as possible' (pg. 27). To clarify, the iterative nature of the analysis process reflects a cyclical pattern, with an almost constant movement between theory, gathering, analysis, and reporting (i.e. writing up). Also, within the language data itself, during the coding process, I move back and forth between field notes, transcripts and audio files and identified themes and categories, as I work to develop and refine the picture of my participants' cognition in action. However, as O'Reilly (2005) argues, it is also necessary to sometimes divide your time 'in a linear way' (pg. 177) since analysis cannot begin until gathering does and gathering will need to stop at some point to give way to formal extensive analysis. By 
inductive, the approach accepts that the majority of the insights gained, i.e. the evolving theory, will emerge from the data. However, the approach also accepts that it is nearly impossible (not to mention, impracticable) to approach data without some supporting theory. As a researcher I had specific questions in mind, which I read extensively on in preparation for the field work. These questions guided my actions throughout the research process, before I set out to gather data, while I was gathering data, and after gathering, throughout the analysis and reporting. As Ezzy (2002) proposes 'all data are theory driven' and researchers need to engage in a dynamic process of 'deduction and induction, of theory building, testing and rebuilding' (pg. 10). Therefore, an iterativeinductive approach is predicated on an ongoing movement between the various interconnected factors of data construction. It appreciates the influence of theory and researcher preconceptions while at the same time allowing for new knowledge to emerge from the data. It is an informed but fluid and flexible approach to analysis.

\section{Transcription, translation \& description}

The process of translating and transcribing functions as an additional link, or 'point of transition' (Patton, 2002, pg. 441) between data gathering and analysis. In fact, it is an integral level of analysis, as it is a highly interpretive procedure potentially reflecting an inherent research bias. Through this intensive and laborious process, researchers begin to more formally understand patterns in the data, as well as recognising their own influence as interviewers, or co-constructors of meaning. As Podesva and Sharma (2014) state, 'linguists are never as close to their object of study as when they are transcribing' (pg. 237). With that said, a researcher's approach to transcription and translation should reflect their study's objectives.

For this research, I transcribed the first set of interviews in Spanish. Next, I listened to the interviews again and translated them directly into English, while constructing more refined descriptions. However, over time this transcription-translation process shifted. I began to use large chunks of thick description in English supplemented by verbatim Spanish transcription. The English descriptions provided context and the Spanish text represented the actual language used within this discursive context, i.e. the interview. This ensured that I was staying as true, or as close, as possible to the transcribed data. Later, I found the most efficient and effective method for dealing with my translation-transcription challenge was to transcribe directly into English, essentially creating English transcriptions with large chunks of Spanish in areas where the talk was particularly thick with content relevant to either the research questions, participant relevant themes (which I came to know over time working them), and other emerging concepts. The large chunks of Spanish were included when something was particularly relevant or significant (e.g. talk related directly to elements of their cognition; linked directly to their described language-related interaction; related directly to a common discussed theme; representative of a key event). Translating from Spanish to English was not a problem in terms of meaning or nuance. If there were individual terms I was not 
familiar with - for example some Colombian slang - I asked for clarification and was always given a clear explanation. Therefore all the transcripts I worked with contained a mix of English and Spanish (see appendix $\mathrm{G}$ and $\mathrm{H}$ for examples of the transcription/translation process).

As mentioned above, along with transcriptions, I also created detailed descriptions of all the interviews. These descriptions coincide with the initial stages of formal thematic/content analysis (Barkhuizen et al., 2014; Dörnyei, 2007). Through repeated listening and reading of the transcripts, I compiled extensive notes, or memos, on topics as they emerged from each discussion in an effort to further develop ideas. Dörnyei (2007) proposes that these 'analytic memos' are essential in facilitating second-level coding and can contain 'the embryos of some of the main conclusions to be drawn from the study' (pg. 254). Since the focus of my study is the development of language learner cognition, the majority of the descriptions are in direct reference to this phenomenon.

\section{Codification}

As mentioned above, the data analysis procedure had to remain flexible in order to account for complexity of the phenomena under investigation. This includes being open to and aware of the multiplicity of themes which might emerge from the coding of data. As Duff (2012) maintains, any thematic analysis might reveal insights on a range of 'issues or expressions including identity, agency, motivation, community membership, frustration, or (other) affective stances toward the learning or use of the L2' (pg. 108). Furthermore, beyond looking at how themes are expressed over time, I also look at how they relate directly (or indirectly) to specific language-related behaviour. This adds an additional layer of complexity, as the intention is to move beyond analysis of participant statements and incorporate information as it connects with everyday activity. This reflects Woods' (1996) position in his study on language teacher cognition which supports the need to move away from conventional categorisation of cognition into the exploration of the relationships between different mental constructs themselves, and how they interplay with individual behaviour. This added layer of analysis further stresses the need to rigorously account for the identification of particular themes and the selection of examples and excerpts. Below is a detailed description of and commentary on the systematic coding procedures I followed throughout for this study.

After all the interviews were translated, transcribed and described I embarked on a more formal codification process. I adapted Burnard's (1991) framework, grounded in content analysis, to analyse the interview data. Burnard's original method, assuming the interviews have been transcribed, consists of 14 stages. I adopted the relevant stages, reducing the process to nine stages. These include: 
1. Making notes after each interview regarding topics discussed in the interview

2. Reading transcripts and making further notes on general themes within the transcripts

3. Open-coding (Berg, 2001; Strauss \& Corbin, 1990) re-reading the transcripts creating categories to describe aspects of 'content'

4. Surveying the list of categories and creating 'higher-order' categories; reducing the number of categories by 'collapsing' similar categories into broader ones

5. Eliminating similar or repetitious higher-order categories to produce a final list

6. Re-reading transcripts alongside the final list of categories to evaluate the degree to which categories cover relevant aspects of the interviews

7. Transcripts are coded according to the final list of categories

8. Themes will be created based on the coded transcripts

9. Coded transcripts are discussed in light of research questions

Next, I present a few important comments in reference to the coding process described above. First, during step two, the creation of general codes, I began by looking for the themes which appear as 'issues' in the conversations between the participants and myself. 'Issues', Woods (1996), elaborates, 'are signalled by recurring use of certain terms to express concepts important to the participant, by explication and elaboration of those terms, by opposition to other terms and especially by evaluative comments about the concepts the terms refer to and the relationships among them' (p. 32). To put it another way, the issues emerging throughout the interviews (verbalisations) are coded into categories; from these categories themes, based on learners' embedded cognitions, are created. Also, I explored all explicit mention of cognition-related language. For example, I noted instances where phrases such as 'I think'; 'I believe'; "I know'; 'I feel' were used. However, this was meant only to identify explicit mention of statements which may relate to the participants' cognition. I was following Woods' (1996) idea that an initial mention of a BAK or Affect-related idea should be understood as a hypothesis (even when overtly stated) and was cautious against immediately accepting these statements as real evidence of anything (pg. 72). For instance, it might simply be a statement more representative of an ideal than a reality, or a statement intended to please the interviewer. To argue for a significant relationship between a statement of thought or feeling and a participant's larger, working cognition, it must first be confirmed by such means as further/frequent communication of the same idea, or observed behaviour of this idea in action. Finally, it is important to reiterate that coding was not focused on creating categories of cognition. Rather, I was looking at the interplay between descriptions of prior experience, language-related interactions, and expressed cognition. In fact, I posit that to a large degree, it is within these very descriptions that evidence of cognition is most evident. During the second-level coding and beyond, I was trying to identify the more latent inter-relationships between what participants thought or felt and what they did or said they did in relation to language learning activity and use. This analysis process connects with the theory of complexity which Larsen-Freeman and Cameron (2008b) advance within an applied linguistic context. It is rooted in the idea that to capture a complex system in action (e.g. an adult's learning development), studies need to first recognise that these systems are made up of numerous subsystems, nested one within another 
across time scales and next explore the ways in which these nested levels and scales operate in relation to each other and other sub-systems (pg. 205). To appreciate how systems operating at different levels affect and are affected (i.e. change) by what happens on other levels and scales, the analysis of data must therefore be focused on relational, or process, patterns; in terms of this study this means the dynamic interaction between cognition and behaviour. Coding of participants accounts over time therefore becomes a powerful and practical tool in exploring these interconnections; it helps cultivate what Larsen-Freeman (2007) calls the 'dialectical relation between parts and wholes in order to identify the appropriate functional units of analysis', which is of course something that is likely to require ongoing redefinition, depending on the inquiry' (pg. 37). Before moving on to the findings and discussion, I comment on the generalisability and validity of this research.

\subsection{Generalisability \& Validity}

\section{Generalisability}

This study, foregrounding the languaged experiences of Colombian adult English learners living in New Zealand is in many ways an exploration into particularity. Rather than looking to uncover universal categories or predictors of behaviour within and across populations, the aim is to understand and represent the unique features of an individual's language-learning experience and the meanings ascribed to this experience. I believe that this type of fine-grained examination can lead to valuable insights into second language learning and use. Particularly, in regards to the adult learner, whose experiences are oft marginalized and under theorized in second language learning. In other words, while this study's sampling procedure (purposeful) and participant population make it difficult to generalize or predict (at least not in the traditional sense) beyond the scope of the current context, it nevertheless can contribute to our understanding of an issue in SLA.

That said, while this research does not set out to make any large-scale generalisations about groups of people (adult language learners) or cultures in a particular place and time (Colombians living in New Zealand), it does overtly seek to advance 'analytic generalisation'. Analytic generalisation, according to Duff (2008) is made 'not to populations but to theoretical models... which take into account the complexity of $\mathrm{L} 2$ learning or other phenomena and the multiple possible outcomes or relationships that exist among factors' (pg. 50). It is essentially a way of advancing scholarly theory and everyday expectation of experience. As Yin (2003) claims, theory generated through case studies can be useful in 'generalising results to other cases' (pg. 5). This advancement of theory is a common attribute of qualitative research. However, O'Reilly (2005) contests this idea, arguing that while informing theory is an admirable endeavour 'it is not sufficient reason to entirely dismiss any attempt to make broader inferences, draw comparisons, or make generalisations' (pg. 82). With this in mind, I have chosen to explore a case study because I believe 
that in depth exploration of a single case can lead not only to more intricate theorizing and more robust understanding, but also to a type of 'naturalistic generalization', which is potentially more useful for guiding real world actions than 'abstract statements of law' (O'Reilly, 2005, pg. 84). By looking not only at commonalities, but also at the differences and uniqueness between and across an individual's experience, this process can, as Duff (2008) asserts, advance our knowledge of the ways in which certain principles operate within and beyond a current context, as well as expanding 'the repertoire of possible interpretations and narratives of human experience' (pg. 52). This shift, essentially from prescription to understanding, mirrors the move from a simplified, reducible view of social reality toward a more complex and intricate appreciation of lived experience and its relation to everyday behaviour.

\section{Validity}

Research validity, or credibility, is a crucial consideration in conducting a qualitative study. It is to a large extent what gives a study its meaningfulness and usefulness. According to Davis (1995), researchers interested in advancing knowledge in their field must, through their adopted methods and in their interpretations and findings, look for ways of illustrating the credibility of their 'reconstructions' (pg. 445). However, the process of selecting validity procedures is rarely clearly defined and can be a perplexing endeavour. In a paper describing this often confusing, but integral component of research, Creswell and Miller (2000), outline the nine most commonly used and cited validity procedures in qualitative investigations:
1. Triangulation
2. Disconfirming evidence
3. Researcher reflexivity
4. Member checking
5. Prolonged engagement in the field
6. Collaboration
7. The audit trail
8. Thick, rich description
9. Peer debriefing

The description of these procedures reflect other researchers' discussions regarding qualitative research validity procedures (Davis, 1995; Duff, 2006; O'Reilly, 2009). Of these nine validity-promoting procedures, five can be found throughout this study. They are:

- Triangulation of data methods Combining interviews, observations, and documents helps ensure that the reconstructions I advance are in a sense, cross-referenced. Furthermore, adopting an ongoing (i.e. iterative-deductive) analysis procedure is an effective way of checking, confirming and refining my understanding of the data. This type of 'methods triangulation' offers different angles with which to view the participants, the context, the language-related behaviour, and their storied experiences. Extensive field notes also add to the triangulation, as these were constructed not only in relation to observed behaviour and 
pre-post interview discussion, but also to the broader socio-cultural context of the participants' lives in and around Wellington. In the end, the triangulation of data helped me construct a more robust picture of the individuals in different language learning contexts by helping see a spectrum of data and also allowing me to engage with this data in a variety of ways.

- Prolonged engagement in the field Spending over a year with the case-study participants carried numerous benefits in relation to credibility. I was able to develop a strong rapport and familiarity with them, which was useful in removing some of the associated stigma of research; consequently, this helped produce more naturally occurring data. The participants grew comfortable with me and as time passed, were more and more willing to open up about their daily experiences. In addition, this extended time with these individuals helped establish an insider's view into their daily lives. Also, in terms of analysis, the prolonged time helps me move back and forth between data and data sources. I can observe and interview, analyse, examine what I have, conduct additional interviews and observations, and continue with the analysis, all the while developing my understanding of the participants' varied perspectives. Moreover, a prolonged engagement is instrumental in studies making claims about development in behaviour and thinking (as this study does).

- Thick, rich description Composing deep, detailed and coherent descriptions of interviews, observations, documents and field notes provides a way for readers to step into the experiences of the participants and draw their own conclusions about what is being examined (Duff, 2008, pg. 44). It is a way of putting the readers into the story. In a sense, thick description contextualises the situation in order to facilitate understanding of the narrative being told. A positive consequence of this is that it also offers a way of evoking interest in a story. In other words, it can balance a study's social or disciplinary relevance with personal relevance. Readers want to know that in reading the account, they can learn something about the participants in question but also about broader SLA issues being addressed. Essentially, through thick description, readers can determine to what extent certain claims can be made to their particular situation or situations allowing for a personal contextual generalisation. As Gall, Gall, and Borg (2003) detail, a well-assembled thick description of participants and sites 'allows readers of a case study report [to] determine the generalizability of findings to their particular situation or to other situations'. (pg. 466).

- Researcher reflexivity Disclosing my own beliefs and biases, and positioning myself within the study as a key contributor adds an important element of transparency, integral in the promotion of research credibility. Throughout the study, I try to state and make clear, not only the assumptions I carry and construct, but also the instances where these might influence the collected and analysed data. I make a concerted effort to avoid completely removing myself from the process of conducting research and instead highlight my role in the co-construction of information and knowledge. I provide interpretive commentary regarding my role on the process of both data collecting and analysis, in an effort to keep as much as possible out in the open.

- Peer debriefing Asking colleagues and supervisors to look at my data and to offer their own interpretations of sections helps cast alternative critical lenses over the recorded experiences. It is a useful way of helping me see what I might not be able to see as a result of being too deep into the data.

The selection of validity measures is not a simple or well-defined affair. It carries no set rules to follow. For each study, this process must carry its own unique characteristics. The fascinating thing about choosing validity procedures in qualitative research is that they are often built in to the 
data gathering and analysis methods. In other words, for this project, the validity measures used are both a natural consequence of the research design and the result of conscious decision-making.

\subsection{Summary}

This chapter has provided a rationale for my research design and outlined the main data generation methods (participant observation; ethnographic interviews; document analysis) and analysis methods (content analysis) used to explore the research questions. I have discussed the process of gaining access to and maintaining access with the participants, as well as describing the value of using narrative accounts to better understand language-related experiences in naturalistic settings. Ethical considerations have also been described to help ensure that the methodology is not only appropriate to answer the research questions, but is also ethically responsible to and beneficial for the participants. Next, Chapters 4 and 5 present the findings for this study in light of these methodological considerations. It is divided into two chapters, each specifically addressing a relatedresearch question (i.e. Chapter 4 explores RQs 1 and 2; Chapter 5 explores RQs 3 and 4). Chapter 6 , dealing exclusively with the fifth and final research question, is a detailed discussion of the findings. 


\section{Chapter 4 Findings (I)}

\subsection{Introduction}

Chapters 4 and 5 present the study's findings. They are divided according to research questions (RQ). In Chapter 4, RQs 1-2 interweave to frame a picture of the participants as language learners before New Zealand. The chapter examines the participants' educational backgrounds, with a focus on prior language learning experiences and the ways in which these experiences have influenced the construction of their L2-related BAK.

\subsection{The impact of prior language learning experiences on the construction of L2 BAK: A portrait of participants' pre-New Zealand language education}

As mentioned, RQs 1-2 function as interrelated parts to examine the different ways in which participants' previous language learning experiences have contributed to their thinking about language learning, including perceptions of themselves as language learners and beliefs about foreign language education. RQs 1-2, as tandem questions, help to construct a profile of the participants' language learning experiences, as well as providing insight into some of the experiential processes involved in developing language-related cognition. Because of the inherently interconnected nature of the respective queries, they will be discussed in relation to each other.

RQ 1. What are the prior language learning experiences of a group of adult migrant learners living in New Zealand?

RQ 2. How have these prior language learning experiences influenced the construction and development of their beliefs, assumptions, knowledge (BAK) about language learning?

\subsubsection{Samantha}

Samantha mentions no prior language learning experiences while growing up in Colombia from the ages of 0-13. When asked explicitly about any language learning experiences during this time she says that in those days English was not taught in schools ${ }^{1}$. She does however talk about her experiences with formal education and explains how her parents encouraged all eight of their children to attend at least primary school. Growing up, her family's economic situation was difficult. They worked on farms and struggled to provide beyond basic necessities. However, despite these socio-economic challenges and the lack of opportunity for improved living conditions, the value of basic education was recognised. As a result she, along with three of her siblings, did attend primary school. The picture Samantha paints of her school experience in Colombia, though, is quite negative. 
She mentions abusive and strict teachers, as well as uninteresting classes, and describes a situation where she and her friends saw little value in this formal education:

...back in our time we studied so as not to stay at home my mother would say that we had to at least study primary but we didn't see I mean at least I thought and why am I going to study? to wash dishes? to work on a coca farm? others would say you don't need to study to work on a farm why waste that time?

$$
\text { (initial interview) }
$$

The lack of exposure to any meaningful or quality language learning experiences in Colombia suggests that up until this stage of her life, Samantha did not have the opportunity to form BAK in relation to foreign language education, generally, and learning English specifically. While there are examples of BAK regarding general education (e.g. waste of time; lacking value) rooted in her descriptions of her childhood (e.g. poverty; majority of acquaintances coca leaf farmers; unskilled workers; unpleasant school life), language learning BAK lacks the experience and exposure to a foreign/second language required for adequate construction.

Around the age of 14 or 15, Samantha moved from Colombia to Ecuador. She was having difficulty at home and her parents suggested she go somewhere safer and with less distraction. It was during this time that she was first exposed to both informal and formal language learning. Firstly, when talking about the difficult move from Colombia to Ecuador, she describes the challenge of having to learn a lot of new words because the Ecuadorian variety of Spanish is different from the Colombian variety she had used all her life. She says that while working in a restaurant (a job she held for the first seven years of her life in Ecuador) she struggled initially to understand many of the words her customers used:

D: ... when you moved from Colombia to Ecuador how did you feel? can you remember? S: eh at first it was difficult it was difficult because... I didn't understand many words because they aren't the same

D: ahh it's a different language

$S:$ the language is the same but they use different words for things

(initial interview)

In addition, I mention that the pronunciation must have been challenging and she agrees, saying it was very different. This experience with an unfamiliar type of Spanish serves as one of her first instances of direct exposure to a different language for communicating. From it, we can assume that she became aware of intra-language variety, recognising from personal experience how the same language can be spoken in different ways, and how this variation can sometimes lead to confusion and other interactional challenges. It is also likely that through this experience she developed a preference (as a type of evaluation) for one variety of Spanish over another. Because Paco, Silvana, and Constanza all also lived in Ecuador for numerous years, they would have had a similar experiences with the varity of Spanish. Some studies (Alford \& Strother, 1990; Yager, 1998) 
that have looked at language varieties and dialects have found that both indirect and indirect interaction with a particular variety of the language will affect the construction of certain attitudes toward the variety.

Secondly, when I ask Samantha to recall what she remembers about English or learning English she says that it was in Ecuador, as an adult woman, while attending secondary school, where English classes were compulsory, that she first experienced formal language education. The quality of the classes however was poor and she did not feel she learnt anything of use (a view of English classes echoed by almost all of the participants). The focus of the lessons, typical of a lot of foreign language education in primary and secondary schools, was not, as described later in Paco's narrative, on learning to use the language but more on completing translation activities, conjugation work, and passing written exams. In fact, these English classes were all carried out in Spanish, with minimal (if any) opportunity to speak or listen to English. Having spent a significant amount of time 'learning' English but not being able to use the language seems to have resulted in a negative evaluation of formal foreign language learning. However, even though she critiqued the quality of her English education, she admits to having developed an interest in English from this exposure - an interest which says ignited her dream to one day live in the United States. Samantha constructed an idea in her head that she wanted to leave Ecuador and look for a future and regarded life in an English speaking country as a kind of ideal. In the U.S., she heard from friends and people around her (i.e. word of mouth), that life was good - that there was work and the possibility of earning good money - and so she constructed an image of herself living a better life in the United States. In this sense she has developed a positive view of English and what it could offer her as a socio-economic resource. It should be noted however that this view of English presents an abstract or idealised view of its value. The BAK she formed is rooted more in the concept of English as means of attaining $a$ better life in the United States then in personal experience using or learning English.

Finally, as a mother of three, Samantha was exposed again to formal language learning in Ecuador through her children's education. She makes explicit reference to both Sebastian and Jimena's English learning in Ecuador. She suggests that the formal language learning her children experienced was more useful (i.e. better) than the learning she was exposed to as a young woman. This may be due to possible changes in approaches to foreign language education, where communicative language teaching has become increasingly popular throughout the world. Obviously, the English teaching methods used in classes would still carry certain limitations, particularly the lack of focus on authentic language use or communication. However, it can be assumed that more recent approaches to teaching-learning English would focus more on speaking and listening to English. In fact, Samantha comments with obvious pride on how Sebastian always spoke English very clearly and how in school he was the best at speaking English. She also explains how Jimena's rapid English development (in New Zealand) is likely related to her English classes in Ecuador. According to Samantha, Jimena always really liked English and received the highest grades 
in English class. These comments, highlighting a different type of exposure to English education in Samantha's pre-New Zealand life, suggest a shift to a more positive view of current approaches to formal English instruction.

The table below summarises Samantha's prior language learning experiences and their influence on her BAK:

Table 7: Samantha's prior language learning experiences \& BAK

\begin{tabular}{|c|c|c|c|}
\hline $\begin{array}{c}\text { COLOMBIA } \\
0-13 \text { (years of age) }\end{array}$ & BAK & $\begin{array}{c}\text { ECUADOR } \\
14-30 \text { (years of age) }\end{array}$ & BAK \\
\hline \multirow[t]{3}{*}{$\begin{array}{l}\text { No evidence of } \\
\text { prior language } \\
\text { learning experience }\end{array}$} & $\begin{array}{l}\text { No evidence of } \\
\text { foreign } \\
\text { language/language } \\
\text { learning BAK }\end{array}$ & $\begin{array}{l}\text { Exposure to } \\
\text { different variety of } \\
\text { Spanish; (Colombian } \\
\text { vs. Ecuadorian } \\
\text { Spanish) }\end{array}$ & $\begin{array}{l}\text { Recognition of intra-language } \\
\text { variety; awareness of the } \\
\text { difficulty in navigating this } \\
\text { difference }\end{array}$ \\
\hline & & $\begin{array}{l}\text { Exposure to } \\
\text { language learning } \\
\text { through secondary } \\
\text { school English } \\
\text { classes }\end{array}$ & $\begin{array}{l}\text { Perception of foreign language } \\
\text { learning classes as inadequate } \\
\text { in preparing one to use } \\
\text { English; Perception of English } \\
\text { as a means to a better life }\end{array}$ \\
\hline & & $\begin{array}{l}\text { Exposure to } \\
\text { language education } \\
\text { through children's } \\
\text { English classes }\end{array}$ & $\begin{array}{l}\text { Shift in perception of foreign } \\
\text { language education (current } \\
\text { methods viewed as 'better' } \\
\text { than before) }\end{array}$ \\
\hline
\end{tabular}

\subsubsection{Constanza}

Throughout Constanza's narrative of her time in Colombia, she presents what she refers to as an unstable upbringing. She describes a nomadic life from the age of $0-15$, moving often to new locations with her mother. At the age of 15 , Constanza separates from her mother and begins to live independently. As a result of this constant moving, her formal education was quite sporadic. She explains that she stopped going to school completely from around the age of 14 . But even before, she did not attend school on a consistent basis and was rarely at one place for a prolonged period of time. She laments her past for lacking opportunity and explains how if she had been born in a different situation, she would have enjoyed studying. However, she was able to acquire a basic education, including literacy skills. In terms of language education, Constanza mentions no prior formal language learning experiences while growing up in Colombia from the ages of 0-30. In fact, like Samantha, she remarks that in those days English was not taught in schools: 
D: ...in Ecuador or in Colombia ahh did you study English or nothing?

C: no not me no because there at that time almost they didn't teach English no now these days it's when they are teaching English in the schools also since I was in school for only a short time

(initial interview)

As a consequence of her lack of exposure or experience to language learning, she does not carry well-formed BAK in regards to learning or studying English.

However, despite this lack of opportunity to experience formal foreign language learning, Constanza developed an affinity for foreign languages. She describes her childhood dream of attending a foreign language university and finding a career related to languages. She explains that while other children may dream of becoming doctors or pilots, she was always interested in working in some capacity with languages. Of all the participants, Constanza was the most excited about the opportunity to learn English, referring to it as a dream come true. When I asked how her interest in foreign languages, which she explains has never wavered, developed, given that she had such limited contact with language learning, she attributes it to various little experiences throughout her life. For example, she recalls observing tourists visiting Colombia talking in their foreign language and was curious about what they were saying. She remembers thinking how she would have loved to understand them:

\section{I didn't understand but I WANTED ${ }^{2}$ to understand}

$$
\text { (initial interview) }
$$

Another example of the kind of experience which stimulated her interest in foreign languages was her work in various chifas (Chinese restaurants). She recalls a certain fascination when listening to her Chinese colleagues speaking their language. Finally, her position as a nanny for a Dutch family, taking care of two children, represents a significant experience with a foreign language which influenced her idealisation of becoming a competent L2 user. She explains how the family, who spoke Dutch with each other but Spanish with her, wanted to take her to Holland but because she was underage (17) she needed parental consent, which her mother refused. These stories serve to describe Constanza's initial interest in languages, but also clarify that she did not study a foreign language because of a lack of opportunity, not because of a lack of interest. They are also noteworthy in that they illustrate the development of L2-related BAK from informal exposure to foreign languages. Constanza's BAK about foreign language use, as a type of ideal skill, rather than rooted in personal learning experiences, developed from her observations of others using different languages. In a different world, she says, where she had different parents and more money, languages would have played a larger role in her life. Unfortunately, the opportunity to formally learn an additional language never arose:

\footnotetext{
${ }^{2}$ CAPITALISATION represents an emphatic or emotional utterance
} 
D: Were there people around you who spoke English? or almost no one everyone

C: oooh no one no one no one just my dreams were like one day I'll study when I was a little girl my childhood dreams were that when I get older I'll study languages at university

(initial interview)

At around the age of 30, Constanza escaped to Ecuador after receiving threats on her life. She lived there illegally for over a decade, before obtaining refugee status. When I asked about her language learning experiences in Ecuador, she explains that life was even harder than in Colombia. Unlike Samantha, whose language learning experiences increased in Ecuador, Constanza's accounts of life in Ecuador offer no evidence of L2-related experience. Instead, what she portrays of her time in Ecuador is a picture of intense discrimination and ongoing struggle for her and her children to survive.

Thus, Constanza has no formal language learning experience prior to arriving in New Zealand. Even possible exposure to her children's formal education in Ecuador was limited as her children were denied schooling for a long time because of their Colombian background. However, in her descriptions of life in Colombia there is evidence of exposure to and familiarity with foreign languages which resulted in her constructing an idealised view of herself as an L2 user, living a better life in a foreign country.

The table below provides a summary of Constanza's prior language learning experiences and their influence on her BAK:

Table 8: Constanza's prior language learning experiences \& BAK

\begin{tabular}{|c|c|c|c|}
\hline $\begin{array}{c}\text { COLOMBIA } \\
0-30 \text { (years of age) }\end{array}$ & BAK & $\begin{array}{c}\text { ECUADOR } \\
30-40 \text { (years of age) }\end{array}$ & BAK \\
\hline $\begin{array}{l}\text { No evidence of prior } \\
\text { language learning } \\
\text { experience }\end{array}$ & $\begin{array}{l}\text { No evidence of } \\
\text { foreign language } \\
\text { learning BAK }\end{array}$ & $\begin{array}{l}\text { No evidence of language } \\
\text { learning } \\
\text { experience/exposure to } \\
\text { foreign language }\end{array}$ & $\begin{array}{l}\text { No evidence of } \\
\text { foreign } \\
\text { language/language } \\
\text { learning BAK }\end{array}$ \\
\hline $\begin{array}{l}\text { Exposure to foreign } \\
\text { language through } \\
\text { employment (e.g. } \\
\text { Chinese restaurants; } \\
\text { nanny for Dutch family) }\end{array}$ & $\begin{array}{l}\text { Idealisation of } \\
\text { self-as L2 user } \\
\text { (ideal life- } \\
\text { scenario } \\
\text { attached to L2) }\end{array}$ & & \\
\hline
\end{tabular}

\subsubsection{Sandra Milena}

Unlike the other participants, Sandra Milena arrived in New Zealand as an immigrant, not as a refugee. In her mid-70's she is also significantly older than the other participants. Similar to the other participants, she comes from a large family (nine brothers and sisters). Her father was often absent due to his work, selling produce in neighbouring cities. While he was too busy to be interested in their education, her mother encouraged them all to study. All of her brothers and 
sisters were in fact required to complete primary school. This recognition of the value of a basic education is communicated by almost all of the participants in their descriptions of childhood. However, only two of her siblings completed secondary school; Sandra Milena herself did not, until years later. Instead, after two years of secondary school she entered a course preparing her for office work. At around the age of 17-18, she began working in an office where she met her future husband and father of her two daughters. Years later, Sandra Milena divorced and assumed responsibility for raising her daughters. As an adult at the age of 30 , she returned to school to get her high school diploma. She says she felt ignorant without this qualification and did not feel good when her daughters asked questions about their homework that she could not answer. She uses this story to highlight her appreciation of formal education, commenting that: when one is learning one wants to learn more and explore more. She attended weekend classes for a year and a half until receiving her high school diploma. When I asked if they taught English (or any foreign language) in these adult classes, she says that they did not. In fact, she explains that before arriving in New Zealand she had no formal (classroom) English education. Foreign language study seems not have played a role in Sandra Milena's life during her formative education or beyond. However, in preparation for her first visit to New Zealand, she attempted self-study by watching an English learning program on $T V$ which served as her first direct experience with language learning:

D: ... and before coming here to New Zealand did you study or speak another language? SM: no no however when I knew I was going to come I put myself... there was this television program to learn English I really concentrated on learning English

D: ok when you knew you were coming here to live?

$S M$ : no no not to live

$D$ : to visit?

SM: to visit and so I watched this program because no to enter a language academy in Colombia is very expensive and I would learn this and this and a word and I would repeat repeat repeat and the next day I would be in front of the TV and I would forget everything everything that I had studied before

(initial interview)

Sandra Milena's experience of trying unsuccessfully to learn English from television introduced her personally to the challenge of learning a second language as an adult. She recognises issues with recalling language and although admitting to being able to pick out a word here and there, is aware that communicating in an $\mathrm{L} 2$ will be significantly more difficult. She admits to preferring to rely on her Spanish-English dictionary than on her study to help her manoeuvre through her travel to New Zealand. Her limited, unsuccessful language learning experiences have thus resulted, like many of the other participants, in the construction of a type of 'shallow' BAK regarding language learning. In other words, her language learning cognition, prior to arriving in New Zealand, has not experienced sufficient exposure or practice in L2 learning to have a clear conception of what it means to learn a language as an adult, particularly in a self-study context. She does however have some appreciation that learning English is difficult. 
While experience with L2 learning was limited in Sandra Milena's educational background, there are noteworthy prior contact experiences with foreign languages, particularly English. One example of this exposure is through her daughters' education. Like Samantha, Sandra Milena was also incidentally in contact with English (including approaches to its learning and teaching) through her children's education. However, Sandra Milena's exposure to English language teaching and learning was not with public but rather private language education. Sandra Milena describes how she enrolled her daughters in 'Columbo', a very expensive English school because she believed that learning English would be a useful skill for their futures. While the eldest daughter stopped attending shortly after, Diana, her youngest, seemed to value and enjoy the classes and was more consistent in attending. In fact, Diana completed all of the levels before eventually immigrating to New Zealand where she built a new life. According to Sandra Milena, the English classes served Diana well on her journey to New Zealand, giving her the skills and the confidence to explore outside of Colombia. This experience with private English language education and the successful migration of her daughter in an English speaking country influenced the belief that useful language learning can be acquired in a formal context. When I asked her what stimulated her decision to put her children into English classes after previously stating that she had no interest in languages, she refers to her interest in a family contact living in Australia:

D: I find this interesting you put both your daughters in Columbo this English school but you told me before that you had no that you weren't interested in languages SM: But like she told you (Diana) because my niece lived with us and when she lived with us she came from Australia she was married with a gentleman and this gentleman had family in Australia and (she said) hey girls come to Australia when I am over there and so I thought Oh HOW INTERESTING

(initial interview)

Sandra Milena is suggesting that her exposure to English through members of her family sparked her interest in English as a socio-economic resource. She saw the potential English offers (at least for her daughters) for a life outside of Colombia, made possible by the ability to speak English. She explains that the decision to put her daughters in a costly private English school was very much influenced by the interaction with members of her family, where English was playing a significant role in their changing life. From this exposure to English - her family members' immigration to Australia; her daughter's private English education; her daughter's immigration to New Zealand Sandra Milena has constructed a view of English as a useful tool or skill that can help create opportunities for improving one's quality of life.

Sandra Milena's prior experiences with language learning indicate a variety of informal exposure to English as a foreign language and English education, and limited self-directed experience with language learning. From interactions with her relatives, and their contact with English, and all the opportunity it offered her daughter, Sandra Milena developed the belief that English is an 
important language to know, offering opportunity and prosperity. From her personal self-study with English, she developed a firsthand, initial understanding of how difficult it can be to learn an L2.

Below is a summary of Sandra Milena's prior language learning experiences and their impact on her L2-related BAK:

Table 9: Sandra Milena's prior language learning experiences \& BAK

\section{COLOMBIA \\ 0-71 (years of age) BAK}

Exposure to foreign language through family

(niece in Australia; married to an Australian)

Exposure to foreign language teaching and learning from daughters' private English lessons

Exposure to foreign language use through family (youngest daughter's migration to New Zealand; married to an English-speaking New Zealander)

Exposure to foreign language learning through English educational television program
Understanding of English as a valuable-socio economic resource

View that formal language instruction can lead to effective language acquisition

Understanding of English as a valuable-socio economic resource

Belief that English in a self-study context as an adult is difficult

\subsubsection{Paco}

Of the six participants, Paco, along with Sandra Milena (both holding high school diplomas), spent the most time in a formal learning context. Incidentally, Paco also provides the most detailed descriptions of formal language education prior to New Zealand. He describes experiences with compulsory English classes, depicting a grammar-translation, teacher-centred approach. Similar to Samantha, who studied English in middle school, English, which was taught in Spanish, was not learned for the purpose of communication. Paco stresses the fact that he was not required to speak or listen to English. In fact, prior to arriving in New Zealand, he had no experience with communicative L2-use:

...there wasn't any dialogue or anything like that and the teachers like us only spoke Spanish the only thing they used was the greeting good afternoon class - good afternoon teacher

(initial interview)

Paco acknowledges that English classes essentially incorporated activities meant to prepare students for tests, affecting whether you passed or not: 
D: ...so you didn't learn to use it?

$P$ : yeah not to use it was like material I completed like that I used as part of a curriculum but it was never like important but at the same time I had to beat it I had to pass because well they put you in your year for this

(initial interview)

Paco's L2-learning cognition rooted in years of formal English learning through public schooling in Colombia resulted in the construction of a critical view of traditional approaches to classroom language learning. He feels that this type of learning was ineffective in providing him (or his family; see below) with the necessary skills to navigate his day-to-day language-related interactions in New Zealand. Like Samantha, and her experience with middle school English, he seems to resent having spent a significant amount of time learning an L2 but not being able to use it. Rather than focusing on conjugating verbs or reading and writing (i.e. translating), Paco believes language classes need to focus on practicing using the language:

...so I think if someone wants to teach English to a child in a Latin American country in a country where they speak Spanish with eyes on the future I wouldn't do so much writing and none of that instead I would listen to English listen to English so that you can understand what they are asking you and so you can give them a response to what they are asking

(initial interview)

Pablo did not learn or use English after moving to Ecuador at around the age of 30. His main focus in Ecuador was to find employment. He dealt with heavy discrimination for the first six months. As Colombians, Paco and his family were forced to manage the poor reputation Colombian migrants carry in Ecuador, an experience communicated by each of the refugee-background participants. For Paco, the lack of employment presented a significant struggle. However, after some time, his situation improved. His description of life in Ecuador becomes more positive as he finds work which he enjoys and allows him to provide for his family, but at the same time introduces a different challenge: their eldest daughter was being bullied at school for being Colombian. And according to Paco, the teachers and the administration were not doing enough to combat this problem. In fact, Paco accuses the school administration of negligence. This experience suggests again that contact with school was less than positive. There is actually no mention of the children's education, including their foreign language education while in Ecuador or Colombia. Instead, Paco constructs an unpleasant picture of his and his family's experiences with school as an educational institution. These negative experiences with school have played significant roles in the construction of Paco's distrust toward formal education.

While Paco did not engage in further language learning after secondary school, there is evidence of different types of exposure to English. First, there is exposure to English through his employer. Paco, when recalling his exposure to English in Ecuador, produces a detailed story about his employer, someone he respected and perceived as successful, speaking English fluently while 
conducting business. Through the story, Paco communicates a type of admiration for this ability to interact in English in real life situations. Moreover, we see that Paco associates a certain prestige with the ability to communicate in English. Second, Paco describes weekly English conversation classes that Silvana would attend in preparation for their migration to New Zealand. The classes were offered by a non-profit organisation and the teacher was a native English speaker from the United States who spoke English perfectly, and with little Spanish ability, which Paco perceives as positive. While Paco himself did not attend the classes, instead continuing to work, his description of the classes indicates that he had some idea of the type of topics and activities used in typical English conversation classes. However, unlike the positive description of his employer's English skills and experience learning English when in America, Paco sees little value in the language learning Silvana and the girls experienced through these lessons. He comments that when the family arrived to New Zealand, it was Paco who navigated the various L2-interactions because the others were not able to. In his thinking, the classes did not adequately prepare them for day-to-day interaction:

...I didn't go to a single English class that she (Silvana) went to I continued working they would got to classes and they went to various Mondays before arriving here and when we arrived here the first one who was in charge was ME You see? Like it's not like they wasted their time but at the same time if they didn't get the points exactly

(initial interview)

Paco's account of the conversation classes that Silvana and the children took in preparation for their move to New Zealand reinforces his view of learning languages in a classroom context, particularly what he sees as classroom learning's failure to prepare individuals to navigate authentic L2-interaction. Paco explains how for all the learning that his wife did in her classes with an English speaking teacher, and his children in school, his own naturalistic methods have proven more useful and successful.

Therefore, we see how through various experiences and contact with English, Paco seems to have developed clearly distinct views. First, he does not seem to recognise the value of L2-learning conducted in classrooms. Both his English education in Colombia and his family's more contemporary experiences learning English in Ecuador, have not been successful in teaching them how to communicate in English. However, in observing his employer navigating a business transaction in English, he ascribes a kind of prestige to English when used for authentic communication. A summary table of Paco's prior L2 experiences and BAK is outlined below: 
Table 10: Paco's prior language learning experiences \& BAK

\begin{tabular}{cccc}
\hline \hline $\begin{array}{c}\text { COLOMBIA } \\
\text { 0-30 (years of age) }\end{array}$ & BAK & $\begin{array}{c}\text { ECUADOR } \\
\mathbf{3 0 - 3 4} \text { (years of age) }\end{array}$ & BAK \\
\hline \hline $\begin{array}{c}\text { Exposure to } \\
\text { (foreign) language } \\
\text { learning through } \\
\text { public school } \\
\text { English classes }\end{array}$ & $\begin{array}{c}\text { Perception of } \\
\text { foreign language } \\
\text { learning classes as } \\
\text { inadequate in } \\
\text { preparing one to use } \\
\text { English }\end{array}$ & $\begin{array}{c}\text { Exposure to foreign } \\
\text { language through } \\
\text { professional contact } \\
\text { (employer used English) }\end{array}$ & $\begin{array}{c}\text { Understanding of English } \\
\text { as a valuable-socio } \\
\text { economic resource } \\
\text { (English as symbol of } \\
\text { prestige) }\end{array}$ \\
& & $\begin{array}{c}\text { Exposure to language } \\
\text { education through Silvana } \\
\text { and the children's } \\
\text { preparatory English lessons } \\
\text { (English conversation } \\
\text { classes offered in Ecuador) }\end{array}$ & $\begin{array}{c}\text { Reinforced perception of } \\
\text { foreign language } \\
\text { learning classes as }\end{array}$ \\
& & $\begin{array}{c}\text { inadequate in preparing } \\
\text { one to use English }\end{array}$ \\
& & & \\
\hline \hline
\end{tabular}

\subsubsection{Silvana}

Silvana, in describing her experiences with formal education, explains how in her home life, education was explicitly promoted. In fact, her mother, despite the fact that she was often absent, encouraged all of the children to study as education could bring valuable opportunities. Her descriptions of her public school experience were similar to the other participants; with strict, authoritarian teachers who frequently hit students and tolerated little interactive learning. Also, she comments that the approaches to learning, including the content of the classes, were dull and related little to her own interests. She remarks that she found the overall school experience hard and difficult to engage with.

In terms of language learning experiences, Silvana explains that English was a compulsory subject and she was the best student, getting top grades in her classes. However, Silvana critiques the English taught in these classes, as introducing only the most basic things, which essentially served for nothing. In discussing the content of her English classes, she remarks that what she was learning would be of no practical use in helping her communicate in authentic situations; the English she was being taught was not what she perceived as 'useful':

...in the United States they don't have what was in the classes TOTALLY DISTINCT

(initial interview)

Like Paco and Samantha, her formal public schooling English education has been of little use to her in New Zealand, leading her to recognise the limitations of these experiences. When talking about the ineffectiveness of the language learning education she had growing up, she explains that now, living in New Zealand, she is on a daily basis confronted face to face with the challenges of $L 2$ 
interaction in an immersion setting; now she is learning what it means to know English. Silvana stopped attending school at around the age of 15 . She stresses that it was completely her decision to leave school, preferring instead to find employment. For the next 15 years of her life, Silvana would have no exposure to formal education, including language learning.

Beyond personal experience with language learning, Silvana also provides accounts of different informal exposure to foreign languages. First, she recognises that English seemed to carry a certain prestige or status for those around her. She recalls often being told that the two most important languages to learn are English and Spanish. Her mother emphasised that English was used all over the world. In addition, she describes interactions with a childhood friend from the United States whose mother was Colombian. When this family would visit, everyone became excited and were curious to learn about life in America. Silvana also had employers from the United States who would occasionally visit their business. Her employers spoke in English and Silvana would listen to them, feeling surprised and impressed with how well they communicated. Finally, Silvana, like Sandra Milena, also had family members who exposed her to foreign languages. She describes an aunt who lived in Holland. Silvana's aunt would visit her hometown with her husband and their daughter. While her aunt and uncle could communicate in Spanish, her cousin could not. As a result, Silvana often heard her speaking Dutch, and would wonder with interest (much like Constanza and the tourists and her Chinese colleagues) what they might be talking about. This informal exposure to foreign language presented a positive experience for Silvana, stimulating curiosity and interest. However, they are not particularly critical experiences, significant enough for her to form clear BAK in regards to using a foreign language. Instead, this exposure to $L 2$ use, similar to much of the exposure to foreign languages in the other participants' accounts, reflects a kind of casual association with languages; associations that can be recalled and evaluated in retrospect but which may not have had a particularly powerful impact on her cognition. It is possible however that they led her to underestimate how difficult it can be for adults to navigate an L2 immersion setting. In fact, the important people she knew who were able to communicate in an L2 learned through immersion; it is possible that she assumed at some level that living in an English speaking country would be sufficient to acquire the $L 2$.

In her early 30's, Silvana moved to Ecuador with her family. Exposure to foreign languages and language learning was limited to indirect contact, until the final few months where she began attending English conversation classes. Firstly, unlike in Colombia, there were many tourists in Ecuador from all over the world. Also there were numerous non-profit and non-government agencies in Ecuador employing foreigners. While Silvana worked primarily in the fast food industry, preparing and selling food, she also volunteered at a non-profit aid agency, working with a women and children's group. At this agency, Silvana came across many foreigners but explains that communication was conducted in Spanish. Finally, before moving to New Zealand she attended English classes with a teacher from the United States. Her language learning in English conversation 
classes is noteworthy as they represent the only example of formal adult language learning prior to New Zealand from any of the participants. Silvana creates a positive description of the teacher, referring to her as a beautiful person. She suggests that at the time she was enjoying the English classes and was under the impression that this preparation would be useful for her transition to life in New Zealand. The classes were more communicative in nature, focusing on basic speaking and listening. However, she has become critical of the English she learned through these classes, as it has been of little use to her in New Zealand. It is possible that at least part of this criticism is the result of having a teacher from the United States, using a commonly (at least for the majority of Latin Americans) recognised and heard variety of English. Through her weekly classes, Silvana experienced a different (from the New Zealand variety) variety of English (North American) which she may have grown comfortable with. When arriving in New Zealand the exposure to an unfamiliar variety of English surprised Silvana, leading her to comment on the marked difference (it's not the same). This suggests that she may not have been aware of, or had not properly considered, the differences between varieties of English. Later in the discussion (chapter 6) the effects of this unfamiliarity are explored in a more nuanced manner, illustrating how beyond 'surprising' migrant language learners, a lack of 'preparation' for $\mathrm{L} 2$ variety can result in the construction of negative attitudes and consequently impact the willingness to communicate. In addition, this experience with classroom English instruction and its eventual ineffectiveness in helping her communicate in English in an English-speaking country has influenced her beliefs about formal language learning. Similar to Paco, she has developed a scepticism toward L2-learning conducted in a classroom. More specifically, she is doubtful that the $L 2$ one learns in a classroom can be of use across different naturalistic contexts.

Table 11: Silvana's prior language learning experiences \& BAK

\begin{tabular}{|c|c|c|c|}
\hline $\begin{array}{c}\text { COLOMBIA } \\
0-32 \text { (years of age) }\end{array}$ & BAK & $\begin{array}{c}\text { ECUADOR } \\
\text { 32-36 (years of } \\
\text { age) }\end{array}$ & BAK \\
\hline $\begin{array}{l}\text { Exposure to (foreign) } \\
\text { language learning } \\
\text { through public school } \\
\text { English classes }\end{array}$ & $\begin{array}{l}\text { Perception of } \\
\text { foreign language } \\
\text { learning classes as } \\
\text { inadequate in } \\
\text { preparing one to } \\
\text { use English }\end{array}$ & $\begin{array}{l}\text { Exposure to } \\
\text { foreign languages } \\
\text { through volunteer } \\
\text { work }\end{array}$ & $\begin{array}{c}\text { Understanding of English as } \\
\text { a valuable-socio economic } \\
\text { resource (English as symbol } \\
\text { of prestige) }\end{array}$ \\
\hline $\begin{array}{l}\text { Exposure to foreign } \\
\text { language though } \\
\text { personal relationships } \\
\text { (Mother; American-born } \\
\text { friend; Family living in } \\
\text { Holland; American } \\
\text { Employer) }\end{array}$ & $\begin{array}{l}\text { Ascribed prestige } \\
\text { to English; Positive } \\
\text { view of foreign } \\
\text { language ability }\end{array}$ & $\begin{array}{l}\text { Exposure to } \\
\text { language learning } \\
\text { through English } \\
\text { conversation } \\
\text { classes }\end{array}$ & $\begin{array}{c}\text { Reinforced perception of } \\
\text { foreign language learning } \\
\text { classes as inadequate in } \\
\text { preparing one to use English; } \\
\text { Developed awareness about } \\
\text { English varieties }\end{array}$ \\
\hline
\end{tabular}




\subsubsection{Clara}

Clara's formal education was significantly different from the other participants. She was educated at a Christian commune starting from the age of 12. Before this, Clara had received no formal education. It was also through this commune experience that she first encountered language learning, as she was taught English by North American missionaries. Clara depicts her introduction to formal education as quite a negative experience; partly because of her age (she was much older than the other children in primary school) and partly because of the informal manner in which the lessons were delivered (no textbooks; no desks or chairs; etc.). She is also critical of the fact that she had to learn English in Colombia. To illustrate this issue, she gives an account of the evening meals, where the commune members ate together and the missionaries struggled to use Spanish. According to Clara they would resort to English, which she resented: Why would they come to my own country to use English? It is worth noting that of all the participants who studied English formally, only Clara received instruction in English, rather than Spanish. Despite her issues with having to learn English, Clara admits that if she had made the effort to learn, life (later on) may not have been so difficult for her. However, being young, she felt she could not have appreciated the opportunity to learn a foreign language. From the accounts of her experiences learning English in Colombia as a young child, Clara communicates an unfavourable view of learning English. However, because she avoided talking specifically about actual classroom activities and practice, it is difficult to gauge clearly how she felt about the approaches to learning or the learning experience.

Like Sandra Milena and Silvana, Clara also presents evidence of exposure to foreign languages through family. She refers to an elder sister who knows English and lives in Argentina. In comparing herself with her sister, Clara describes herself more as a worker, while she views her sister as an intellectual. In her elaboration, Clara explains how her sister is intelligent and good at school while Clara is better at work. She also explains that her sister lived with a North American couple, where according to Clara, she began to really learn English. Clara seems to associate the ability to learn and use a foreign language with intellectual activity; a kind of activity which she is not confident in engaging in. She explains that for an unknown reason, studying and learning languages was not her style. Unlike her sister or even her son, who she also regards as intellectual, she never saw herself as particularly studious, failing to view formal education as a worthwhile endeavour she preferred to work.

When she was 42, Clara moved to Ecuador. She says that in Ecuador she had no language education at all, nor any exposure to foreign languages. In fact, she explains that learning a foreign language while in Ecuador was never a consideration. Similar to Constanza's account of life in Ecuador, Clara paints a picture of continuous struggle with little time to consider education for herself. As an unskilled single mother, she admits to having little confidence in her ability to learn a language (including finding the time for study). Regarding her time in Ecuador she says the best she could imagine for herself was part time work in the fast food industry. 
Clara presents unfavourable accounts of her formal education generally, and language learning (including exposure to foreign languages) specifically. She resented not only having to learn English from North American missionaries, but also having to interact in English with them outside the classroom. In addition, she did not appreciate the informal nature of the learning. Clara's exposure to foreign languages and foreign language learning beyond her study was also influential in the construction of her cognition. There is evidence of her being exposed to English from a family member who she holds in high esteem. When talking about her own contact with foreign languages, she describes the successes of her elder sister, nearly boasting about her varied achievements. There appears to be a kind of tension in Clara's cognition as a result of her prior L2 learning experiences and her exposure to L2s. On the one hand, she carried negative feelings toward her formal English education and perceived little value in this endeavour for herself. On the other hand, she acknowledges that L2 ability can carry significant value, lamenting her lack of interest and effort. In other words, Clara seems to recognise the value of English, just not necessarily for her. Her perception of herself as a worker, not an intellectual, seems to be interplaying with her selfconfidence, acting as a kind of barrier to further development.

Table 12: Clara's prior language learning experiences \& BAK

\section{COLOMBIA \\ 0-42 (years of age)}

\section{BAK}

Exposure to (foreign) language learning through classes at a Christian commune

(North American English variety)

Exposure to foreign language through interaction with missionaries

Evidence of exposure to foreign languages through family (Elder sister employed by American employer)
Critical of informal approach to language learning; Low self-confidence in ability to learn L2

Critical of having to learn L2 in Colombia

Ascribed prestige to English; Positive view of foreign language ability; perception of L2 ability as an intellectual activity

\subsection{Summary}

This section presented the prior (before arriving in New Zealand) language learning experiences of the participants. It highlighted formal and informal L2 learning and use, as well as presenting various examples of exposure or personal contact with the L2. The majority of the exposure and learning was with English as a foreign language. Almost none of the participants have experience learning foreign languages for communicative purposes. It also seems that no participant has any substantial experience using a foreign language, such as English in naturalistic interaction. There is some evidence of formal language learning in their younger years, but as adults, only Silvana 
and Sandra Milena have any type of language learning experience. However, evidence of a variety of exposure to foreign languages throughout their lives, in and across different contexts, does exist. And this exposure, while not extensive, seems to have influenced the construction of certain thoughts and feelings regarding learning and using foreign languages. For example, this informal exposure to foreign languages seems to have resulted in a type of abstract or idealised understanding of (1) what it means to know a foreign language and (2) what knowing a foreign language like English, can offer in terms of socio-economic opportunity. The participants' experiences with foreign languages did not seem to adequately prepare them for challenges involved in learning and using an L2 as adults in an immersion setting. There was little awareness or knowledge regarding the various process involved in learning a second language. Also, there was a notable lack of appropriate recognition regarding differences in English variety, and the effects of these differences on face-to-face interaction. In sum, the participants were not fully aware of the host of L2-related issues that would affect their lives in New Zealand. In fact, there is evidence suggesting that participants believed learning English in New Zealand would be somewhat easy and that it would inevitably lead to a better quality of life. This can be expected, as it is a common misconception that living in an immersion setting will provide adequate exposure and opportunity to use the L2 (Ortega, 2014a), making the acquisition process easier. Thus, it can be argued that limited foreign language learning experience (either through formal education or in naturalistic settings) resulted in their inability to construct any clear or specific beliefs or feelings about learning or using a second or additional language prior to arriving in New Zealand.

It is also worth noting that in all but Constanza's accounts of prior experiences with formal learning, the participants refer explicitly to a 'recognition' of the value of education. All of the participants communicate an appreciation for formal study, at a general level and language learning at a specific level. However, because of various socio-economic and personal reasons, the participants were not able to fully engage in formal study. The focus of their lives instead was on navigating, to the best of their abilities, their day to day challenges, including providing basic necessities for themselves and their respective families. L2 education, while perceived by many of the participants as a means to an improved quality of life (e.g. facilitates migration), is identified, through the descriptions of educational trajectories, as having had quite limited impact on their life. For many of the participants, the thought of learning a language prior to New Zealand was never a serious consideration; it was essentially a luxury they could not afford, economically nor in terms of time and energy.

It is also significant that most of the participants lack a significant educational background. As mentioned, only Paco and Sandra Milena hold a high school diploma. Constanza did not finish primary school; Samantha and Clara did not complete middle school; Silvana stopped school at the age of 15. While, research which has looked at the educational backgrounds of refugees in New Zealand is limited (Benseman, 2012), Blaker and Hardman (2001) have indicated that since 1995, 
$80 \%$ of adult quota refugees entering New Zealand have not completed primary school. Similarly, a report by Teachers of English to Speakers of Other Languages Aotearoa New Zealand (2003) states that since $1994,40 \%$ of quota refugees have had less than seven years of schooling. The relationship between educational background and the ability to acquire an L2 is obviously a complex phenomenon, with numerous factors at play. However, Bigelow and Schwarz (2010), citing Gombert (1994) in their study on adult English learners argue that the more education one has, the easier it is to learn a new language. Whether this correlation is a direct one or not, it is likely that quality of the experiences in a general formal learning context will affect one's cognition toward classroom language instruction. This in turn, will impact on individuals' L2 learning success (including perceived success). Finally, it is important to highlight that not all of the participants were equally comfortable talking about or reflecting on their past (i.e. prior to New Zealand). This meant that exploring prior language education and exposure was an endeavour I needed to handle with great sensitivity; I had to be careful not to put the participants in situations they did not feel comfortable in. Clara and Constanza, for example, seemed to avoid in-depth discussion regarding their life in Ecuador.

RQ 1 and RQ 2 have painted a picture of the participants' prior language learning experiences and produced a 'profile' of their cognition in relation to these experiences. Next, RQ 3 and RQ 4 shift the focus to their current L2 immersion context. RQ 3 begins by exploring the different perceived needs the participants have for English in their lives. In answering this question, we are also able to observe the range of contexts across which the participants engage in languagerelated activity, and how interaction across these contexts impacts on their perceived needs for English. RQ 4 builds on this information, by focusing specifically on the different ways (i.e. what they do and don't do) these adults engage in these activities, including the strategies and resources they employ. 


\section{Chapter 5: Findings (II)}

\subsection{Introduction}

This chapter presents findings for RQs 3-4, concentrating on the participants as language learners in New Zealand. RQ 3 describes the developing role they see English playing in their current lives, while RQ 4 explores the range of ways in which the participants engage in language related activity in situations beyond the classroom, providing illustrative accounts of this day-to-day engagement in the $L 2$.

\subsection{The perceived need for English in the participants' lives in New Zealand}

RQ 3 explores the participants' personal accounts of life in New Zealand to highlight their developing thinking about the role and significance of English in their day-to-day life. It raises various issues regarding the relationship between $\mathrm{L} 2$ learning and integration in an immersion context. As all of the participants are adults (over 30) with a shared L1 (Spanish) and low proficiency in the L2, living in Wellington (an ESOL context) for a relatively recent length of time (1-2 years), it can be assumed that certain needs for English will be shared. There is also evidence of unique or individual languagerelated needs.

RQ 3. What is their perceived need for English in their current socio-cultural context?

In this section, I describe the different perceived needs for English reported by the participants and illustrate how these needs function as a response to their current living situations, i.e. as non-English speaking background adult migrants living in New Zealand. The needs identified are either: (1) explicitly identified needs, where the participants directly communicate this particular need for English; (2) implicitly identified needs, where the participants' descriptions of life in New Zealand, mainly their descriptions of day-to-day language-related interactions, suggest a particular need for English. Below is a comprehensive list of the participants' perceived need for English:

\section{Employment}

Employment was mentioned by all six of the participants in some capacity as a reason for needing English. In fact, English as a necessary means to employment was one of the most talked about challenges faced by the participants. Clara's comment below reflects a common idea amongst the participants regarding the need for English in their lives: 
D: ...and now what do you think about the role of English in your life now the importance of English now?

C: I think that now if I want to continue living in New Zealand I think it is like the major part of my life that I need

$D$ : Yes? that's why you are studying so hard

C: $m m m$ hmm and it's like without English one's life wouldn't be worth anything

D: $m m m$

C: because what do I get out of meeting with you and talking and talking about a lot of things or meeting someone who speaks Spanish? But I have to go to work and I have to take a bus

(initial interview)

It is worth noting that, while Clara clearly perceives the need to learn English in order to procure employment, she was not employed. In fact, of the six participants, for the duration of this study only three of the participants (Samantha, Silvana, and Paco) were engaged in employment. There were different reasons for this. For example, in Constanza's case, while she recognises the need to work and expresses a desire to work, she also rejects the pressure to find work at any cost. For Constanza, menial work, or the kind of work she used to do in Ecuador, is not something she wishes to engage in again. Instead, she hopes to attain a certain proficiency in English to help her find a different, more prestigious type of job - something that can keep her motivated and that she can enjoy. The excerpt below reflects this sentiment:

D:...if you are thinking maybe looking at the future in four or five years what would you like to do with English?

C: ahhh be able to do? Well work

D: yeah?

C: work... it's like I would like to work in something that isn't routine not something that I have already lived I've already worked I am tired of that routine

$D$ : you want to try something that you haven't done before

$C$ : something I haven't done that's it a super different job not a job that has always been routine for me

$D$ : and that

C: because there is a lot of work here that... there is cleaning work in cleaning work it is not important if you speak English

D: yeah

C: but I don't I don't like I'm tired of that

(initial interview)

Silvana echoes this idea of needing English to help procure a higher standard of employment. Although she is employed and relatively satisfied and happy with her job, she does hope to someday find something different: 
D: its takes time and sometimes

S:... I say to Paco I am very happy at my job but I would like to look for a little job where they pay me better... I would like to work at the mall... picking up trays

D: yeah yeah yeah

S: and mopping I see that they must pay well there... but I need my English

D: yeah right

S: I need my English... first understand it well and then talk it well

(indirect observation interview one)

Like Constanza and Silvana, Samantha perceives the need for English as a means to better employment. However, her goals are slightly different in that she is interested in studying for a qualification that can eventually help her enter into a long-term career; possibly in nursing, child care, or professional cookery. Samantha recognises the need to first attain a certain proficiency in the $L 2$ to help her enter and succeed at a technical college. She understands that she needs English for employment, but the type of employment she hopes to find requires further education. She investigated the various types of courses offered at various colleges in the Greater Wellington area, noting the prerequisite English proficiency levels required for each course. Throughout the length of our investigation, the idea of furthering her education as a means of finding a career was a common theme - Samantha wanted something with a future that she could enjoy and would also put her family in a more financially stable situation. As a single mother of three, this need becomes quite significant. Again, similar to Constanza, she is adamant that she will not settle for 'just any job', as she makes clear to Work and Income New Zealand (WINZ) in the extract below:

S: so this is what has happened to me two meetings that I went to - How is your English? no my English is not that great... they say but to help in a restaurant or to do some cleaning work you don't need that much English so I said WHO SAID I WANTED TO DO CLEANING WORK?

D: hahaha yes...

S: who said I wanted to do that? I DIDN'T COME HERE TO DO CLEANING WORK I said I came here to prepare myself for a better life not for the life that I had in the country I was in

(indirect observation eight)

In terms of employment, Samantha wants 'something different' for herself and is willing to devote the time needed to develop the necessary English skills to help her work toward this objective.

Sandra Milena was the only participant who did not recognise the need for English for employment for herself. In talking about her English development, she admits that English might be necessary for some people who are looking for work - like the refugees she knows from my study who need to work to support a family - but explains that she is not interested in finding employment. In other words, for Sandra Milana, a retiree, living at her daughter's home with her grandchildren and son-in-law, employment is not a priority, and therefore English for employment 
purposes is also not a perceived need. However, in acknowledging the idea of English for employment, she illustrates her awareness that for other migrants, learning English quickly will be a priority.

\section{Access to information and services}

Accessing information and services, like employment, was one of the most prevalent perceived needs for English. Again, all six of the participants, explicitly and implicitly mentioned needing English to gain access to different types of essential information and services in their day-today lives. Examples of the types of information and services they struggle to access due to languagerelated issues include:

- meeting with and discussing school-related issues with children's teachers and school administrators

- visiting hospitals, including discussions with general practitioners (GPs), nurses, psychologists and emergency staff

- communicating in banks

- applying for and taking driver's license examinations

- using public transportation

- meeting with government agencies such as WINZ

- purchasing household necessities such as appliances; home and mobile phones; internet connection; beds

- navigating public facilities such as, libraries and community centres

In Silvana's initial interview, an example of this need for English to access health care services is illustrated through an account of one of her first experiences having to use English in New Zealand:

D:... and do you remember the first time you had to speak or use English in Auckland for example?

S: oh yeah it was difficult we didn't know how to make ourselves understood it was extremely difficult... my daughter Rosario got sick there she got quite a strong pain in her molar and she cried and cried and I was with Paco and I said no let's see what is happening we didn't even know how to explain what was wrong with her and between them they said with the little that Paco understood that that they would take her to a hospital and this and that... they took us with the girl to a place for a health centre nearby and they tried to help but we understood NOTHING

$D$ : nothing right

S: NOTHING NOTHING NOTHING and a man from immigration came with us because we didn't know how to explain it was horrible yeah oh my god it was infuriating I would say to Paco what are they saying? Paco also would say no no no we don't understand what are they talking about.... and so then the only thing was to give her medicine but OH IT WAS HARD

(initial interview)

Silvana's account highlights the kind of frustration and vulnerability the participants' experience as a result of not being able to communicate well in English. In witnessing her daughter 
in pain, her instinct to help is constrained by her inability to both clearly explain the problem and understand what the issue is. It also foregrounds the urgency of the need to acquire the L2 so as to not experience a similar situation in the future.

Constanza's accounts of her relationship with her children's schools present a similar issue in regards to accessing important information and services. During our talks, I often began by inquiring about the children, curious to learn about how they were settling in to life in New Zealand and adapting to different situations. According to Constanza, she had no information regarding the children's education because of her inability to understand English:

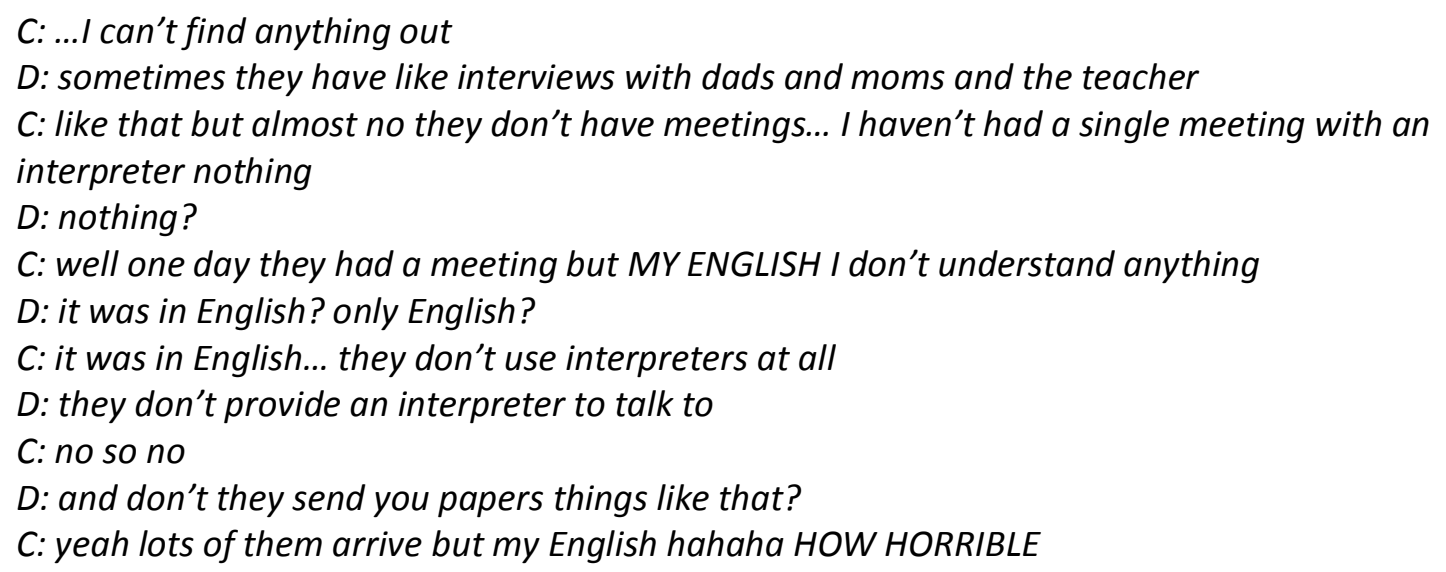

(indirect observation interview four)

Similar to Silvana, Constanza is expressing a frustration at not being able to access vital information about her children. In lacking the ability to communicate with teachers and school administration, Constanza is denied a significant opportunity for involvement in the development of her children. This issue illustrates the type of context where adults who are responsible not only for their own well-being but also for their children's will particularly perceive the need for English.

\section{Relationship building}

All six participants identified needing English to build relationships and socialise. The view that English was instrumental in helping them meet people outside the Colombian, Spanish-speaking community was in fact quite strongly held. For example, Clara, in our initial interview talked extensively about the different groups she joined in order to meet people and try new things. She volunteered at a playgroup, which she loved, she took knitting classes, and also volunteered at a nearby primary school working on their vegetable garden, all with the aim of interacting with people in English. However, as we can see from the excerpt below, interpersonal interactions in English remains a cause for concern: 
C: ...our neighbour our houses are right next to each other and he sometimes greets me talks to me gives me a hose to water the garden or something

D: yeah

C: and he talks to me and I would rather like hide so that he won't keep talking to me

D: yeah

C: this seems terrible because I am NOT LIKE THIS

D: no

C: I want to talk but

$D$ : this is very interesting to me because look when you are in Spanish

C: uh huh

D: you can act like you feel like you are...

C: ah yeah

D: but in English you have to change

C: EXACTLY

$D$ : you are forced to change

C: exactly yes exactly and Alvaro says to me but you scrunch up your face and change your face in church he says to me CHANGE THAT FACE put on a nice face I say Alvaro it is too hard for me having to understand and to talk to them for me it is TOO MUCH... I am making a friend there as well at church but it is terrible because I say if it depends on English I am never going to become his friend because...

(initial interview)

This excerpt depicts a common experience among the participants. It emphasises the very real tension between wanting to build relationships and meet people and the inability to communicate well in English. It depicts an implicit need for English, as a tool to connect and build important friendships and avoid what can at times be an overwhelming feeling of isolation as migrants navigate their settlement and eventual integration into their new communities.

Sandra Milena's account of needing English to socialise with people in her community her own age, while more positive than Clara's, communicates a similar message: that the demand to learn English can largely be motivated by the desire to establish relationships:

SM: yeah for me to study is a therapy

$D$ : yeah why?

SM: because it's something different for me it is something different in the life and now I like it I like studying, $\mathrm{mmmm}$ ? and to be able to be in contact with my neighbours I have many neighbours of my age so this pushes me more to learn to be able to someday communicate with them

D: that's good

(indirect observation interview five)

Finally, in the excerpt below from a conversation with Samantha we see how the need to learn English is again strongly motivated by the need to cultivate friendships and share ideas and feelings with others: 
S: ... who encourages me? haha

D: haha

S: oh I am encouraged by THE NECESSITY

D: yeah?

S: yeah that motivates me to speak to want to learn I am motivated by the necessity of wanting to communicate with people let's say that I get to watching the people who speak English perfectly and so I say I want to talk like that exactly I would love to one day speak exactly like I would like to in five years to be speaking English perfectly believe that is what pushes me that I want to speak that I want to open myself up

(indirect observation interview eight)

These excerpts express on the part of the participants' acute awareness of the need to develop their English in order to be able build worthwhile relationships. And in making these important connections with others, they recognise that they will also be creating the opportunity to express their various ideas and ambitions, communicate their experiences and feelings, and generally begin to feel a part of a larger community where they can play a role.

\section{Religious activity}

All six of the participants are Christian and religion has played, and continues to play, a major role in their lives. They all attend church on a weekly basis. Access to Spanish-speaking church and religious discourse in around the greater Wellington area is limited. In fact, except for Samantha, who is a member of a Spanish-speaking church group, the others all attend English-speaking churches. The participants all explicitly mentioned their need for English in navigating their churchgoing experience; whether this meant making sense of the actual content of each sermon or in their interaction with members of the congregation. Constanza, for example provides a lengthy description of the type of language-related issues experienced by the participants in a religiouscontext, highlighting the perceived need for English. In her account, Constanza begins by detailing events which led her to leave her original church. She explains how she used to go to an Englishspeaking church with a Colombian friend who interpreted the sermons for her. However, the interpreting seemed to cause a noticeable disturbance which led to their eventual move to the cafeteria, so as not to bother the other members. This upset Constanza and resulted in her leaving. She eventually found a new church near her home which she tried to visit. However, the stress of not being able to speak or understand English, was too much for her:

Y...I ran out of the church I was so nervous because this man sat next to me and he started to talk with me to talk with ME saying hello and I felt so embarrassed because this man oh this man he asks me these things and I don't know what to say haha I was worried I was overcome by a huge concern and after I went out and I left

$D$ : you didn't talk?

Y: yes no no I didn't talk I couldn't understand anything that he was trying to say to me... then I left 
While Constanza's experience may represent an extreme case, it does serve to underpin the importance of church in the lives of the participants, and the constraints the lack of English proficiency carries over to this context. The need for English in this religious setting is connected to the facility with which they can gain access to an important service as it relates directly to their belief-systems and identities as Christians. Being able to understand and appreciate the sermons, establishing relationships with priests and interacting with the different members of the congregation, are all activities directly contingent on the participants' ability to use English. Church is also an important site for potential relationship-building and facilitating valuable social cohesion with members of the community. As a result, the need for English in this context is quite obviously perceived and appreciated.

\title{
5. Independence
}

Four of the six participants viewed English as necessary in helping them re-assert their sense of independence. As adult language learners with minimal prior exposure to or experience with learning and using a foreign language, it is a struggle to adjust to a situation where they are dependent on others (e.g. children; interpreters; volunteers) to help them do the types of things they are used to doing without assistance. English as a tool for gaining and maintaining independence was thus identified as a significant need. The two examples below highlight different ways the participants' ability to use English impacts on their ability to act independently.

First, in Paco's account of one of his first experiences using English in New Zealand, he describes a disconcerting language-related interaction at the local library. In this narrative, Paco explains how he had gone to the local library on his own to return some CDs which he had borrowed with the help of his volunteer. However, unable to verbally understand the exact procedure of library returns, one of the staff members ends up physically demonstrating what he needs to do:

\begin{abstract}
D: ...you had to
P: I passed it there and she didn't want to take it and she explained to me and she explained and she explained and I would say I'm sorry no understand English... and she tried other ways and she looked this way and that way and people were looking at us like what happened there? so the woman gets up and she grabs my hand like a child and she grabs my hand LIKE THIS and she puts me in the elevator and we go down in the elevator and she takes my hand like this and says $\mathrm{OH}$ This was the most embarrassing experience IN MY LIFE Haha...
\end{abstract}

(initial interview)

We can see from this account, how the struggle to communicate in English can sometimes leave individuals feeling disempowered and helpless in a range of situations that would ordinarily be considered low-stakes. Managing this feeling of impotence, which Paco communicates through his attempt to return a $C D$ at a library, is one of the main justifications the participants put forth throughout their various accounts for needing English. 
In Silvana's description of opening a bank account, we are presented with an example of a successful interaction. Nevertheless, the need for English is still very much prevalent. Her account reveals the role $\mathrm{L} 2$ ability in an immersion context plays in being able to exercise one's independence:

S: ...at the bank too I had to go to the bank on my own

D: the bank too?

S: yeah I had to go to the bank alone and before starting to talk I told them that I hope they can understand what I am going to tell them because I don't speak English that well...

D: oh THAT'S GREAT

S: I went there by myself I went alone full of nerves but I spoke and they understood me and I understood I said I AM GOING

D: sometimes it's like that you can't take it anymore and you go... ok

S: $\mathrm{mmm} \mathrm{hmm} \mathrm{it} \mathrm{was} \mathrm{getting} \mathrm{late} \mathrm{and} \mathrm{I} \mathrm{said} \mathrm{no,} \mathrm{I} \mathrm{am} \mathrm{going} \mathrm{girl} \mathrm{I} \mathrm{said} \mathrm{I} \mathrm{CAN} \mathrm{DO} \mathrm{THIS} \mathrm{I} \mathrm{CAN} \mathrm{and}$ slowly before speaking I repeat I go thinking about what I have to say and I translate words in my head and well I got there

(indirect observation interview one)

The above excerpts illustrate some of the different ways the participants' need for English is related to their own developing independence. It also serves to show how challenging these interactions can be and why often to avoid these embarrassing and nerve-wracking language-related interactions, some adult migrants develop a dependency on interpreters. Throughout the research there were frequent references to the negative consequences of dependence on interpreters; whether it was the children, a friend, or professional interpreting services. Paco's observation of $L 2$ parents becoming the children's children, where the adults depend on the younger generation to get things done, is in fact something all of the participants were concerned and directly involved with. Again, this sense of impotence, or inability to manage the often mundane, day-to-day tasks of running a family, is acutely felt as a result of not having the ability to use English.

\section{Asserting oneself}

Closely connected to the idea of English-for-independence, four of the six participants (Constanza, Paco, Samantha, and Sandra Milena) discussed needing English to defend themselves. For example, Constanza when explaining her motivation for learning English in her current context explicitly mentions this need for English:

D: and now in these days in your life here in Wellington who is pushing you?

C: on my own hahaha

D: yeah?

C: yeah

D: and where does it come from?

C: let's see well I start to think to encourage myself above all well to study no? I push myself because I say that I have to learn to defend myself to be able to know how I should talk that I don't want to be I don't want to live like this like a mute here

(indirect observation interview six) 
The participants seen to associate this idea of defending or asserting themselves with being able to understand and respond appropriately to what is being said across a range of contexts and interactions. For example, when Paco talks about the importance of being able to respond appropriately in language-related-interactions, he is quite concerned with not being able to understand what is being said. He describes scenarios where people might be insulting him without him knowing. For Paco, this is quite a distressing thought. Thus, the participants, as adult language learners, view the need for English as vital in helping them make sense of what is happening around them and being able to respond to each situation accordingly. As a means of helping them assert their identities and sense of self, as well the means to 'stick up for themselves' when they feel like they are being treated unfairly, the need for English in their lives develops into a significant necessity.

\section{Additional perceived needs}

Three other perceived needs were identified throughout the different accounts. However, many of these were not as 'universally' prevalent in the participants' narratives. In most cases only one participant highlighted it as a need. While these perceived needs may not carry the same significance as ones consistently identified by the majority of the participants, they are nevertheless worth noting. This is particularly true, when many of the identified needs for English are as evident in their day-to-day language-related activity as they are in their descriptions of this activity. In other words, the fact that these needs were recognised by the researcher and the participants in both observed behaviour and languaged experience suggests a particular value. Below is a description of the more 'individually' perceived needs for English amongst the participants:

\section{- Integration}

Paco's description of his graduation in Mangere, being praised in front of all the newly arrived refugees for his effort and progress in settling in and learning the language, highlights the need for English in order to integrate into New Zealand society. He explains how his English teacher, in front of all of Mangere exclaimed you are going to be a Kiwi in no time. He says he realised that Spanish was no longer going to be of use to him. After six weeks of living in Mangere he understood that if he is going to complete a successful integration into New Zealand and be accepted as a Kiwi, he would have thrown himself completely into the culture and to do this, he would need to throw himself into using the language.

\section{- Passing time}

Both Sandra Milena and Clara talked about learning English to pass the time or to fight boredom. Learning English here then is needed as a type of entertainment. Sandra Milena, 
particularly, mentioned often that she enjoyed learning English and welcomed it as an important way to spend her time.

\section{- Helping out at home}

Sandra Milena mentioned needing English to be able to help out at home. Activities like shopping and dealing with deliveries or repairmen, for example, required her to use English. She liked feeling useful and understood that being able to use English would go a long way in helping the family.

\subsection{Summary}

The needs described above appear to be fairly standard. They are the types of needs one would assume most adult migrants would have, underpinned by a 'quality of life' theme. In fact, many of these needs have been identified in other studies on adult migrants in New Zealand (Ministry of Education, 2003; Roach \& Roskvist, 2007; Watts et al., 2001; Watts et al., 2002). However, the nuanced description of these needs as identified in their storied accounts of life in New Zealand, adds a more fine-grained perspective to the picture we have of adult language learners as they navigate their daily lives in New Zealand. Also, as mentioned above, investigating the participants' perceived needs for English has allowed us to more clearly see the range of settings in which the participants engage in language-related activity. We can see who they interact with, where, for what purpose, and also the impact of these interactions on their developing cognition regarding their need for English. In the next section I build on this information and look more closely at how they engage in these activities. In other words, I present examples of the types of strategies and resources they employ as they engage in these high stakes interactions.

\subsection{A description of adult language learners' L2 activity beyond the language classroom}

This final section describes some of the different ways in which the participants engage in language-related activities in an immersion context beyond the formal language classroom. I begin by outlining the most common and influential language-related contexts to establish a general picture of the participants navigating their lives in Wellington. Each description is followed by illustrative account which serves to paint a more nuanced picture of the different ways these adult migrants engage in naturalistic language-related activities, focusing primarily on the various strategies and resources they adopt and adapt. It is within these pictures of their described engagement, as interpretations of experience, which glimpses of their cognition at work (including its construction) can be gleaned. 
RQ 4: How do adult migrant language learners engage in language related activities beyond the classroom?

\subsection{Participants' stories: Accounts of language-related activity}

The tables below highlight the range of contexts across which the participants engage in language-related activity. They also describe the type of language-related activities conducted in these contexts. Additionally, within these contexts, the participants adopt and adapt a variety of strategies to help them make sense of and manage the interactions. The series of shorter narratives below serve to depict the participants engaging in language-related activity in naturalistic settings.

\subsubsection{Language-related activity in a 'religious' context}

Table 13: Language-related activities' contexts and types: Religious

\begin{tabular}{|c|c|c|c|}
\hline \multirow[t]{2}{*}{ CONTEXT } & \multicolumn{2}{|c|}{ SETTING } & \multirow[t]{2}{*}{ ACTIVITY-TYPE DESCRIPTION } \\
\hline & PEOPLE & PLACES & \\
\hline Religious & $\begin{array}{l}\text {-bible study group } \\
\text {-congregation } \\
\text {-ministers } \\
\text {-friends } \\
\text {-family }\end{array}$ & $\begin{array}{l}\text {-church } \\
\text {-home }\end{array}$ & $\begin{array}{l}\text { - } \quad \text { translating sermons from } \\
\text { English to Spanish (preparation } \\
\text { for weekly worship) } \\
\text { - } \quad \text { translating bible with family } \\
\text { - } \quad \text { speaking with English-speakers } \\
\text { attending sermons in Spanish } \\
\text { - } \quad \text { listening to sermons in English } \\
\text { - } \quad \text { interacting in English bible } \\
\text { - study groups } \\
\text { - } \text { speaking with neighbours } \\
\text { - } \text { about religion } \\
\text { hosting religious celebrations } \\
\text { at home }\end{array}$ \\
\hline
\end{tabular}

Religion and religious activities, such as attending church and studying the bible, play an important role in the lives of all the participants. This particular context acts as an important catalyst in stimulating interaction and promoting social cohesion, not only within the Colombian, Spanishspeaking community, but also within the wider L2 community, including English speakers and English texts. Whether it was reading or translating religious scripture, participating in 'small talk' with members of the congregation, listening to sermons, or discussing religion with other religiouslyinclined members of the community (i.e. neighbours) outside of church, the religious-context accentuated some of the different context-specific strategies the participants adopted and adapted in their effort to manage language-related interactions.

Sandra Milena prepares for church: Learning through translation (part I) 
... because she (Constanza) suffers a lot from not being able to understand English so I say one thing that I will suggest that you start developing your independence when you go the church it's better to get some of the sheets from your church where they present the themes for the upcoming week and pick these up and take them home and prepare them and when you go to church to listen to these themes you can follow along with what the pastor or whoever is saying because this has helped me a lot

(indirect observation interview two)

Sandra Milena met with a home language tutor every week for the past two years. At first, the 90-minute, one-on-one sessions in English presented quite a challenge. She suffered from headaches and anxiety and was not able to learn much, often feeling overwhelmed. In an effort to combat this, after some discussion between her daughter, the tutor, and herself, the sessions were reduced to 60-minutes. In addition, to manage the strain of having to speak and listen to English for an entire session, Sandra Milena's tutor introduced graded-readers (with accompanying audio) as a study resource. The incorporation of graded readers was a welcome initiative, as they provided Sandra Milena the opportunity to prepare and review (at my own pace) language before and after each session. Sandra Milena described how each evening she would begin by reading a section of the book she was working on, making a note of any unknown language. Later, after compiling a list of unfamiliar language (almost exclusively vocabulary items) she would use her English-Spanish dictionary to translate these words into her L1. After the translation work, she would re-read the section for meaning, referring back to the recently translated language. Her tutor also prepared comprehension questions as a means of further structuring the self-study, and to provide focus for their weekly meeting. Sandra Milena also often had to translate these questions. The process of preparing for her L2-related interaction (e.g. the tutoring sessions) through translation is an activity that Sandra Milena believed to be useful for her learning. It allowed her to become familiar with the themes she and her tutor would discuss, which in turn, helped her feel more confident and less worried about the interaction. Moreover, it is an activity that she was able to incorporate into to her church-going experiences.

Sandra Milena attended an all-English Catholic Church near her home. She recalls that at first she was not able to understand what was being spoken, but went regardless to feel connected to her religion. Later, she noticed that her church provided the members of the congregation with the themes for each of the upcoming week's sermons. Each week's sermons were written on pages which she could take home and translate. Translating the pages from English to Spanish, similar to the translation of sections of her graded readers, was an activity she adopted to help facilitate and support engagement during her weekly visits to church: 
$D$ : ...that is a good idea

SM: VERY GOOD because you prepare your themes with your lectures and you can

concentrate paying attention to the theme they are reading and explaining there (at church)

(indirect observation interview two)

Relying on direct translation of texts, while carrying certain inherent issues for L2 development, allowed Sandra Milena to familiarise herself with the language she encountered at church. She explains how this activity helped her become aware of the words they are speaking and as result was able to more clearly understand the themes of each weekly sermon. Equally important, she felt more comfortable and confident attending church knowing what topics were going to be discussed. Finally, translating as a means of preparing for L2-related activity helped maintain her sense of independence (something she highly values); she did not need to depend on the assistance of an interpreter or other outside help. Instead, through this translation-activity, she learned that she could work at her own pace, without feeling overwhelmed with pressure or anxiety, and enjoy the gatherings, knowing that she had done all she could to take full advantage of this experience. As the excerpt at the beginning describes, Sandra Milena appreciated the role of translation in helping her navigate her church-going experiences, as well as maintaining independence, to the extent that she suggested to Constanza to pick up this practice. Unfortunately, Constanza paid no heed to this potentially useful advice, and continued to struggle in her church interactions.

\section{Samantha and the children study the bible: Learning through translation (part II)}

...they come home from school and they prepare we have one bible in English and one in Spanish

(indirect observation interview three)

Samantha had come to New Zealand a Catholic but converted to Pentecostalism after some discussion and reflection with people she had met during her time in Mangere. She said she did not quite feel connected to the Catholic Church, and was looking for something more compatible with her beliefs. Shortly after arriving to Wellington, a close friend (another Colombian refugee who had been living in Wellington for some time) introduced Samantha to her local Pentecostal church. Samantha described the church in positive terms and seemed to enjoy the experience of going to the weekly gatherings. The children in particular enjoyed this routine. Eventually, Samantha and the children were baptised into the new religion, and officially accepted as members of the congregation. Throughout our time working together, these church gatherings as religious, social, and languagelearning activities were often described and discussed. Samantha explains how initially, there was a mix of English and Spanish speakers, but the sermons were conducted in English. However, as the Spanish-speaking members of the group grew in size, they were eventually able to form their own 
group, where the sermons were delivered in Spanish. They found a new location and began to meet each Saturday morning. With the sermons in Spanish, the majority of the members attending the meetings were L1-Spanish speakers. However, some L1-English speakers, with some Spanish ability, continued to attend the Spanish group's gatherings. A consequence of this was that Samantha and the children would sometimes need to interpret, from Spanish to English, the parts of the sermon that were not particularly clear for the L1-English speakers:

S: ...and also with the kids so there are people who there are Kiwis who come to the group at church so we have to translate from Spanish to English

D: yes yes yes

S: so with the kids we have adopted this theme here at home

D: ok

S: so because every afternoon we study the bible at home so what happens is one reads in Spanish and the other translates

(indirect observation interview three)

Interpreting sections of the sermon for the English-speaking members of the church group was a challenge for Samantha and the family, but also an opportunity to practice and develop their English. Unlike Sandra Milena, who mostly relied on translating from English to Spanish, Samantha and the family needed to also translate from Spanish to English. In their attempts to prepare for these language-related interactions (and possibly a result of the challenges these interactions posed), Samantha and her children developed the practice of using both an English and a Spanish bible during bible study. This served the dual purpose of helping them better understand the religious messages in the bible, and also learn English. The children would take turns reading in one language, and writing out what they understood in the other, all the while learning new language and gaining deeper understanding of the religious themes in English. Translating religious texts from Spanish to English, as a way of preparing for L2-interactions at church, highlights another way in which translation as a means of preparation assists the participants in navigating engagement in English in a religious context. This illustrative example describes the different ways Samantha has learned to make use of the children within a religious activity context to help with English:

D: ...that is great and so every day you are reading $S$ : this is how they do their (bible study) they come home from school and they prepare we have one bible in English and one in Spanish so Jimena speaks in English and Sophia translates to Spanish or if not Sophia in Spanish and Jimena in English and I am sitting here listening and I UNDERSTAND EVERYTHING and sometimes Sophia can't translate so I HELP HER hahaha

$D$ : oh that is great

S: yes but I don't know this year if feel like

(indirect observation interview three)

Moreover, in this particular case, the translation, beyond introducing new language, carries additional language development benefits. First, it can be assumed that Samantha would have the 
opportunity to practice using the new language she learned in spoken interaction. It is possible that as she learns more of this specific religious-language, she can more easily interpret and therefore discuss these themes in face-to-face settings. Also, it is important to note that the translation (and eventual spoken interpretation) of self-selected texts (sermons; bible passages; etc.) allows for greater learner control over the vocabulary they learn. While this self-selected language may not be the most 'important' or 'useful' language for them to learn, based on principled approaches to $L 2$ vocabulary development (cf. Nation, 2001), it is however language the participants have, through their daily lives, identified as valuable; it is useful language for them in that it carries a specific use, based on the contexts through which they interact. Translation as a means of preparing (i.e. learning) language that they expect will be used in church, can therefore be seen as promoting their agency as learners and affording the participants more control over their $L 2$ development.

\subsubsection{Language-related activity in a 'work' context}

Table 14: Language-related activities' contexts and types: Work

\begin{tabular}{|c|c|c|c|}
\hline \multirow[t]{2}{*}{ CONTEXT } & \multicolumn{2}{|c|}{ SETTING } & ACTIVITY-TYPE DESCRIPTION \\
\hline & PEOPLE & PLACES & \\
\hline Work & $\begin{array}{c}\text {-employment officers } \\
\text {-employers' family } \\
\text {-employers } \\
\text {-colleagues } \\
\text {-customers } \\
\text {-volunteers }\end{array}$ & $\begin{array}{c}\text {-meeting rooms } \\
\text {-work sites } \\
\text {-offices } \\
\text {-homes } \\
\text {-WINZ }\end{array}$ & $\begin{array}{l}\text { - } \text { writing CVs } \\
\text { language } \\
\text { - } \text { speaking with and listening to } \\
\text { employers, colleagues, and } \\
\text { customers } \\
\text { - reading notes from employers } \\
\text { - reflecting on interactions with } \\
\text { employers, colleagues, and } \\
\text { customers } \\
\text { - } \\
\text { speaking on the phone with } \\
\text { customers and employers }\end{array}$ \\
\hline
\end{tabular}

Employment for these adult migrants, beyond bringing in the necessary financial means to help them manage their day-to-day living, also served as a useful space for language-related activity. All of the participants who were able to one way or another procure paid work commented on the significance of this context in providing them with opportunities to interact and socialize in English. Whether it was interacting with their employers, colleagues, or customers, the working participants in this study used work as a means of learning and practicing English; learning that had valuable effects both in the work context and beyond. 


\title{
Silvana goes to work: Learning through the support of others in the workplace (part I)
}

\begin{abstract}
S: ... in Ecuador an extreme amount of discrimination from the Ecuadorians to the Colombians not all of them because we do have a lot of good Ecuadorian friends even now but here it has been totally different at this moment the language is what is most troubling me but but anyway I am getting involved in everything
\end{abstract}

(initial interview)

From the first time I met Silvana and Paco, they communicated to me very clearly that they saw themselves as hard working individuals, willing to engage in whatever was necessary to take care of, and provide for, their family. Silvana, from her early teens had been employed, believing that it made more sense for her to be working than to continue with education. In Ecuador as well, she described the different jobs she used to have (mainly serving fast food), including her position as a volunteer for an NGO nearby to her home. Now in New Zealand, after months of language classes, Silvana felt again that it made more sense for her to enter the work force. She explained that it was better for her to be earning (and saving) money for the family than to be going to the daily language classes. Through the help of a neighbour Silvana eventually found a job at a fast food restaurant near her home. It was a business owned by a Sri Lankan family who had grown up in the Greater Wellington area. While Silvana was grateful for the employment, and the financial security it offered, she also recognised the learning potential from this work context, noting for example the quality of her employer's English ability.

S: I am getting involved with the language... my employer helps me a lot

D: yeah

S: she is from Sri Lanka but now speaks English perfectly the same as my colleagues and the one who helps me is my boss

(initial interview)

Silvana, working alongside her employer (who was aware of her employee's English challenges), was able over time to learn the language necessary for her to complete the daily tasks. As Silvana would take up a task, the employer would explain what she was doing in English, asking Silvana to repeat the expressions aloud. This employer-employee interaction, helped introduce new (context-specific) vocabulary and grammar. In addition, it helped develop Silvana's pronunciation and listening skills in regards to specific tasks. Initially, this language instruction was limited to Silvana's responsibilities in the kitchen (e.g. cutting and preparing food; cleaning up; mopping): 
S: ... last week she was helping me while I cut the lettuce she would say Silvana this is pronounced like this... we were talking on Friday about how to say when one is mopping that just recently Paco had told me I thought that to mop was to sweep but that was 'brush' D: yeah

S: but 'brush' is the broom

$D$; yes yes yes

S: and she would say to me Silvana, you sweep now? and I said to her ahhh and I understood and I said 'brush' because you told me brush but brush is the broom and I was like so she goes on teaching me and teaching me and like this everything gets in and when we were doing the orders for the salads she was watching me and she says Silvana jalapeno is 'hot sauce' not spicy... and now I know what 'hot sauce' is and so little by little

(initial interview)

However, as Silvana gained proficiency, and her employer confidence in her ability to use English, she began to work behind the counter, in direct contact with customers; this situation in turn, introduced new opportunities for language development. Thus, as Silvana's proficiency developed, her responsibilities at work also underwent important changes in line with this progress.

Silvana's story serves as an illustration of the type of language learning opportunities afforded the participants across different work-related contexts. In Silvana's case, her employer is one of the few people in her life who she regularly uses English with. Acting as a type of 'language teacher', the employer is able to introduce relevant language (i.e. job-specific terminology) as it appears in their interactions. We see how at work with her boss, more than with colleagues, Silvana was able to make the most out of her opportunities to learn and practice new words and expressions, including how to pronounce and recognise language. This in turn, allowed her to gain confidence in using and understanding English beyond the work setting.

\section{Samantha's first day: Learning through the support of others in the workplace (part II)}

S: ...uh huh 'vacuum clean' I know what 'vacuum clean' was but now imagine this I had to first dust because it said 'dust'

D: ah ok

S: but I didn't know what 'dust' was so when the lady arrived I said the truth is I didn't understand this I have no idea what this is so she took me around these 'sheets' are these D: I see

S: sheets

(indirect observation interview seven)

Similar to Silvana, Samantha also prided herself on her work ethic. In fact, the description above is in relation to an interaction Samantha had at one of her many housecleaning jobs she managed to pick up over the years. The excerpt is referencing one of her first days of work where her client had left her a note listing different jobs that needed attending around the house.

Samantha is describing how she struggled in this particular interaction to make sense of the word 
sheets. In addition to the descriptions of her efforts in Ecuador to come out on top, she also talked extensively about possible career and business opportunities which could help provide her and her family with the kind of lifestyle she wanted for them in New Zealand. However, as a single mother of three, her situation was slightly more constricting. She did not have the support of a partner to help take care of the family or to bring in supplementary income. In addition, her employment opportunities were limited because of the medical condition of her son. She explained that she could not work too far from the home, in case something happened to Sebastian and she needed to attend to him. Nevertheless, Samantha searched for flexible employment opportunities that could supplement the benefits provided by the New Zealand government. She eventually found work near (or around) her home, cleaning houses and taking care of children. The hours were flexible, allowing her to 'work around' her daily English classes, which she was required to attend if she wished to receive full financial benefits. Beyond providing Samantha with additional income, working in homes and interacting with the various employers, also provided valuable language learning opportunities. In fact, she reflected on her language development, by comparing her first $\mathrm{L} 2$ employer-employee interactions with the type of interactions she is now able to more competently engage in:

D: ... and you have to do this all of it of course these contracts and everything in English right? S: uh huh D: you are talking about money the hours about the types of things you have to clean S: yeah haha I remember the first time I went to work at the baby's mom's house it was my first job and I was so Oh my English was AWFUL

$D$ : about how long ago do you think this was?

S: one year

$D$ : one year it's been a year

S: yeah and look my English is I understood but let's say regarding reading I didn't understand a lot of things

(indirect observation interview seven)

Through the various L2-related interactions with her employers, including explicit textual and verbal instruction, as well as modelling and simplified explanation, Samantha developed her English proficiency. She gained both ability and confidence in communicating in English, appreciating that her skills as an English-user extended beyond her ability to speak and listen to English, to L2 literacy: 


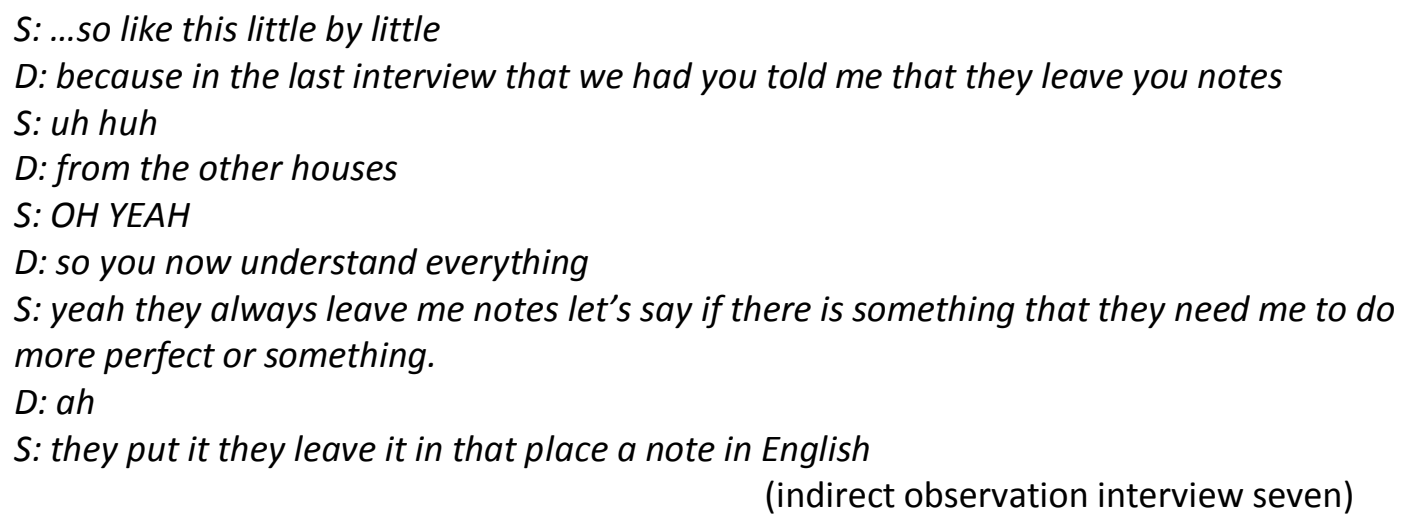

Samantha's story about her first day of work, reiterates the important role employers can play in the language learning of the participants in a work-related context. Like Silvana speaking with her boss at the restaurant, it highlights the type of 'teaching' (e.g. introducing new language; practicing pronunciation of new language; physically demonstrating what certain words mean) employers can provide adult migrant employees when there is a communication issue or a noticeable lack of language, as well as describing the kind of 'learning' these particular interactions often generate.

\subsubsection{Language-related activity in a 'volunteer' context}

Table 15: Language-related activities' contexts and types: Volunteer

\begin{tabular}{|c|c|c|c|}
\hline CONTEXT & \multicolumn{2}{|c|}{ SETTING } & ACTIVITY-TYPE DESCRIPTION \\
\hline & PEOPLE & PLACES & \\
\hline Volunteer work & $\begin{array}{l}\text {-volunteers } \\
\text {-colleagues }\end{array}$ & $\begin{array}{l}\text {-elderly care } \\
\text { centres } \\
\text {-community } \\
\text { centres } \\
\text {-local schools } \\
\text {-Salvation Army }\end{array}$ & $\begin{array}{l}\text { - } \quad \text { speaking with colleagues } \\
\text { - } \quad \text { laying with children } \\
\text { - listening to conversations } \\
\text { - } \text { amongst English-speakers } \\
\text { - } \quad \text { reflecting on interactions }\end{array}$ \\
\hline
\end{tabular}

The participants often communicated a sense of urgency in their search for opportunities to practice using English. This perceived need led many of them to volunteer. The common understanding being that in this particular context, they would be able to exchange their services and time for the chance to engage in language-related activity. While the work would be unpaid, the interactions in English would be valuable in helping develop necessary skills and confidence; skills, which they believed would eventually help them procure paid employment. However, this exchange was not always possible, and the precarious nature of volunteering for English became evident. 


\section{Samantha washes dishes: Learning to say no}

$D$.... the other day when we were talking you told me that sometimes with English you feel tied up

S: yes yes

D: do you think it's not that you don't look for but you don't put yourself in situations where you can practice more or use the language more? or it's not this there isn't enough time or something else?

S: well I don't know really I don't a while back I went to volunteer because I wanted to learn to talk

D: yeah

S: so I went to volunteer I wanted to learn to cook and I thought I WOULD speak so I went to a hospital that they have for elderly people around here... one because I really like being in the kitchen and cooking and I said I'm going to learn to cook food from New Zealand... and two because I said I will talk but I went for three months and didn't go again because I didn't talk

D: what do you mean?

S: I didn't cook and the only thing I did was wash dishes

(indirect observation interview one)

Samantha's issues with English were not from a lack of effort. As mentioned earlier, she took great pride in her work ethic and was always willing to sacrifice time and energy in order to meet her objectives. She was well aware that to navigate her daily life in a way that would satisfy her socioeconomic needs, English was going to play a major role. In fact, in talking with Samantha she consistently communicated a strong desire to advance her skills so that she could transition to a more independent and financially stable life. She felt that the exposure to English she received through her daily language classes was insufficient and as a result began searching for alternative opportunities to practice using English. The volunteers who helped Samantha settle into her life when she first arrived were aware of Samantha's desire for more English practice and in an effort to assist her, arranged a position for her as a volunteer at a local elderly home. Samantha described it as an ideal situation which would serve the dual purpose of helping her practice speaking and listening, while also helping her learn how to cook food from New Zealand. Samantha was quite interested in cooking, having worked in restaurants for a large part of her life. In fact, she strongly considered the possibility of entering a cookery program at a technical college. In this regard, she believed that this volunteer position was going to be of great benefit for her overall development. Unfortunately, the situation was not what Samantha hoped for and after three months of washing dishes and scant L2 interaction with the other workers, Samantha made the decision to stop volunteering: 
$S:$...there were other women who were the ones who cooked they spoke amongst themselves but they only used me to wash dishes

$D:$ and the other women were 'Kiwis'?

S: they were 'Kiwis' and so they spoke together they cooked but me they only used me to wash dishes I was just washing dishes

D: and they didn't speak with you

S: exactly and I said no to wash dishes I'll stay home

$D$ : but did they know that you wanted?

S: ...I talked with my volunteers and they were the ones who went to arrange it all that I wanted to speak and learn how to cook they knew well what my intentions were

D: ok

S: but no no they didn't do what I wanted

$D$ : And you stayed three months?

S: 3 months I stayed there I saw that I wasn't getting anything out of it (indirect observation interview one)

This seemingly negative situation, one that other participants also experienced, while not being particularly useful in a language learning capacity context, did provide Samantha with some insight about what it means to learn an $L 2$ as an adult in an immersion setting. Through this experience, Samantha gained a glimpse into how challenging it can be, not only for the adult migrants, but also for members of the host community, to turn L2 interaction into learning opportunities:

S: what I noticed when I was doing my volunteer work was that they don't have the time to help someone... they don't have the time to dedicate themselves to someone who is trying to learn to speak they don't have the time... they do their job and that is all $D: . .$. yeah if someone has these types of experiences of course you aren't going to return right?

S: ... it is difficult... it is difficult because one feels afraid and asks... and now what? and sometimes the woman who I work with asks me why don't you volunteer... taking care of kids...

D: Like child care?

S: yes and she said I could go to these places one to learn how to take care of children and have an eye on the future and also to speak and I thought... what will happen if I go again and it doesn't work and I quit early and what will they say about me?

(indirect observation interview one)

Samantha's account of her volunteering experience illustrates the extent to which many newly arrived adult migrants from non-English speaking backgrounds will go to in order to learn the L2. Unpaid volunteer work can be quite a time consuming effort, particularly for single-mothers who are taking care of children and organising the household, while at the same time trying to learn as much of the language as possible. Unfortunately however, as the story illustrates, volunteer opportunities, which may appear as ideal ways to interact with English speakers, do not always have the desired effect. For a host of reasons, the idealized L2-interaction promoted in these contexts does not always come to fruition. In fact, they can sometimes have an inverse effect, serving to demotivate learners and pushing them away from potentially valuable interactions. As the story shows, what can happen as a result from these negative experiences is that individuals will consequently 
avoid interaction in these contexts. It is worth noting that Samantha's story lists other friends and acquaintances who have had similar experiences which have also discouraged them from volunteering. In addition, not only did this experience lead her to avoiding further volunteer opportunities, it also left her feeling used and insecure about how people might regard her. Finally, the story highlights the different challenges associated with language-learning endeavours in a naturalistic context. Often great effort, patience and time is required to help people develop sought after language skills; and the reality is that not everyone will be able to put in the time or effort to adequately meet these challenges

\subsubsection{Language related activity in 'family' context}

Table 16: Language-related activities' contexts and types: Family

\begin{tabular}{|c|c|c|c|}
\hline \multirow[t]{2}{*}{ CONTEXT } & \multicolumn{2}{|c|}{ SETTING } & ACTIVITY-TYPE DESCRIPTION \\
\hline & PEOPLE & PLACES & \\
\hline Family & $\begin{array}{l}\text {-grandchildren } \\
\text {-children } \\
\text {-spouses } \\
\text {-in-laws }\end{array}$ & $\begin{array}{c}\text {-supermarkets } \\
\text {-schools } \\
\text {-homes } \\
\text {-church } \\
\text {-WINZ }\end{array}$ & $\begin{array}{l}\text { - } \quad \text { listening to children speaking } \\
\text { - } \quad \text { asking for feedback on } \\
\text { pronunciation/grammar } \\
\text { - } \quad \text { asking for meaning of words } \\
\text { and expressions } \\
\text { - } \quad \text { asking children to } \\
\text { translate/interpret } \\
\text { - practicing speaking English } \\
\text { with children } \\
\text { - preparing English-Spanish } \\
\text { shopping lists } \\
\text { watching English cartoons with } \\
\text { children } \\
\text { children correcting parents' } \\
\text { language use } \\
\text { reading in English with } \\
\text { children } \\
\text { listening to English radio with } \\
\text { children }\end{array}$ \\
\hline
\end{tabular}

One of the most common types of language-related activity for the participants was within the 'family' context. Sons and daughters, grandchildren, in-laws, and spouses all served as important language learning resources, providing a safe and trusting setting in which to practice and use English. Family as a language learning resource, beyond minimising the anxiety sometimes associated with naturalistic language use, also carried the added benefit of providing bilingual support. Access to bilingual L2 support was almost non-existent in the participants' accounts of their 
L2 interactions outside of the family context. Moreover, language-related activity carried out with family members was often conducted in the participants' home, adding an important element of comfort and security. While there were instances of the children teasing the parents for marked pronunciation or incorrect grammar, the majority of the accounts of family L2 interaction were perceived as positive and helpful. The story below presents Sandra Milena's unique strategy for accessing her son-in-law and grandson's authentic English use.

\title{
Sandra Milena eavesdrops on Douglas and Daniel: Learning from L1 parent-child interaction
}

\author{
... From all over from India there are a lot so I would say OH HOW CAN I don't understand \\ when they are speaking with me I DON'T UNDERSTAND ANYTHING
}

(indirect observation interview five)

Sandra Milena often presented her inability to understand people's spoken English as one of her biggest language-related obstacles. She struggled in class to understand classmates; struggled around town to understand neighbours; and struggled at home to understand her grandchildren and her son-in-law, Douglas. In recognition of this issue, both her classroom teacher and her home tutor suggested she take more advantage of her family as an L2 resource. Both teacher and tutor, aware of her tendency to use Spanish at home, recommended she start engaging more with her grandchildren and her son-in-law in English. The idea being, that practicing English in this context would help her become more accustomed to the sounds of naturally spoken English while also providing her the opportunity to output the language she is learning in class and during the home tutorial meetings. While she found it difficult to speak with her grandchildren directly in English, preferring to use Spanish, she did occasionally attempt to engage Douglas in L2 interaction. One of the ways she devised to take advantage of Douglas's English was by listening to his homework interactions with Daniel (her youngest grandson): 
SM: ...l am practicing here a lot with Douglas at dinnertime he is helping the boy with his homework so he is dictating the words to the boy over there and because he pronouncing hard for Daniel who is seven years so I am struggling to make sense of how how just a few words

D: so Douglas has a list of words for example

SM: of course well the kids have a journal well they have this journal with a whole bunch of words that they have to practice writing

$D: o k$

SM: so the dad has to dictate

$D$ : So the dad has the list

SM: uh huh

$D:$ he dictates the word

SM: uh huh... and he has to write it

$D$ : and then you are there listening

SM: of course... I am there listening and I try because he has to speak slowly to the child so the child can pick up the word to write it down I am paying very close attention to the words $D$ : that is great very interesting

(indirect observation interview five)

Sandra Milena, acutely aware of her difficulties in understanding Douglas when he speaks with her (... God I don't understand I don't understand Douglas at all), discovered an alternative way of accessing his English. Instead of speaking with him face-to-face, she can listen to his English when he is working with Daniel on his vocabulary/dictation homework. During these homework sessions, Sandra Milena recognised that Douglas needs to speak more clearly and more slowly, so that Daniel can understand each dictated word and write it down. While father and son would be working at the dinner table, Sandra Milena would station herself at the kitchen counter, seemingly occupying herself with other tasks, and listen intently to the different words, repeating them to herself and 'checking' to see if she understood them. This activity presents an example of the kind of novel methods the participants in this study adopted within the 'family' context to help them practice English. 
Table 17: Language-related activities' contexts and types: Social transaction

\begin{tabular}{|c|c|c|c|}
\hline \multirow[t]{2}{*}{ CONTEXT } & \multicolumn{2}{|c|}{ SETTING } & \multirow[t]{2}{*}{ ACTIVITY-TYPE DESCRIPTION } \\
\hline & PEOPLE & PLACES & \\
\hline $\begin{array}{c}\text { Social } \\
\text { transactions }\end{array}$ & $\begin{array}{c}\text {-neighbours } \\
\text {-friends }\end{array}$ & $\begin{array}{c}\text {-neighbourhood } \\
\text {-bus stops } \\
\text {-homes } \\
\text {-church } \\
\text { streets }\end{array}$ & $\begin{array}{l}\text { - visiting neighbours' homes } \\
\text { - } \quad \text { listening to neighbours' } \\
\text { 'authentic' speech } \\
\text { - having pronunciation } \\
\text { corrected } \\
\text { - being introduced to new } \\
\text { words and expressions } \\
\text { - comparing English with } \\
\text { - Spanish } \\
\text { - } \text { practicing new language } \\
\text { - lanking questions about } \\
\text { - deriving meaning of words and } \\
\text { expressions from examples }\end{array}$ \\
\hline
\end{tabular}

Another significant context across which the participants engage in language-related activity is the 'social transaction' context. It is within this setting that the participants interact with friends, neighbours, and other members of their local community. It is also within this context that the challenges of building and maintaining meaningful social relationships as adult language learners are acutely perceived. Fortunately, the majority of the participants in this study were able to cultivate important interpersonal relationships with members of their community and neighbourhood which had a positive effect on their language development and facilitated their integration into New Zealand society. Many of these friends and neighbours themselves were also from L2 backgrounds, making them more sensitive to their needs as language learners. Because they had been living in New Zealand considerably longer than the participants, their English ability was considerably more advanced, and consequently perceived as helpful.

In the story below, Paco describes a visit to a neighbour's home. The story serves both to highlight his preference for naturalistic language learning over classroom based learning, and to illustrate the type of context-specific language-learning which can emerge from this context. 


\section{Paco visits his neighbour: Learning through feedback}

... when I got there I was like well she was here for three years but she doesn't speak any English no but she can't even introduce herself THREE YEARS I am not going to learn anything here when I realised it wasn't this (attending class) but rather the interactions with other people look I arrive here to home and I go straight over to my neighbour's house here four houses down

(indirect observation interview one)

Of all the participants, Paco was the most critical of the language learning conducted in classrooms. As a youth in Colombia he had studied English for several years without learning how to use the language. Now as an adult in New Zealand, his experiences in language classes reinforced his belief in the ineffectiveness of classroom learning to properly prepare individuals for naturalistic L2 interaction. He feels that his time in New Zealand has forced him to confront what it means to be an L2 learner; specifically, he now appreciates the specific skills (e.g. listening to authentic English) essential to navigating life in an English speaking country. And through this confrontation, he has realised that the language instruction in classes is not properly preparing him for what he needs as an adult L2 user. In discussing his decision to withdraw from formal language learning, choosing instead to work, he observed how there were numerous adults similar to him (Colombians, ALL OF THEM) who had been attending classes for several years and were still struggling with basic language issues. He questioned the rationale for spending time learning English within the classroom context if one was not willing to practice what they were learning beyond the class:

$P:$... and when I was in class I was the new one at first but the next year other new students came and when I introduced myself there was this other woman who was there for THREE YEARS

D: yeah

$P$ : but when it was her turn to say my name is like that she had horrible pronunciation she only said her name and I am from Colombia and she sat down see? And she couldn't say anything more

$D$ : and why

P: why Diego that is what I am saying because because they don't practice

(indirect observation interview one)

In other words, for Paco, using English in real situations (i.e. outside of the classroom) with real people (i.e. not language learners) was the most effective way to develop his skills as an L2 user. He had observed firsthand how people who do not put effort into practicing English and resort to using Spanish the moment they leave the class fail to make any significant progress and had decided that this was not a useful way of learning a language for him. His way, rather, was by engaging in the L2 with L1 speakers. With this new awareness, Paco began to frequent different neighbours' homes. Sometimes to watch the rugby and other times to simply engage in conversation. He met his closest 
neighbour and friend through friends of his children and explained how they welcomed him to visit their home anytime:

$P:$... when I realised it wasn't this (attending class) but rather the interactions with other people look I arrive here to home and I go straight over to my neighbour's house here four houses down

D: you mean Ramon?

P: no Ramon is the uncle but the one I spend time with is called Chamy we met through the kids because they kids get together and all thatwhen I went to that house I KNEW that this is my way

(indirect observation interview one)

Paco's descriptions of the type of language-related activities he immersed himself in through these neighbourly visits depict significant examples of a variety of language learning opportunities. For example, when Paco produced certain statements or said certain words in English in ways that were not considered 'correct' or standard, his neighbour would provide feedback, allowing Paco to reflect on his own language use and consequently correct himself:

P:... and I would say No Silvana and me fighter and he would laugh but he understood me and then he said to me Paco, it is not fighter it's fightA

$D$ : ah he was correcting your pronunciation

$P$ : yeah because here they don't use the $R$ and the $R$ here is the $A$

D: yeah

P: like see you later is see you latA and so he started to show me like this and I was like OK and later he says and it's not fighter it's fightING

D: ok

P: 'fighting is the action'

D: ok

P: 'fighter is the player'so fighter is 'peleador' and fighting is 'peleando' and so I said 'Silvana and I are fightING and so he started to show me and so what I was learning I could put into practice with him you understand?

(indirect observation interview one)

Paco's story illustrates how the 'social transaction' context can provide an almost ideal space for the participants to practice using English; it offers a natural but safe environment for learning, as the interactions take place with people who are invested in their well-being and interested in their development. It also serves to highlight some of the different ways in which the participants were able to practice and learn from these interactions. For example, through this language-related contact, Paco was made explicitly aware of different aspects of his language use. We see for example in his story, both lexico-grammatical and pronunciation issues being brought up as marked, analysed, practiced and revised. Through this learning episode, Paco would ideally be able to transfer the feedback to other similar instances of language use. His story also highlights the value of finding people and places where one can learn new and useful language in an authentic setting. 
Finally, Paco's account is also noteworthy in its depiction of the perceived limitations of the classroom as a space for language practice. His critique of classes suggests possible reasons why many of the participants eventually withdrew, or at least expressed interest in withdrawing, from their formal language instruction.

\subsubsection{Language related activity in a 'transactional interactions' context}

Table 18: Language-related activities' contexts and types: Transactional interactions

\begin{tabular}{|c|c|c|c|}
\hline \multirow[t]{2}{*}{ CONTEXT } & \multicolumn{2}{|c|}{ SETTING } & ACTIVITY-TYPE DESCRIPTION \\
\hline & PEOPLE & PLACES & \\
\hline $\begin{array}{c}\text { Transactional } \\
\text { interactions }\end{array}$ & $\begin{array}{c}\text {-receptionists } \\
\text {-mechanics } \\
\text {-shop staff } \\
\text {-cashiers } \\
\text {-doctors } \\
\text {-tellers } \\
\text {-nurses }\end{array}$ & $\begin{array}{c}\text {-appliance stores } \\
\text {-grocery stores } \\
\text {-mechanics } \\
\text {-doctors } \\
\text {-banks } \\
\text {-shops } \\
\text {-WINZ }\end{array}$ & $\begin{array}{l}\text { - } \quad \text { reading \& translating notices } \\
\text { - } \quad \text { preparing language \& notes } \\
\text { - } \text { gesturing for interpreters } \\
\text { - } \quad \text { writing down information } \\
\text { - } \text { asking for repetition } \\
\text { - } \text { askingining language limitations } \\
\text { - } \quad \text { ignoring notifications } \\
\text { - } \text { avoiding interactions } \\
\text { - reflecting on interactions }\end{array}$ \\
\hline
\end{tabular}

Unlike the language-related activities that the participants take part in with family and friends, and to a large extent with their employers, the 'transactional interactions' context presents a much less familiar dimension. In these situations, the participants' language-related activities are with people and in places they rarely know well. Also, people in the public sphere, for a variety of reasons, will not always have the time or inclination to make affordances for language learners and as a result the language-related activity that takes place in these contexts is often perceived as more high stakes. Therefore, engaging in language related activity within this context, whether it is at the local supermarket, the mechanic, the doctor's office, or at WINZ, can often evoke strong feelings of anxiety and stress. Nevertheless, interaction in this context is extremely important to all the participants as it makes up a large part of their naturalistic interactions. When these interactions are managed successfully, such as Silvana's encounter at the bank, they can evoke strong positive feelings of accomplishment and relief. A (perceived) successful interaction across the transactional context seems to demonstrate to the learners that they are developing, both as language users and learners. In other words, reflection on these types of $L 2$ related activities can function as a type of indirect feedback on their language use, including the language learning strategies they employ to support this use. As a result, the participants have come up with various effective, and often 
inventive, strategies to navigate these situations, carrying important implications for their readiness to interact and consequent language-related activity.

\section{Constanza visits the bank: Learning through rehearsal}

... and so they understood me they understood me totally they understood me because I already knew what it was all about

(indirect observation interview one)

Constanza experienced significant issues using English in naturalistic settings. She preferred to use interpreters whenever possible, and if this was not possible, relied heavily on the assistance of her children to act as interpreters. She was also fairly dependent on translating. In class and out, Constanza made frequent use of electronic translators to help her manage her L2 interactions. It was clear to Constanza that she was not able to understand people when they spoke to her in a face-toface context but also that people could not understand her. The latter issue caused Constanza particular frustration, as she felt certain that she was using the right word. She was certain she was using the right words because she almost always prepared what she considered to be the necessary language, with the use of electronic translation (e.g. Google Translate), for her L2 interactions:

D: ... but the thing is to first be able to understand the word and then to be able to use it this is another level understanding C: yes I also have learned a bit doing like what I said sometimes I need to say something and so in this situation I translate and I learn that verse or that part that verse and I go and I speak and yup they understand me

(indirect observation interview one)

Many of Constanza's accounts of her daily or weekly L2 interaction, beyond the classroom, took place at a bank. Banks are not required to provide interpreters with their services and her children tended to refuse her request to accompany her to the bank. This meant that often, if there was any type of financial matter to be addressed (requiring contact with bank), she was forced to act on her own.

This example however describes an event where Constanza's interaction at the bank was in response to a friend's (a recently arrived Colombian neighbor with almost no knowledge of English) request for assistance. A friend of Constanza's had called the house to see if Mateo was home, hoping he would be able to accompany her to the bank as the ATM had not returned her card. However, Mateo was not at home and so Constanza offered her assistance. Initially, worried that there was no one to help, she considered what she herself could do to help:

... and now I'm like I don't know no one is here and I am home alone but wait I'm going to translate on the translator to see what to say haha 
As the above excerpt describes, Constanza's first instinct was to consider in Spanish what she will need to say at the bank to explain the situation and then use the translator to produce the corresponding English. Translating language to prepare for L2 communication is a strategy all of the participants adopted to help them guide similar interactions. Often the participants' explained the practice of writing down on paper the translation of what they wanted to say and took these notes to help them communicate in a certain potentially problematic situations. However, Constanza's approach was slightly different. Rather than write down the language, she memorised and rehearsed it:

...so I started translating in Spanish that 'she needs'... and the translator laid it out for me there in English and I copied it out on... a piece of paper and I LEARNED IT AND WELL I went there and I had learned that I went and I said it and THEY UNDERSTOOD ME ...I LEARNED IT and I knew when I got there I said well first please forgive me as I don't know English well I said that 'she needs'

(indirect observation interview one)

Constanza's illustrative extract depicts some of the most common strategies adopted by the participants to help manage interactions in this context, namely resorting to the use of electronic translators and interpreters. It also shows the ways in which she, recognising her difficultly in making herself understood, tried to address this limitation. Rather than choosing to simply rely on a paper copy of the translation she had used to prepare for this situation, she opted instead to rehearse and memorise the necessary language. In an effort to challenge herself and to practice using English, certain that she has the correct words, she approaches the bank teller and manages to speak in an intelligible manner what she has prepared and learned, explain that her friend had lost her ATM card and that she needs a replacement. Her happiness and feeling of accomplishment are also made evident in her account, as she repeats rather excitedly how she was able to make herself understood. This story also shows how a successful interaction can act as model for consequent interactions. In other words, Constanza, perceiving the usefulness of this rehearsal activity, would reproduce a similar activity the next time she encountered this type of situation.

L2 interactions in the transactional context offer some of the most significant challenges to adult L2 learners. As a result they also act as powerful influences on how learners perceive and approach this particular type of contact. They present opportunities for learning through preparation, through the interaction itself, and through reflection on the interaction. They can act as a type of gauge, indicating to L2 learners some of their particular strengths and weaknesses, as well as helping them recognise their potential (and limitations) as L2 users. Finally, the significance these L2 learning adults ascribed to transactional interactions meant that they needed to put into practice some of their most thoughtful and considered language learning-using strategies; strategies which they reproduced and revised as they perceived necessary to maximize the success of their languagerelated activity. 
Table 19: Language-related activities' contexts and types: Self-study

\begin{tabular}{|c|c|c|c|}
\hline \multirow[t]{2}{*}{ CONTEXT } & \multicolumn{2}{|c|}{ SETTING } & ACTIVITY-TYPE DESCRIPTION \\
\hline & PEOPLE & PLACES & \\
\hline Self-study & $\begin{array}{c}\text {-messenger 'friends' } \\
\text {-family members } \\
\text {-Skype 'friends' } \\
\text {-home tutor } \\
\text {-researcher }\end{array}$ & $\begin{array}{l}\text {-homes } \\
\text {-online }\end{array}$ & $\begin{array}{l}\text { - } \quad \text { reading \& listening to audio } \\
\text { - } \quad \text { Youtubing language learning } \\
\text { classes } \\
\text { - } \quad \text { translating texts \& questions } \\
\text { - } \quad \text { ansing graded readers } \\
\text { - } \text { questions } \\
\text { - } \text { sutching movies (without } \\
\text { - } \quad \text { chatting } \\
\text { - } \text { messenger } \\
\text { - } \text { sping (English-Spanish/ } \\
\text { asking researcher language } \\
\text { - } \text { questions } \\
\text { Skyping }\end{array}$ \\
\hline
\end{tabular}

Almost all of the participants engaged in self-study as a type of language-related activity. The types of activities and usefulness or effectiveness of many of these activities, however, varied considerably. Some participants, such as Sandra Milena, were intensely involved in self-study throughout the duration of the study, while others like Clara and Constanza, were more sporadic in their study outside the language classroom. In terms of activities there was also great variety in what the participants chose to do. Some read and listened to graded readers, translating passages and doing self-dictations; others turned to online and technological resources, such as English lessons on YouTube, chatting on messenger, or Skyping (a combination of spoken and written interaction). Below, the two stories serve as illustrations of the kind of strategies and resources the participants made use of as they worked on developing their language. The stories also outline the potential effects of these types of activities on the participants' 22 cognition. 


\section{Sandra Milena reads a graded reader: Learning with a tutor}

...I am very committed to my reading and listening reading and listening because this is what my tutor asks me to do

(indirect observation interview two)

As described earlier, Sandra Milena's home tutor was a significant influence on her development as an L2 learner. Of all the participants, she was the one who worked with a tutor the longest. Also, outside of class, the relationship with her tutor represented her most significant form of $L 2$ contact. In many ways the relationship between Sandra Milena and her tutor went beyond language tutor-student; as time passed the familiarity between the two grew deeper, and an important bond was established. Sandra Milena followed diligently the advice of her tutor, and was appreciative of the impact her assistance had on her development (this is noteworthy since Constanza and Samantha for example, who also met a home tutor, seemed to regard the time as less than useful, citing numerous issues with these instructional interactions).

The story below describes the type of weekly work Sandra Milena did with the guidance and support of her tutor. It describes a read-listen-repeat activity that she engaged in on an almost nightly basis. It shows a strong dependence again on translation and also highlights how specific issues with pronunciation (a major problem cited by all the participants who studied at home was that they could read or write but had trouble saying and sometimes hearing how words and sentences are spoken) were addressed:

SM: ...yes I am repeating every day she brings me the cassette with the book and she asks me to read let's say like 18 pages and so

D: you have to read 18 pages?

SM: yes in English yeah because I have to but they are small but for me it is a lot because I have to look up a lot of words that I don't know

$D$ : So your tutor brings you like every week?

SM: or every 15 days a book and we analyse it together in one week depending on the length of the book and so she asks me to read and she corrects me and corrects me

$D$ : and you read out loud?

$S M$ : yes and she corrects me my pronunciation above all the pronunciation

$D:$ and are there some words or sounds you have problems with?

MO: OH SUPER super let's say last week it was very difficult for me to say 'liberty' $D$ : liberty? $O k$

(indirect observation interview two)

The excerpt describes the kind of self-study tasks Sandra Milena performs in preparation for her meetings. She reads and listens to passages from graded readers, looking up unknown words and translating them into Spanish. She also practices speaking these unfamiliar words, focusing on pronunciation. It is an activity she finds useful and believes that it has had a great deal of benefit on her learning, stating explicitly that she can understand more English now than before: 
...yes that is what I said to Diana I feel good I'm happy because I am understand more than last year last year there were a lot of things a lot of themes I couldn't understand

(indirect observation interview two)

Sandra Milena performs a similar type of text-translation activity (described earlier) to help her prepare for her church gatherings. Meeting with a tutor each week and having a clear idea of what she needs to do in preparation for these meetings, reflects a type of structured self-study approach to her L2 learning. For example, each day she allots a certain amount of time for her reading and listening activities (including translating and repeating), she has scheduled times to meet her tutor, to practice what she has been studying, and also sets aside time to review the various topics and themes discussed during the tutorial meetings. The structure ensures that Sandra Milena feels secure in the effort she is putting in each week to better her skills. However, it also highlights the little exploration she attempts in personalising her learning. She seems to have settled on this these learning activities, feeling safe within the routine and confident that the instruction she is getting from her tutor is working in her best interest:

$D:$...and you are doing it by yourself right?

SM: yes alone because here I don't have who to Diana doesn't have time to help and my tutor is the one who helps when she comes Monday for two hours or Wednesdays she offers me a couple of hours which for me is very interesting

D: you like it?

$S M$ : yes of course very interesting because she corrects me and lots of times she helps me do the Thursday homework

D: and what do you think when you are when you are reading and repeating and listening? Is it doing good for you? Do you like it?

$S M$ : Yes yes yes... because the accent of a lot words starts to stick

(indirect observation interview two)

As an example of the type of L2-related activity within the 'self-study' context that learners engage in, Sandra Milena's account shows how having a clear, well-defined learning plan can evoke positive evaluation of one's effort and progress. It also highlights how having level-appropriate resources which learners find, to some extent, interesting can contribute to the perception of these materials and the accompanying activity as useful, or effective. Additionally, Sandra Milena's description of her weekly self-study raises important issues regarding the effectiveness and relevance of this type of language learning in adequately addressing learners' language needs. Sandra Milena struggles to interact in face-to-face contact in English. She feels that people speak too quickly with her and she cannot understand their pronunciation. Also, when she speaks she has trouble not only recalling the correct language, but also speaking it in an intelligible manner. However, the self-study activities, while providing her with some important language and opportunities to listen to spoken English, do not seem to go far enough in providing her with necessary practice which can help her focus on and improve these particular weaknesses. With that said, in terms of how this learning affects her cognition as a language learner, she seems to value her 
approach to learning and as a result continues to invest in it, devoting significant time and attention to her L2 study. Her weekly self-study may not be the most effective use of her time, but it does ensure that she remains committed and interested in learning.

A noteworthy observation in the participants' $L 2$ self-study was their use of technology. Learner autonomy research, work in computer assisted language learning, and other similar areas in language education, have illustrated the numerous ways technology can support and in some cases, enhance, language learning opportunities (Benson, 2001; Little, 2007; Mozzon-McPherson, 2007). It is inexpensive, provides flexibility and convenience, and offers numerous other benefits, such as bilingual support. The use of technology can also be used to study, practice or use the L2. Below, Constanza's story illuminates one of the noteworthy ways participants' adopted technology to their self-study.

\section{Constanza chats online: Learning with technology}

D: ...I wanted to ask you about you are sometimes talking on the chat (chatting on Facebook's Messenger-an online program incorporated into Facebook where people exchange real-time messages in text form) right? you are using chat?

C: yeah I speak with people English people but with these people I only learn to write (indirect observation interview two)

In terms of L2 contact, Constanza was the most isolated of the participants. While she was able to establish social relationships with members of the Colombian community and other Spanish speakers, her interactions in English were severely limited. She did attend English classes regularly. In fact, she had tried various classes at various schools but her relationships with her teachers and classes were never quite satisfactory. She did not interact with classmates outside of class, she did not communicate with her neighbours, and she did not work or volunteer either. She had a home tutor visit her on a weekly basis but explained that she could not understand her tutor and essentially communicated through translation. Eventually, the tutor stopped visiting Constanza. Even in church, a context where many of the other participants were able to comfortably practice using their L2, Constanza struggled significantly to communicate. Her L2 isolation and her failure to make meaningful contact with English speakers is also noteworthy because of all the participants she carried the strongest interest in foreign/second language learning. Recognising the urgency of her need to practice using English, Constanza turned to online resources. She had been using YouTube for some time however, she was aware that this only allowed for receptive input of language and she wanted to practice using more English. Eventually, through her Facebook, she found 'friends' who she would chat with in English:

...yeah sometimes when I have time... and on Facebook... I have like four friends that I keep in touch with IN ENGLISH and when I am connected they write me in English and then I check out what they say... and sometimes I translate 
Constanza appreciated this opportunity to communicate in English, and felt that it helped her learn useful language. Chatting online also meant that she could translate any language she was unsure of. Moreover, it seemed to reduce the anxiety she experienced when having to use English. Communicating in an L2 in an online context affords individuals certain control over their interactions which they do not ordinarily have in a face-to-face setting. Through online L2 communication, there is more time to respond if needed, and also there is a virtual 'space', which can make the interaction feel significantly less threatening. Constanza explained how most of the learning she did through chatting involved vocabulary which she considered valuable:

C: ... yeah there I translate check what it says I write it down but I have learned various words there like the word 'dinky'

$D$ : daycare?

C: 'dinking' that thing to think

D: THINKING

C: ahhh thinking so I learned that word they use that word to mean believe right?

$D$ : yeah it's the same in Spanish when you say 'I believe...' it's like saying 'I think...'

(indirect observation interview two)

However, after time, she began to note some limitations for her development inherent in this form of self-study. She realised that while texting could help her learn new and useful language in a relatively secure manner, she was not able to work on her most noted weaknesses: understanding and pronouncing English:

...yeah I learned these while chatting so when I go to class the teacher talks like this she writes them down and so I already know that I word I already know this word means that and this word is this so then in class I pay close attention to how the teacher pronounces the word because I only learned how to write it but I don't know how to pronounce it (indirect observation interview two)

Constanza's incorporation of technology into her self-study, illustrates how over time and through reflection (a type of self-analysis) this context can help learners not only make significant language gains, but also develop their skills as self-directed learners. Through self-directed language study, Constanza gained deeper awareness of her needs as a learner. She knew, through her various interactions (in and out of class) that she struggled to make sense of what people were saying. In addition, she knew that she struggled to make herself understood to others. So while, communicating through Facebook's messenger helped her develop her vocabulary and consequently gain confidence in her knowledge and understanding of English, she also understood that it was insufficient in helping her address her more immediate issues. Eventually, Constanza used Messenger less and less, explaining how it was not particularly useful for what she wanted. In response to this realisation, she began to search for other technological means to help her practice speaking and listening to English. 
As the two stories above illustrated, the participants will adopt approaches to their $\mathrm{L} 2$ selfstudy which reflect their own perceived needs and interests as language learners. Sandra Milena preferred a well-structured, study-heavy approach, with little actual language use. Her learning revolved primarily around reading, listening, translating, and repeating. She seemed to enjoy the self-study and devoted a considerable amount of time to it each day. In addition, the time and effort she spent on her learning, along with her increased ease in which she interacts with her tutor, led her to the recognition that she is making progress. Constanza's self-study was much more sporadic. The challenge of being a single mother of three seemed to present certain restrictions on what she could do and when. Her use of Facebook's Messenger to interact with English speakers nevertheless does introduce an interesting example of how participants can learn through authentic language use. It also shows a developing awareness of her language strengths and weaknesses, pointing out that although she is learning new useful language through texting, she continues to struggle with the oral production of these expressions. This awareness pushes Constanza to seek new and more appropriate (for her needs and interests) methods for L2 self-study (further discussion of this search and the processes it involves are discussed in the case study presented in Chapter 6).

The self-study dimension is interesting because, the findings related to RQ 1, the participants have had very little experience with formal education, not to mention the dearth of experience with foreign/second language education. This might suggest that their knowledge and dexterity in planning and implementing helpful language learning activities outside of a classroom would be quite limited. Additionally, their lack of familiarity with homework-like or at home study-like activities might mean that these individuals would struggle in planning and implementing activities in this type of personalised language learning context. However, the lack of formal experience did not appear to be too much of a limitation, as again most of the participants found innovative and personally interesting ways to manage their $L 2$ self-study, admitting at times that the learning they did on their own at home was sometimes more valuable than the learning they had done, or were doing, in the formal language classroom. This is a belief reflected in their experiences in naturalistic settings.

\subsection{Summary of findings}

The significant findings for this research project were presented in two parts (chapters 4 \& 5). The first half presented a description of the participants' prior language learning experiences, including any history of formal language learning and any incidental exposure to foreign languages while living in Ecuador and Colombia. This chapter illustrated how different experiences can influence and impact the construction of individuals' language learning cognition. The limited language learning endeavours across the six participants suggests that before arriving in New Zealand, their current L2 immersion context, their perceptions regarding learning and using an L2 were not fully formed or well-defined. In other words, because of their limited experience using and 
learning a foreign language before coming to New Zealand, none of the six participants carried clear ideas about what it means to be an adult language learner, how to manage language learning, or even how this process would affect them throughout their day-to-day lives.

The second half of the findings (chapter 5) shifted the focus to look more closely at the participants in their current L2 immersion context to evaluate how they engage in language-related activities outside the formal language learning classroom. Through in depth analysis of my participants' narratives (as reflections of their actual experiences as adult language learners), I have essentially provided what Menard-Warwick (2009) deems 'insights' into the ways in which these different learners position themselves within their families, communities, and society, and have evaluated how this positioning can 'facilitate or impede L2 learning over time' (pg. 50). Specifically, I have used a series of illustrative examples to highlight the different strategies these adult L2 learners develop and use as they engage in language-related activity across various contexts. The stories painted rich portraits of the participants' language learning beyond the classroom. These portraits showed the participants identifying specific language needs and wants, as well and particular interests as learners. There were also examples of the participants diagnosing and self-evaluating various $\mathrm{L} 2$ related problems rooted in their day-to-day interaction. It was these personal interpretations, of perceived needs and interests, as well as the evaluations of individual strengths and weaknesses as English users, which carry underlying cognition; cognition which governed a large part of their activity. They participants prepared according to these constructs to help manage their different perceived issues. In fact, given their lack of prior quality language learning education and current lack of language support, it is noteworthy what they could accomplish. For example, they were able to tailor certain learning activities specifically to their individual learning needs. Moreover, they were capable of transferring successful strategies and reflecting and revising less effective ones; this activity (for good or for worse) is testament as much to the development of certain beliefs about language learning as it is about self-beliefs about themselves as language learners. Thus, the storied experiences of the learners were particularly useful in illustrating how approaches to and reflections of these interactions reflected underlying L2-related cognition, and also to a large extent facilated the construction of this cognition. In the following section, I present a detailed discussion of the findings framed around the fifth and final research question:

RQ 5: How can this language learning behaviour be reflected in a model of language learner cognition?

I will look at how a single participant's language-related activity interplays with her developing language learner cognition across different spatial and temporal dimensions. Moreover, I will explore how this complex process can be viewed as a type of catalyst for development, and in some cases represent actual development in action. I use Constanza as a focal participant (i.e. case 
study) to allow for a more in-depth investigation throughout the discussion. When looking at complex processes, such as the interplay between thinking and behaving in adult migrants over a prolonged period of time, it can be most effective to narrow the range and deepen the scope. In other words, a case study approach allows me to more intensively and minutely look at how these adults' cognition is affecting and being affected by their language-related activity. As Mercer (2011) argues, case studies 'can generate rich, detailed data particularly well-suited to providing insights into complex psychological experiences, such as self-concept development, as well as revealing possible individual variation' (pg. 173). However, it is important to reiterate that the focus of my argument is less on the uniqueness of each individual's emerging and developing cognition, and more on the ways in which cognition is constructed, and how it operates as a consequence of this construction. In other words, I am not aiming to categorise or describe individual cognition-types and the effects of this cognition on particular approaches to $L 2$ use, instead I am looking to highlight the multifaceted and dynamic nature of the process of cognition in action; I am focusing on how the complexity of a multitude of factors will impact on a system as it evolves over time. 


\section{Chapter 6 Discussion}

\subsection{Introduction}

\section{Setting the scene I: Contextual commonalities}

I begin this chapter with a description of the macro-level context through which to situate Constanza's case study. Much of this contextual information may already be known, however because of the primacy of socio-cultural context not only in impacting behaviour, but also in helping make sense of described events, it is worth revisiting. While Constanza's varying interactions discussed throughout the case study will be presented as idiosyncratic events, unique to her, as a particular participant, best understood through her own eyes (i.e. micro-level context), much of the value derived from this discussion comes from the ability to transfer the observations of cognition in action to similar contexts and situations. The macro-level context is essentially what connects all of the participants, and it is within this commonality that the variation of activity and experience can most significantly be appreciated as a consequence of a complex, developmental system at work.

In this study, all of the participants share in common an entry experience, arriving as adult L1 Colombian-Spanish speakers, with minimal exposure to additional language learning (formal or informal), to an unfamiliar Anglophone context. Moreover, they are all at least 15 years removed from any type of formal education and the experience of studying and learning a new language in an immersion setting will be completely unfamiliar to them. They arrived in New Zealand with limited understanding not only of what learning an additional language entails but also equally important, their cognition in regards to themselves as language-learners (e.g. L2-self related beliefs) had limited opportunity for meaningful development. Their lack of significant prior experience interacting in an L2 also meant that they did not have clear ideas about how they would perform as L2 users. However, each of the participants had been living in New Zealand between 13 and 26 months at the time of the start of the research. Over this time they would have had various opportunities to experience language learning and language use both in formal and informal contexts. These experiences will have affected the construction of their developing language learner cognition. Thus, it is within this larger common context - of a recently-arrived, low-beginner, Colombian adult migrant, learning English as an additional language in the Greater Wellington area in New Zealand which this discussion is situated.

\section{Setting the scene II: Positioning the participant as a case study}

A major motivation of this study is the need to explore in detail how learner cognition, as a socio-psychological construct, drives and affects the ways in which individuals manage their language learning. Essentially, this research focuses on a dynamic, multifaceted process at work across a range of language-related contexts through time. The challenge therefore lies in finding a 
way to look at as many of the system's factors as possible to produce a nuanced picture of them in action. Thus, as I have already argued, to meet this challenge, and to make this discussion manageable and meaningful, certain parameters need to be established. One such parameter is to narrow the focus of the discussion to a single participant. In using one participant as an exemplar, a more detailed evaluation of the substantial amount of collected data can be undertaken. It is important to note that the crux of this discussion is less on uncovering and describing a range of different learners' cognition and more on investigating the processes behind the creation and development of this cognition and what impact this construct has on language-related activity. In other words, the discussion aims to highlight more a process than a product. With that said, pertinent information regarding the participant (including a justification for her selection) is presented here.

Firstly, because I spent the most amount of time working with Constanza, her case offers the richest pool of data to draw from. She was the most committed and engaged of the participants, frequently requesting more meetings. She was also loquacious, readily elaborating on her accounts of her L2-related experiences. Also, my relationship with Constanza was the most involved, using our meetings for language support, interpreting and translation assistance, as well as companionship. Constanza was the most isolated of the participants. She had few friends and although she spent some time with members of the Colombian community, she was not particularly close with the group or anyone in particular. As a consequence, I was able observe her with more frequency in L2 related activity, including actual L2 use (e.g. she often asked me to check her speaking). I also selected Constanza because her issues with $L 2$ development were quite marked. In comparison with the other five participants, she had the lowest English proficiency. Alongside this issue, her professed affinity for and interest in language learning was also a significant feature.

With these macro (general) and micro (idiosyncratic) contextual considerations in mind, I feel that a picture of the interplay between cognition and L2 activity can be produced through Constanza's case.

\subsection{The storied experiences of an adult language learner in New Zealand: A case study of language learner cognition in action}

Below, I use Constanza's tales of $L 2$ use to help bring a picture of language learner cognition to life. Through in-depth evaluation of her accounts of naturalistic L2 interaction, I present glimpses into the different ways in which socially constructed mental constructs determine not only what language learners do, but also how they think and feel. Moreover, I explore how this process may be realised in a model of language learner cognition in action. 


\subsection{Constructing cognition: A tale of tension, reflection, and discovery}

\section{Constanza's childhood dreams: Observations of early BAK \& affective}

factors

I begin by outlining some of Constanza's pre-existing (prior to New Zealand) beliefs about and feelings toward second language learning. These particular constructs, as key components of her cognition as a language learner, help establish a type of departure point from which to commence the discussion.

Firstly, in evaluating Constanza's comments regarding foreign languages prior to arriving in New Zealand (see Chapter 4, RQ: 1), we see her carrying a clearly positive attitude toward languages in general and English specifically. Even though she had never studied English, nor did she have any family or friends around her who could use English, her childhood dream has always been to study languages at a university in hope of someday procuring a career connected with languages. However, she lamented never having the chance, or facility, to pursue this dream. Constanza clarifies in our discussions that it was more a lack of opportunity and finances than a lack of interest which kept her from pursuing her interest in languages. She proclaims how in fact she loved the idea of knowing a foreign language and if she had the money (or different parents), she would have studied languages (indirect observation interview six). Her professed desire to acquire English, which runs the duration of the project, can therefore be seen extending beyond its utility in helping her navigate day-to-day interactions, toward a long-standing enthusiasm for languages, which she developed in Colombia. She explains that what most attracted her to the idea of moving to New Zealand, a country she knew nothing about, other than that it was very far away, in the middle of the ocean, and very small, was the fact that it was a country where English was the dominant language. In other words, Constanza felt happy at the prospect of moving to New Zealand because people spoke English and she had always liked English (initial interview). While it is not perfectly clear in the data how Constanza developed these childhood dreams or ambition to learn an additional language, it is likely that positive exposure to foreign languages in Colombia (e.g. working as an au pair for a Dutch family; working in various foreign owned and operated restaurants; observing international tourists) however scant, resulted in the construction of a powerful, affective attraction to foreign languages. For Constanza, foreign language ability represents the potential realisation of her desire to live in a different country (indirect observation interview number three); she perceives the ability to use an additional language as the means to an idealised life, outside of Colombia and Ecuador.

In close relation to this idea, it is also probable that Constanza believed that foreign language ability could help her attain a better standard of living. By 'better', she remarks how life outside of Ecuador would be better organized, cleaner, safer, and allow for a higher quality of education and study. For Constanza, as for the rest of the participants, living in a 'developed', English-speaking country like New Zealand held the promise of an improved quality of life. 
Numerous studies (Crystal, 2012; Kachru \& Nelson, 2006; Nunan, 2003; Pan \& Block, 2011;

Pennycook, 2000) have shown that English, as the language of globalization and internationalization, is commonly associated with socio-economic advantage and progress, often serving as a primary motivator for people striving to learn the language. We can see how Constanza, living a rather challenging, nomadic life in Colombia as a young girl on her own, struggling with fundamental necessities such as a basic education, constructed an ideal-self scenario as a proficient foreign language user, living a pleasant, international life outside of Latin America. In other words, she developed a belief that English ability would not only help her improve her life, but it would also allow her to live the kind of life she dreamed of. The ideal L2-self, which Constanza constructed, and holds on to tenaciously, has been shown to be an influential factor affecting language learners' motivation and approaches to language-related activity (Dörnyei, 2005; Dörnyei \& Ushioda, 2009; Magid \& Chan, 2012). In fact, Constanza communicates her strong desire to dedicate herself to language study, recognising that now, here in New Zealand, she finally has the opportunity to learn English (Indirect observation interview one). However, she also remarks that due to a lack of time, she has not been able to fully commit to her studies. This conflict, between the realisation of a cherished childhood dream and her inability to find time to study English introduces elements of Constanza's ' $L 2$ investment'. The notion of investment in a language learning context is important because it helps, according to (Peirce, 1995), make sense of the inevitable contradictions between an individual's ambition or intention to acquire the $L 2$ and their 'sometimes ambivalent desire to learn and practice it' (pg. 17); a contradiction, or tension, which plays a significant role in the ongoing development of Constanza's cognition.

In sum, at the commencement of the research, Constanza's cognition toward foreign languages is quite affirmative, carrying a well-established, positive emotive dimension; we see evidence of beliefs and feelings which recognize L2 ability both as a valuable asset (potential for improved quality of life) and more importantly, as an admirable and desired skill (personal interest) which she very much wants to acquire. We also observe elements of Constanza's L2 investment, where the suggestion of a tension exists between her professed desire to learn English and the issue of finding the necessary time. This section introduced significant, pre-existing BAK and affective factors which play an important role, as subsets of cognition, in Constanza's L2 activity. Building from this, the next section explores Constanza's development of self-related, L2 constructs (also subsets of cognition). It examines how perceptions of herself as an L2 learner, rooted in her experiences trying to communicate in English, interplay with pre-existing BAK and affective factors, and impact on her overall cognition. 


\section{Face-to-face with the L2: Emerging L2 self-concept through language- related activity}

It is rather significant that in spite of Constanza's pre-existing, positive evaluation of (i.e. attitude) and beliefs toward foreign languages, coupled with her declared desire to learn English, she has struggled considerably for the past two years to make progress with the L2. Throughout the duration of the research she is critical of her lack of development, providing numerous accounts of unsuccessful interactions and an inability to communicate in the most basic of interactions. She believes that there is a key to language learning which she has not been able to discover and suggests that it is this inability to find the 'right' way to learn a language, rather than her lack of L2 study, support, practice, and use, which is limiting her improvement (indirect observation three). On an almost daily basis, Constanza is confronted with her lack of L2 development. Whether at the supermarket, at WINZ, at the bank, at her children's schools, at the doctor's office, on the telephone, in shops around town, or even in English classes - essentially throughout the majority of her language-related interactions - she comes face-to-face with the reality that communicating in English has become for her an overwhelming endeavour. Moreover, through these day-to-day struggles to communicate in English, she derives insights into perceived personal deficiencies as an English user which serve as illustrations of her developing L2 self-related constructs. In other words, our meetings, which serve as a 'place and time' for Constanza to talk about her various L2 endeavours, function concurrently as explorations into possible reasons and rationales for her experienced difficulties. In reflecting on her daily English use, Constanza is at the same time trying to make sense of what she might be doing wrong as an L2 learner, or what may be inherently wrong with her as an L2 user. The discussions generated through the interviews therefore form an integral component of the context which impacts her developing cognition as a language learner. That qualitative interviews can operate as sites for reflection has been well documented in social science research (Connelly \& Clandinin, 1990; Polkinghorne, 2005; Seidman, 2013). Furthermore, reflection, as a positive consequence of qualitative interviewing, is regarded by scholars involved in the psychology of foreign language learning, as key in helping develop learners' self-related perceptions and evaluations in an L2 context. Self-related constructs, such as self-concept (Mercer, 2011a) and self-efficacy (Mills, Pajares, \& Herron, 2007; Pajares \& Miller, 1994) in second language research, are essential sub-sections of a language learner's cognition, interplaying with other L2-related beliefs and emotions. After all, L2 learners, like Constanza, are guided as much by how they 'evaluate and perceive themselves as learners' (Mercer's self-concept), and their 'assessment of competence to perform a specific task' (Pajares and Millers' self-efficacy), than by what they think about second language learning generally (beliefs about SLA) and specifically (beliefs about speaking English).

In her reflective accounts of language-related activity, Constanza inevitably analyses her interactions, often simply as a 'successful' or 'unsuccessful' language-related activity. It is primarily 
through these subjective assessments of her communicative performance that her beliefs, assumptions, and knowledge in relation to herself as an L2 learner take shape. Thus, within the interview context where Constanza has the opportunity to reflect on her various naturalistic L2 activity, not only does she manifest elements of her cognition but we can also observe the emergence of cognition as it relates to her understanding of herself as an English learner in an immersion setting. In our discussion regarding her expectations of learning English, Constanza refers to her initial orientation at Mangere, where she was told through the testimonies of 'settled' refugees that if she studied hard and committed herself to learning English, in six months she would be able to speak English well, and in one year, find a good job. However, believing that L2 learning is more difficult for her, she adjusted this time frame, allowing herself instead one to three years to acquire the language. Unfortunately, she acknowledges that this has been far from the case, declaring that in the two years she has been here she has learned nothing (indirect interview six). Instead, because of how difficult it is to learn English for her, she has become mute, dependent on interpreters for the majority of her out-of-home interaction, and isolated. Constanza believed that by now, nearly three years into her life in New Zealand, she would be capable of communicating considerably more than she is. In her mind, English was a bridge to a better world and life; to an ideal life, in fact, but instead in her current context, English is inhibiting her ability to settle into her new life, as well as constraining her personal development. Her problems with English have curbed her capacity to form meaningful relationships with others and her ability to productively participate in New Zealand society (i.e. find employment; engage with children's education; assert her identity), keeping her on the periphery.

It is possible that if she had a clearer understanding about learning a second language, including more realistic expectations about what she herself may be able to accomplish as a language learner in a limited amount of time, she may not have developed such a negative 'selfconcept' of herself as an L2 learner in this immersion setting. Mercer (2011a) defines language learner self-concept (within the foreign language learning context) as 'an individual's selfdescriptions of competence and evaluative feelings about themselves' as language learners (pg. 14). As a component of cognition, it relates directly to an individual's beliefs, feelings, and personal knowledge, about their general abilities as a second language learner. In addition, Mercer argues that self-concept also carries a stronger emotive dimension, foregrounding the inseparability of emotion and cognition. Pelligrino's (2005) research into self-concept, also in the FL context, showed the powerful impact of this construct on the different ways language learners organize and manage their language-related activity, including their willingness to communicate in another language. She argues that when using a second or additional language, individuals risk being misunderstood linguistically, as well as in communicating who they are and how they see themselves, to others. In Constanza's case, this problem is magnified, as her inability to form significant connections with 
members of the English-speaking community conflicts directly with her willingness to learn English and her desire to become a capable English user.

The inherent reflection on and self-evaluation of language-related activities promoted through the context of the research interviews are painting personal portraits of the different ways experience shapes the construction and evolution of BAK and emotion. In turn, these constructs (BAK and affective factors) are feeding in to the learner's larger cognition. Thus, through her mediated accounts of L2 interaction, Constanza is communicating the various adverse and unpleasant experiences which both justify (almost simultaneously) and affect her reluctance to engage in spoken English interaction. An example of how Constanza's negative self-concept impacts her capacity to interact was described earlier (chapter 4) when she talked about the fear she felt attending a new church. In this account of her language-related activity, she explains how a person she did not know tried simply to say hello to her, but she was too afraid to even respond, opting instead to lower her head and ignore the opportunity to interact. She describes (quite often) her fear of being laughed at and misunderstood; she is afraid of being exposed as a person who cannot speak English, and therefore feels, as in the church, that she does not belong in places where English is the expected medium for interaction (indirect observation five). Because she sees herself as somehow lacking the ability to learn and use English, her sense of anxiety and trepidation when speaking with people is heightened. There is little doubt that naturalistic interaction with unfamiliar people, as an adult in an L2 setting, can be a sensitive endeavour. The interpersonal, interactive nature of L2 use can make a person feel exposed and vulnerable, particularly when basic language skills are limited. As Mercer's (2011) research shows, using an L2 is 'a highly visible process, at least in terms of oral communication and can consequently be a relatively face-threatening undertaking that may require a particularly strong and stable sense of self' (pg. 23). If an L2 learner's sense of self is not particularly strong or stable, but instead fragile and unstable, it can lead to adverse conditions for language development. The self-concept that Constanza constructed, rooted in her many 'unsuccessful', often embarrassing, stressful, or confrontational language-related interactions, thus impacts her agency (i.e. the capacity to communicate) as a learner. In other words, a negative selfevaluation of herself as an English user is inhibiting her ability to interact with others. This ability or capacity to interact across a range of $L 2$ settings - this ' $L 2$ agency' - becomes, to a large extent, the manifestation of the interplay between her L2 cognition and her language-related behaviour. Unfortunately, in Constanza's case, this interplay results in a type of 'incapacity' to engage in meaningful L2 contact including the ability to communicate practical (e.g. what she wants and needs), interpersonal (e.g. who she is and wants to be), and psychological (e.g. what she thinks and feels) messages. In turn, this tension as a kind of personal dialectic, between her inability to successfully engage in the $L 2$ and her strong desire to acquire the $L 2$, pushes her to examine possible causes. And through this self-examination, facilitated by the research interviews, we recognise the 
emergence and development of not only a negative $L 2$ self-concept, but more detailed self beliefs, which evaluate specific language skills.

\section{From reflection to awareness: The development and role of self-efficacy on language-related activity}

As mentioned, a consequence of our many meetings together is the construction of a type of on-going, reflective dialogue, which beyond describing L2 use, seeks to evaluate possible reasons for Constanza's reported struggles and lack of language development. Her search for understanding becomes a kind of trial-and-error exchange, where she considers a host of possible issues, ranging from the inherent (e.g. poor memory; age) to the contextual (e.g. lack of time; lack of prior language learning experience). These varied justifications become illustrations of her L2-related cognition, as she attempts to make sense of (i.e. add meaning to) what she is experiencing when using English. Woods' (1991) study on language teacher cognition, also adopting in-depth interviews, showed how the teacher-participants, in seeking to understand their practice, produced 'explicit statements of belief and implicit presuppositions and assumptions' which regulated their 'actual behaviour' (pg. 27). Furthermore, the more opportunity for guided reflection participants are afforded, the more detailed their self-perceptions can become. In this regard, we see how Constanza, beyond being able to articulate a holistic assessment of her competence as a language learner (i.e. self-concept), is over time also capable of communicating a nuanced evaluation of her language-specific abilities. In other words, through reflection on her L2-related activity, she reveals feelings, self-beliefs and selfknowledge, which pertain directly to language-skill-specific issues. Constanza clearly believes that her biggest challenge regarding her lack of progress with English stems from an inability to communicate effectively in face-to-face interaction. She asserts that the main problem she has as an English learner is her inability to make sense of people's spoken speech and to make her own speech understandable to others:

C: ...people don't understand me and I don't understand them because there are lots of times when they write I understand more or sometimes I know it

$D$ : yeah because you were just showing me those [papers] and you understand the words

C: what it means yes but what good is it for me to know what it means if I don't know how to say it I don't know how to pronounce it or sometimes I KNOW IT but they are speaking to me and I have no idea what they are saying and I am stuck not knowing

(indirect observation interview one)

This excerpt introduces Constanza's perceived issues with L2 intelligibility. 'Intelligibility', as defined by Rajadurai (2007) as a language-specific concept, in its most general sense deals with 'the extent to which a speaker's message is understood by a listener' (pg. 88). In Constanza's case, it functions both in the reception and production of language, meaning that she sees herself struggling 
not only to understand speakers' talk but also in making her own speech understood. These everyday struggles with English intelligibility result in what she believes are breakdowns in communication. Constanza describes being laughed at in stores and in class, yelled at in hospitals and at WINZ, hung up on by various receptionists, and not being understood by her interlocutors, even when using what she asserts is the correct language. We can observe from these breakdowns in L2-related activity, feelings of anxiety, embarrassment, and powerlessness, emerging and interplaying with her developing interpretations of her language ability. In evaluating her incapacity to interact in spoken English, Constanza is constructing and conveying self-efficacy beliefs. Bandura (2006) refers to 'the efficacy belief system' as a 'set of self-beliefs linked to distinct realms of functioning' (pg. 307). Pajares and Miller (1994), working more closely in education, define selfefficacy beliefs as a 'judgement of one's capabilities to execute specific behaviours in specific situations' (pg. 194). Thus, we observe Constanza carrying low self-efficacy beliefs in regards to intelligibility; more specifically, she perceives herself to be a poor listener, i.e. someone who needs things spoken slowly and repeated often, and a poor speaker, i.e. someone who is missing knowing how to say the words, how they are pronounced (indirect observation interview four /indirect observation interview seven). Self-efficacy beliefs, as mental constructs, are essentially a personal understanding of one's ability to do something in a specific context, and can act as powerful influences on language learners' behaviour. It is important to note however, that while research in this domain (Mills, Pajares, Herron, 2007) argues that these types of beliefs do not depend on one's actual abilities, but rather 'on what one believes might be accomplished with one's personal skill set' (pg. 418), what 'one believes might be accomplished' is often primarily the result of the reflective self-analysis of one's actual abilities in action. In other words, our confidence in performing certain tasks is largely derived from our actual performances, or the perception of these performances. This highlights the cyclical, dynamic interplay which is responsible for providing learners with their sense of 'continuity' (Mercer, 2011, pg. 2). Moreover, while these perceptions of performance may not always be wholly accurate or objective, they often do carry significant evidence regarding actual ability. In other words, it is not simply self-belief which is constructed from our assessment of interactions but also a type of self-knowledge. Mercer's (2011) research has shown that once developed, these beliefs (and knowledge), like all other elements of a learner's larger cognition, will almost immediately and tenaciously interplay with present-time interaction and mediate expectations of future performance. Constanza's evolving self-efficacy beliefs in her ability to both understand and make herself understood in face-to-face encounters are therefore very much products of a context-specific evaluation (i.e. guided reflection) of her using English. Furthermore, these self-beliefs, embedded in an overall self-concept, underlie her almost instinctive decisions to avoid L2-related activity, including her assumptions regarding prospective interaction.

While she offers several accounts of her language-related activities that can shed light on her developed reluctance to participate in face-to-face interaction, I present two illustrative 
narratives which Constanza repeatedly references, serving as object lessons of how her cognition regarding intelligibility emerges, changes and interplays over time with her (un)willingness to speak with others in English. Furthermore, these narratives beyond their value in illustrating the type of naturalistic language-related activity that Constanza engages in, serve also to highlight the significant role context plays across these interactions.

\section{The Tutor and the Apple: Constanza's 'comprehension' issue and the construction of self-efficacy}

Constanza, like the majority of adult learners learning English as an additional language (EAL) in New Zealand, recognises the importance of finding opportunities for authentic language use. She is keenly aware of the fact that to improve her English ability, she needs to practice using English. However, as studies on EAL learners in New Zealand (Couper, 2002; Wright, 2006) have shown, accessing these opportunities is a significant problem for many people. In fact, in Constanza's case, finding friends or people to speak English with has indeed proved very difficult, as she has no Englishspeaking friends or acquaintances. However, one way which Constanza is able to practice using authentic English, in a relatively friendly context, is with her ESOL home tutor, who visits Constanza for a 1-2 hours, on a weekly basis. Home tutors are part of the New Zealand government's ESOL provision programs set up to assist recently arrived adult migrants and refugees with their 'resettlement' (n.a., 2006). They are trained volunteers who work with individual learners on their English with an expected minimum commitment of six months. Constanza's tutor had been working with her for over one year.

Constanza recognises her home tutor as one of the few people in her life who can help her practice using English in a face-to-face context outside of the classroom on a continuous and consistent basis. She understands that her tutor's 'job' is to help her practice and progress her skills as an English user, and therefore is aware of the patience and effort she brings to their encounters. The tutor is there to help; she will repeat things as needed and explain unknown language, establishing a familiar and unthreatening context through which Constanza is meant to build confidence and proficiency. Unfortunately, through numerous problematic language-related interactions with her tutor, Constanza seems to have instead developed negative self-beliefs about her ability to understand spoken English; that is to say, her low self-efficacy beliefs in regards to her English comprehension skills in face-to-face contexts have largely emerged and been refined through her L2-engagement with her home tutor. Constanza, when discussing her problem understanding people's spoken English, on numerous occasions referred to a particular incident with her tutor where she struggled to understand the word apple. For Constanza, the word apple represents a basic, simple word which she learned during her first few weeks of arriving in New Zealand. It is a word she knows and can use. However, when spoken to her, in the comfort of her own home, by 
someone she is familiar with (i.e. not a particularly threatening interaction) she failed to make sense of what was being communicated: it was the first word I learned and I COULDN'T UNDERSTAND (indirect observation interview one). Her inability to understand a basic, simple word like apple leads Constanza to the evaluation of herself as having a significant issue with listening to spoken English. In fact, Constanza admits that the majority of her interactions with her tutor, as a result of their struggles to understand each other, are conducted through written text and translation. Thus, Constanza believes that if she cannot make sense of even the simplest, spoken English in the comfort of her own home with a person she knows well, then it is no surprise that she will struggle to understand any English spoken to her outside of the home. Furthermore, this leads her to question her value as a person that others (i.e. 'native' English speakers) will want to interact with: but who wants a friend like this... someone who doesn't understand (indirect observation interview four).

Undoubtedly, over the many months of living in New Zealand Constanza has experienced numerous unsuccessful L2 interactions which have also contributed to her self-assessment as being a poor listener. However, it is with her tutor, who she meets with on continuous basis, using often simple language, where these issues becomes particularly marked and influential:

C: ... my tutor I don't know the other day she was talking to me about an apple and I couldn't understand

D: apple

$C$ : she would say A-Apo-APPa I don't know I thought she was saying that word with $u$ and $p$ to make that word

D: up

C: up and I ended up really confused until she got up and showed me and I said apple and she said upA

D: apple

C: yes she talks like because she is like Kiwi-Kiwi they speak really difficult

(indirect observation interview four)

The above excerpt is also noteworthy in that it not only illustrates how she has developed a critical assessment of her listening ability, but also introduces the suggestion of an issue with the language itself, or more specifically, with the variety of the language and its native speakers. In other words, Constanza's BAK in her inability to understand English seems to be extending from what initially appeared to be a perception of a personal deficiency (i.e. an innate problem she carried as an L2 listener) to a more external factor (i.e. New Zealand English, L1 speakers). Through this reflective account of struggling to understand her tutor, she advances the idea that it is not simply a case of having a problem understanding English, but it may be that she cannot understand the variety of English used in New Zealand. However, as it is the first time the issue of New Zealand English is mentioned it is not yet possible to make any substantial claims. 
This section has provided an illustrative description of Constanza's developing self-efficacy beliefs in relation to her English listening comprehension skills. In addition it has noted the possibility of an emerging evaluation toward New Zealand English, its native English speakers, and the facility with which this variety of English can be clearly understood. Below, I continue the discussion on Constanza's developing self-efficacy in relation to her intelligibility issues, highlighting what she perceives as her problem in making herself understood to others.

\section{The mirror \& the mattress: Constanza's 'speaking' issue and the continuing construction of self-efficacy}

As mentioned, Constanza's intelligibility issue extends beyond understanding spoken English. In fact, over time Constanza's accounts suggest that understanding English becomes slightly less problematic than making herself understood. This is understandable, as second language learners, similar to L1 acquisition, will often advance in receptive skills (i.e. listening and reading) more quickly than productive ones (i.e. speaking and writing). With increasing insight, she recognises that the biggest challenge for her in learning and using English, is not a lack of vocabulary or not knowing the grammar, which she referred to in our initial meetings, but rather with getting lost over the pronunciation. Struggling to communicate often the simplest of ideas, she judges her problem with spoken communication as not having developed adequate control of the phonology of English. This assessment, operating as a type of self-knowledge, manifests itself in her reflective accounts of her L2 use:

...if I had learned the pronunciation I am sure I would know a little more because I already know a lot of written words the only thing missing is knowing how to say this word how it's pronounced

(indirect observation seven)

Adding to her feelings of frustration in struggling to make herself understood is the certainty that she is in fact using the correct language to communicate what she needs and wants. Constanza, as a way of managing her naturalistic interaction, and in an effort to limit the confusion and embarrassment of using English, relies frequently on her electronic translator and Google Translate to prepare the appropriate language for interaction. Thus, she carries into her language-related activities a type of certainty in the language she will produce in order to communicate her message. However, even though she has the necessary words prepared and ready to use, she encounters significant problems in conveying her messages. During our conversations, Constanza often combined two related stories (both about a shopping excursion) to describe her perceived issues with speaking English intelligibly. In this narrative, Constanza begins by explaining how a new Colombian friend had seen some nice and cheap mirrors for sale at a local retail department store. 
Not having a car of her own, she asked Constanza to accompany her. Constanza, in preparation for this interaction looked up the word for mirror in her dictionary and felt confident that they would be able to explain to the shop staff what they wanted to purchase:

...and we asked where can we find the mirrors we asked the lady there in English we say mirrOR right? And we told her mirrOR and she didn't understand and [the shop staff responded] I don't understand and we asked her for the mirrORs that were outside and the lady couldn't understand what a mirrOR was hahaha I said mirrOR and they couldn't understand

(indirect observation interview four)

To emphasise her message that she cannot make herself understood when using English in face-to-face interaction, Constanza adds to the story a similar experience she had on her own, looking to buy a new mattress:

...the other day too I was asking about a mattress... I translated it and I went with the word I learned... the word mattress... but they didn't understand either... [the shop staff] I no understand I no understand... MATTRESS I said MATTRESS and they didn't understand me and that is when I get like sad... to know that I learn the words but they aren't correct

(indirect observation interview four)

Similar to the apple story, Constanza refers to the mattress and the mirror narrative when emphasising how difficult and frustrating it is for her to say what she wants to say in English. We can see how demotivating it is for Constanza, trying to engage outside of class in the $L 2$ and take charge of her life as an independent adult living in New Zealand after two years, to communicate and to use the language she has long wanted to acquire. After each encounter she feels more and more disheartened. Again, we can see how these language-related activities become a powerful part of Constanza's experiences with the L2, impacting the construction of her BAK and the development of L2-related emotions. In Bandura's (1997) Social Cognitive Theory, 'mastery experiences', are integral in developing self-efficacy. Mills (2014), adopting Bandura's framework for the SLA context, argues that while successful experiences with the $L 2$ raise self-efficacy beliefs, unsuccessful ones weaken them. In addition, she suggests that after 'repeated successful performances, it is unlikely that occasional failures will undermine beliefs in one's capabilities' (pg 8). In Constanza's case, the same principles are at work, only the inverse: Constanza's repeated unsuccessful experiences, i.e. 'failures', have in fact impaired her self-efficacy beliefs, while the (few) successful experiences she has had have not been sufficient in strengthening her assessment of her abilities as an English speaker. In other words, we can observe Constanza's self-related BAK and feelings regarding her inability to interact in face-to-face interaction emerging out of these day-to-day experiences with English; rather than strengthening belief in herself as an L2 user, Constanza's L2 interactions are evoking feelings of inadequacy and frustration, along with the belief, or knowledge, that she cannot pronounce words the way they are meant to be pronounced. 
Combined, the apple and the mirror and mattress stories provide insight into Constanza's issues with intelligibility; of how she struggles to understand what people say to her, as well as to make herself understood. They help illuminate the significance of the tension between her cognition and behaviour, where on the one hand she fears and thus avoids spoken interaction whenever possible, while on the other hand she is highly interested and invested in her $\mathrm{L} 2$ development. She cannot understand why English doesn't go in. According to her beliefs about learning, if you really like something (she offers driving a car as an example), you will learn it quickly (indirect observation interview three). However, in terms of learning to listen and speak English this has not been the case. Even though she really likes English, is dedicated to learning it, and wants to speak with people, she feels she has not made adequate progress. Moreover, she has developed an anxiety as a result of these intelligibility issues toward face-to-face communication which impacts in an adverse manner her willingness to communicate. Observing this dynamic interplay between internal and external factors across an individual's L2 learning system is integral to understanding changes within systems. As Engeström, Miettinen, and Punamäki (1999) argue in their research on human behaviour, it is these 'tensions and contradictions' at play in complex systems which 'are the motive force of change and development' (pg. 9).

In the section below, I expand on these 'tensions' to see how they impact change in Constanza's cognition and her approaches to $L 2$ interaction.

\section{Pushing and pulling across context(s): Balancing the fear of practice with a desire to learn}

Through analysis and observation of Constanza's accounts and naturalistic interactions and varied language learning activities, a picture of the contradictions that drive her behaviour begins to emerge. Her reluctance to engage in spoken English interaction (stemming from feelings of heightened anxiety and shame, and self-beliefs reflecting inadequacy as an L2 learner, which are in turn born of her negative evaluations of language-related activity) clashes with her aspiration and very real need to learn and acquire the L2. We see for example, that despite her issues with intelligibility, Constanza still very much wants to connect with people and be able to express who she feels she really is:

...yeah I believe that when one speaks more it is better but like I told my tutor now that I need more things like that like conversations I asked her to converse with me so she is taking me to the park now I want to talk more to not be scared I am NOT LIKE THIS

(indirect observation interview two)

Through a mixture of socio-economic need and personal investment and interest, including the recognition of the opportunity she has for a better life and the desire to build meaningful interpersonal relationships, we see evidence of Constanza's will to learn English. Also, quite 
importantly, she recognises the value of authentic communication, i.e. the belief that practicing to use the $\mathrm{L} 2$ will help improve her listening and speaking skills. In turn, she believes that by learning English she will no longer feel defenceless or mute in the immersion setting. Therefore, while she may not yet be able to enjoy, or at least feel comfortable in face-to-face interaction, she is able to present the occasional positive accounts of a successful language-related activity, as testaments of her desire and effort. She describes visiting a bank, explaining to the teller that her English is not good and eventually succeeding in setting up a car loan (a potentially complicated undertaking). Another anecdote shows her going to two different mechanics to inquire about the cost of an oil change before finding her preferred and sought after service; there is even an exchange (albeit with some assistance from her daughter) with a doctor, where although she did not speak well, could understand almost everything. These (rare) descriptions of successful interactions, beyond highlighting the inevitability of $L 2$ interaction in an immersion setting, also point to a readiness to use English. Finally, in addition to these examples of successful L2 use in naturalistic interactions, Constanza also describes her self-study work. Essentially, to feed her desire to communicate and improve her interactive speaking and listening (while recognising that face-to-face interaction with other English speakers in the traditional context is not working), she turns to and relies on alternative means of language interaction and practice. She uses an English language-learning page on YouTube, where a North American teacher introduces useful language, including vocabulary items and grammar points (e.g. the possessive) which she proclaims, serve her well. In addition to this she uses Facebook's Messenger application, where through textual exchanges, she chats online with different people. It is through her practice with Messenger, Constanza explains, that she has developed not only her reading and writing skills but also her vocabulary knowledge. Unfortunately, she explains, these language-related activities, while offering some value to her L2 development, do not serve her well in spoken interaction. Thus, recognising the fact that she is not getting enough practice with spoken English, and growing frustrated with her lack of progress, Constanza decides to try something slightly unusual to help her engage in more face-to-face $L 2$ interaction, but without the anxiety she associates with this face-threatening activity. She describes visiting a site linked to her Facebook account, where she can make friends and Skype with different people. She mentions that the site is meant to operate primarily as a dating site, but that her intentions are strictly to practice listening to and speaking English. Constanza elaborates that over the past two weeks, she has made friends with some people living in Wellington. They put on the Skype and talk with each other for hours (e.g. $9 \mathrm{pm}$ to $1 \mathrm{am}$ ). When she cannot understand something they write it down for her, she quickly translates it, and they patiently teach her how to pronounce certain terms. Curious about this new innovation in her approach to English study-practice, I asked her how the idea came about: 
D: ... and from where did you get this idea?

C: ...I said I am going to make friends I have to make friends in English that's why I don't

speak English I keep only speaking Spanish I DON'T HAVE ANYONE TO SPEAK ENGLISH WITH

(indirect observation three)

Later, clarifying the origin of this activity, she describes how through a conversation with another Colombian, the value of having someone to speak and practice authentic English with takes on a new significance:

C: ...I was listening to a friend who says she learned to speak English when she found herself a friend and there she learned to practice English and another lady also told me that her daughter learned to speak more English when she found a boyfriend because she has a Kiwi boyfriend and she learned more English with her boyfriend which is how people learn $D$ : people say that having a partner in another language is a good way to learn the language C: ... at the beginning I would write and write and write and I would just write and I would translate and I would learn new words but I didn't know how to pronounce them so a better idea is that if they ask me to Skype I am going to take advantage of this

(indirect observation three)

This excerpt reveals the extent to which Constanza is willing to go in order to find opportunities to practice face-to-face interaction in English. It also demonstrates her awareness of the relationship between her lack of progress with English and the challenge of finding people to speak and use the language with. While face-to-face communication for the most part has been a negative experience for Constanza, one that up to now she has avoided when possible, she is also growing increasingly frustrated with her inability to advance. This intrapersonal tension, or what Freeman (2006) refers to as an individual's 'either/or choices', is pulling Constanza towards not only change in how she perceives the practice of language learning but also in how she actually practices it. As Freeman maintains, the momentum and dynamism within complex systems necessary for individual development is the result of the process where one particular purpose 'trumps' another (pg. 250). Constanza is tired of not being able to speak; not being able to understand; not being able to defend herself; she is tired of being laughed at and disrespected. She wants to improve and she wants a job doing something interesting and to meet people outside the Colombian community. Furthermore, she wants to realise her childhood dream of learning English. As a result she is willing to try almost anything in order to find opportunities to speak more, including joining an adult dating site. Furthermore, the excerpt highlights the effort she has committed to learning English outside the classroom and the impact it has had on her L2 development. Finally, it depicts her growing confidence (i.e. self-efficacy beliefs) in her ability to read and write English, which stands in opposition to her inability to speak and listen.

This section highlighted the type of internal tensions, or personal dialectics, at work within individuals which can lead to changes in behaviour. It also served to reveal the powerful role context(s) play(s) in influencing this often highly idiosyncratic behaviour. In the case of Constanza for 
example, we see a suggestion of how the New Zealand context (e.g. unfamiliar variety of English), beyond impacting the construction of a negative L2 self-concept, also leads her self-directed search for more familiar and therefore intelligible varieties of English (e.g. North American English via YouTube) to aid her language study. There is also the context of the Colombian community, where she turns to not only for social contact but also for language learning advice and support. Contact with the Colombian community however, also leads to self-disparaging feelings of guilt, believing that spending too much time using Spanish is having an adverse effect on her English. The online world (e.g. Facebook and Skyping with L1 English speakers) as well, is an example of a context impacting her L2-related BAK and the associated affective dimension. Consequently, we see how context-specific, language-related activity is in dynamic interplay with the development of Constanza's language learning cognition, including emerging, personal evaluations of herself as an English learner and user and her judgments regarding the value of particular self-directed language learning activities. Furthermore, it is inevitable that these interactions, across varied contexts and over time, including the guided reflection inherent in the research interviews, also have a powerful impact on cognition in relation to more external L2-related factors (e.g. beliefs about the best ways to study English; beliefs about the role of English in helping procure employment; feelings toward other language learners). In Constanza's case, beyond observing the construction of self-related BAK and affect, there is also evidence of the development of beliefs and emotions regarding the English language as a conceptual entity.

In the following section, I describe Constanza's BAK \& affect about the sounds and varieties of English, arguing that these subjective evaluations, in conjunction with her self-concept, beliefs, and self-knowledge, impact her willingness to use English, which itself operates as a type of language-related behaviour.

\section{BAK and affect regarding the English language: Evaluating the sounds of English}

Through the (re)construction, or telling, of Constanza's accounts of L2-related activity an underlying cognitive element in the form primarily of an emotive evaluation of the sound of English is conveyed. More specifically, in her critiques of electronic translators, other L2 speakers' pronunciation, and the intelligibility of certain varieties of English (i.e. North American vs. New Zealand variety) Constanza communicates a personal perspective regarding how she feels English should and should not sound, and what constitutes clear and unclear spoken English. It is a component of her cognition, rooted primarily in her $L 2$ engagement across a range of settings, which not only travels over time, appearing throughout the project, from the initial to the final interview, but also one which assumes various manifestations and operates at nested levels. 
First, at a general, abstract level, there is evidence of Constanza presenting beliefs about the quality of certain English sounds. For example, noting that her main problem regarding $L 2$ use is her ongoing struggle with English pronunciation, I often suggested to Constanza (who made frequent use of electronic dictionaries and translators) to adopt the voice function which provides 'spoken' or oral examples of the word or expression she is trying to learn. However, she rejected these suggestions on the basis that the translators' pronunciation was somehow unattractive:
C: ...I write with the translator and that way I learn the words I want to say
$D$ : yes and you can also try because sometimes the translator has something for pronunciation too so there's a button you can press and it tells you how it sounds... $C$ : yeah but that translator is really ugly pronounces ugly
D: oh yeah?
C: yes it pronounces strange ugly it pronounces really ugly like that word you just said D: future
C: yeah future but it says feture with an e and I think why do they use an e if there is a $u$ there translates ugly REALLY UGLY

(initial interview)

This excerpt illustrates Constanza's belief, enveloped within strong emotional undertones, that the English produced through electronic translators is unappealing and unpleasant; that these electronic tools produce inappropriate language, saying the words bad (indirect observation one) and admitting that she prefers not to use them for this purpose. Furthermore, her evaluation of some English as ugly or strange, reflecting a disparaging belief toward particular sounds, is also revealed throughout her descriptions of interactions with other $L 2$ users. In my attempts to gauge the quality and frequency of her spoken interaction in English beyond the language learning classroom, we would sometimes discuss her relationships with other English learners. She explained that for the most part she had very little contact with these individuals and did not suggest the possibility of wanting more contact. As the excerpt below suggests, this decision may have largely been the result of her beliefs that other L2 users, do not pronounce English properly:

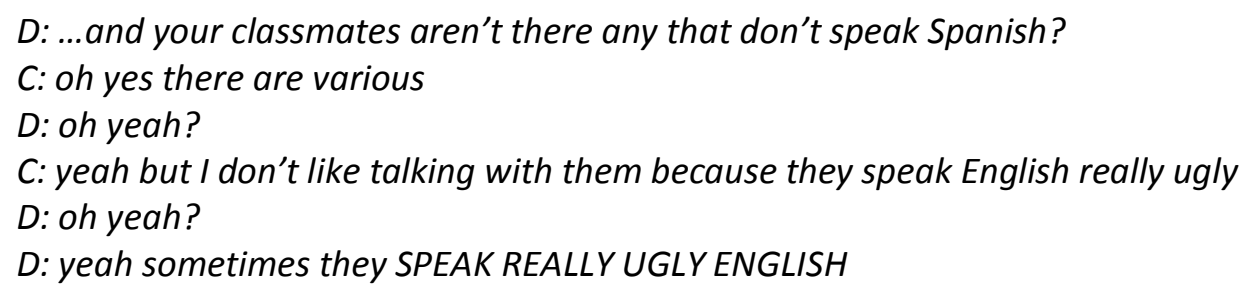

(initial interview)

While displaying disparaging beliefs regarding the sounds of English produced by other learners, Constanza is at the same time presenting a lack of confidence in being able to learn or develop her English through communication with other non-native English speakers. She clarifies 
these sentiments, explaining how she believes that they aren't pronouncing well and aren't talking well; in fact, they aren't talking the way they should be (indirect observation interview six).

These examples of Constanza's personal observations of how machines and people say or pronounce English clearly depict a negative appraisal regarding certain sounds of English. They show Constanza carrying, as a subsection of her cognition, particular beliefs and feelings which imply a 'good' or 'bad' way of pronouncing spoken English. The conception of some types of spoken English as being ugly is particularly noteworthy, as it reveals a powerful emotional evaluation focused on an abstract sound system. Consequently, this component of her cognition can also be seen affecting her L2-related activity; most obviously in her reluctance to learn pronunciation from electronic resources and her avoidance of prolonged interaction with other L2 learners. Constanza, in refusing to make consistent use of electronic translators to study and practice pronunciation is, unfortunately denying herself one of the most convenient and readily available sources of phonological instruction and feedback. Moreover, despite admitting that she can speak more easily with other $\mathrm{L} 2$ learners, as they tend to be more patient and speak more clearly (she understands them more than L1 users), her feelings regarding their inadequate sounding English severely limit her opportunity to practice using English in a meaningful manner; as a result, her L2 development is noticeably hindered. Finally, the belief that some sounds of English are ugly or strange at the same time implies an evaluation of an ideal, more pleasant sounding English. It is therefore possible that if Constanza encountered this more adequate sounding English, her willingness to engage with it would be substantially higher.

Next, further exploration of Constanza's cognition in regards to the sounds of English at a more specific, less abstract level, reveals a personal assessment in the form of beliefs and feelings toward the intelligibility of certain varieties of spoken English. After two years in the New Zealand context, Constanza has had what can be considered extensive exposure to New Zealand English. As a result of this exposure she has developed, largely in the form of a comparison, a judgement regarding the sound of the New Zealand variety of English. The excerpt below illustrates this constructed belief:
D: ...there are people here who speak all kinds of English
C: yeah it's that this British English is more
D: difficult?
C: complicated the people don't say their words clearly enough yeah I understand American English more they speak more clearly

(indirect observation four)

As I have previously argued, Constanza at the outset of the research, clearly expresses a positive affective position towards the English language. In fact, she seems to revere English, evaluating it as a symbol and means to an ideal self and way of life. Her positive perceptions toward English in many ways reflect McKenzie's (2008) assertion that 'non-native attitudes' toward English tend to conceptualise the English language as a single, homogenous 'entity' (pg. 66). Thus, it is not 
unusual for incoming migrants to carry an assumption (as a component of their BAK) that all Englishes are essentially the same. However, over time and through Constanza's various experiences (i.e. language-related activities), we see development of this evaluation of English. Her initial, uncontested affinity for the $\mathrm{L} 2$ becomes refined into an awareness that, in fact, not all Englishes are the same. In other words, Constanza through her exposure to New Zealand English begins to recognise the disconcerting effects of language variety, most clearly through her (in)ability to comprehend what is being spoken to her. Similar to her experiences living in Ecuador, she becomes acutely aware that, like Spanish, English carries its own variable idiosyncrasies in terms of vocabulary, grammar, and of course, phonology. However, this time her experiences with language variation are as an L2 learner rather than an L1 user. Prior to arriving to New Zealand, Constanza would have been exposed to North American (most likely from the United States) English. Studies investigating the development of L2-related attitudes have shown that these types of constructs are often dependent on the 'exposure' to the language (McKenzie, 2008; Zhang \& Hu, 2008). Interestingly however, Zhang and Hu (2008) found that while 'L2 learners have more positive attitudes towards the varieties of English they have been exposed to' these attitudes are not necessarily related to the 'understandibility' of the variety (pg. 342). In Constanza's case, New Zealand English was completely unfamiliar. As a consequence of this lack of familiarity she contends that this particular variety of English is indeed a challenge to understand. She states that she cannot make sense of what is being spoken to her because people here eat their words (indirect observation eight), while she finds the North American English much clearer. In other words, Constanza is asserting an explicit preference, rooted in the intelligibility of the variety (as a consequence largely of phonology), for North American English. This observation calls into question McKenzie's (2008) claim that learners' 'familiarity with the variety' through different exposure mediums leads to the construction of more favorable conceptions (pg. 66). However, Constanza has had significantly more direct exposure to New Zealand English than to American English, yet she seems to more highly regard the variety of English she has had less direct exposure to. Starks and Paltridge's (1996) study in some ways corroborates this, as they found their participants (Japanese students studying in New Zealand) to be more interested in learning more standard American or British varieties. While this issue is quite complex and is undoubtedly linked with concepts associated with 'language prestige' and 'English as an international language', it is worth mentioning here the importance of considering actual exposure experiences of individuals. I suggest however, that it is not simply a case of American English being clearer than New Zealand English. Constanza's ongoing communication breakdowns throughout her time in New Zealand, the consequent developed feelings of shame and fear, along with low self-concept and her resulting isolation, are all contributing factors to this emergent cognition in regards to this variety of the L2. Participants with more positive experiences, who have managed to develop relationships outside of the Spanish-speaking community, who have found employment, who have managed to make significant progress with English, while indeed 
commenting on some of the challenges of learning English, do not seem to carry the same opinions toward New Zealand English. There are comments on how the variety of New Zealand English has been unfamiliar and challenging, but overall they do not communicate a preference for one variety over another; nor is their evaluation particularly unfavourable. With that said, Constanza's case shows how adults migrating to English speaking countries will form nuanced BAK and affect toward the type of English they are being exposed to as they manage their expectations of and engagement with the English-speaking context. We can observe the development of BAK and affect in regards to the sound of English as it relates with her personal appraisal of how it should sound and larger issues of L2 intelligibility. In turn, these developed constructs will underlie and guide her consequent language-related activities.

The following section, building on this idea of Constanza's cognition regarding the sounds of English and her lack of progress with the language, presents a picture of an emerging belief, in the shape of an 'aversion' toward speaking English. This evaluation of her feeling toward spoken English is used as a type of justification for her reluctance to engage in face-to-face, L2 interaction and to rationalise her inability to develop her spoken English ability.

\section{Constructing cognition: Constanza's aversion to English}

During the last three months of our work together, Constanza began to exhibit a change in her L2 use. First, in the actual interviews, she was speaking English more frequently with me, as well as using longer, more complex sentences. Whereas before, when using English in the interviews she would limit herself to a word or two, she recently began to produce full statements, albeit with limited fluency and obvious pronunciation issues. Second, in her accounts of language related activities, she presented more successful interactions. She told a story of a conversation she had on the telephone, successfully navigating the scheduling of an appointment, and clearly excited about the fact that she understands what they tell her now (indirect observation seven, September $29^{\text {th }}$ ). She also provided a lengthy, rather involved narrative about speaking in her English class, in front of all her classmates and the teacher. On this occasion Constanza asked a guest speaker, a director of health, about the cost of receiving an operation at a hospital. She was particularly pleased with this story as she was able to engage in face-to-face interaction in English and participate in a rather complex interaction:

...and so she understood me she understood me UNDERSTOOD ME and she (the director of health) asked me if I had taken along my residency (to the hospital) and I said no and she said that that was why they were charging me all that money but imagine I MADE MYSELF UNDERSTOOD

(indirect observation interview eight) 
Curious about this change in her $\mathrm{L} 2$ behaviour, I questioned her about what prompted this sudden willingness to speak more English, mentioning explicitly that it seemed to me like she was trying to talk more. She responded by asserting that she indeed wants to speak more but gets too nervous, as a result of $a$ foolish thing in her head. Elaborating, she explains that for her, saying certain words in English (e.g. buy) sounds stupid and makes her feel embarrassed. This is the first mention of her feeling that certain words in English sound foolish or silly. In the previous section, I have discussed how she carries certain beliefs regarding the sounds of English however, these beliefs were mainly talked about in the context of other L2 users, electronic translators, or English variety. Moreover, in referring to this emerging foolish idea in her head, which leads her to believe that this isn't the way she should speak... that saying certain words in English is something stupid (indirect observation interview eight, October $25^{\text {th }}$ ), she is making a connection that this feeling toward speaking English words is interfering with her own capacity to speak. This relationship between her negative evaluation of English, as a silly sounding language, and her reluctance to use English becomes fully realised in the final interview when I again comment on the change I have noticed in her English use:

D: ...these last few months I've noticed a change you are speaking more [English]... using more complex sentences

C: and so... I always when...I get to thinking because I always looked at English looked at English like something STUPID for example there was a word that says buy which means 'comprar' and this word made me embarrassed to speak it buy is the same as to say goodbye so I couldn't bring myself to say it bye or to say pie It made me remember that when I was a little girl I had an aunt... an aunt who was like a little [mentally] sick and instead of saying 'gracias' she'd say pie PIE she'd say like you say thanks and this word was like for people

(exit interview)

Constanza in this excerpt reaches back to the far past, to a childhood recollection, to clarify her newfound realisation that her reluctance to speak English is rooted in an aversion, as a powerful, negative emotional reaction, to the sounds of some English words. To clarify further, she explains that although this is how people say things, i.e. this is how English is spoken, for her these words are not meant to be spoken. She got this stupid idea in her head about these words which to her sound horrible and again, ugly and make her feel embarrassed to speak (exit interview, December $15^{\text {th }}$ ). Thus Constanza is not simply admitting a feeling of embarrassment at speaking English incorrectly and consequently being laughed at, but instead her feelings of embarrassment in speaking English is more akin to a kind of shame about the language. In commenting that it is possible (and something I had not considered) that associations with words similar to Spanish from her childhood might make her feel strange, Constanza reveals that she avoided saying these strange words... the words that that for her seemed like they should not to be spoken. Mercer (2011) has found that learners, when constructing a self-concept in the foreign language domain, will at times make 'some kind of comparison with their mother tongue' (pg. 46). In the case of Constanza, this comparison seems to 
have had a detrimental effect on not only her willingness to use English but also on her BAK and affect in relation to English. In other words, Constanza is explaining that through her comparison of the sounds of some English words with certain Spanish sounds, she has created a foolish idea in her head which has limited her capacity to use and interact in English. And it has been through this realisation, or acknowledgement, of an aversion to spoken English that she has been able to address her issues and consequently adjust her behaviour. It is worth noting that this change in her willingness to interact (realised in her increased attempts at L2 interaction) seems to have less to do with how she feels when interacting in spoken English - admitting that she continues to feel nervous and anxious - and more with how she perceives English and its silly sounds. Finally, Constanza's emergent awareness of her aversion, as a type of developed or constructed feeling toward English, relates closely with her previously discussed issues of intelligibility and pronunciation challenges. There are connections, linking the sound and spoken production of English, which undoubtedly are most perceptible through face-to-face communication.

The section below, elaborates on Constanza's developing recognition of her own cognition as a language learner and discusses how this awareness impacts both her $L 2$ related activity and the revision of different aspects of her BAK and affect, including her self-concept and her self-efficacy.

\section{Observing change: An emergent awareness of her struggle to communicate}

\section{in face-to-face interaction}

Throughout the duration of the research Constanza is searching for a way of making sense of her inability to develop her English. One clear realisation which she comes to is that her lack of engagement in spoken interaction (i.e. her reluctance to use English) has acted as a major limitation on her progress. It is clear in the exit interview, when she offers advice to an imagined adult language learner, that she feels the best way to improve one's L2 ability is to find authentic opportunities to use the language. In advising the 'learner' to overcome the fear of talking and to throw yourself into conversations, to take chances to speak what you have learned, Constanza communicates her belief that learners need to find ways of conquering any anxiety or adverse feeling and beliefs that may be hindering their capacity to use the L2. Essentially, she believes that you need to speak in English in order to improve, and learners must strive to do what they can to talk. However, up until recently she has not been able to take her own advice. A palpable discordance has been running through Constanza's language learner cognition, where certain L2related beliefs were not reflected in her behaviour. As this discordance or conflict developed and grew a consequence of ongoing, guided self-reflection over time, an emergent cognition was constructed. Constanza realised that she had been avoiding speaking because she carried an unconscious, but powerful, aversion to certain word sounds in English, stemming from childhood experiences as well as a comparison with her L1. Thus, we can observe Constanza's rationalization, 
or personal evaluation (an extension of her cognition as a language learner), of what has been limiting her language development emerging out of her search for answers to her L2 learning and using issues. She has become aware, in the final interview, that she has been too ashamed to use (and hear) certain words and sounds in English and as a result, has experienced a host of issues with her language learning and settlement. Furthermore, it is integral to note that the effect of this aversion on her interactions has undoubtedly been intensified by the fact that the majority of interaction in New Zealand inevitably takes place across a range of English-speaking contexts. Thus, the $L 2$ context in an immersion setting can be seen interplaying with all elements of a learner's cognitive construction and interrelated language-related activity.

It is important to appreciate that Constanza's L2-related issues are more complex than her perceived awareness of an aversion to English. While she believes she avoids interaction because does not want to speak the horrible sounding English, we must assume that it is also very much a case of the anxiety and fear she developed as a result of the intelligibility issue reported earlier. L2 interactions, because of her problems with pronunciation and comprehension, have for years been a struggle for Constanza. She has been laughed at and yelled at; she has felt embarrassed and scared; she has not been able to build important interpersonal relationships with anyone outside the Colombian community because of her failure to learn English. In turn this has left her feeling isolated and defenseless - essentially voiceless - as well as perpetuating her inability to advance. However, with this developed awareness of the powerful impact L2-aversion has had on her willingness to interact in English, she now believes she will be able to experience further positive change and improve her $\mathrm{L} 2$ proficiency. Over time Constanza has come to recognise her aversion as the critical detriment to her progress; this foolish idea in her head has been the reason up until now that she has avoided face-to-face interaction in English. And as a negative consequence of this (in)activity she has failed to progress her L2. At the same time, she has been observing and noting that others like her - Colombian classmates for example - can communicate what they need to, using language she herself knows and can use:

D: ...no but you are talking and you are at least before you understood more but now you also making yourself understood more C: yeah I try to see how others say things sometimes I listen to the other Colombians and they say to the teacher this and this and this and I get to thinking all of that I can also say MYSELF and I don't dare because I think that's not it but they are saying it like that $D$ : so you are listening to for example a Colombian and they say a sentence or something for example and then you know you recognise all the words C: yeah I know it all and I listen to it like the questions they ask the teacher or whatever like why they aren't going to come to the next class or why they didn't come and I listen to what they say and I think well all of that I can say too but sometimes I don't DARE to but they do and why not

(exit interview) 
Her observations of other L2 users progressing and getting things done with the L2 serves as a motivating factor for her own engagement. In addition, she alludes to the support I offered her in affirming her attempts to use English. Mills et al (2007), in their work on the role of self-efficacy on achievement and motivation in language learners, show that confidence in one's various language learning abilities may be 'nurtured' by creating opportunities for students to experience vicariously the successes of their peers, and receiving positive feedback (pg. 436). While that work was looking specifically at support within the classroom language learning context, it appears that 'positive feedback' beyond the classroom can be a benefit to learners as well. No longer restrained by her aversion to spoken English, her confidence in her ability as an L2 learner begins to grow. Mercer's work (2011) provides an excellent example of the role of 'social comparison' in an individual's formation of 'domain-specific self-concepts', such as a self-concept as an L2 learner in an ESOL immersion domain (pg. 87). Social comparisons, then can, as key internal factors, guide learners' evaluations of their abilities. These evaluations she argues, are based largely on needs, such as the need to self-enhance or self-evaluate. In Constanza's case we can see these needs extend to an individual's need to engage with and practice the L2. As Mercer (2011a) states, learners may compare themselves with others to ultimately 'gain an accurate evaluation of their own abilities' (pg. 87). What Constanza is communicating through accounts of her growing confidence is that she has, through this practice of social comparison, come to realise that as long as she can overcome her aversion regarding spoken English, she can do what other L2 adults like her can do with English. In other words, if she can move on from this belief that English sounds horrible and foolish, she too will be able to acquire English; she will be able to ask questions and offer responses; she will be able to establish interpersonal relationships with others; she will be able to assert herself and begin developing and participating, both as a learner and as an adult navigating her settlement into New Zealand society. In concluding the exit interview, I questioned Constanza about her future - I asked her to construct an ideal image, of what would make her most happy:

\section{D:... in five years what would you like to be doing? C: well in five years I'd like to have already learned English well and a GOOD job to have a good job and to talk well \\ D: ok a good job and English}

(exit interview)

With growing awareness of the role of her cognition as an L2 learner on her behaviour, and her longstanding desire to learn a second language, Constanza in our final talk asserts an explicit change in her feelings about language learning generally and herself as a language learner personally. She communicates a growing willingness to communicate, along with a more positive self-concept and developing beliefs in her abilities to interact in English. She does admit to still 
feeling apprehensive when speaking English, but is now aware that when she engages, she can succeed.

In sum, when considering the influence or role of L2-related cognition on a learner, there are inevitable questions regarding the truth or validity of these constructed beliefs. In other words, what a learner believes some will argue is not an objective or even accurate representation of what is actually transpiring across the L2-related endeavours. In Constanza's case, her discovered aversion to the sounds of English, offered in the final interview as a reason for her lack of development might not be as 'true' a reason for her limited progress as the fact that she simply did not want to practice speaking English, or that she failed to complete her homework, or that she spent more time speaking Spanish at home and beyond than using English. Nevertheless, it is integral to research looking at the myriad of factors guiding a language learner's development, including improvement in use and production of the $L 2$, that the perceptions of the learners (including what they 'assume' and 'know' about themselves) are carefully considered. As this research shows, these perceptions play a crucial role in how learners see themselves and others, the $L 1$ and $L 2$, the practice and process of language learning, and a host of their L2-related factors, and ultimately it is these perceptions, as reflected in a complex cognition, which is guiding a significant part of their engagement and interaction. Barkhuizen (1998) has remarked on this idea, noting that unfortunately too often language learners are not 'overtly' or 'systematically' asked about their learning experiences. However it is often through their own understanding of their language-related experiences that we can derive a more nuanced picture of what drives their behaviour. As Riley (1997) attests, learners' 'subjective reality' or their own constructed truths, more than anyone else's, ultimately determine how they approach L2 learning (pg. 127).

The final section of this discussion chapter explores how the key components influencing a learner's L2-related behaviour might be realized in a model.

\section{Putting the pieces together: A model of language learner cognition in action}

The final research question for this project asks: How can an adult's language learning behaviour in naturalistic contexts be reflected in a model of language learner cognition? In exploring an adult $\mathrm{L} 2$ learner's development over time, the above discussion has highlighted various, multifaceted factors which when considered in chaotic (i.e. oft, unpredictable), dynamic interplay can be used to construct a model of a cognition in action. It very much reflects the complexity of $L 2$ development advanced in much of the current social psychology work being conducted in SLA and Applied Linguistics (Atkinson et al., 2016; Beckner et al., 2009; Larsen-Freeman, 2007; LarsenFreeman \& Cameron, 2008a; Mercer, 2011a)) However, before putting these key elements together in a conceptual representation of this process, I offer a brief elaboration of each part of the model below: 
i. 'Context' is framing and guiding activity in the system; it is impacting and being impacted on by this activity (however, this research has focused exclusively on the impact of context on an individual; future research should look at the nature of the impact of the 'individual' on the external context).

ii. 'Language related activity' is the context-specific interaction and engagement in the L2, including the guided reflection on these communicative episodes; Storied accounts and reflection on this L2-related activity 'turns' the language-related activity into Experience; echoes Richardson's (1991) and Borg's (2006) reference to 'prior experience'.

iii. BAK and Affect as rooted in this Experience

- both through direct engagement in experience and indirect engagement in the telling of experience

- includes self-concept and self-efficacy, as well as other beliefs about various L2 issues including personal assessments of language study activities, judgements about the language, evaluations of users of the language (e.g. other L2 learners; L1 users)

iv. Cognition, a holistic, multifaceted, complex construct, largely made up of types of BAK and Affect where the different elements interplay across places and over time - impacts directly on language related activity (as a type of behaviour).

These elements in action (in dynamic motion across contexts and over time), impacting on each other, reflect a picture of the social construction of a language learner's cognition. Figure 1 is a visual representation of this developmental process, describing the dynamic, chaotic process of an L2 learner's cognition:

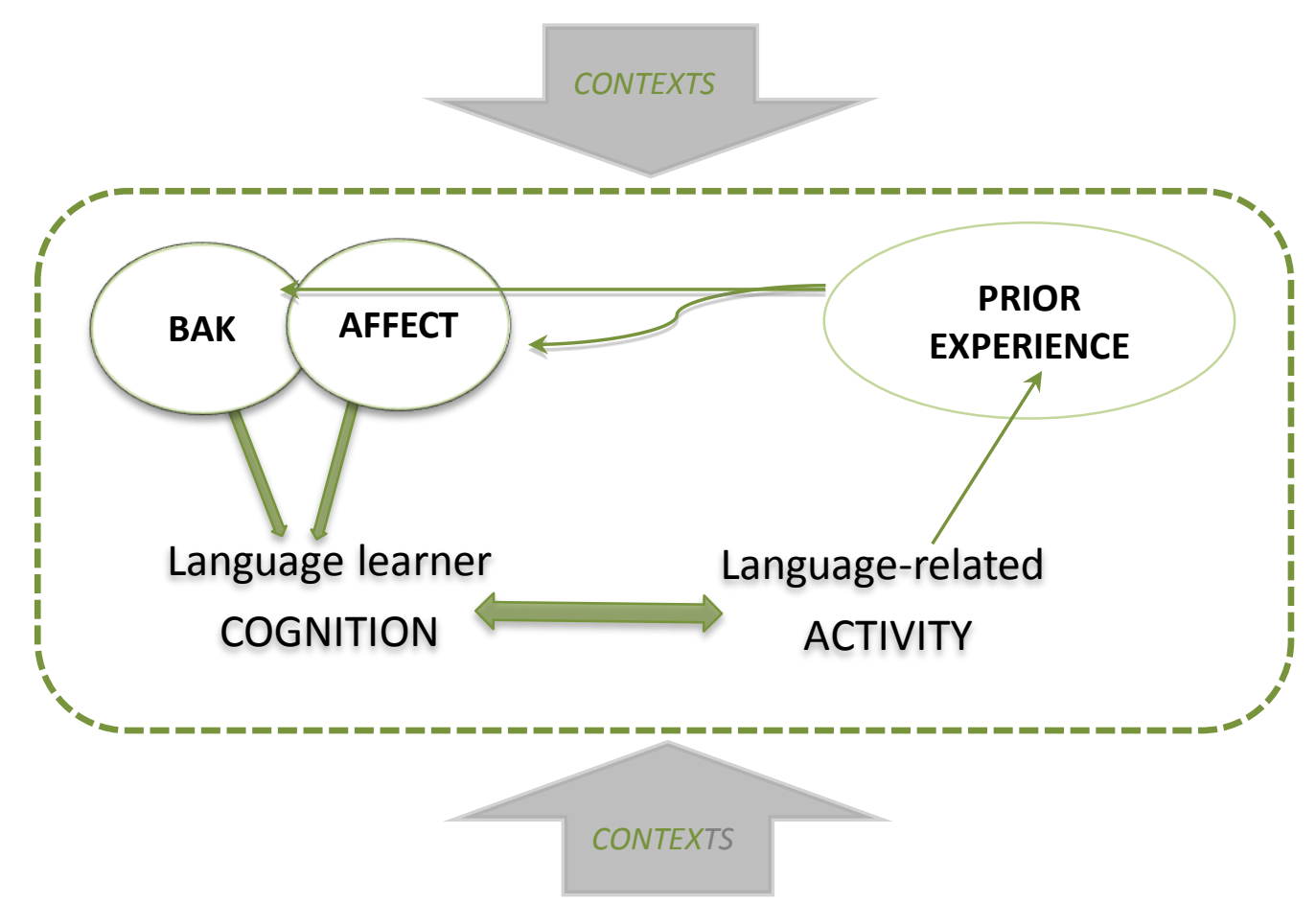

Figure 1: A model of language learner cognition in action 
The model's inherent dynamism and interconnected nature means that essentially there is no predetermined point of origin, or starting point. A general description of the model therefore could start with any of its core components. For the purpose of this description, I begin with 'Language-related activity'. In the model, language-related activity is any social (inter-personal) interaction in the participants' second language. This activity, after time and reflection, consequently becomes an individual's 'prior experience'. Thus, we see a uni-directional arrow from LRA to 'Prior Experience'. It is important to note, that the conversations (unstructured interviews) shared between the participants and me over the many months, acting as a type of guided reflection (i.e. participants were encouraged to talk about their L2-related activity), were integral in shaping this activity into lived experience. Thus reflection, while not explicitly referenced in the model, provides a key function in shaping this evolving experience. Experience, across the literature in learner beliefs, language teacher cognition, and numerous other sources associated with the social psychology of language learning, is depicted as a principal player in the construction of learners' (and teachers') thoughts and feelings. The uni-directional arrow this time is therefore shown moving from what is essentially L2-related prior experience toward the participants' beliefs, assumptions, knowledge, and feelings. These interconnected components (i.e. 'BAK and Affect'), along with other related sociopsychological factors shaping how the $L 2$ is used, are depicted by the two-thicker arrows and are what I refer to as Cognition. 'Language learner cognition' and (second) 'Language-related activity' are centralised in the model connected by a thick double-ended arrow, to emphasise the dynamic, embodied interplay between a learner's internal and external worlds. It is meant to show how, just as cognition impacts behaviour, so too (with equal force and frequency) behaviour impacts cognition. Finally, enveloping this ever-emergent, ongoing process is the authority of 'Context'. Context in the model should be understood as working (i.e. shaping and guiding behaviour as much as itself being impacted and influenced by social activity) concurrently at nested levels, from the macro to the micro. For example, the ESOL context of New Zealand is operating at the macro level of context. Each L2-related activity, whether it is talking on the telephone with a receptionist at the local medical clinic or visiting the local library to return CDs, can be seen as the micro, socialinteractional context. The research interviews also represent an important context that needs to be considered and accounted for when detailing the process of cognition construction.

Atkinson et al. (2016 pg. 24-25) offer a similar but more elaborate illustration of the role of 'specific multilingual contexts of action and interaction' through their own model of 'the multifaceted nature of language learning and teaching' (pg. 25). In this framework, the group proposes three, interconnected levels of context impacting on L2 development:

(1) at 'the micro level of social activity' the focus is on individual neurological mechanisims and cognitive capacities, as well as on 'individuals engaging with each other'

(2) at 'the meso level of sociocultural institutions and communities' the focus expands to 
explore the role of family, school, work, places of worship, the community, and similar organised bodies of influence; at the meso level, the aim is to understand how 'access' to different social experiences is restrained or enabled across these institutional conditions

(3) at the 'macro level of ideological structures' larger, wide-reaching ideologies related specifically to language learning and use are seen as both shaping and being shaped by what is happening at both the micro- and meso-levels; each level is therefore seen existing only through constant interaction with the others and all are 'essential to understanding SLA'

Each model as a way of making sense of L2 development carries context at its core.

Figures 2 and 3 are examples of populated models. Figure 2 is depicting the transactional context and figure 3 , the social transaction context. They adopt and adapt key pieces of information from the above discussion on Constanza's language-related activity and to show more specifically how it might inform our understanding of the process of an individual's cognition in action. Key elements are shown at work, 'interplaying' within and across each other. Again, it is important to note, that while the models do not depict the role 'guided reflection' plays in turning activity into meaningful experience, it was nevertheless found to be an integral component in raising awareness and impacting change. 


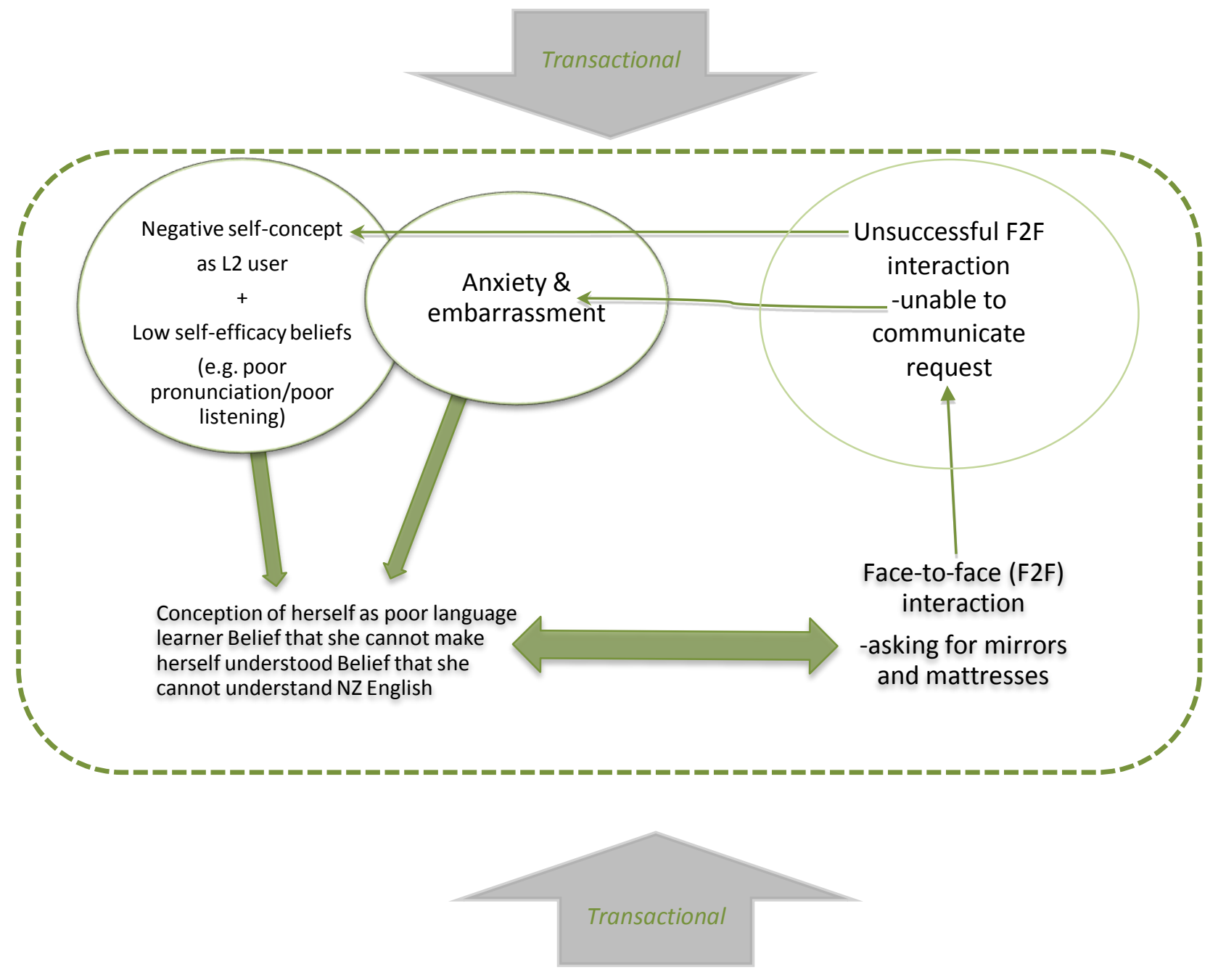

Figure 2: A populated model of language learner cognition in action: Transactionial context 


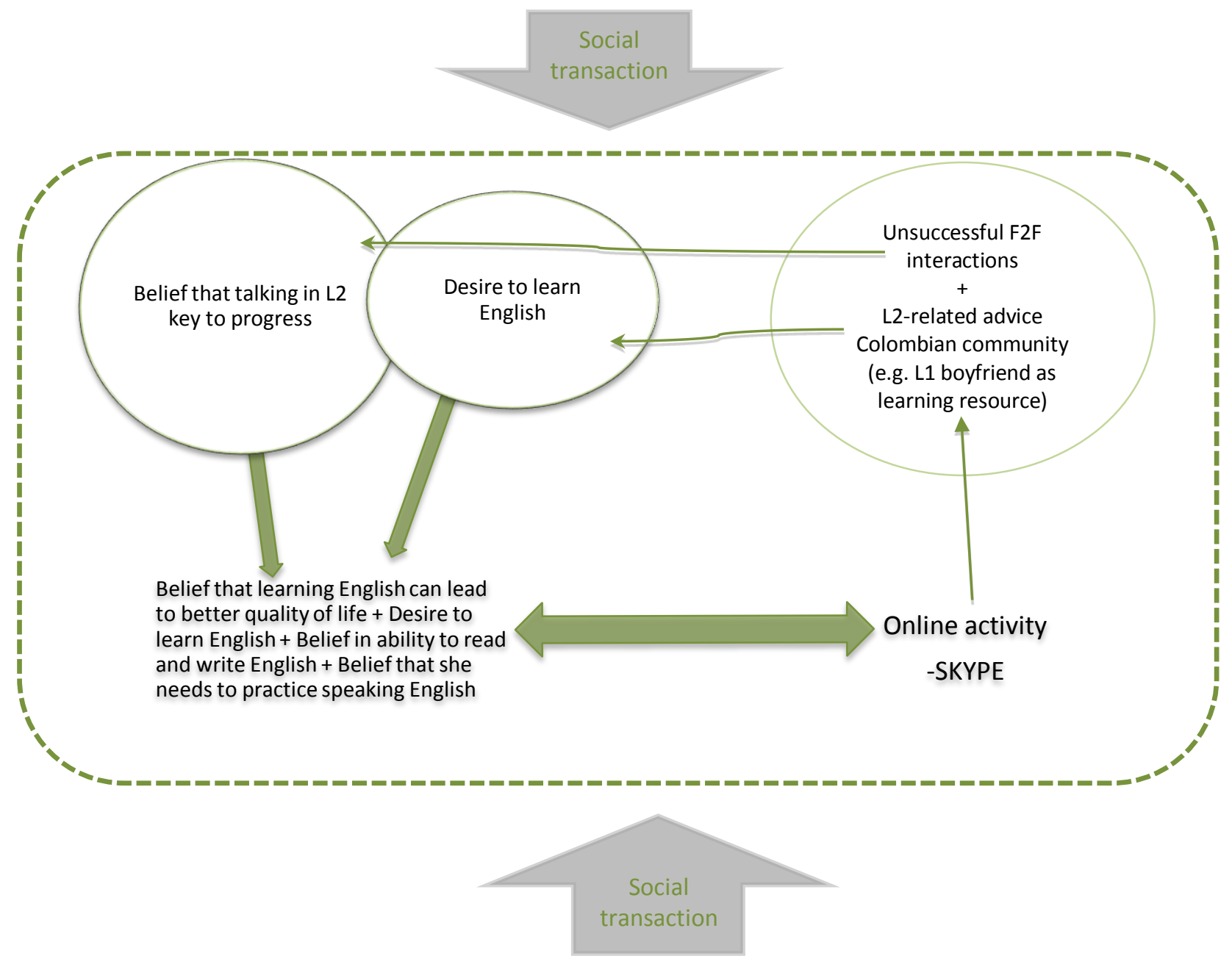

Figure 3: A populated model of language learner cognition in action: Social transaction context

\section{Rationale for the model}

A model which adopts as its focal point the multifaceted, non-linear interaction between different elements of language learning allows us to continue to expand our ideas of what language education might entail. One way that we can approach this need to vary the focus and expand our conceptions of $L 2$ development is by incorporating a framework which centralises the learner in action, and to situate language learning as a type of personalized behavioural development. Calls for this type of 'agent-based framework' have been made in the past. In language acquisition studies for example, the 'Five graces group' (FGG, 2009) have argued that a complex adaptive system (CAS) of language needs to be understood within an agent-based framework which inherently recognizes that different individuals will 'exhibit different linguistic behaviour and may interact with different members of a community as it happens in reality' (pg. 13). Dörnyei (2009), specifically points out that in second language acquisition research there is a dearth of knowledge regarding the interplay among language, agent, and environment' (pg. 231). Both the FGG and Dornyei's comments relate specifically to the acquisition (and use) of language, however, as the discussion above has illustrated, 
an agent-based framework can also aid in the development of our understanding of language learner cognition. The model I have developed reflects these features, centralising the learner and taking at its unit of analysis the process of individuals in language-related activity over time. By concentrating on these processes, we can better understand how the different components of the system impact developing behaviour, including which of the system's mechanisms most strongly affect emergent behavior and which have little consequence (FGG, 2009, pg 13).

\section{Description of model}

The model, in many ways, acts as a lens through which to explore a language learner's agency, where agency is a manifestation of their cognition in interplay with not only behaviour but also with what Menard-Warwick (2009) refers to as 'local resources and constraints' (pg. 74). At the same time, the model also foregrounds the process in which a learner's agency and the consequences of this activity 'feedbacks' into their evolving and emerging psychology. A similar framework is Mill's (2014) 'triadic reciprocity' model, where the ways in which we behave is 'collectively influenced by personal agency, self-beliefs, and external factors' (pg. 7). However, Mills (2014) looks at learners' capacity to act, i.e. agency, exclusively in relation to self-efficacy, which has been described as a highly context-specific, strongly cognitive construct (Mercer, 2011, pg. 15). Instead, my model carries a more comprehensive appreciation of the psychological factors affecting behaviour, including the emotive dimension. In my conception of learner cognition, I incorporate not only self-concept and related self-beliefs, but also domain-specific beliefs, emotions, and other mental constructs which play a role in impacting how individuals approach $L 2$ learning. In other words, language learner cognition incorporates learners' thinking about the process of language learning along with their thinking about themselves as language learners and the contexts across which this learning takes place. The framework (described in Table 20) strives to capture some of these critical factors useful in illustrating how learners' cognition develops, grows, is modified, and changes, and how this cognition interacts with language-related activity and the interpretation of it. 
MODEL Learner cognition in language learning

ORIGIN Language learner cognition; learner beliefs; Socio-cultural theory

SYSTEM Dynamic; Complex

COMPONENTS Language learner cognition; Prior experience (personal experience; experience with schooling and instruction; experience with formal knowledge); Affect; BAK; Contexts

PURPOSE Explain elements and processes of learner cognition in language learning; Guide investigations into language learner cognition in action

INNOVATIONS Changes language teacher cognition to language learner cognition; Positions BAK as a subset of learner cognition; categorises types of experience; Highlights the interconnectedness of Experience-Affect-BAK and how the interplay between these factors over space and time essentially constructs cognition

The model presents a synthesis of core concepts derived from theories and research grounded in language teacher cognition, learner beliefs, self-related constructs (e.g. self-concept) and complex systems theory and sociocultural theory. It describes a dynamic system, emphasising the inseparability of an individual's mind, their behaviour and a 'socially stratified world' (Sealey \& Carter, 2004, pg. 184), where individuals function both as 'products and producers of their environments' (Mills, 2014, pg. 7). Contextual factors are positioned as 'dimensions of the system' (Larsen-Freeman \& Cameron, 2008, pg.204) where changes in context impact directly and indirectly on different levels of the system. The model is rooted in the idea that complex adaptive systems themselves exist at varying interconnected levels, such as the inter-intra personal, the home, the classroom, the community, and the nation (Byrne, 2002). To account for development, it focuses specifically on the interplay over time between language learner cognition and language learning activity. As an adaptive system, it considers that the development of behaviour is based on the intermingling of prior and present-day interactions. As the FGG (2009) argue, 'speakers" behaviour is based on past interactions, and current and past interactions together feed forward into future behaviour' (pg. 2). Classifications of experience, BAK, and affect are shown to directly influence the construction of a learner's larger cognition. Moreover, as subsets of this overarching cognition, BAK, affective factors, self-concept, and self-beliefs, are in dynamic interplay within and across this socially developed, mental phenomenon. Prior experience, a 'crucial factor affecting an individual speaker's linguistic behaviour' (FGG, 2009, pg.13) also influences the development of BAK and affect. Additionally, different types of day-to-day language-related activity 'become' prior experience. The process of internal and external reflection, as guided here through in-depth discussion and narrative construction, is key in helping transforming this $L 2$ activity into meaningful experience. 
By presenting and describing essential components and processes borrowed from diverse traditions in language education, the model can serve as an analytical tool with which to collect, analyse, and discuss data related to the language learning process. In terms of innovations, first, the model centralises the language learner. Second, it foregrounds the relevance of quality of experience, including a distinction of types of experience, including: 'personal experience'; 'experience with schooling and instruction'; and 'experience with formal knowledge' (Richardson, 1996, pg. 105-106). Third, it positions experience, affect, and BAK as interwoven subsets of a larger more sophisticated cognitive system. They become the focal points for examination, while recognising that cognition is more than just the sum of these parts. Finally, the model is predicated on established theories of development which stress how the interaction between various contextual elements is as much a factor in the construction of 'learner cognition' as is the interplay between thoughts (the mental) and behaviour (the social). This model is meant to operate less as a precise account of the processes of language learning development and more as a framework to help organise and examine particular phenomena which has been systematically identified as relevant to second/foreign language education. It is a lens to help manage the exploration of the context-specific complexity involved in an individual's experience with language learning.

The model is also very much addressing the importance of incorporating a historical perspective (Jensen, 1939; Wertsch, 1998) on the holistic study of learner development. By accounting for a learner's history, i.e. prior experiences, it centralises the idea of change over time and recognises how our current and future cognitive-behavioural make-up is rooted in past interaction. Like any social activity, language learning outside of the classroom takes place in and over time and space; it is a dynamic process, where 'everything involved', including the participants, 'comes from somewhere; everything has a past' (Freeman, 2006, pg. 250). In other words, our prior experiences shape not only how we behave now but also how we may behave in the future. The past, therefore, is not some static or finite feature, but instead a continuously influencing force, directing today's and tomorrow's language-related behaviour. Freeman (2006) cautions against the tendency to ignore the past when centralising the present. He argues that an overreliance on the 'immediacy' of teaching-learning behaviour, i.e. focusing on 'the here and now', risks ignoring important trajectories of individual development which are crucial in the search for a robust understanding of learning (pg. 251). This model of learner cognition, through its dynamism and its underlying emphasis on the interconnectedness between mental and social lives, recognises language learning development as contextualised movement through both time and space. 


\section{Chapter 7 Conclusion}

'The world is a story we tell ourselves about the world'

Vikram Chandra

\subsection{Introduction}

\section{Investigating the experience of learning an additional language}

This research sought a holistic picture of the L2-learning process. Framed within an ESOL immersion context it investigated the language-related activity of a group of adult migrants beyond the formal language learning classroom. More specifically, it adopted an ethnographic approach to examine the complex interplay between language learning behaviour and the varying sociopsychological factors influencing it. The study was less concerned with learners' linguistic achievement and more with the process through which L2-related activities influence the emergence, revision and change over time in thoughts about and feelings toward L2-related issues. Bell (2002) has argued that applied linguistic research, with its tendency to overemphasise learning 'outcomes', needs to more adequately account for the 'impact of the learning experience' (pg. 209). Thus, in recognising this gap this study was in essence an exploration into the experience of learning an additional language naturalistically. This meant that beyond examining the different ways participants used and studied the L2, it explored their personal evaluations of this activity, including assessments of themselves as L2 learners. 'Experience' equated to both actual L2-related activity (i.e. using and studying the L2) and the participants' interpretation of this activity (i.e. reflecting on the use and study of the L2). Furthermore, in studying accounts of context-specific, L2-interaction from the perspective of the participants it became possible to observe how a language learner's cognition (i.e. what learners' think, know, believe, and feel in relation to their language-related behaviour) is constructed and develops over time. Concurrently, it became possible to observe how this cognition can impact consequent L2-related behaviour. The nuanced observation of cognition in action resulting from this study is able to contribute insight to similar research areas concentrating on the social psychology of language learning; namely learner belief (and belief-related) and teacher cognition studies.

Work in language teacher cognition ( e.g. Allwright, 2003) and learner beliefs (Dufva, 2003), including self-concept also carrying at their core an inherent interest in a macro-level, comprehensive view of the language learning process, has demonstrated the different ways in which certain mental constructs (e.g. beliefs; assumptions; self-knowledge) guide approaches to language learning and teaching. It is worth noting that while language teacher cognition research concentrates exclusively on teachers and learner beliefs on learners, the underlying premise running through both these fields remains the same. In other words, both language learner belief studies and research on language teacher cognition advance the position that it is this underlying mental 
construct, developed through context-specific activity and experience and in interplay with interrelated sub-constructs which govern L2 learning. With that said, the findings from this work contributed to these respective fields through a mixture of corroboration and innovation.

For example, this study's discussion (chapter 6), in illustrating the dynamic process through which a language learner's cognition emerges and develops, presented a clear reflection of Borg's (2006) assertion that while cognition and behaviour interact in a non-linear and multi-directional often unpredictable fashion (pg. 231), their mutually-informing impact is significant. Further, this research found that the communication of experience, through in-depth, reflective conversation, results not only in the 'uncovering' of underlying cognition (as Dufva 2003, has argued), but also in the consequent construction of this governing construct. In other words, talking at length and over time about L2-related activity (as a mode of experience) functioned in this study as a way of 'making sense' of this L2-related experience, for both the researcher and the participants.

The following sections provide a summary of the main findings for this study before detailing potential methodological and theoretical implications for research into the language learning process. The chapter closes with a word on directions for future research.

\subsection{Summary of main findings}

\section{RQs 1 \& 2: The impact of prior language-related experience on BAK construction and consequent L2 learning and use}

In chapter 4, RQs 1 and 2 explored the role of prior language learning experience on the construction of the participants L2-related BAK prior to arriving in New Zealand. The findings revealed that BAK develop 'with equal force' from both formal (e.g. study and use) and informal (e.g. word-of-mouth) experience with the L2. In fact, in settings where opportunity for more direct or formal experience with an $\mathrm{L} 2$ is not always possible, BAK and related affective constructs will nevertheless emerge through other means (e.g Constanza's and Silvana's observing employers communicating in a foreign language). And if the opportunity arises, this relatively abstract BAK will impact consequent experience with L2 learning and use.

The findings in chapter 4 also suggest that in contexts where the socio-economic background of individuals is not particularly stable, individuals will sometimes construct an idealised view of $L 2$ ability as a potential means to a better quality of life, for themselves and their families. However, this idealisation, rooted less in actual experience and more in 'imagination', inevitably tends to overlook or ignore many of the actual challenges involved in acquiring an additional language. In other words, the perceived promise enveloped in the ability to use a language like English (which carries a particular global prestige) often fails to recognise the very real struggles of $L 2$ learning; struggles which are amplified by a range of factors including, age and educational background. 
In relation to direct experience with the language learning process, a noteworthy finding revealed evidence across almost all of the participants of exposure to and management of language variety (Colombian Spanish vs. Ecuadorian Spanish). However, this exposure was through their L1. The participants had not considered the impact of language variety as an L2 experience. This was significant given the fact that almost all of the English language learning experiences of the participants (the primary form of experience) as Latin Americans, was through a North American variety of English; that is, the English they most experience learning and listening to was predominantly from the United States. This inevitably meant that they were not sufficiently prepared for the inherent challenges of learning a different variety of English. This lack of anticipation or recognition meant that when the participants were confronted directly with the New Zealand variety of English, their cognition needed to find ways of accommodating this phenomenon. For some, like Paco and Samantha it became a matter of adapting to this form of speaking in order to facilitate integration, while for others, like Constanza, it became, a a point of conflict, a way of understanding her lack of progress.

Finally, it was important to explore the prior language related experiences of the participants in order to catch a glimpse of their language-related BAK as they arrived in New Zealand. In understanding these key sub-sections of their cognition developed before New Zealand, I was able to more intricately explore the ways in which more current L2-interaction was impacting their cognitive development. Interestingly, only in Clara's case was there explicit evidence of developed self-related beliefs (carried low self-confidence in ability to use L2). However, all the other participants had developed, through a variety of means, individual BAK and affect which played a major role in their language (and language learning) development, which in turn, as RQ 4 makes explicit, played a significant role in their integration and settlement experiences.

\section{RQ 3: The perceived need for English across integration and settlement experiences}

While the ideal for this study would have been to work with participants who had just arrived in New Zealand to see how their immediate interactions and contact with English were interplaying with the construction of their cognition as adult language learners, this was not possible. Instead, the participants I worked with already had significant experience (approx. 1-2 years) with learning and using English in New Zealand. A positive consequence of this however, was that they were able to clearly articulate particular perceived needs for English in their current ESOL immersion context. In the first section of chapter 5 , these perceived needs, as relayed through their narratives, were outlined. There were a total of six needs identified which related to all or almost all of the participants. A seventh category identified a further three needs for English. However, these needs were only identified in one or two cases. The perceived needs for English, as the participants 
engaged and navigated their lives in Wellington, were for the most part fairly obvious and had largely been identified in other studies on immigrants and refugees in New Zealand (Watts et al., 2001; Watts et al., 2002). The results showed the following reasons for needing English:

\author{
1. Employment \\ 2. Access to information and services \\ 3. Relationship building \\ 4. Religious activity \\ 5. Independence \\ 6. Asserting oneself \\ 7. Additional \\ - Integration \\ - Passing time \\ - Helping out at home
}

The participants, in communicating their needs for English, framed a picture of their daily lives as adult language learners. In their portrayal of the various day-to-day situations where they used and 'needed' English, they outlined the different kinds of people and places they interacted with, as well as providing important personal insight into and reflection on these interactions. In fact, it was primarily through these accounts of successful and unsuccessful interactions that I was able to derive their needs for English. At the same time, through these accounts of their needs for English, it was also possible to pull out important elements of their L2-related cognition; most significantly the perception of English as an integral tool for their successful settlement into life in Wellington. In other words, as they described their needs for English, it was possible to also see, in a nuanced, richly descriptive manner, the underlying motivations for their consequent language learning endeavours. In learning about how they perceived the need for English, it was also possible to better understand what was driving their L2-related behaviour. Finally, this research question was significant in helping frame some of the significant contexts across which the participants used English. As a result it was possible to transition into an exploration of 'how' they engaged in L2activity and to what extent this engagement-type was shaping and being shaped by their cognition as language learners.

\title{
RQ 4: Storied accounts of language-related activity beyond the language learning classroom
}

The second part of chapter 5 presented a series of illustrative narratives as accounts of the participants' day-to-day experiences with English. Structured across seven contexts (i.e. religious; work; volunteer; family; social transaction; transactional interaction; self-study), the findings from these accounts revealed a variety of strategies and approaches to their L2-interaction. Moreover, these participant-accounts, as evaluations of L2-related experience, offered glimpses not only into how interaction was guiding the construction of cognition but also how it was itself being influenced 
by cognition. In the religious context for example, Sandra Milena's and Samantha's stories regarding their practice of 'translating' texts from English to Spanish, as well as from Spanish to English, revealed a positive evaluation for this activity as a means of helping navigate their L2 interactions. In Sandra Milena's case her desire to function independently as an $L 2$ user led her to adopt the practice of translating English sermons into Spanish in preparation for weekly mass (an activity she practiced regularly with her home tutor). Through this activity she developed an important self-confidence in her abilities as an effective self-directed L2 learner. This story also illustrated Sandra Milena's belief that being able to understand English is more of a priority, at the moment, than speaking; an additional example of an L2-related, self-belief.

Samantha's account of translating illustrates her BAK and affect in regards to the relationship between language learning and language maintenance. The description of her family's practice of using both a Spanish and English bible to make sense of their different lessons is positioned as a useful way of helping her and the children learn English while at the same time providing important exposure to Spanish, which she fears the children may be losing. This practice also illustrated her evaluation of this activity as being particularly useful for her face-to-face encounters at church meetings. Rooted in her experiences at church where English speakers would ask her to interpret the Spanish being used into English, she recognised that learning bible-specific language could help her communicate more clearly and accurately.

RQ 4 was useful in presenting different accounts which showed the participants learning in a variety of ways and across a variety of contexts. They learned for example through the support of others at work, through rehearsal and through self-study. The social transactional context as another example, provided an important account of the impact authentic, naturalistic interaction can have on an L2 learner's cognition. In Paco's story we observed him learning certain grammatical and phonological features through feedback from a neighbour, which he perceives as useful for his life. At the same time, his evaluation of this type of learning activity as 'superior' to the kind of interaction and learning he encountered in formal classes, communicates his negative evaluation for classroom language learning, seeing it mostly as irrelevant and incapable of teaching him the language or the skills he needs to manage his daily activity. In other words, Paco's beliefs about classroom learning (e.g. not particularly useful), beliefs about learning through authentic interaction (e.g. learn valuable language and culture; preferred method of learning), as well as beliefs about himself as a language learner (e.g. struggling with pronunciation; struggles to understand) are made evident through the construction of his account of a specific visit to a neighbour's home.

RQ 4, through a series of small, illustrative excerpts provided insight, as glimpses, into the ways in which context, cognition, and activity interplay and shape how learners approach L2interaction. However, it was limited in that it did not explore the development over time of this process. This endeavour was instead addressed in RQ 5. 
The discussion in chapter six used these glimpses to extend the description of the interplay between a group of adult migrants' developing L2 cognition and its impact on their language learning activity. It used data from a single participant to build a more nuanced portrait of the process of cognition in action. A case study approach was useful in helping look closely at the process of language learner cognition in action.

\section{RQ 5: Language learner cognition in action}

The final research question was framed around a detailed discussion (chapter 6) of the process involved in developing L2-related beliefs, assumptions, self-knowledge, and affective factors; constructs essential to the language learning process. The discussion aimed to explore how language related behaviour, as a series of $\mathrm{L} 2$ interactions or activity, could be portrayed in a model of language learner cognition. In essence, it was an attempt to depict what the process of cognitive development might 'look like', illustrating integral components affecting its change over time. A single participant was selected for this in-depth exploration, as a case study approach allowed for more fine-grained exploration, not only of L2-activity but also into the subjective representation of this activity as experience. The case study showed how in talking about and reflecting on day-to-day L2 interactions, the participant was not only communicating elements of her underlying cognition but was also constructing certain beliefs and developing certain emotions about a variety of $L 2$ related issues including (but not limited to) how she perceived herself as an L2 learner (selfconcept), how she felt about different varieties of English (attitudes toward the L2), what she believed about certain language learning activities (beliefs about language learning) and what she felt was in the end, the major barrier in her developing the ability to use English (feelings toward the sound of English). In exploring accounts of $L 2$ use over time it was also possible to see how different elements of an individual's BAK, including self-beliefs, and varying emotive reactions interplay with each other, often in chaotic and unpredictable ways, within a larger cognition. As mentioned, the discussion was particularly illuminating in depicting how through reflection on L2 activity, learners construct ways of making sense of their behaviour. In Constanza's case, her struggles to develop her speaking and listening skills, in spite of her professed determination and socio-economic need, led her, through a series of hypothesising and revising, to the 'realisation' that she carried an aversion to the sounds of English. And it is possible that this previously unrecognised distaste has affected her ability to progress with English. Over the course of the research, through a combination of our indepth conversations and her own self-reflection, she recognised that her aversion toward certain sounds in English, rooted in past experiences (e.g. recollection of unpleasant interaction with a relative and from a comparison with Spanish) was, according to her, the primary reason why she avoided speaking English, and as a result has been unable to adequately develop as an L2 learner. I also observed through her stories of $\mathrm{L} 2$ learning experiences, numerous descriptions of communication breakdowns on account of her inability to understand or produce spoken English. 
Thus, we could see how her struggles to communicate across different day-to-day L2 interactions create certain tensions (e.g. varying and conflicting BAK and affect) which impact her understanding of these experiences, and how this understanding operates across different levels of awareness and influence.

Finally, it was possible to observe a powerful dynamism at work between the context of interaction, the learner's cognition, and the L2-related activity. For example, in a face-to-face, social transactional context, Constanza has developed negative feelings and beliefs about herself and her capabilities as an L2-user. Her evaluation of these interaction-types impacts her to the extent that she avoids, whenever possible, this L2-related activity, all the while aware that this is precisely the type of communication she needs to take advantage of if she wants to advance her English. When the context is 'switched' however, and face-to-face interaction becomes (spoken) online communication, Constanza carries more positive beliefs in her ability to communicate, and her feelings of anxiety and embarrassment are reduced. The very fact that she is attempting spoken interaction (as opposed to running away from it), something she would normally not engage in, reflects the powerful influence of context on cognition in action.

Through the discussion, constructed around a different analytical dimension, five crucial, macro-level components (Experience; BAK \& Affect; Cognition; Language related activity; Contexts) in dynamic interaction were identified as integral to language learning development. It was these components which when looked at as perpetually in action, over time, reflected a model of language learner cognition; a model which I hope can contribute to how L2 research explores languagelearning experience. The sections below describe potential theoretical and methodological contributions for this study.

\subsection{Theoretical contribution}

This study's primary theoretical contribution lies in the conceptual model of language learner cognition presented in chapter six. While previous work in language teacher cognition has been successful in producing models of teachers' cognition at work (Woods, 1996; Borg, 2006: Macalister, 2010) across a range of contexts and in relation to various language related topics, including approaches to teaching reading (Johnson, 1992), pronunciation (Baker, 2014), and grammar (Phipps \& Borg, 2009), work on language learning and learners has not been as diligent in producing a framework with which to explore the totality of the L2 learning process. With the exception of Mercer's (2011) excellent -'network' based framework, which argues that learners make 'unanticipated connections' across contexts and belief systems, models centralising the learners within a complex, social constructionist view of development and learning are almost nonexistent.

The model I present builds on the work conducted in language teacher cognition, which at its core takes an expansive view of the mental constructs guiding L2-related behaviour. In other 
words, it argues that beyond beliefs there are a host of other socially constructed variables, including attitudes, assumptions, self-concept, self-knowledge, and varying emotions at play across a learner's mental life. Moreover, in regards to beliefs, it illustrates a varying range of beliefs (e.g. selfbeliefs; beliefs about speaking English) in dialectic interaction. The model also recognises some of the limitations of learner belief studies which seek to describe learners' behaviour through overlynarrow or particular aspects of their psychology. However, in centralising the language learner as an active agent in the $\mathrm{L} 2$ learning process, it incorporates an essential (the most essential) component from research conducted on learner beliefs. A learner's experience in L2 interaction is situated as the primary unit of analysis, carrying particular implications for research interested in understanding not only how, but also why, individuals do what they do in their roles as L2 learners. The model, offering a way of theorising a language learner's cognition in action, can add value to the field of second langauge acquisition, particularly when it is adopted across a range of formal and informal contexts.

\subsection{Methodological contribution}

In terms of methodological contributions, this study demonstrated the value of adopting indepth, unstructured interviews in the exploration of L2-related cognition. As mentioned, cognition, whether in language learners or teachers, operates often at an unobservable level. Furthermore, individuals themselves are often unaware of their own cognition and its impact on their own behaviour. Through conversation-like interviews, told over time, in the participants' L1, the participants, as novice language learners, constructed stories or narratives which carried these underlying beliefs, assumptions, feelings, and attitudes regarding the $L 2$ learning process to the surface and allowed them to be evaluated, by both the researcher and the participants. While narratives have been used often across the social sciences to explore experience in a variety of different settings (Barkhuizen, 2011, 2013; Barkhuizen et al., 2014; Bell, 2002; Clandinin, 2006; Menard-Warwick, 2009), very few investigations have used this approach with the explicit intention of investigating learners' cognition. This may be partly rooted in the challenge of defining what constitutes 'evidence' of cognition. In Borg's (2006) discussion of the methodologies adopted to examine language teacher cognition, he comments that 'Different kinds of evidence reflect different assumptions about the nature of teacher cognition' (pg. 279). The majority of studies on learner beliefs and teacher cognition adopt self-report instruments, semi-structured interviews, and stimulated recall in conjunction with some forms of observation. The assumption is that participants can, when asked, talk about their cognition. The main issue with these approaches is in recognising how accurately these statements and reports can reflect the complexity and interrelationship of an individual's thoughts and feelings. When a person is asked to talk specifically about their beliefs, such as learning pronunciation, or to explain what they were thinking while analysing recorded behaviour, it is likely that they only present a fraction of the cognitive system underlying their activity and interaction. However, when the participants talk at length, guiding the discussion of 
their own accord and providing descriptions of their experiences over time, it becomes possible to 'see' how certain underlying mental constructs are at work behind their activity. Moreover, as the methods for this research have shown, talking about experience, not only facilitates the communication of cognition, it also sparks its construction and consequent evolution.

\subsection{Implications \& directions for future research: Language learner cognition across contexts}

\section{Implications}

This study yielded some important implications. First, it has helped raise awareness of the everyday, lived experiences of adult migrants and refugees in New Zealand as it relates to learning and using English. Specifically, this research offers a rare, rich and nuanced picture of some important integration and settlement issues facing New Zealand society as a whole. The Office of Ethnic Affairs (2014) in their relatively recent publication, 'Language and Integration in New Zealand', informs us that the majority of migrants arriving in New Zealand are from non-English speaking backgrounds, a trend which shows no indication of slowing down. In order for New Zealand as a nation (i.e., local and national government, communities,schools, other private and public institutions), to best accommodate and manage this phenomenon in an equitable and beneficial manner for all parties involved, it will be important to put together both a macro and micro-level understanding of what is taking place across a range of settings. Large-scale government-supported research on refugees and migrants has been conducted (cf. Ministry of Social Development, 2008; Office of Ethnic Affairs, 2014; Watts et al., 2001; Watts et al., 2002) and has been integral in informing policy and action. For example, the call for easier, more affordable access to English language provision for migrants and refugees in New Zealand was met with increased funding and promotion from the government. However, very few studies, beyond some very important work in language attrition and bilingualism, (Kim \& Starks, 2010), maintenance (Revis, 2015), L2 identity construction (Soltani, 2015; Walker, 2004), and language shift and loss (Roberts, 1999) have explored at a qualitative-interpretive level the 'migrant' or 'refugee experience' as it relates to L2 challenges in New Zealand (see also the work of Joudi Kadri, 2009). Thus, with this picture of L2related integration and settlement in New Zealand continuing to grow, this study can make a positive contribution to its ongoing development. Through highly personal accounts and stories of their everyday lives, the participants take us into their homes, their communities, their classes, as well as to a host of different social interactions, inviting us to experience with them what it means to be an adult language learner in a second language immersion context. And equally important, we can imagine with confidence very similar types of experiences for the majority of incoming L2 adult migrants. 
This research also carries implications for New Zealand's approach to a national language policy. The different ways each of the participants approached their language learning and use (including their interactions in the L1) and the different ways they perceived the management of L1L2 use at home and beyond was primarily a result of personal intuition, and thus it could be argued that this reflected choices made without adequate awareness of the consequenecs of their decisions. The families in this study all lacked the necessary support to help them make the best decisions possible for themselves and their children regarding language use and language learning. An official language policy formally recognising the value of a multilingual nation would make it possible to set up different national and local institutions to help incoming adult migrants better understand their choices when it comes to balancing their L1-L2 use. These institutions would be able to provide resources and information, including specific strategies and family language plans, that would ensure not only more effective integration but also a more positive experience for both the migrants and the host community. Calls have previously been made for New Zealand to adopt an official language policy (Waite, 1992) as a means of supporting heritage language maintenance and L2 learning (Office of Ethnic Affairs, 2014). This research illustrates, from the perspective of the migrants, some of the issues directly connected with this challenge as it can affect, again, not only Colombian immigrants and refugees, but also all other unique speech communities from non-English speaking backgrounds living and learning in New Zealand.

\section{Future directions}

With that said, holistic approaches to research such as this one, despite their attempts to include rather than reduce, will inevitably need to sidestep key aspects of the phenomenon under investigation. This study which carried at its core an interest in exploring the naturalistic L2 experiences of a group of migrants, while providing insight into a relatively undocumented area of investigation, was forced to disregard certain conditions equally significant to the $L 2$ learning process. However, in many ways that is the nature of research; questions are asked, parameters are set, investigations are conducted, and knowledge is built. And from this knowledge, new questions arise. In this study, while the focus was specifically on out of class L2 interaction and its impact on learner development, it became increasingly obvious that an influential variable affecting this development was the in-class language learning that these migrants were experiencing. In other words, as much as their day-to-day interactions were impacting their cognition as L2 users, their more formal communication in the classroom was also shaping them and their perceptions as $\mathrm{L} 2$ learners; perceptions which were impacting their out of class interaction. To what extent the pedagogical approaches adopted by their classroom teachers were effective, as well as the influence of working alongside other L2 learners, was not considered. Future research would benefit from adopting the model of language learner cognition introduced in chapter six to a more formal language learning context. This application would serve to further refine and test the value of this 
framework in helping us gain deeper understanding of learners' behaviour and a richer appreciation of their $L 2$ experiences as they relate to learning both in and out of the classroom.

Additionally, studies on adult migrants in New Zealand would benefit from a closer exploration of the language teaching and learning practices adopted across classrooms. As Roach and Roskvist (2007) have previously argued, very few studies have investigated the effectiveness of adult ESOL programs (pg. 55). Furthermore, questions regarding what this 'effectiveness' entails would benefit from systematic study. For example, research needs to look at the impact of ESOL classes on learners' acquisition of the language (How effective are these lessons in helping the learners become competent language users?). There were numerous suggestions throughout the narratives of my participants that the classes were deemed ineffective in preparing adult learners for the management of their daily lives. While it is difficult to comment on the validity of these statements, it is nevertheless worth further exploration.

Beyond the need to look at the effectiveness of the pedagogy, it would be equally important to study the content, or ideas, being transferred to these particular types of language learners. For example, how are questions of bilingualism, language loss and maintenance, and integration and settlement, being addressed? How are lessons impacting the evolving identities of these individuals? Again, while this study did not explicitly explore classroom communication, there were glimpses of learners feeling (and being) marginalised or disempowered, largely as a consequence of their L2 ability. Also, opportunities to help empower learners through the process of language learning (i.e. in class activity or content or content) did not seem to be at all prevalent in their accounts. Magro (2007) has argued that 'resettlement issues cannot be separated from language development and teachers should work from a broad definition of literacy that includes not only numeracy, problem solving, and the ability to read, write and speak English, but also emotional and social literacies such as motivation, interpersonal effectiveness, critical thinking, and cultural awareness' (pg.8). Thus, exploring the implementation and impact of more critical pedagogies such as Canagarajah (1999) and Phillipson (2006) have advocated, on learners' cognition and consequent behaviour would be a worthwhile endeavour. Adult migrants from non-English speaking contexts in ESOL settings remain largely on the periphery; a disempowered group whose key to socio-econimic and personal growth and well-being is intrinsically linked to an L2 and its use. If however, communities and classrooms can come together, through a mixture of principled pedagogy and more critical applied linguistic practice, at best it could have an empowering effect on these individuals' perceptions of themselves, and at least serve to raise expectations of what and who they can become. 


\section{References}

Agar, M. (2004). We have met the other and we're all nonlinear: Ethnography as a nonlinear dynamic system. Complexity, 10(2), 16-24. doi: 10.1002/cplx.20054

Alanen, R. (2006). A sociocultural approach to young language learners' beliefs about language learning. In P. Kalaja \& A. M. F. Barcelos (Eds.), Beliefs about SLA: New research approaches (pp. 55-85). New York: Springer.

Alford, R. L., \& Strother, J. B. (1990). Attitudes of native and nonnative speakers toward selected regional accents of US English. Tesol Quarterly, 479-495.

Allen, L. (1996). The evolution of a learner's beliefs about language learning. Carleton Papers in Applied Language Studies, 13, 67-80.

Allwright, D. (2003). Exploratory practice: Rethinking practitioner research in language teaching. Language Teaching Research, 7(2), 113-141. doi: 10.1191/1362168803Ir118oa

Altinkaya, J., \& Omundsen, H. (1999). " Birds in a Gilded Cage": Resettlement Prospects for Adult Refugees in New Zealand. Social Policy Journal of New Zealand, 31-42.

Anning, A. (1988). Teachers' theories about children's learning. In J. Calderhead (Ed.), Teachers' professional learning (pp. 128-145). London: Falmer

Appel, R., \& Muysken, P. (2006). Language contact and bilingualism. Amsterdam: Amsterdam University Press.

Aragão, R. (2011). Beliefs and emotions in foreign language learning. System, 39(3), 302-313. doi: 10.1016/j.system.2011.07.003

Aro, M. (2015). In Action and Inaction: English Learners Authoring Their Agency Beliefs, Agency and Identity in Foreign Language Learning and Teaching (pp. 48-65). New York: Springer.

Ashton, P. (2015). Historical overview and theoretical perspectives of research on teachers' beliefs. In H. Fives \& M. Gregoire Gill (Eds.), International handbook of research on teachers' beliefs (pp. 31-47). New York: Routledge.

Atkinson, D., Byrnes, H., Doran, M., Duff, P., Ellis, N. C., Hall, J. K., . . Negueruela, E. (2016). A Transdisciplinary Framework for SLA in a Multilingual World. Modern Language Journal, 1947.

Baker, A. (2014). Exploring teachers' knowledge of second language pronunciation techniques: Teacher cognitions, observed classroom practices, and student perceptions. TESOL Quarterly, 48(1), 136-163.

Bandura, A. (1997). Self - efficacy. New York: W.H. Freeman and Co.

Bandura, A. (2006). Guide for constructing self-efficacy scales. In F. Pajares \& T. Urdan (Eds.), Selfefficacy beliefs of adolescents (Vol. 5, pp. 307-337). Greenwich: Information Age Publishing.

Baquedano-Lopez, P., \& Figueroa, A. M. (2011). Language socialisation and immigration. In A. Duranti, E. Ochs \& B. B. Schieffelin (Eds.), The handbook of language socialization (pp. 536563): Blackwell Publishing 
Barcelos, \& Kalaja, P. (2011). Introduction to beliefs about SLA revisited. System, 39(3), 281-289. doi: http://dx.doi.org/10.1016/j.system.2011.07.001

Barcelos, A. M. F. (2000). Understanding teachers' and students' language learning beliefs in experience: A Deweyan approach (Unpublished PhD dissertation). The University of Alabama.

Barcelos, A. M. F. (2006). Researching beliefs about SLA: A critical review. In P. Kalaja \& A. M. F. Barcelos (Eds.), Beliefs about SLA: New research approaches (pp. 7-33). New York: Springer.

Barcelos, A. M. F. (2015). Student Teachers' Beliefs and Motivation, and the Shaping of Their Professional Identities Beliefs, Agency and Identity in Foreign Language Learning and Teaching (pp. 71-96). New York: Springer.

Barkhuizen, G. (1998). Discovering learners' perceptions of ESL classroom teaching/learning activities in a South African context. Tesol Quarterly, 85-108.

Barkhuizen, G. (2011). Narrative knowledging in TESOL. Tesol Quarterly, 45(3), 391-414. doi: $10.5054 /$ tq.2011.261888

Barkhuizen, G. (2015). Learning English with a home tutor: Meeting the needs of migrant learners. In D. Nunan \& J. C. Richards (Eds.), (pp. 282-292). New York: Routledge.

Barkhuizen, G. (Ed.). (2013). Narrative research in applied linguistics. Cambridge: Cambridge university press.

Barkhuizen, G., Benson, P., \& Chik, A. (2014). Narrative inquiry in language teaching and learning research. New York: Routledge.

Barkhuizen, G., \& Knoch, U. (2005). Missing Afrikaans:'Iinguistic longing'among Afrikaans-speaking immigrants in New Zealand. Journal of Multilingual and Multicultural Development, 26(3), 216-232.

Barkhuizen, G., \& Wette, R. (2008). Narrative frames for investigating the experiences of language teachers. System, 36(3), 372-387. doi: 10.1016/j.system.2008.02.002

Barnard, I. (2006). Anti-Ethnography? Composition Studies, 34(1), 95.

Beckner, C., Blythe, R., Bybee, J., Christiansen, M. H., Croft, W., Ellis, N., . . Schoenemann, T. (2009). Language is a complex adaptive system: Position paper. Language learning, 59, 1-26.

Bell, J. S. (2002). Narrative inquiry: More than just telling stories. Tesol Quarterly, 36(2), 207-213.

Bellingham, L. (2004). Is there language acquisition after 40 ? Older learners speak up. In P. Benson \& D. Nunan (Eds.), Learners' Stories: Difference and Diversity in Language Learning (pp. 56-68). Cambridge: Cambridge University Press.

Benseman, J. (2012). Adult refugee learners with limited literacy: Needs and effective responses. English Language Partners New Zealand. Retrieved from http://unitec.researchbank.ac.nz/bitstream/handle/10652/2107/adult-refugee-learnerswith-limited-literacy-needs-and-effective-responses.pdf?sequence=1\&isAllowed=y

Benson, P. (2001). Teaching and researching Autonomy in language learning. Harlow: Pearson Education. 
Benson, P. (2004). (Auto)biography and learner diversity In P. Benson \& D. Nunan (Eds.), Learners' stories: Difference and diversity in language learning (pp. 4-21). Cambridge: Cambridge University Press.

Benson, P. (2011). Language learning and teaching beyond the classroom: An introduction to the field. In P. Benson \& H. Reinders (Eds.), Beyond the language classroom (pp. 7-16). UK: Palgrave Macmillan.

Benson, P., \& Reinders, H. (Eds.). (2011). Beyond the language classroom. UK: Palgrave Macmillan.

Berg, B. L. (2001). Qualitative research methods for the social sciences (4th ed.). Boston: Allyn and Bacon.

Bigelow, M., \& Schwarz, R. L. (2010). Adult English language learners with limited literacy. National Institute for Literacy.

Blaker, J., \& Hardman, S. (2001). Jumping the barriers: Language learning with refugees groups in New Zealand. Paper presented at the I.A.C.D Rotorua.

Block, D. (2005). Multilingual identities in a global city: London stories. New York: Palgrave Macmillan.

Blommaert, J., \& Jie, D. (2010). Ethnographic fieldwork. Bristol: Multilingual Matters.

Borg, S. (1998). Teachers' pedagogical systems and grammar teaching: A qualitative study. Tesol Quarterly, 32(1), 9-38. doi: 10.2307/3587900

Borg, S. (2003). Teacher cognition in language teaching: A review of research on what language teachers think, know, believe, and do. Language Teaching, 36(2), 81-109. doi: $10.1017 /$ S0261444803001903

Borg, S. (2006). Teacher cognition and language education: Research and practice. London: Continuum.

Borg, S. (2011). The impact of in-service teacher education on language teachers' beliefs. System, 39(3), 370-380. doi: http://dx.doi.org/10.1016/i.system.2011.07.009

Borg, S. (2012). Current approaches to language teacher cognition research: A methodological analysis. In R. Barnard \& A. Burns (Eds.), Researching language cognition and practice: International case studies (pp. 11-29). Bristol: Multilingual Matters.

Britzman, D. (1991). Practice makes practice: A critical study of learning to teach. New York: State University of New York Press.

Brousseau, B. A., Book, C., \& Byers, J. L. (1988). Teacher beliefs and the cultures of teaching. Journal of Teacher Education, 39(6), 33-39.

Browne, K. (2005). Snowball sampling: using social networks to research non-heterosexual women. International Journal of Social Research Methodology, 8(1), 47-60. doi:

10.1080/1364557032000081663

Bryman, A. (Ed.). (2001). Ethnography (Vol. 1 of 4). London: Sage. 
Buehl, M. M., \& Beck, J. S. (2015). The relationship between teachers' beliefs and teachers' practices. In H. Fives \& M. Gregoire Gill (Eds.), International handbook of research on teachers' beliefs (pp. 66-84). New York: Routledge.

Burnard, P. (1991). A method of analysing interview transcripts in qualitative research. Nurse education today, 11(6), 461-466. doi: 10.1016/0260-6917(91)90009-Y

Byrne, D. (2002). Interpreting quantitative data. London: Sage.

Cameron, D., Frazer, E., Harvey, P., Rampton, B., \& Richardson, K. (1993). Ethics, advocacy and empowerment: issues of method in researching language. Language \& Communication, 13(2), 81-94. doi: 10.1016/0271-5309(93)90001-4

Canagarajah, A. S. (1999). Resisting linguistic imperialism in English teaching. Oxford: Oxford University Press.

Carlgren, I., Handal, G., \& Vaage, S. (1994). Teachers' minds and actions: Research on teachers' thinking and practice. London: The Falmer Press.

Chapelle, C. A., \& Duff, P. A. (2003). Some guidelines for conducting quantitative and qualitative research in TESOL. Tesol Quarterly, 37(1), 157-178. doi: 10.2307/3588471

Clandinin, D. J. (2006). Narrative inquiry: A methodology for studying lived experience. Research studies in music education, 27(1), 44-54. doi: 10.1177/1321103X060270010301

Clandinin, D. J., \& Connelly, F. M. (1987). Teachers' personal knowledge: What counts as 'personal' in studies of the personal. Journal of Curriculum Studies, 19(6), 487-500. doi:

$10.1080 / 0022027870190602$

Clark. (1980). Choice of a model for research on teacher thinking. Journal of Curriculum Studies, 12(1), 41-47. doi: 10.1080/0022027800120105

Clark, \& Clark, E. (1977). Psychology and language: An introduction to pyscholinguistics. New York: Harcourt Brace Jovanovich.

Cobb, P. (1994). Where is the mind? Constructivist and sociocultural perspectives on mathematical development. Educational Researcher, 23(7), 13-20.

Cole, M. (1985). The zone of proximal development: Where culture and cognition create each other. In J. V. Wertsch (Ed.), Culture, communication, and cognition: Vygotskian perspectives (pp. 146-161). Cambridge: Cambridge University Press.

Collins, J., Slembrouck, S., \& Baynham, M. (2009). Globalization and language in contact: Scale, migration, and communicative practices. London: A\&C Black.

Connelly, F. M., \& Clandinin, D. J. (1990). Stories of experience and narrative inquiry. Educational researcher, 19(5), 2-14. doi: 10.3102/0013189X019005002

Cotterall, S. (1999). Key variables in language learning: what do learners believe about them? System, 27(4), 493-513. doi: 10.1016/S0346-251X(99)00047-0

Couper, G. (2002). ESOL course evaluation through a survey of post-course experiences. The TESOLANZ Journal, 10, 36-51. 
Coviello, N. E., Brodie, R. J., \& Munro, H. J. (2000). An investigation of marketing practice by firm size. Journal of business venturing, 15(5), 523-545.

Cowie, N. (2009). Observation. In J. Heighanm \& R. A. Croker (Eds.), Qualitative research in applied linguistics: A practical introduction (pp. 165-181). New York: Palgrave.

Creswell, J. W. (2009). Research design: Qualitative, quantitative, and mixed methods approaches (3rd ed.). Thousand Oaks: Sage Publications.

Creswell, J. W. (2012). Qualitative inquiry and research design: Choosing among five approaches. Thousand Oaks: Sage Publishing.

Creswell, J. W., \& Miller, D. L. (2000). Determining validity in qualitative inquiry. Theory into practice, 39(3), 124-130. doi: 10.1207/s15430421tip3903_2

Cross francis, D., Rapacki, L., \& Eker, A. (2015). The individual, the context, and practice: A review of the research on teachers' beliefs related to mathematics. In H. Fives \& M. Gregoire Gill (Eds.), International handbook of research on teachers' beliefs. New York: Routledge.

Crystal, D. (2003). English as a global language (2nd ed.). Cambridge: Cambridge University Press.

Crystal, D. (2012). English as a global language (2nd ed.). New York: Cambridge University Press.

Davis, K. A. (1995). Qualitative theory and methods in applied linguistics research. Tesol Quarterly, 29(3), 427-453.

Day, C., Calderhead, J., \& Denicolo, P. (Eds.). (1993). Research on teacher thinking: Understanding professional development. London: The Falmer Press.

de Vaus, D. (2001). Research design in social research. Thousand Oaks: Sage Publications.

DeMarrais, K., \& Lapan, S. D. (2004). Preface. In K. DeMarrais \& S. D. Lapan (Eds.), Foundations for research: Methods of inquiry in education and the social Sciences (pp. xi-xiii). Mahwah, New Jersey: London.

Divita, D. (2011). Becoming multilingual: An ethnographic approach to SLA beyond the classroom. In P. Benson \& H. Reinders (Eds.), Beyond the language classroom (pp. 72-87). UK: Palgrave Macmillan.

Donato, R., \& McCormick, D. (1994). A sociocultural perspective on language learning strategies: The role of mediation. The Modern Language Journal, 78(4), 453-464. doi: 10.1111/j.15404781.1994.tb02063.x

Dörnyei, Z. (2005). The psychology of the language learner: Individual differences in second language acquisition. Cambridge: Cambridge University Press.

Dörnyei, Z. (2007). Research methods in applied linguistics: Quantitative, qualitative, and mixed methodologies. Oxford: Oxford University Press.

Dörnyei, Z. (2009). Language as a complex adaptive system In N. Ellis \& D. Larsen-Freeman (Eds.), Language as a complex adaptive system. Malden, MA: Wiley-Blackwell.

Dörnyei, Z., \& Ryan, S. (2015). The psychology of the language learner revisited. New York: Routledge. 
Dörnyei, Z., \& Ushioda, E. (2009). Motivation, language identity and the L2 self (Vol. 36): Multilingual Matters.

Duff, P. (2006). Beyond generalizability: Contextualization, complexity, and

credibility in Applied Linguistics. In M. Chalhoub-Deville, C. A. Chapelle \& P. A. Duff (Eds.), Inference and generalizability in applied linguistics (pp. 65-95). Amsterdamn: John Benjamins.

Duff, P. (2008). Case study research in applied linguistics. New York: Taylor \& Francis.

Duff, P. (2012). How to carry out case study research. In A. Mackey \& S. Gass (Eds.), Research methods in second language acquisition: A practical guide (pp. 96-116). Malden, MA: WileyBlackwell.

Dufva, H. (2003). Beliefs in dialogue: A Bakhtinian view. In P. Kalaja \& A. M. F. Barcelos (Eds.), Beliefs about SLA: New research approaches (pp. 131-151). New York: Springer.

Dunstan, S., Roz, D., \& Shorland, P. (2004a). Refugee Voices: A Journey Towards Resettlement, Wellington. Wellington, New Zealand.

Duranti, A., Ochs, E., \& Schieffelin, B. B. (Eds.). (2011). The handbook of language socialization (Vol. 72): Wiley-Blackwell.

Dyson, A. H., \& Genishi, C. (2005). On the case: Approaches to language and literacy research. NY, New York: Teachers College Press.

Early, M., \& Norton, B. (2013). Narrative inquiry in second language teacher education in rural Uganda. In G. Barkhuizen (Ed.), Narrative Research in Applied Linguistics (pp. 132-151). Cambridge: Cambridge university press.

Ellis, N., \& Larsen-Freeman, D. (2006). Language emergence: Implications for applied linguisticsIntroduction to the special issue. Applied linguistics, 27(4), 558-589. doi: 10.1093/applin/aml028

Ellis, N., \& Larsen-Freeman, D. (Eds.). (2009). Language as a complex adaptive system (Vol. 3): John Wiley \& Sons.

Ellis, R. (2008). The study of second language acquisition (Second ed.). Oxford: Oxford University Press.

Engeström, Y., Miettinen, R., \& Punamäki, R.-L. (1999). Perspectives on activity theory. Cambridge: Cambridge University Press.

Erickson, F. (1986). Qualitative methods in research on teaching. In M. C. Wittrock (Ed.), Handbook of research on teaching (pp. 119-161). New York, NY: Collier-Macmillan.

Ezzy, D. (2002). Qualitative analysis: Practice and innovation. London: Routledge.

Feiman-Nemser, S. (1983). Learning to teach. In L. Shulman \& G. Sykes (Eds.), Handbook of teaching and policy (pp. 150-171). New York: Longman.

Feldman, M. S., Bell, J., \& Berger, M. T. (2003). Gaining access: A practical and theoretical guide for qualitative researchers. Oxford, UK: Rowman Altamira.

Fincham, B. (2006). Back to the 'old school': Bicycle messengers, employment and ethnography. Qualitative Research, 6(2), 187-205. 
Fives, H., \& Buehl, M. M. (2012). Spring cleaning for the "messy" construct of teachers' beliefs: What are they? Which have been examined? What can they tell us. In K. R. Harris, S. Graham \& T. Urdan (Eds.), APA educational psychology handbook: Vol. 2 Individual differences and cultural and contextual factors (pp. 471-499). Washington, DC: American Psychologist Association.

Font, J., \& Mendez, M. (Eds.). (2014). Surveying ethnic minorities and immigrant populations. Amsterdam: Amsterdam University Press.

Forgas, J. P. (Ed.). (2001). Feeling and thinking: The role of affect in social cognition. Cambridge: Cambridge University Press.

Franken, M., \& McCormish, J. (2003). Improving English language outcomes for students receiving ESOL services in New Zealand schools, with a particular focus on new immigrants. Wellington, New Zealand: Report to the Ministry of Education.

Freeman, D. (1996). "To Take Them at Their Word": Language Data in the Study of Teachers' Knowledge. Harvard Educational Review, 66(4), 732-762.

Freeman, D. (2002). The hidden side of the work: Teacher knowledge and learning. Language Teaching, 35, 1-13. doi: 10.1017/S0261444801001720

Freeman, D. (2006). Teaching and learning in the age of 'reform': The problem of the verb. In S. Gieve \& I. K. Miller (Eds.), Understanding the language classroom (pp. 239-262). Basingstoke: Palgrave Macmillan.

Freeman, D. (2012). Focus groups: Commentary. In R. Barnard \& A. Burns (Eds.), Researching language teacher cognition and practice: International case studies (pp. 68-89). Bristol: Mulitlingual Matters.

Gaddis, J. L. (2002). The landscape of history: How historians map the past. Oxford: Oxford University Press.

Gall, M. D., Gall, J. P., \& Borg, W. T. (2003). Educational research (7th ed.). White Plains: Pearson Education.

Geraghty, B., \& Conacher, J. (Eds.). (2014). Intercultural Contact, Language Learning and Migration. London: Bloomsbury

Gharibi, K., \& Boers, F. (under review). Influential factors in incomplete acquisition and attrition of young heritage speakers' vocabulary knowledge. Language Acquisition.

Golombek, P. R., \& Johnson, K. E. (2004). Narrative inquiry as a mediational space: examining emotional and cognitive dissonance in second-language teachers' development. Teachers and Teaching: Theory and Practice, 10(3), 307-327.

Gombert, J. E. (1994). How do illiterate adults react to metalinguistic training? Annals of Dyslexia, 44(1), 250-269.

Gregoire Gill, M., \& Fives, H. (2015). Introduction. In M. Gregoire Gill \& H. Fives (Eds.), International handbook of research on teachers' beliefs (pp. 1-10). New York: Routledge.

Grol, R., \& Grimshaw, J. (2003). From best evidence to best practice: effective implementation of change in patients' care. The Lancet, 362(9391), 1225-1230. 
Guskey, T. R. (2002). Professional development and teacher change. Teachers and Teaching: Theory and Practice, 8(3), 381-391.

Haddix, M. (2009). Black boys can write: Challenging dominant framings of African American adolescent males in literacy research. Journal of Adolescent \& Adult Literacy, 53(4), 341-343.

Hayes, D. (2005). Exploring the lives of non - native speaking English educators in Sri Lanka. Teachers and teaching, 11(2), 169-194.

Heyl, B. S. (2001). Ethnographic interviewing. In P. Atkinson, A. Coffey, S. Delamont, J. Lofland \& L. Lofland (Eds.), Handbook of ethnography (pp. 369-383). London: Sage.

Holland, J., Thomson, R., \& Henderson, S. (2006). Feasibility study for a possible qualitative longitudinal study: A discussion paper. London: South Bank University, 21, 1-61.

Holstein, J. A., \& Gubrium, J. F. (2003). Active interviewing. In J. F. Gubrium \& J. A. Holstein (Eds.), Postmodern interviewing (pp. 67-80). Thousand Oaks: Sage.

Horwitz, E. K. (1985). Using student beliefs about language learning and teaching in the foreign language methods course. Foreign Language Annals, 18(4), 333-340. doi: 10.1111/j.19449720.1985.tb01811.x

Horwitz, E. K. (1988). The beliefs about language learning of beginning university foreign language students. The Modern Language Journal, 72(3), 283-294. doi: 10.1111/j.15404781.1988.tb04190.x

Horwitz, E. K. (1999). Cultural and situational influences on foreign language learners' beliefs about language learning: A review of BALLI studies. System, 27(4), 557-576. doi: 10.1016/S0346$251 \times(99) 00050-0$

Hosenfeld, C. (2006). Evidence of emergent beliefs of a second language learner: A diary study. In P. Kalaja \& A. M. F. Barcelos (Eds.), Beliefs about SLA: New research approaches (pp. 37-55). New York: Springer.

Jensen, K. (1939). Genetic method. Review of Educational Research, 491-497.

Johnson, K. E. (1992). The relationship between teachers' beliefs and practices during literacy instruction for non-native speakers of English. Journal of Literacy Research, 24(1), 83-108.

Johnson, K. E. (1994). The emerging beliefs and instructional practices of preservice English as a second language teachers. Teaching and teacher education, 10(4), 439-452. doi: 10.1016/0742-051X(94)90024-8

Johnson, K. E., \& Vasudevan, L. (2012). Seeing and hearing students' lived and embodied critical literacy practices. Theory Into Practice, 51(1), 34-41. doi: 10.1080/00405841.2012.636333

Joudi Kadri, R. (2009). Resettling the unsettled: The refugee journey of Arab Muslims to New Zealand. $\mathrm{PhD}$, Auckland University of Technology, Auckland.

Kachru, Y., \& Nelson, C. L. (2006). World Englishes in Asian contexts. Hong Kong: Hong Kong University Press. 
Kagan, D. M. (1990). Ways of evaluating teacher cognition: Inferences concerning the Goldilocks principle. Review of Educational Research, 60(3), 419-469. doi:

$10.3102 / 00346543060003419$

Kalaja, P. (2006). Research on students' beliefs about SLA within a discursive approach. In P. Kalaja \& A. M. F. Barcelos (Eds.), Beliefs about SLA: New research approaches (pp. 87-108). New York: Springer.

Kalaja, P., \& Barcelos, A. M. F. (Eds.). (2006). Beliefs about SLA: New research approaches (2nd ed.). New York: Springer.

Kalaja, P., Barcelos, A. M. F., Aro, M., \& Ruohotie-Lyhty, M. (2015). Beliefs, agency and identity in foreign language learning and teaching. New York: Springer.

Kelly, R. (1996). Language counselling for learner autonomy: the skilled helper in self-access language learning. In R. Pemberton, E. S. L. Li, W. W. F. Or \& H. Pierson, D (Eds.), Taking control: Autonomy in language learning (pp. 93-113). Hong Kong: Hong Kong University Press.

Kim, S. H. O., \& Starks, D. (2010). The role of fathers in language maintenance and language attrition: the case of Korean-English late bilinguals in New Zealand. International Journal of Bilingual Education and Bilingualism, 13(3), 285-301.

Knowles, J. G. (1992). Models for teachers' biographies. In I. Goodson (Ed.), Stuyding teachers' lives (pp. 99-152). New York: Teachers College Press.

Korthagen, F. A. (2010). Situated learning theory and the pedagogy of teacher education: Towards an integrative view of teacher behavior and teacher learning. Teaching and teacher education, 26(1), 98-106.

Kramp, M. K. (2004). Exploring life and experience through narrative inquiry. In K. deMarrais \& S. D. Lapan (Eds.), Foundations for research: Methods of inquiry in education and the social sciences (pp. 103-121). New Jersey: Lawrence Erlbaum Associates.

Kvale, S., \& Brinkmann, S. (2009). Interviews: Learning the craft of qualitative research interviewing. Los Angeles: Sage.

Labov, W. (1972). Language in the inner city: Studies in the Black English vernacular (Vol. 3). Philadelphia: University of Pennsylvania Press.

Lantolf, J., \& Thorne, S. (2006). Sociocultural theory and the genesis of second language development (Vol. 398). Oxford: Oxford University Press.

Larsen-Freeman, D. (2007). On the complementarity of chaos/complexity theory and dynamic systems theory in understanding the second language acquisition process. Bilingualism language and cognition, 10(1), 35. doi: 10.1017/S136672890600277X

Larsen-Freeman, D., \& Cameron, L. (2008a). Complex systems and applied linguistics. Oxford: Oxford University Press.

Larsen-Freeman, D., \& Cameron, L. (2008b). Research methodology on language development from a complex systems perspective. The Modern Language Journal, 200-213.

Lave, J. (1991). Situating learning in communities of practice. Perspectives on Socially Shared Cognition, 2, 63-82. 
Lave, J., \& Wenger, E. (1991). Situated learning: Legitimate peripheral participation: Cambridge University Press.

Lemke, J. L. (2000). Across the scales of time: Artifacts, activities, and meanings in ecosocial systems. Mind, culture, and activity, 7(4), 273-290. doi: 10.1207/S15327884MCA0704_03

Lerman, S. (2002). Situating research on mathematics teachers' beliefs and on change. In G. C. Leder, E. Pehkonen \& G. Torner (Eds.), Beliefs: a hidden variable in mathematics education ( $p p$. 233-243). Netherlands: Springer.

Lewis, C., \& Tierney, J. D. (2013). Mobilizing emotion in an urban classroom: Producing identities and transforming signs in a race-related discussion. Linguistics and Education, 24(3), 289-304. doi: 10.1016/j.linged.2013.03.003

Lin, A., \& Martin, P. W. (2005). Decolonisation, globalisation: Language-in-education policy and practice (Vol. 3). Clevedon: Multilingual Matters.

Little, D. (2007). Language learner autonomy: Some fundamental considerations revisited. International Journal of Innovation in Language Learning and Teaching, 1(1), 14-29.

Lortie, D. (1975). Schoolteacher: A sociological study. Chicago: University of Chicago Press.

Macalister, J. (2010). Investigating teacher attitudes to extensive reading practices in higher education: Why isn't everyone doing it? RELC Journal, 41(1), 59-75. doi:

10.1177/0033688210362609

Macalister, J. (2012). Narrative frames and needs analysis. System, 40(1), 120-128. doi: http://dx.doi.org/10.1016/j.system.2012.01.010

Macalister, J., \& Musgrave, J. (2015). Dissonance and balance: The four strands framework and preservice teacher education. In T. Farrell (Ed.), International perspectives on English language teacher education (pp. 74-89). New York: Palgrave.

Mackey, A., \& Polio, C. (2010). Multiple perspectives on interaction: Second language research in honor of Susan M. Gass. New York: Routledge.

Magid, M., \& Chan, L. (2012). Motivating English learners by helping them visualise their Ideal L2 Self: lessons from two motivational programmes. Innovation in Language Learning and Teaching, 6(2), 113-125.

Magro, K. (2007). Overcoming the Trauma of War: Literacy Challenges of Adults Learners. Education Canada, 47(1), 70-74.

Mahn, H., \& John-Steiner, V. (2002). The gift of confidence: A Vygotskian view of emotions. In G. Wells \& G. Claxton (Eds.), Learning for life in the 21st century: socio-cultural perspectives of future education. (pp. 46-59). Oxford: Blackwell Publishing.

Mann, S. (2011). A Critical Review of Qualitative Interviews in Applied Linguistics. Applied linguistics, 32(1), 6-24. doi: 10.1093/applin/amq043

McKenzie, R. M. (2008). Social factors and non - native attitudes towards varieties of spoken English: a Japanese case study. International Journal of Applied Linguistics, 18(1), 63-88.

McLeod, J. (2011). Qualitative research in counselling and psychotherapy. London: Sage. 
Meijer, P. C., Verloop, N., \& Beijaard, D. (1999). Exploring language teachers' practical knowledge about teaching reading comprehension. Teaching and Teacher Education, 15(1), 59-84.

Menard-Warwick, J. (2009). Gendered identities and immigrant language learning. Bristol: Multilingual Matters.

Mercer, S. (2011a). Language learner self-concept: Complexity, continuity and change. System, 39(3), 335-346. doi: http://dx.doi.org/10.1016/j.system.2011.07.006

Mercer, S. (2011b). Towards an understanding of language learner self-concept (Vol. 12). New York: Springer.

Mercer, S., Ryan, S., \& Williams, M. (Eds.). (2012). Psychology for language learning: Insights from research, theory and practice. New York: Palgrave Macmillan.

Mercer, S., \& Williams, M. (Eds.). (2014). Multiple perspectives on the self in SLA. Bristol: Multilingual Matters.

Miller, G. A., Galanter, E., \& Pribram, K. H. (1960). Plans and the structure of behavior. New York: Holt

Mills, N. A. (2014). Self-efficacy in second language acquisition. In S. Mercer \& M. Williams (Eds.), Multiple perspectives on the self in SLA (pp. 6-22).

Mills, N. A., Pajares, F., \& Herron, C. (2007). Self - efficacy of college intermediate French students: Relation to achievement and motivation. Language learning, 57(3), 417-442.

Ministry of Education. (2003). The Adult ESOL Strategy. Retrieved September 31, 2013, from http://www.minedu.govt.nz/ /media/MinEdu/Files/EducationSectors/TertiaryEducation/Ad ultESOLStrategyPDF.pdf

Ministry of Social Development. (2008). Diverse communities - Exploring the migrant and refugee experience in New Zealand. Strategic social policy group.

Mishler, E. G. (1986). Research interviewing: Context and narrative. Cambridge, Massachusetts: Harvard University Press.

Morrison, B. R., \& Navarro, D. (2012). Shifting roles: From language teachers to learning advisors. System. doi: 10.1016/j.system.2012.07.004

Mozzon-McPherson, M. (2007). Supporting independent learning environments: An analysis of structures and roles of language learning advisers. System, 35(1), 66-92.

Mozzon-McPherson, M. (2014). The skills of counselling in advising: language as a pedagogic tool. In L. Carson \& J. Mynard (Eds.), Advising in language learning: Dialogue, tools and context (pp. 43-64). New York: Routledge.

Munby, H. (1982). The place of teachers' beliefs in research on teacher thinking and decision making, and an alternative methodology. Instructional Science, 11(3), 201-225.

Muñoz, C. (2008). Symmetries and asymmetries of age effects in naturalistic and instructed L2 learning. Applied Linguistics, 29(4), 578-596. 
Muñoz, C., \& Singleton, D. (2011). A critical review of age-related research on L2 ultimate attainment. Language teaching, 44(01), 1-35. doi: 10.1017/S0261444810000327

Mynard, J., \& Carson, L. (Eds.). (2014). Advising in language learning: Dialogue, tools and context. New York: Routledge.

Mynard, J., \& Navarro, D. (2010). Dialogue in self-access learning. Paper presented the JALT, Tokyo.

n.a. (2006). Settlement through English: A history of ESOL Home Tutors, from http://englishlanguage.org.nz/sites/englishlanguage/files/kcfinder/files/Settlement\%20Thro ughEnglishWeb.pdf

Nation, I. S. P. (2001). Learning vocabulary in another language. Cambridge: Cambridge University Press.

Navarro, D., \& Thornton, K. (2011). Investigating the relationship between belief and action in selfdirected language learning. System, 39(3), 290-301. doi: http://dx.doi.org/10.1016/j.system.2011.07.002

Nespor, J. K. (1985). The role of beliefs in the practice of teaching: Final report of the teachers beliefs study: University of Texas at Austin. R\&D Center for Teacher Education.

Norton, B. (2013). Identity and language learning: Extending the conversation: Multilingual matters.

Nunan, D. (2003). The Impact of English as a Global Language on Educational Policies and Practices in the Asia - Pacific Region*. TESOL Quarterly, 37(4), 589-613.

Nunan, D., \& Richards, J. C. (2015). Language learning beyond the classroom. New York: Routledge.

O'Loughlin, M. (2006). Embodiment and education: Exploring creatural existence (Vol. 15). Netherlands: Springer.

O'Reilly, K. (2005). Ethnographic methods. London: Routledge.

O'Reilly, K. (2009). Key concepts in ethnography. Los Angeles: Sage.

Ochs, E. (1991). Socialization through Language and Interaction: A Theoretical Introduction. Issues in Applied Linguistics, 2(2), 143-147.

Office of Ethnic Affairs. (2014). Language and intergration in New Zealand. Wellington: Retrieved from http://ethniccommunities.govt.nz/sites/default/files/files/LanguageandlntegrationinNZ.pdf.

Ortega, L. (2014a). Experience and success in late bilingualism. Paper presented at the AILA world congress, Brisbane, Australia.

Ortega, L. (2014b). Understanding second language acquisition. New York: Routledge.

Ortega, L., \& Iberri-Shea, G. (2005). Longitudinal research in second language acquisition: Recent trends and future directions. Annual Review of Applied Linguistics, 25, 26-45. doi: $10.1017 /$ S0267190505000024

Ostrander, S. A. (1993). "Surely you're not doing this just to be helpful" Access, rapport, and interviews in three studies of elites. Journal of contemporary Ethnography, 22(1), 7-27. 
Oxford, R. L. (1989). Use of language learning strategies: A synthesis of studies with implications for strategy training. System, 17(2), 235-247.

Pajares, F. (1992). Teachers' beliefs and educational research: Cleaning up a messy construct. Review of Educational Research, 62(3), 307-332. doi: 10.3102/00346543062003307

Pajares, F., \& Miller, M. D. (1994). Role of self-efficacy and self-concept beliefs in mathematical problem solving: A path analysis. Journal of educational psychology, 86(2), 193.

Pan, L., \& Block, D. (2011). English as a "global language" in China: An investigation into learners' and teachers' language beliefs. System, 39(3), 391-402.

Patton, M. Q. (1990). Qualitative evaluation and research methods (2 ed.). Newbury Park: Sage Publications.

Patton, M. Q. (2001). Purposeful sampling. In A. Bryman (Ed.), Ethnography (Vol. 2, pp. 106-121). London: Sage.

Patton, M. Q. (2002). Qualitative research and evaluation methods (3rd ed.). Thousand Oaks: Sage Publications.

Pavlenko, A. (2007). Autobiographic narratives as data in applied linguistics. Applied Linguistics, 28(2), 163-188. doi: 10.1093/applin/amm008

Pearson, N. (2004). The idiosyncrasies of out-of-class language learning: A study of mainland Chinese students studying English at tertiary level in New Zealand. Paper presented at the Proceedings of the Independent Learning Conference 2003.

Peirce, B. N. (1995). Social Identity, Investment, and Language Learning. Tesol Quarterly, 29(1), 9-31.

Pellegrino, V. A. (2005). Study abroad and second language use: Constructing the self. Cambridge: Cambridge University Press.

Peng, J.-E. (2011). Changes in language learning beliefs during a transition to tertiary study: The mediation of classroom affordances. System, 39(3), 314-324. doi:

10.1016/j.system.2011.07.004

Pennycook, A. (2000). English, politics, ideology: From colonial celebration to postcolonial performativity. Ideology, politics, and language policies: Focus on English, 6, 107-120.

Pettigrew, A. M. (1990). Longitudinal field research on change: Theory and practice. Organization Science, 1(3), 267-292.

Phillipson, R. (2006). Language policy and linguistic imperialism. An introduction to language policy: Theory and method, 346-361.

Phipps, S., \& Borg, S. (2009). Exploring tensions between teachers' grammar teaching beliefs and practices. System, 37(3), 380-390.

Podesva, R. J., \& Sharma, D. (2014). Research Methods in Linguistics. Cambridge: Cambridge University Press.

Polkinghorne, D. E. (2005). Language and meaning: Data collection in qualitative research. Journal of Counseling Psychology, 52(2), 137. doi: 10.1037/0022-0167.52.2.137 
Putnam, R. T., \& Borko, H. (2000). What do new views of knowledge and thinking have to say about research on teacher learning? Educational researcher, 4-15. doi:

10.3102/0013189X029001004

Rajadurai, J. (2007). Intelligibility studies: A consideration of empirical and ideological issues. World Englishes, 26(1), 87-98.

Rampton, B. (2007). Neo - Hymesian linguistic ethnography in the United Kingdom. Journal of Sociolinguistics, 11(5), 584-607.

Ranta, L., \& Meckelborg, A. (2013). How much exposure to English do international graduate students really get? Measuring language use in a naturalistic setting. Canadian modern language review, 69(1), 1-33.

Revis, M. S. (2015). Family language policies of refugees: Ethiopians and Colombians in New Zealand. $\mathrm{PhD}$, Victoria university of Wellington, Wellington.

Richardson, V. (1996). The role of attitude and beliefs in learning to teach. In T. Buttery, E. Guyton \& J. Sikula (Eds.), Handbook of research on teacher education: A project of the Association of Teacher Educators (pp. 102-119): New York: Macmillan.

Richardson, V., Anders, P., Tidwell, D., \& Lloyd, C. (1991). The relationship between teachers' beliefs and practices in reading comprehension instruction. American educational research journal, 28(3), 559-586. doi: 10.3102/00028312028003559

Riessman, C. K. (1993). Narrative Analysis. Newbury Park, CA: Sage.

Riley, P. (1997). The guru and the conjurer: Aspects of counseling for self-access. In: P. Benson \& P. Voller (eds.) Autonomy and independence in language learning (pp. 114-131). New York: Longman.

Roach, K., \& Roskvist, A. (2007). ESOL provision for adult immigrants and refugees in New Zealand: Policy, practice and research. Prospect: An Australian journal of TESOL, 22(3), 44-63.

Roberts, M. L. (1999). Immigrant language maintenance and shift in the Gujarati, Dutch and Samoan communities of Wellington. PhD, Victoria University of Wellington, Wellington.

Rock, P. (2001). Symbolic interactionism and ethnography. In P. Atkinson, A. Coffey, S. Delamont, J. Lofland \& L. Lofland (Eds.), Handbook of ethnography (pp. 26-38). London: Sage.

Rogers, C., R. (1951). Client-centered therapy: Its current practice, implications and theory. Boston: Houghton Mifflin.

Schoenfeld, A. H. (2011). How we think: A theory of goal-oriented decision making and its educational applications. New York: Routledge.

Schutz, P. A., \& DeCuir, J. T. (2002). Inquiry on emotions in education. Educational Psychologist, 37(2), 125-134. doi: 10.1207/S15326985EP3702_7

Sealey, A., \& Carter, B. (2004). Applied linguistics as social science. London: Continuum

Seals, C., A. (forthcoming ). Pasifika Heritage Languages in New Zealand. In O. Kagan, M. Carreira \& C. Chik (Eds.), Handbook on Heritage Language Education: From Innovation to Program Building. New York: Routledge. 
Seidlhofer, B. (1999). Double standards: Teacher education in the expanding circle. World Englishes, 18(2), 233-245.

Seidlhofer, B. (2005). English as a lingua franca. ELT journal, 59(4), 339.

Seidman, I. (2006). Interviewing as qualitative research: A guide for researchers in education and the social sciences. New York: Teachers college press.

Seidman, I. (2013). Interviewing as qualitative research: A guide for researchers in education and the social sciences. New York: Teachers College Press.

Sfard, A. (1998). On two metaphors for learning and the dangers of choosing just one. Educational researcher, 27(2), 4-13. doi: 10.3102/0013189x027002004

Shavelson, R. J. (1976). Teachers' decision making. In N. L. Gage (Ed.), The psychology of teaching methods: The 75th yearbook of the national society for the study of education (pp. 372-414). Chicago: University of Chicago Press.

Shavelson, R. J., \& Stern, P. (1981). Research on teachers' pedagogical thoughts, judgments, decisions, and behavior. Review of Educational Research, 51(4), 455-498. doi: 10.3102/00346543051004455

Shulman, L. (1986). Those who understand: Knowledge growth in teaching. Educational researcher, 4-14.

Shulman, L. (1987). Knowledge and teaching: Foundations of the new reform. Harvard educational review, 57(1), 1-23.

Shulman, L., \& Shuman, J. (2004). How and what teachers learn: A shifting perspective. Journal of Curriculum Studies, 36(2), 257-271. doi: 10.1080/0022027032000148298

Skehan, P. (1991). Individual differences in second language learning. Studies in second language acquisition, 13(02), 275-298.

Skott, J. (2015). Towards a participatory approach to 'beliefs' in mathematics education. In B. Pepin \& B. Roesken-Winter (Eds.), From beliefs to dynamic affect systems in mathematics education (pp. 3-23). Dordrecht: Springer.

Soltani, B. (2015). International students' language socialization in New Zealand tertiary institutions: A spatial analysis. PhD, Victoria University of Wellington

Spence, G. P. (2004). The Practice of Policy in New Zealand. Current Issues in Language Planning, 5(4), 389-406. doi: 10.1080/14664200408668265

Starks, D., \& Paltridge, B. (1996). A note on using sociolingustic methods to study non - native attitudes towards English. World Englishes, 15(2), 217-224.

Strauss, A., \& Corbin, J. (1990). Basics of qualitative research: Grounded theory procedures and techniques. Thousand Oaks: Sage Publications.

Sutton, R. E., \& Wheatley, K. F. (2003). Teachers' emotions and teaching: A review of the literature and directions for future research. Educational Psychology Review, 15(4), 327-358. doi: 1040-726X/03/1200-0327/0 
Swain, M. (2013). Cognitive and affective enhancement among older adults: The role of languaging. Australian Review of Applied Linguistics, 36(1).

Swann, J., \& Maybin, J. (2008). Sociolinguistic and ethnographic approaches to language and gender. In K. Harrington, L. Litosseliti, H. Sauntson \& J. Sunderland (Eds.), Gender and language research methodologies (pp. 21-28). Basingstoke, UK: Palgrave Macmillan.

Talmy, S. (2010). Qualitative interviews in applied linguistics: From research instrument to social practice. Annual Review of Applied Linguistics, 30(1), 128-148. doi: http://dx.doi.org/10.1017/S0267190510000085

Teachers of English to speakers of other languages Aotearoa New Zealand. (2003). Refugees learning English

Thompson, A. G. (1992). Teachers' beliefs and conceptions: A synthesis of the research. In D. A. Grouws (Ed.), Handbook of research on mathematics teaching and learning (pp. 127-146). New York: Macmillan.

Trainor, J. S. (2008). The emotioned power of racism: An ethnographic portrait of an all-white high school. College Composition and Communication, 6(1), 82-112.

UNHCR. (2014). UNHCR resettlement handbook (New Zealand). Geneva: Retrieved from http://www.unhcr.org/46f7c0ee2.pdf.

Vygotsky, L. L. S. (1978). Mind in society: The development of higher psychological processes. Cambridge: Harvard University Press.

Waite, J. (1992). Aoteareo: Speaking for ourselves: A discussion on the development of a New Zealand languages policy. Learning Media, Wellington.

Walker, U. T. (2004). Language migration and continuity of being - notions of migrant language proficiency and self-concept among migrants in Aotearoa-New Zealand. Doctor of Philosophy, Massey University

Watson-Gegeo, K. A. (1988). Ethnography in ESL: Defining the essentials. Tesol Quarterly, 22(4), 575592. doi: $10.2307 / 3587257$

Watts, N., White, C., \& Trlin, A. (2001). English language provision for adult immigrants and/or refugees from non-English speaking backgrounds in educational institutions and training establishments in New Zealand. Palmerston North: New Settlers Programme, Massey University.

Watts, N., White, C., \& Trlin, A. (2002). New Zealand as an English-language learning environment: Immigrant experiences, provider perspectives and social policy implications. Social Policy Journal of New Zealand, 148-162.

Wenden, A. L. (1998). Metacognitive Knowledge and Language Learning. Applied linguistics, 19(4), 515-537. doi: 10.1093/applin/19.4.515

Wertsch, J. V. (1998). Mind as action. New York: Oxford University Press.

Wetherell, M. (2012). Affect and emotion: A new social science understanding. Los Angeles: Sage Publications. 
White, C. (1999). Expectations and emergent beliefs of self-instructed language learners. System, 27(4), 443-457. doi: http://dx.doi.org/10.1016/S0346-251X(99)00044-5

Woods, D. (1996). Teacher cognition in language teaching: Beliefs, decision-making and classroom practice. Cambridge: Cambridge University Press.

Woods, D. (2006). The social construction of beliefs in the language classroom. In P. Kalaja \& A. M. F. Barcelos (Eds.), Beliefs about SLA: New research approaches (pp. 201-229). New York: Springer.

Woolfolk Hoy, A., Davis, H., \& Pape, S. J. (2006). Teacher knowledge and beliefs. In P. A. Alexander \& P. H. Winne (Eds.), Handbook of educational psychology (2 ed., pp. 715-737). Mahwah: Erbaum.

Wright, C. (2006). Speaking English beyond the classroom: Identifying barriers and effecting change. The TESOLANZ Journal, 14, 32-46.

Yager, K. (1998). Learning Spanish in Mexico: The effect of informal contact and student attitudes on language gain. Hispania, 898-913.

Yang, J.-S., \& Kim, T.-Y. (2011). Sociocultural analysis of second language learner beliefs: A qualitative case study of two study-abroad ESL learners. System, 39(3), 325-334. doi:

http://dx.doi.org/10.1016/j.system.2011.07.005

Yin, R. K. (2003). Applications of case study research. Thousand Oaks: Sage.

Yinger, R. J. (1986). Examining thought in action: A theoretical and methodological critique of research on interactive teaching. Teaching and Teacher Education, 2(3), 263-282. doi: $10.1016 / 50742-051 \times(86) 80007-5$

Zembylas, M. (2005). Beyond teacher cognition and teacher beliefs: The value of the ethnography of emotions in teaching. International Journal of Qualitative Studies in Education, 18(4), 465487. doi: $10.1080 / 09518390500137642$

Zhang, W., \& Hu, G. (2008). Second language learners' attitudes towards English varieties. Language Awareness, 17(4), 342-347. 


\section{Appendix A: Information sheets (English \& Spanish)}

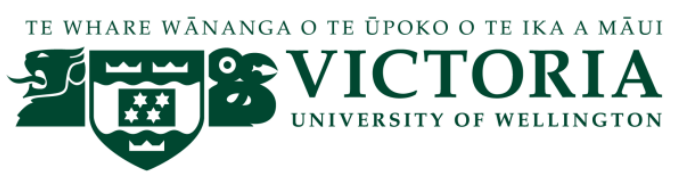

\section{The interaction between thinking and activity in migrants' language-related experiences}

I am a researcher (PhD candidate) in the School of Linguistics and Applied Language Studies at Victoria University of Wellington. I am interested in studying how your thoughts and actions interact across different language-related situations. The Victoria University of Wellington Human Ethics Committee has granted ethical approval for this research.

I would like to talk with you, about your language learning experiences (past and present). I would also like to observe you interacting in different language related settings. These conversations will take no longer than one hour. We can discuss times and venues of these interviews. As I am interested in exploring how your different interactions relate to development in your thinking, I would like to work with you for an extended period of time. Observations will be carried out over a period of one year. We can negotiate the dates and times of these observations as we progress with the study.

No names will be used in this study, and all data will be presented anonymously.

During the project all data will be stored securely. Only my supervisors and I will have access to the data. All data will be destroyed two years after the completion of the research project. Findings may be presented at seminars, conferences or in publications.

Your participation in this project is completely voluntary. You may withdraw up to six months from the date your first interview. If you choose to withdraw, your records will be removed from the data.

If you have any questions about this research project, please feel free to talk to me about it. My contact details are at the end of this sheet.

Thank you.

Diego Navarro

diego.navarro@vuw.ac.nz

Tel: 4635637

Office: VZ 411
John Macalister (Primary Supervisor)

John.Macalister@vuw.ac.nz

Tel: 4635609

Office VZ 211 

experiencias relacionadas con el idioma de los migrantes

Soy un investigador (candidato a doctorado) en la Escuela de Linguística y Estudios Aplicados de la Lengua en la Universidad Victoria de Wellington. Estoy interesado en estudiar cómo los pensamientos y acciones interactúan a través de diferentes situaciones relacionadas con el idioma. El comité de ética humana de Victoria University of Wellington ha concedido la aprobación ética para esta investigación.

Me gustaría poder hablar con usted sobre sus experiencias de aprendizaje de idiomas (pasado y presente). También me gustaría observarle interactuando en diferentes situaciones relacionadas con los idiomas. Las conversaciones no duraran más de una hora y podemos conversar sobre el lugar y fecha que le sea más cómodo.

Me interesa explorar cómo sus diferentes interacciones están relacionadas con el desarrollo de su pensamiento, por lo que me gustaría trabajar con usted por un período de tiempo prolongado. Las observaciones se realizarían por el período de un año. Podemos negociar las fechas y los tiempos de estas observaciones mientras que progresamos con el estudio.

Ningún nombre se utilizará en este estudio, y todos los datos se presentarán de forma anónima.

Durante el proyecto todos los datos se almacenarán de forma segura. Sólo mis supervisores y yo tendremos acceso a los datos. Todos los datos serán destruidos dos años después de la terminación del proyecto de investigación. Los resultados pueden ser expuestos en seminarios, conferencias o publicaciones.

Su participación en este proyecto es completamente voluntaria. Usted podrá retirarse hasta seis meses desde la fecha de su primera entrevista. Si opta por retirarse, los registros se eliminarán de los datos.

Si tiene alguna pregunta sobre este proyecto, por favor no dude en contactarse conmigo. Mi información de contacto está al final de esta página.

Muchas gracias.

Diego Navarro

diego.navarro@vuw.ac.nz

Tel: 4635637

Office: VZ 411
John Macalister (Primary Supervisor)

John.Macalister@vuw.ac.nz

Tel: 4635609

Office VZ 211 


\section{Appendix B: Consent forms (English \& Spanish)}

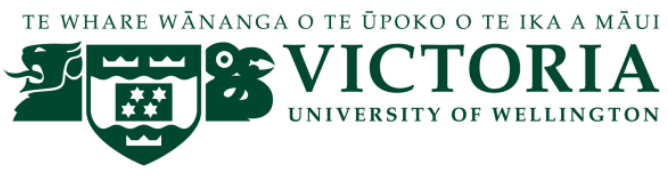

Please sign and date this form to indicate you are willing to participate in this project

- I have read the information sheet for this research project.

- I have had the details explained to me.

- I have had an opportunity to ask questions.

- I understand that participation in this study is voluntary.

- I understand that I can withdraw from this project for any reason up to six months after the date of my first interview.

- I understand that any data I provide will be confidential, and that no names will be used in any report of the project.

Name

Signature

Date

Please tick here if you wish to receive a copy of a written summary of the study at the end of the project, and give below an e-mail address to which this summary can be sent: ?

Email address: 
Por favor firme y feche este formulario para indicar que está dispuesto a participar en este proyecto.

- He leído el documento de información para este proyecto de investigación.

- Me han explicado todos los detalles.

- He tenido la oportunidad de hacer preguntas.

- Entiendo que la participación en este estudio es voluntaria.

- Entiendo que puedo retirarme de este proyecto por cualquier razón, hasta seis meses después de la fecha de mi primera entrevista.

- Entiendo que cualquier dato que proporcione será confidencial, y que ningún nombre se usará en el proyecto.

\section{Nombre}

\section{Firma}

\section{Fecha}

Por favor marque aquí si desea recibir una copia del resumen escrito del estudio al final del proyecto e indíquenos una dirección de correo electrónico a la cual enviarlo: [?

correo electrónico 


\section{Appendix C: Human ethics approval}

TE WHARE WENANGA O TE OPOKO O TE IKA A MAUT

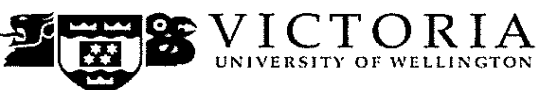

MEMORANDUM

Phone $\quad 0-4-4635676$

Fax $\quad 0-4-4635209$

Email Allison.kirkmaneruw.ac.n

\begin{tabular}{l|l}
\hline TO & Diego Navarro \\
\hline COPY TO & John Macalister \\
\hline FROM & Dr Allison Kirkman, Convener, Human Ethics Committee \\
\hline
\end{tabular}

\begin{tabular}{l|l}
\hline DATE & 5 June 2013 \\
\hline PAGES & 1 \\
\hline
\end{tabular}

SUBJECT $\quad$ Ethics Approval: 19847

Adult migrants' language learning beyond the classroom: A

sociocultural exploration of cognition in action

Thank you for your application for ethical approval, which has now been considered by the Standing Committee of the Human Ethics Committee.

Your application has been approved from the above date and this approval continues until 31 October 2015. If your data collection is not completed by this date you should apply to the Human Ethics Committee for an extension to this approval.

Best wishes with the research

Allison Kirkman

Human Ethics Committee 


\section{Appendix D: Indirect observation tool (English \& Spanish)}

\section{Interacting in English}

\section{(1) What did you do this week?}

- $\quad$ Give details of the interactions you had where you used English

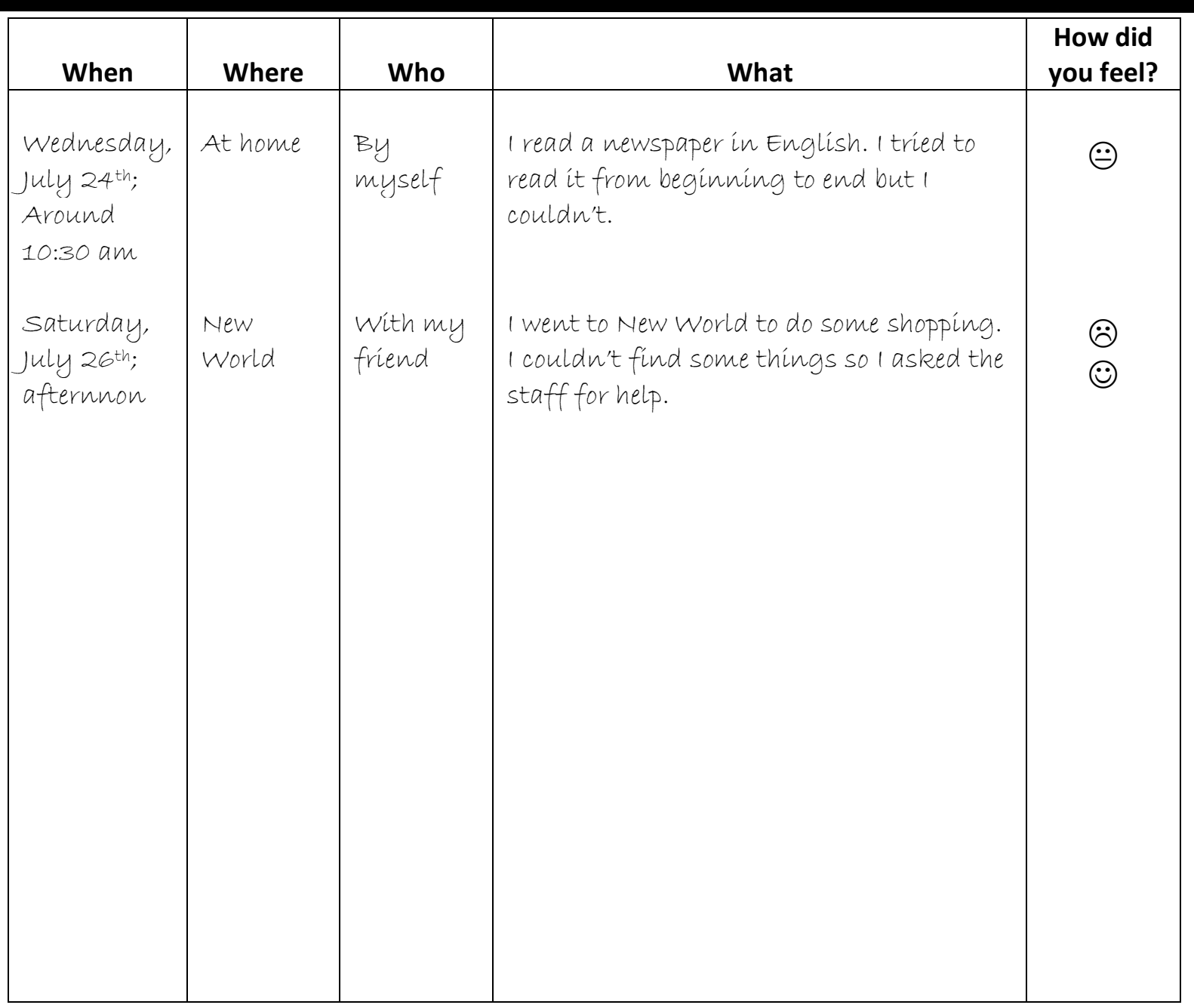

2 Comments: Feel free to write about the experiences you listed, or their effects on you

Reading the newspaper was a little boring and hard. I didn't feel good that I couldn't finish it all. I am not sure if I will try it again. And going to New world was a little confusing - it was hard trying to find the food I wanted and reading all the information in English. I wasn't too comfortable because it was really crowded and there were so many people. Still, I could ask for what I wanted and understand what the staff said-1 felt good about that. 
Interactuando en inglés

(1) ¿Qué hiciste esta semana?

- Dar detalles de las interacciones que tuviste cuando usastes el inglés

\begin{tabular}{|c|c|c|c|c|}
\hline Cuando & Donde & $\begin{array}{l}\text { Con } \\
\text { quien }\end{array}$ & Que & $\begin{array}{l}\text { ¿Cómo te } \\
\text { sentiste? }\end{array}$ \\
\hline $\begin{array}{l}\text { Miércoles, } \\
24 \text { de } \\
\text { julio; } \\
\text { Alrededor } \\
\text { de 10:30 }\end{array}$ & En mí casa & Sola & $\begin{array}{l}\text { Lé el periódico en inglés, trate de leerlo de } \\
\text { principio a fin pero no pude. }\end{array}$ & $\bigodot$ \\
\hline $\begin{array}{l}\text { sábado, } \\
26 \text { de } \\
\text { julio; en } \\
\text { la tarde }\end{array}$ & supermercado & $\begin{array}{l}\text { conmi } \\
\text { amiga }\end{array}$ & $\begin{array}{l}\text { Fui al supermercado para hacer algunas } \\
\text { compras pero me fue dificil encontrar } \\
\text { todo lo que quería, asi que pedi ayuda al } \\
\text { personal. }\end{array}$ & $\begin{array}{l}\ddot{\theta} \\
\ddot{\theta}\end{array}$ \\
\hline
\end{tabular}

(2)omentario: Sientete libre de escribir sobre las experiencias que has puesto en la lista y los efectos que han tenido en ti.

Leer el periódico fue un poco díficil y aburrido. No me sentí bien porque no pude terminarlo todo. No se si lo intentaré otra vez.

Ir a Nuevo Mundo fue un poco complicado porque fui dificíl encontrar la comida que quería y leer la informacion en ingles. No me senti cómodo porque habia mucha gente, pero aun asi pude preguntar por lo que buscaba y entender lo que el dependiente me dijo. Me senti bien. 


\section{Appendix E: Interview schedule dates of the interviews for all of the participants}

\begin{tabular}{|c|c|c|c|c|c|c|c|}
\hline $\begin{array}{l}\text { SEPT } \\
2013\end{array}$ & ОСТ & NOV & DEC & $\begin{array}{l}\text { JAN } \\
2014\end{array}$ & FEB & MARCH & APRIL \\
\hline $\begin{array}{c}\text { Paco } \\
8^{\text {th }} ; 30^{\text {th }}\end{array}$ & & & $\begin{array}{l}\text { Paco } \\
15^{\text {th }}\end{array}$ & & & & \\
\hline \multirow[t]{5}{*}{$\begin{array}{l}\text { Silvana } \\
8^{\text {th }}\end{array}$} & & $\begin{array}{l}\text { Silvana } \\
3^{\text {rd }}\end{array}$ & $\begin{array}{l}\text { Silvana } \\
15^{\text {th }}\end{array}$ & & & & \\
\hline & $\begin{array}{l}\text { Clara } \\
14^{\text {th }}\end{array}$ & $\begin{array}{l}\text { Clara } \\
1^{\text {st }}\end{array}$ & & & & & \\
\hline & $\begin{array}{l}\text { Samantha } \\
14^{\text {th }} ; 29^{\text {th }}\end{array}$ & & $\begin{array}{c}\text { Samantha } \\
4^{\text {th }}\end{array}$ & & $\begin{array}{c}\text { Samantha } \\
10^{\text {th }}\end{array}$ & $\begin{array}{c}\text { Samantha } \\
30^{\text {th }}\end{array}$ & $\begin{array}{c}\text { Samantha } \\
28^{\text {th }}\end{array}$ \\
\hline & & & & $\begin{array}{l}\text { Constanza } \\
13^{\text {th }} ; 30^{\text {th }}\end{array}$ & & $\begin{array}{c}\text { Constanza } \\
8^{\text {th }}\end{array}$ & $\begin{array}{c}\text { Constanza } \\
23^{\text {rd }}\end{array}$ \\
\hline & & & & $\begin{array}{l}\text { Sandra } \\
\text { Milena } \\
25^{\text {th }}\end{array}$ & $\begin{array}{l}\text { Sandra } \\
\text { Milena } \\
21^{\text {st }}\end{array}$ & $\begin{array}{c}\text { Sandra } \\
\text { Milena } \\
31^{\text {st }}\end{array}$ & \\
\hline \multirow[t]{3}{*}{ MAY } & JUNE & JULY & AUG & SEPT & OCT & NOV & DEC \\
\hline & $\begin{array}{c}\text { Samantha } \\
23^{\text {rd }}\end{array}$ & $\begin{array}{c}\text { Samantha } \\
30^{\text {th }}\end{array}$ & & $\begin{array}{c}\text { Samantha } \\
1^{\text {st }}\end{array}$ & $\begin{array}{c}\text { Samantha } \\
22^{\text {nd }}\end{array}$ & & $\begin{array}{c}\text { Samantha } \\
15^{\mathrm{TH}}\end{array}$ \\
\hline & $\begin{array}{c}\text { Constanza } \\
24^{\text {th }}\end{array}$ & & $\begin{array}{c}\text { Constanza } \\
2^{\text {nd }} ; 30^{\text {th }}\end{array}$ & $\begin{array}{c}\text { Constanza } \\
29^{\text {th }}\end{array}$ & $\begin{array}{c}\text { Constanza } \\
25^{\text {th }}\end{array}$ & $\begin{array}{c}\text { Constanza } \\
23^{\text {rd }}\end{array}$ & $\begin{array}{c}\text { Constanza } \\
15^{\mathrm{TH}}\end{array}$ \\
\hline $\begin{array}{c}\text { Sandra } \\
\text { Milena } \\
6^{\text {th }}\end{array}$ & & $\begin{array}{c}\text { Sandra } \\
\text { Milena } \\
4^{\text {th }}\end{array}$ & $\begin{array}{c}\text { Sandra } \\
\text { Milena } \\
27^{\text {th }}\end{array}$ & & $\begin{array}{l}\text { Sandra } \\
\text { Milena } \\
2^{\text {nd }}\end{array}$ & $\begin{array}{l}\text { Sandra } \\
\text { Milena } \\
20^{\text {th }}\end{array}$ & $\begin{array}{c}\text { Sandra } \\
\text { Milena } \\
17^{\mathrm{TH}}\end{array}$ \\
\hline
\end{tabular}




\title{
Appendix F: Initial interview topics (English \& Spanish)
}

\author{
Topics for initial conversation
}

1. PERSONAL INFORMATION

"Please tell me about yourself"

"Please tell me about your hometown"

"Please tell me about where you grew up?"

"What was it like growing up in...?"

\section{CURRENT SITUATION}

"How long have you been living in Wellington?"

"What brought you here?"

"What kinds of things do you do here (in Wellington) normally?"

"How would you describe your life now?"

"How would you compare your life now to when you were living in...?"

\section{EDUCATION}

"How is education perceived in your country?"

"How was education perceived by your family/friends/people around you?"

"Has education played an important role in your life?"

"Can you describe your relationship with formal education?"

"Do you remember any of your teachers or classes?"

\section{EXPERIENCES WITH LANGUAGE LEARNING (PAST AND PRESENT)}

"How is language learning perceived in your country?"

"How did your family/ friends perceived language learning?"

"In...did you have friends/know people around you who spoke other languages?"

"What was your impression of your friends/others around you who spoke other languages (English)?"

"Do you remember the first time you had to speak/use another language in real situationoutside the classroom?"

"What kind of experiences have you had with language-learning?"

"Do you think about role of English in your life now?"

"What is your impression of English in your life now?"

"Can you tell me about some of the (English) language-related experiences you have been/are having now while living here?"

\section{FUTURE-SELF}

"What would you like your life to be like in the future?"

"What would need to happen for that life to become a reality?"

"Imagine yourself in your ideal future. Describe it. Where are you? Who are you with? What are you doing?"

"What role do you see (English) language playing in your future?" 


\section{INFORMACIÓN PERSONAL}

"Por favor, cuénteme de usted"

"Por favor, cuénteme de su ciudad natal"

"Por favor, cuénteme sobre donde creció Ud.

“¿Como fue crecer en...?"

\section{SITUACION CORRIENTE}

"Cuanto tiempo has vivido en Wellington?"

"¿Que lo trajo a Ud a Wellington?

"¿Qué tipo de cosas hace Ud. normalmente"

"¿Cómo describiría su vida hoy?"

“¿Cómo compararía su vida de hoy con la vida que tuvo en...?”

\section{EDUCACIÓN}

"¿Cómo es percibida la educación en su país?"

“¿Cómo fue percibida la educación por su familia/amigos/gente alrededor suyo?"

"¿Ha jugado la educación un papel importante en su vida?"

"¿Puede describir su vinculo con la educación formal?"

"¿Usted recuerda alguno de sus profesores o clases?"

\section{EXPERIENCIAS CON EL APRENDIZAJE DE IDIOMAS (PASADO Y PRESENTE)}

"¿Como es percibido el aprendizaje de idiomas en su pais?"

"¿Cómo fue percibido por su familia/amigos/gente alrededor suyo el aprendizaje de idiomas?"

"En ... tuviste amigos que hablaban otros idiomas?/Conociste gente que hablaban otras idiomas?"

"¿Cuál fue su impresión de sus amigos y personas a su alrededor que hablan otros idiomas?" "¿Qué tipo de experiencias ha tenido Ud. con el aprendizaje de idiomas?"

"¿Recuerda la primera vez que tuvo que hablar/usar otra lengua en una situación naturalfuera de un classe?"

"¿Piensa en el papel de inglés en su vida ahora?"

"¿Me puede contar sobre las experiencias que tuvo/tiene con relación a lengua inglesa en este país?"

\section{USTED EN EL FUTURO}

"Como quisiera Ud. que sea su vida en el futuro?"

"¿Qué tendría que suceder para que esta vida sea una realidad?"

"Imagínese Ud. en su futuro ideal. Descríbalo. ¿Dónde está? ¿Con quién estas? ¿Qué estas haciendo?"

¿Qué papel piensa Ud. que el idioma ingles tiene en su futuro?” 


\section{Appendix G: Sample translations/transcriptions (Spanish)}

\section{Paco initial interview \\ September $8^{\text {th }} 2013$ \\ Total time $53 \mathrm{~m} 25 \mathrm{~s}$}

1 D: Cuentame un poco de usted?

Notes

2 P: Aver...primero me llamo Paco. Naci en Palmira Valle. Es una ciudad de

3 Colombia...de Valle de Cauca...con un buen calor...con un ambiente muy

4 allegre y no pues, osea, mi fansia fue muy vacana. Aparte que mi mama

$5 \mathrm{~m}$ pegaba mucho. Pero igual ahora veo que ella lo iso porque ella quiera

6 lo major para uno

$7 \quad(-52.33)$

8 Pero siempre me dio mucha libertad. Yo no tenia prescion (?) Mi papa

9 siempre estuvo con nosotros pero siempre trabajaba lejos en otras

10 ciudades entocnes ella estabava sola y aparte de eso tiene una problema

11 columna...enonces

$12(-52.07)$

13 aparte que no era invalidad o eso...eso tenia mucha molesta de dolor y

14 movimiento entonces nosotros tratamos no hacerla como hacer much

15 exfuerzo, no? Entonces no saiemos la responsilidad en otros. Ellos me

16 daban todo-si yo queria unos zapatos me daba zapatos, entiendes? Y me

17 gusto mucho el football y nunca me dijieron no hay que jugar o nada de

18 eso.

$19(-51.40)$

20 Pero siempre sabia que mi responsilidad era conplico la esquela entonces

21 me ivo muy bien en la esquela muy bien estudiente-pero al igual que

22 Lisete, tuvo una professora los primer 2 anos de studio que fue primero y

23 Segundo de primaria...Ohhh! Tenas!

$24(-51.27)$

25 Yo el otro dia estaba charlando con mis hijos les decia "oye...que ella ya

26 esta en el infierno"-

27 D: Era esquela solo para homres o mexclado? 
28 P: Era una esquela mixta publica. Pero la professor era muy antigua

$29(-50.55)-$

30 "la regla en la mano" - "estas sudando?" Regla!

31 D: Pero no dijiste que Palmira era una ciudad muy caloroso?

$32 \mathrm{P}: \mathrm{Si}$, pero se suppone que el descanso era para salir y tomarse la gaseosa

33 o 'Morning tea' que le llaman

$34(-50.24)$.

35 Pero nosotros eremaos ninos, yo tenia 6 anos-quieres jugar y corer...

36 "Vamos a jugar!" y yo tenia 6 anos...y ella "Llegaron los camellos los

37 chibos...Vengan pa ca"...con los mismos 5-6 (amigos) siempre cola "Hacen

38 cola". 10 en esta mano y 10 en le otra mano. Reglasos! Paaa!

$39(-50.00)$

$40 \mathrm{Y}$ cuando saliemos a leer y yo creo que yo leo bien; me consiero que yo

41 leo bien porque yo lo hecho ahora al ultimo y en otras escuelas tambien

42 leia bien y todo eso lo asia bien. Bueno no una lectura exacta pero

43 igual...para mi era que todo el mundo puede entender...pero cuando me

44 sacaban de lear y era primer ano y la primer ves que (?) la escuela porque

45 no tuve jardin...era muy dificil...Oiii me jalaban las orejas! Espantoso! Y

46 cuando me llamaron mi nombre en la lista "A leer Paco" ooo...ya estaba

47 llorando 


\title{
Appendix H: Sample translations/transcriptions (English)
}

\author{
Constanza April 23 ${ }^{\text {th }}$ \\ Indirect observation interview III \\ Time: $1 \mathrm{~h} 15 \mathrm{~m} 45 \mathrm{~s}$
}

\begin{abstract}
Background
The interview begins with Constanza telling me that she had been looking for some papers (the language-related interactions self-report docs) but says she must have thrown them out. She says she often dumps papers in the recycling... and ends up looking like 'mad' for papers she's thrown away. She says she has been recording her language-related interactions since March and laments that they are now gone. She was looking for the papers the night before in anticipation of our meeting. But they are gone. She may have tossed them in the recycling she said. I ask her if she needs more papers and she says no - she has some and will continue to write the notes.
\end{abstract}

We also talk about her relationship with Sandra Milena. The two of them she says meet every Friday for a bible meeting. It is a Spanish group. She says the woman who comes to teach/ help them with their bible study is Colombian. An immigrant woman. She goes to a church and knows about the teachings of the bible and goes to some homes for 'extra lessons'.

I mention that Sandra Milena -when she goes to church - it is all in English.

$2: 28$

$\mathrm{Y}$ : I go to a church that is all in English but the woman who comes to the house to teach me... she goes to the same church and she translates for me in the church... (D: so you go to the same church and it is all in English) yeah, it is all in English... all in English but she, as she now knows English she... (D: so you sit together and she translates...) translates. Yes.

D: and you go with the kids... all of you?

Y: well the kids... recently they don't come because they don't want to get up... (D: so you go alone?) and on top of that in church the kids get separated...they don't let them stay... they take them to a different place... they don't let them stay... since kids can't sit still so they have a separate room (D: was it the same in Ecuador... did they separated the kids?) Yes (D: when I was a kid and went to church they sometimes tried to separate us too but I never liked it) they don't like it that's why I don't take them. He doesn't like it and he wants to stay there and he starts to make trouble and my other... daughter she doesn't like either because she doesn't understand English she wants to stay there too. And so there is nowhere to put them... so it is better to leave them at home.

Adrianne hears us talking and yells out (I understand English). I ask him if he is speaking English well and if they teach him in school. He gets shy. I ask him if he likes it and he says he likes it.

4:00

$\mathrm{Y}:$ So it is better not to take them.

4:24

Y: sometimes I take Mateo but he is also... he also doesn't want to get up so I go alone.

4:50

D: and how is Mateo?

$Y$ : he is good... studying. 
D: and Mateo knows Samantha's daughter right? They go to the same school right? They say it is a bigger school now... is it secondary school?

$Y$ : no she is in intermediate school... it isn't the same school. It is apart... I am sure it is apart.

D: But they know each other right? (Y: yes...) and Samantha says that this school has more... people who speak Spanish

$\mathrm{Y}$ : ahh, yeah, at the moment more are arriving. And imagine, more Colombians are arriving.

Recently. And because they stay near there (nearby) they go to that school they don't come to this one... and even more people are coming still... (D: and they arrived with children right?)

\section{$5: 46$}

$\mathrm{Y}$ : Yeah, they arrived with lots more children and so they (the kids) are going to get used to speaking Spanish more...

D: but that can be a good thing I think...

Y: well not that good because they get together there and they start speaking Spanish... and while they are learning English they shouldn't be speaking in Spanish... there are a lot of mom's that prohibit (their kids from speaking Spanish). For example there was a boy who just recently entered who used to study at... but the mom has moved him to the other school... because the school here at is very bad (D: why?.. the education?) no not the education... Mateo was there first... and I don't know he didn't want to get up... and said he didn't want to go and he wouldn't get up and he would cry. 